\title{
Coleccionistas y estudiosas: las mujeres en la producción del conocimiento cultural y antropológico de la Argentina (1920-1940)
}

\author{
Lic. Ana Carolina Arias
}

Directora de tesis: Susana Valeria García

Trabajo de tesis para optar al grado de Doctora

Facultad de Ciencias Naturales y Museo

Universidad Nacional de La Plata

2018 


\section{Resumen en español}

En esta tesis se trabaja sobre la participación femenina en la producción de conocimiento y en las redes de circulación de información y objetos relacionados a las culturas indígenas durante el segundo tercio del siglo XX. A partir de una serie de casos de estudio, se profundiza en los itinerarios formativos y laborales, las prácticas científicas, los círculos de sociabilidad y las redes de intercambio y compilación de datos en la Argentina.

El tema de esta tesis surgió al constatar la escasez de estudios que dieran cuenta de la participación de mujeres en la historia de la antropología argentina, especialmente en la primera mitad del siglo XX.

A diferencia de muchos estudios que se dedican a las mujeres en la historia de la ciencia, en esta tesis se trata de mostrar que la participación femenina en las ciencias antropológicas de la Argentina entre las décadas de 1920 y 1940 fue amplia y variada. Las mujeres accedieron a puestos institucionales, participaron activamente de las sociedades científicas, recorrieron el territorio realizando trabajos de recopilación de datos y de objetos arqueológicos, etnográficos y antropológicos, publicaron sus ideas y participaron de los principales debates científicos de la época.

En este sentido, se toman como eje de análisis las prácticas científicas, considerando diferentes experiencias femeninas como casos de estudio para discutir problemáticas de la historia de la ciencia. Esta estructuración permitió abarcar distintos espacios relacionados con las ciencias antropológicas entre 1920 y 1940, como los museos -tanto los grandes museos metropolitanos como los museos regionales y locales-, las sociedades científicas, el espacio del "campo" o terreno y los espacios domésticos y familiares. Asimismo, permitió 
relevar y reconstruir un conjunto amplio y complejo de prácticas y agentes vinculados a la producción y circulación de saberes antropológicos en el período analizado.

Esta investigación se nutre de las diversas líneas desarrolladas en la historia de la ciencia en los últimos treinta años. Las mismas han propulsado modificaciones y nuevas miradas que permiten comprender el desarrollo histórico de las ciencias desde nuevos ángulos: prestando atención a los objetos científicos (Daston, 2000; Rheinberger, 1997) у a las prácticas cotidianas de la actividad científica en sus propios contextos y especificidades, se han propuesto historias no lineales de las ciencias, así como la participación de diferentes sujetos, saberes y lugares en la misma (Penny, 2002; Podgorny, 2004, 2006, 2008). El estudio de los espacios de saber, de las prácticas y los medios técnicos han permitido comprender el carácter colectivo, cooperativo y transaccional de la ciencia (Schapin y Schaeffer, 1985; Rudwick, 1997; Podgorny). Estos enfoques permiten comprender la historia en sus propios términos, evitando la proyección hacia el pasado de los límites disciplinares del presente.

Asimismo, esta investigación se propuso un cruce entre la historia de la ciencia y los estudios de género, buscando detectar hasta qué punto funcionaron ciertos estereotipos sobre las actividades femeninas, por un lado, en la organización de ciertas prácticas científicas y posibilidades de desarrollar una carrera científica-académica y por otro, en los relatos historiográficos sobre las ciencias antropológicas de la Argentina.

A diferencia de muchos estudios que se dedican a las mujeres en la historia de la ciencia, esta tesis trata de mostrar que la participación femenina en las ciencias antropológicas de la Argentina fue tan amplia y variada como los diferentes sujetos que se incluyen en la categoría "mujer". En ese sentido, esta tesis también apunta a problematizar el uso de esa categoría en singular y los relatos historiográficos que reducen las variadas experiencias, resistencias, ambiciones, intereses y estrategias de las mujeres a una imagen de agentes pasivos, solitarios y subordinados al "poder masculino" o con un papel muy secundario en las actividades científicas del pasado. 


\section{Abstract}

In this dissertation the research topic is the feminine participation in the production of knowledge and the networks of circulation of both information and objects from the indigenous cultures during the second third of the $\mathrm{XX}^{\text {th }}$ century. From several case studies, I generate insights in the labor and formation-process itineraries, scientific practices, sociability circles and the networks of exchange and compilation of data in Argentina. The topic of this dissertation emerged from the scarcity of studies related to the participation of women in the history of argentine anthropology, specially in the first half of the $\mathrm{XX}^{\text {th }}$ century.

In complement to many studies that are dedicated to women in the history of science, in this dissertation it is shown that the feminine participation in anthropological science of Argentina durind the 1920' and 1940' decades was wide and varied. Women had access to institutional positions; participated actively in scientific societies; travelled the territory doing collections of archaeological, ethnographical and anthropological data and objects; and participated in the main scientific debates of the epoch.

The core of the analysis are scientific practices, considering different feminine experiences as case studies to discuss different topics of the history of science. This structure allowed to investigate different spaces related to the anthropological sciences between 1920 and 1940, such as museums -both big-metropolitan museums and small-local museums-, scientific societies, the fieldwork, and the domestic-familiar spaces. Also, this structure allowed to assemble and reconstruct a wide and complex batch of practices and agents associated to the production and circulation of anthropological knowledge in the analyzed period.

This research is nourished in the diverse lines developed in the history of science in the last thirty years. Those trends propelled modifications and new views that allow to 
understand the historic development in science from new angles. Taking into account the scientific objects (Daston, 2000; Rheinberger, 1997) and the daily practices of the scientific activity in its own contexts and specificities, no-lineal stories have been proposed, as well as the participation of different subjects, knowledge and places (Penny, 2002; Podgorny, 2004, 2006, 2008). The study of the spaces of knowledge, the practices and the technical means have allowed to comprehend the collective, cooperative and transactional characters of science (Schapin y Schaeffer, 1985; Rudwick, 1997; Podgorny). These approaches allow to understand history in its own terms, avoiding the projection towards the past of the present disciplinary limitations.

Also, this research proposes a junction between the history of science and gender studies, searching to detect till which point some stereotypes functioned over the feminine activities. On one hand, in the organization of certain scientific practices and the possibilities to develop an academic-scientific career; and on the other hand, in the historiographic narratives of the anthropological sciences in Argentina.

In contrast to many studies that are dedicated to the women in the history of science, this dissertation attempts to show that the feminine participation in the anthropological sciences of Argentina was wide and varied as the different subjects that can be included in the category "woman". This dissertation also looks to problematize the use of that category and the historiographic narratives that reduce the varied experiences, resistances, ambitions, interests and strategies of women as an image of passive agents, solitary and subordinated to the "masculine power", or as a secondary role in the scientific activities of the past. 


\section{Agradecimientos}

Esta investigación ha sido posible gracias al otorgamiento de dos becas doctorales (Tipo A y B) de la Universidad Nacional de La Plata, entre los años 2013-2018.

En primer lugar, quiero agradecer a mi directora de tesis, Susana García, quien a lo largo de estos años de trabajo en conjunto me ha enseñado mucho y me acompañó pacientemente en la elaboración de esta investigación. También agradezco a Irina Podgorny, directora de nuestro equipo, por sus consejos y su guía. Ambas me han facilitado, desde lo personal, en sus cursos y charlas y con sus prolíficas investigaciones, la inmersión en las tramas de la Historia de la Ciencia. Asimismo, dejo aquí mi reconocimiento a quienes en distintas instancias y encuentros me han alentado, dando consejos, aportando bibliografía y comentarios a mi trabajo: Máximo Farro, Alejandra Pupio, Andrea Pegoraro, Alejandro Martínez, José Buschini, Marina Rieznik y Gabriela Mayoni. Debo agradecer también a la profesora Nathalie Richard por sus indicaciones y dirigirme durante mi corta estadía de investigación en Paris, que fue posible gracias a un subidio de viajes de la Universidad Nacional de La Plata. Al mismo tiempo, estoy en deuda con las bibliotecarias que desempolvaron libros y revistas para esta tesis, a los/as encargados/as de los diferentes archivos consultados, especialmente a Marisa Scarafoni del Archivo Fotográfico y Documental del Museo Etnográfico y al personal de la Biblioteca Florentino Ameghino del Museo de La Plata. Un agradecimiento especial para Fabiana Bugliani y a la Sociedad Argentina de Antropología, que dispuso generosamente sus documentos para mi consulta, así como para Eloísa Alberto Torres y a Mario Christian Meyer, quienes me brindaron de forma desinteresada información y documentos de sus familiares. A Manu, Ulises y Agus por su colaboración en el procesamiento de datos.

En mis caminos y búsquedas de mi lugar en la antropología, muchas personas me han acompañado y dado aliento para seguir avanzando, para encontrar esto que me encanta y que esta tesis deseo que sea sólo el comienzo. Quizás me quedan algunas afuera, pero no 
dejar de mencionar a Alejandra Mailhe, Pablo Perazzi y Julia Name quienes me guiaron en mis primeras indagaciones sobre la historia de las ideas y de la antropología; a Laura Teves y Marta Crivos por su confianza en mi trabajo; a Graciela Queirolo, quien me acompañó en el Trabajo Final de la Especialización en Educación en Géneros y Sexualidades, alentando la continuidad de mis investigaciones; a mi amigo y compañero de carrera Fernando Franchetti; y a mi compañera de catarsis antropológicas Lena Dávila; a Julián Cueto, Lorena Pasarín y Ana Lamarche compañera/os de cátedra y de inquietudes; a Fernanda Day Pilaría, amiga y consejera de momentos académicos y maternales; y a Josefina Garzillo. A mis compañeras de La Caracola y a mis compañeres de Kula y de Club Hem, que aguantaron mis licencias por tesis y por maternidad.

Esta tesis tampoco hubiera sido posible sin Alexandra Elbakyan, gracias a ella se ha ampliado el acceso libre al conocimiento más allá de las geografías y de las posibilidades económicas.

El agradecimiento más grande es para mi compañero Mati López y para nuestra hija Ema Lihuen, quienes han acompañado día a día el proceso de esta tesis con muchísimo amor y paciencia. A mi mamá Mónica Vulcano y a mi papá Gabriel Arias, por apoyar mi decisión de estudiar antropología y por su aliento hasta el día de hoy. A mis hermanas Gabi y Kei y a mi hermano Manu, que de una forma u otra aportaron para que este trabajo sea posible. A mi padrino Fernando Vulcano por su curiosidad infinita y su apoyo incondicional. A mi familia toda. Gracias. 


\section{Índice general}

Abreviaturas

Introducción

Capítulo 1. Historia de la Ciencia y Género

3. Los estudios históricos de mujeres y ciencia en la Argentina

Capítulo 2. Espacios institucionales y asociacionistas.

La Sociedad Argentina de Antropología (1936-1945)

1. Los espacios institucionales de las ciencias antropológicas 
3. Las primeras socias: proporciones, actividades y sociabilidad

científica

4. Asociacionismo y participación femenina

Capítulo 3. Coleccionismo y prácticas privadas en la ciencia

1. Las cerámicas del Arroyo Leyes y el interés

de los coleccionistas

2. Las prácticas y colecciones de Amelia Larguía 
*Los estudios realizados en la región chaqueña

3. Escritura y temas de investigación

176

4. Trabajo matrimonial en ciencia: actividades entrelazadas

181

Consideraciones finales

185

Anexos

I. Sociedad Argentina de Antropología

192

II. Datos biográficos de algunas mujeres vinculadas a las ciencias

antropológicas argentinas durante la primera mitad del siglo XX

Bibliografía general 


\section{Abreviaturas}

AHMLP - Archivo Histórico del Museo de La Plata

AFDME - Archivo Fotográfico y Documental del Museo Etnográfico

ASAA - Archivo de la Sociedad Argentina de Antropología

AGPC - Archivo General de la Provincia de Corrientes

AHPSF- Archivo Histórico de la Provincia de Santa Fe 


\section{Introducción}

En esta tesis se trabaja sobre la participación femenina en la producción de conocimiento antropológico y en las redes de circulación de información y objetos relacionados a las culturas indígenas durante el segundo tercio del siglo XX. A partir de una serie de casos de estudio, esta tesis propone profundizar en las distintas experiencias y las posibilidades de participación que tuvieron las mujeres en el incipiente campo científico de la antropología argentina entre las décadas de 1920 y 1940. Esto implicó determinar sus itinerarios formativos y laborales, las prácticas científicas, los círculos de sociabilidad y las redes de intercambio y compilación de datos. Asimismo, como se verá en los diferentes capítulos, los casos y experiencias analizados muestran un cuadro más complejo de los diversos espacios y prácticas vinculados a las ciencias antropológicas en el período estudiado, que los relatos tradicionales de la historia de la antropología argentina centrados en unas pocas figuras masculinas y los museos de Buenos Aires y La Plata.

Hace tiempo que los estudios de género y ciencia abrieron varios debates y diversas líneas de indagación en la historia y filosofía de las ciencias. Los análisis de diferentes casos y contextos históricos y nacionales hicieron visible un amplio rango de experiencias y diversas vías de participación femenina en las actividades científicas, generalmente ignoradas por las historias convencionales de la ciencia, basadas en "los grandes hombres" y sus teorías o en la reconstrucción de los linajes y aportes de las figuras consagradas (Kohlstedt, 1995; García, 2011b). Otras investigaciones focalizaron en cuestiones más generales vinculadas a los patrones de división sexual del trabajo científico y cómo operaron las concepciones de género en la organización de las comunidades científicas y en las representaciones y el contenido de las ciencias en distintos momentos históricos (Kohlstedt, 1995; Kohlstedt y Longino, 1997; Lopes, 1998, 2006). De esta forma, analizar itinerarios femeninos o la participación de las mujeres en la actividad científica, permite remitirnos a algo más que al resultado de la voluntad de agentes individuales: el carácter 
colectivo y asociacionista de la ciencia y la materialidad de las prácticas científicas concretas (García, 2006). Desde esta perspectiva, identificar el papel o los papeles desempeñados por las mujeres en la compilación y circulación de objetos y datos sobre las sociedades indígenas y en los ámbitos de sociabilidad científica constituye un intento de construir un panorama más complejo del desarrollo de las ciencias en nuestro país.

A diferencia de muchos estudios que se dedican a las mujeres en la historia de la ciencia, esta tesis intenta mostrar que la participación femenina en las ciencias antropológicas de la Argentina fue tan amplia y variada como los diferentes sujetos que se incluyen en la categoría “mujer". En ese sentido, esta tesis también apunta a problematizar el uso de esa categoría en singular y los relatos historiográficos que reducen las variadas experiencias, resistencias, ambiciones, intereses y estrategias de las mujeres a una imagen de agentes pasivos, solitarios y subordinados al "poder masculino" o con un papel muy secundario en las actividades científicas del pasado. La tesis sostenida en esta investigación doctoral consiste en desarticular la noción de "mujer científica" como una categoría unívoca o como un objeto de estudio homogéneo. Así, se busca demostrar las variadas experiencias y prácticas científicas que dicha categoría puede abarcar, en contextos y momentos históricos específicos. Como se verá en las siguientes páginas, las mujeres estudiadas en esta tesis accedieron a puestos institucionales, participaron activamente de las sociedades científicas, recorrieron el territorio realizando trabajos de recopilación de datos y de objetos arqueológicos, etnográficos y antropológicos, publicaron sus ideas y participaron de los principales debates científicos de la época. Además, estas "señoras" y "señoritas" formando colecciones, excavando las barrancas de los ríos, usando pantalones para viajar "al campo" o internándose en las selvas y en las aldeas indígenas demuestran el rango de libertad de estos sujetos frente a los modelos o las imágenes estereotipadas de “mujer” o de los cánones sociales de género de esos años.

En el período histórico tratado en esta tesis se registra el ascenso de algunas mujeres como profesoras universitarias y una mayor presencia femenina en diferentes carreras universitarias, desempeñando y ocupando diversos puestos, aunque de rango inferior, en las instituciones académicas y científicas. Al mismo tiempo, el período estudiado está 
delimitado por la sanción de dos leyes que amplían los derechos de las mujeres, en el plano civil y político. En 1926, se aprueba la Ley 11.357 que amplió parcialmente los derechos civiles de la mujer (Valobra, 2010; Giordano, 2012; Sieben, 2012). Esta ley terminó con la incapacidad civil de la mujer soltera, la viuda y la separada pero no derogó el artículo 55 del Código Civil, que definía a la mujer casada como incapaz de hecho relativa. Dos décadas después, en 1947 se aprobó la Ley 13.010 que permitió el voto femenino a nivel nacional en las elecciones de 1951 (Valobra, 2010; Giordano, 2012). Durante este periodo, se asistió a algunas transformaciones en el campo de la antropología argentina y la ampliación de sus espacios institucionales. En los inicios de la década de 1930 se produjo un recambio de quienes ocupaban los cargos docentes y científicos de las instituciones de Buenos Aires y La Plata, tras la jubilación y/o la muerte de las figuras que ocuparon esas posiciones desde principios del siglo sin formar discípulos ni consolidar grupos de trabajo (Podgorny, 2004b, García, 2010). Paralelamente se fomentaron las instituciones académicas y los museos en las provincias argentinas (García, 2011a) y la promoción del estudio de las culturas regionales, incentivando el estudio de nuevas localidades y temáticas junto con el estímulo a estas disciplinas a través de la formación docente y cursos. Por otra parte, en 1936 se fundó la primera corporación de antropólogos del país, la Sociedad Argentina de Antropología, donde junto a los pocos "especialistas" se incorporaron los "interesados" en estas disciplinas, incluidas varias mujeres que publicaron trabajos de investigación.

El tema de esta tesis surgió al constatar la escasez de estudios que dieran cuenta de la participación de mujeres en la historia de la antropología argentina, especialmente en la primera mitad del siglo XX. Durante la indagación en los archivos y publicaciones antiguas se constató una presencia femenina más amplia y variada que la señalada en los relatos tradicionales sobre el pasado de la Antropología en el país. El principal desafío consistió en relevar y organizar este conjunto variado de experiencias, compararlas y buscar aspectos en común o divergentes que permitieran un hilo de discusión para la tesis. Así, se tomaron como eje de análisis las prácticas científicas, considerando diferentes experiencias femeninas como casos de estudio para discutir problemáticas de la historia de la ciencia. 
Esta estructuración permitió abarcar distintos espacios relacionados con las ciencias antropológicas entre 1920 y 1940, como los museos -tanto los grandes museos nacionales como los museos regionales y locales-, las sociedades científicas, el "trabajo de campo" y los ámbitos domésticos y familiares. Asimismo, permitió relevar y reconstruir un conjunto amplio y complejo de prácticas y agentes vinculados a la producción y circulación de saberes antropológicos en el período analizado.

Respecto de la organización de la tesis, en el capítulo 1 se presenta de forma sintética la intersección entre algunas perspectivas de los llamados estudios de género y la historia de la ciencia y se analizan los antecedentes sobre mujeres en la historia de la ciencia en la Argentina, considerando también los antecedentes específicos en la historia de las ciencias antropológicas.

El resto de los capítulos se organiza en torno a distintas experiencias y casos específicos que permiten discutir determinadas temáticas. En el capítulo 2 se presenta un panorama general de los ámbitos institucionales de las ciencias antropológicas en el período de estudio de la tesis, mencionando las cátedras e institutos universitarios, los espacios de los museos y la expansión de las instituciones regionales así como los espacios asociativos. Se trabaja en particular con la fundación y los primeros años de la Sociedad Argentina de Antropología y se analiza la afiliación femenina y las trayectorias científico-académicas de algunas de sus primeras socias activas. Con ello se busca mostrar parte de las posibilidades (y también limitaciones) que tuvieron las mujeres en los espacios de sociabilidad científica, de intercambio y de difusión de ideas y de formación y entrenamiento en las prácticas científicas.

El capítulo 3 está dedicado al análisis de las prácticas de coleccionismo privado en el marco de un creciente interés arqueológico por la región del Arroyo Leyes en Santa Fe. En particular, se trabaja sobre la coleccionista santafesina Amelia Larguía de Crouzeilles (1875-1952), quien formó una colección privada de más de cuatro mil piezas e intercambió correspondencias e interpretaciones sobre los hallazgos de la región con diferentes arqueólogos, coleccionistas y aficionados. Asimismo, en este capítulo se muestra cómo 
diferentes interesados en la arqueología participaron de una serie de hallazgos y debates científicos. Larguía formó parte de este conjunto variado de sujetos que se involucraron con la promoción de sitios y materiales arqueológicos, actuando como mediadora entre los científicos de Buenos Aires y La Plata y los pobladores locales.

El capítulo 4 analiza la recopilación de información y objetos etnográficos, la logística del trabajo de "campo" y el comercio que se genera alrededor de la formación de esas colecciones. Para ello se toma como caso de estudio, la actuación de la médica austríaca Wanda Hanke, proveedora de materiales etnográficos a los museos argentinos y de otras partes del mundo, a los cuales ofrecía en venta objetos etnográficos y arqueológicos, financiando así y mediante otras estrategias sus viajes de exploración por el interior de Sudamérica para estudiar diferentes grupos indígenas. El análisis de sus prácticas permite indagar en torno a las prácticas comerciales ligadas a la formación de colecciones etnográficas y a las interacciones con miembros de diferentes comunidades y regiones.

Por último, en el capítulo 5 se analizan las relaciones matrimoniales en la actividad científica, para profundizar en los aspectos vinculados a la organización cotidiana del trabajo antropológico y las relaciones familiares en ciencia. Así, se profundiza en el caso del matrimonio conformado por María Delia Millán (1900-1994) y Enrique Palavecino (1900-1966), quienes realizaron viajes de "campo" en conjunto para el relevamiento de distintos aspectos culturales y lingüísticos de grupos indígenas del norte del país.

Finalmente, en el Anexo se presentan tablas y datos biográficos que ilustran o complementan lo expuesto en los diferentes capítulos. Las tablas del Anexo I contienen información proveniente de la Sociedad Argentina de Antropología, los nombres y las cantidades de socios y socias incorporados en los primeros años en diferentes categorías, las personas que expusieron trabajos en reuniones de la asociación y la frecuencia con la cual participaron de las mismas. En el Anexo II se presentan datos biográficos de algunas mujeres vinculadas a las ciencias antropológicas durante la primera mitad del siglo XX. Los mismos fueron compilados en el transcurso de la investigación y presentan solo una 
muestra de la diversidad de mujeres que en esos años participan de las prácticas antropológicas. La selección de estas mujeres responde a su reiterada aparición en los diferentes documentos y fuentes consultadas, así como a la disponibilidad de información biográfica de las mismas. Si bien en algunos casos los datos relevados son mínimos, se considera que este anexo amplía y apoya la tesis central de esta investigación, señalando una amplia variedad de experiencias de "mujeres" que sin duda requieren futuras indagaciones.

\section{Antecedentes y fundamentación del tema}

En esta tesis se combinan diversos enfoques y perspectivas de análisis, provenientes de diferentes campos de estudio. Entre los principales trabajos con los cuales se vincula esta investigación se pueden mencionar aquellos que se han dedicado a las mujeres en la historia de las ciencias antropológicas y en la historia de la ciencia desde una perspectiva que recupera las prácticas cotidianas y la organización del trabajo científico en diferentes espacios de la ciencia; considerando el carácter colectivo y cooperativo de las actividades científicas.

En la historiografía de las ciencias argentinas, la cuestión de género no ha constituido un campo de indagación particular y son poco frecuentes los trabajos que se detienen en la situación de la mujer en la actividad científica local. Varios de ellos se han focalizado en las primeras décadas del siglo XX en relación a la medicina (Kohn Loncarica, 1976; Kohn Loncarica y Sánchez, 1996, 2000), las ciencias naturales (García, 2006; 2011b) y las ciencias exactas. Dora Barrancos (2000) ha examinado algunos itinerarios científicos femeninos vinculados a las ciencias antropológicas. Dentro de los antecedentes sobre la historia de la participación femenina en los espacios académicos de la Argentina, también se puede citar el trabajo de Aurora Ravina (1997) sobre las dificultades de la representación 
femenina en las academias nacionales. Estos trabajos constituyen un punto de partida para el análisis y comparación de la participación institucional de las mujeres en el período a examinar. Por su parte, Alejandra Pupio $(2005,2011)$ ha mostrado cómo coleccionistas y maestras intervinieron en la formación de colecciones y museos locales en el sur bonaerense durante las décadas de 1930-1950, participando de la recolección e identificación de hallazgos arqueológicos "en el campo", actuando como intermediarios entre la población local y los arqueólogos de los museos de Buenos Aires y La Plata. Como demuestra Pupio, los datos ofrecidos por coleccionistas y aficionados configuraban una suerte de mapa arqueológico del cual se servían los profesionales para conocer nuevas áreas, para confirmar datos o para continuar el trabajo en un yacimiento determinado.

Esta tesis retoma estos antecedentes para combinarlos con los aportes contemporáneos de historia de la ciencia y un marco metodológico que concibe a la práctica científica como una actividad colectiva y asociacionista, no exenta de conflictos y competencias. Desde este marco, también se propone una historia que cuestiona y complejiza la tradicional separación entre "aficionados" y "profesionales", buscando en cambio reconstruir las redes de intercambio de objetos e información y las estrategias para la obtención de los mismos así como el papel jugado por los intermediarios, coleccionistas e informantes locales en las interpretaciones o en la promoción de sitios o temáticas de indagación. Precisamente, las mujeres participaron, con distinto grado de compromiso y posición, en esas redes así como en las tareas burocráticas que se generan en torno a las colecciones de los museos, como se observa para el período a estudiar. No obstante, esto no ha sido demasiado estudiado en la historia de la antropología en la Argentina. Tampoco se han examinado en profundidad las posibilidades de trabajo para las mujeres en los museos y ámbitos académicos ni la composición del estudiantado que asistía a clases de las ciencias antropológicas en una época previa a la creación de estas carreras. Recordemos que en las primeras décadas del siglo XX, la mayoría de los alumnos de los cursos de antropología y arqueología, tanto en la Universidad de Buenos Aires (Buchbinder, 1997) como en La Plata a partir de 1920, pertenecían a las carreras de profesorado, con un alto porcentaje de mujeres (García, 2010). 
Los trabajos de Podgorny (2004a, 2005) son especialmente retomados en esta investigación para contextualizar la situación de la arqueología y la antropología en el período estudiado. Asimismo, se toman como antecedente los trabajos de Susana V. García sobre la enseñanza universitaria y la participación de las mujeres en las ciencias naturales (cf. García, 2006, 2010, 2011b).

En relación con ello, los antecedentes de esta tesis se vinculan con los siguientes ejes de indagación ${ }^{1}$ : a) la relación de las mujeres con los viajes científicos, las expediciones y el trabajo de campo; b) las mujeres y su participación en espacios institucionales y asociativos de la ciencia; y c) las reflexiones historiográficas sobre las "mujeres" en la ciencia.

Para el desarrollo de esta tesis han sido fundamentales los trabajos sobre las relaciones de género y el trabajo de campo en la historia de la antropología y de las ciencias naturales en Brasil (Correa, 1997; Lopes, 2007, 2006, 2008 b, 2008c; Sombrio y Lopes, 2011 y Sombrio, 2013, 2014). Estos trabajos discuten y matizan la idea más clásica de la ausencia de mujeres en los trabajos de campo y en las expediciones científicas, mostrando que había una gran cantidad, que realizaron tareas diferentes y que se vincularon estratégicamente con las principales instituciones científicas, con los estudiosos de la época y también con sus informantes y colaboradores locales.

En cuanto a las mujeres que realizaron viajes, expediciones y trabajo de campo, resulta un antecedente importante el trabajo de Mariana Sombrio (2014), quien analiza las expedicionarias en Brasil en la primera mitad de siglo XX. Esta autora señala que, en cierta forma, los límites menos rígidos de las prácticas científicas en el campo facilitaron la incorporación de las mujeres en estas actividades. La investigación en el campo fue más difícil de reglamentar que aquella de laboratorio: "por siglos las mujeres viajaron hacia lugares distantes registrando sus observaciones en cartas, diarios y pinturas, lo cual permite la construcción de una historiografía sobre mujeres viajantes y que actuaron como

\footnotetext{
${ }^{1}$ Estos aspectos serán considerados con mayor profundidad en el capítulo 1.
} 
investigadoras de campo." (Sombrio, 2014: 19). Su análisis se dedica a las mujeres -tanto brasileras como extranjeras- que solicitaron permiso al Consejo de Fiscalización de Expediciones Artísticas y Científicas (CFE) ${ }^{2}$ entre 1933 y 1968 para realizar sus expediciones o para exportar material artístico. La etnología, señala Sombrio (2014), se encontraba en ascenso en la primera mitad de siglo XX en Brasil y las científicas encontraban espacios donde insertarse en este campo disciplinar ${ }^{3}$. El trabajo de esta historiadora brasileña aporta algunos parámetros y casos de comparación para pensar la situación en la Argentina. Especialmente para reflexionar sobre las experiencias de Wanda Hanke y de Delia Millán de Palavecino. En la Argentina, las investigaciones sobre mujeres en relación a los viajes y las prácticas de campo no son abundantes.

Por otra parte, los trabajos de Margaret Rossiter $(1982,1995,1997)$ sobre las mujeres en la ciencia norteamericana abrieron una línea de investigaciones sobre mujeres e institucionalización de las ciencias, que generó una gran cantidad de estudios sobre historia de las mujeres desde la perspectiva de la historia de la ciencia. Los trabajos de Rossiter rompen con el enfoque habitual de señalar la "excepcionalidad" de las mujeres. Este enfoque se destaca, como señala Lopes (1998), por el tratamiento que hace Rossiter de las mujeres científicas como trabajadoras, cuyas trayectorias y actividades científicas podrían ser interpretadas en términos de criterios socioeconómicos y de sus implicaciones sociales. Por último, Rossiter defiende un propósito continuo, que es romper o subdividir esa "entidad agregada" llamada ciencia; para entender las particularidades de cada campo y subcampo, estudiando intensivamente sus características, pero sin perder de vista las

\footnotetext{
${ }^{2}$ Sobre este organismo, ver el capítulo 4.

${ }^{3}$ Los trabajos dedicados a las mujeres en el "campo" o viajeras son amplios y abarcan diversas disciplinas. Aquí se priorizaron algunos que refieren a las mujeres vinculadas con la antropología y las ciencias naturales. Un trabajo clásico sobre este tema es el volumen editado por Peggy Golde "Women in the Field. Anthropological Experiences" (1970). La botánica también fue una disciplina que admitió ampliamente a las mujeres desde los siglos XVIII y XIX (Shteir, 1996), siendo que muchas de ellas ingresaban a la profesión como ilustradoras y eventualmente desarrollaban carreras científicas en este campo (Henson, 2000). Sobre mujeres en la astronomía puede consultarse el trabajo de Pang (1996). Ver también Junghans (2007) sobre la naturalista y ornitóloga Emilia Snethlage y su amplio trabajo de campo en el Amazonas.
} 
cuestiones que refieren a cómo cada campo difiere, o no, de los otros (Rossiter, 1982, 1995). En la Argentina, constituyen una referencia los trabajos de Susana García (2006; 2011b), quien analiza la participación femenina en las actividades científicas vinculadas a las ciencias exactas y naturales en las primeras décadas del siglo XX, mostrando las posibilidades laborales y las modalidades de ingreso a las instituciones científicas.

Sobre las mujeres en la ciencia y las formas de enfocar el análisis histórico de las mismas la bibliografía es sumamente amplia. La "presencia" de mujeres en la historia de la ciencia y de la antropología ya ha sido demostrada por numerosos trabajos que se dedican a la investigación de estas cuestiones a nivel internacional, especialmente desde la década de 1980 en adelante. En particular, en la Argentina, se ha escrito muy poco acerca de la participación femenina en las ciencias antropológicas, sobre todo en la primera mitad del siglo XX. Las cuestiones de historia y género han sido discutidas en general por los estudios de Historia de las Mujeres, los cuales han tenido un amplio desarrollo en el país sobre todo a partir de la década de 1980. Dora Barrancos señala que la Historia de las Mujeres ha sido fruto de una renovación más amplia en el campo de la investigación histórica, ocurrida sobre todo en las últimas décadas del siglo XX y que ha permitido incorporar nuevas preguntas y sujetos a las indagaciones disciplinares. Esta renovación permite "repensar el pasado a la luz de la condición de varones y mujeres, condición que no es apenas diferente sino desigual" (Barrancos, 2008: 10). Estas investigaciones se ampliaron a partir de la renovación de perspectivas teóricas y de herramientas metodológicas, sobre todo a partir de las preocupaciones provenientes de la Historia Social: la misma se interesa en la cultura de los sectores populares, la familia, las comunidades pequeñas; en fin, en descubrir la dimensión histórica de la vida cotidiana y no tanto de aquellos acontecimientos excepcionales (Bianchi, 1992). Barrancos (2004-5) reconoce un amplio grupo de trabajos que han dado lugar a una Historia de las Mujeres con mayúscula, un conjunto de "nuevos postulados"4 que han sido influenciados por los cambios

4 Remitirse al trabajo de Barrancos (2004-5) para un análisis detallado de los temas y discusiones desarrollados en los distintos trabajos, organizados muy claramente por autores y décadas. 
epistemológicos en las ciencias sociales, la renovación y la difusión de los estudios feministas, las transformaciones en la historia social, el rápido ascenso internacional de la historiografía de género y los procesos políticos y sociales en la Argentina a causa del retorno a la democracia y los cambios que suscitó la introducción de los enfoques de género al ámbito académico.

\section{Algunas cuestiones metodológicas y fuentes documentales utilizadas}

La metodología a aplicada en esta investigación combinó aproximaciones historiográficas vinculadas a la microhistoria, la historia cultural, los estudios de género y la historia de las prácticas y la cultura material de las ciencias. En relación con esto último, también se tuvieron en cuenta las propuestas metodológicas vinculadas a la epistemología histórica y la biografía de los objetos científicos (cf. Daston, 2000; Rheinberger, 1997). Estas diferentes perspectivas fomentan el análisis de las prácticas científicas en el marco de diversas redes de producción y circulación del conocimiento; de formación de colecciones arqueológicas y etnográficas y sus apoyos institucionales. Asimismo, contribuye a articular una historia de la ciencia con las prácticas culturales y ámbitos sociales que trascienden a estas instituciones. Al mismo tiempo, esta investigación se propone un cruce entre la historia de la ciencia y los estudios de género, buscando detectar hasta qué punto funcionaron ciertos estereotipos sobre las actividades femeninas, en la organización de las prácticas científicas y en las posibilidades de desarrollar una carrera científica-académica.

La investigación desarrollada para esta tesis comprendió una serie de actividades de relevamiento y análisis de diversas fuentes documentales y bibliografía secundaria alrededor de los siguientes ejes: 
- Reconstrucción del contexto de funcionamiento de los espacios vinculados a la enseñanza y la investigación de las ciencias antropológicas y la participación de las mujeres en ellos.

- Identificación y análisis de las áreas temáticas y trabajos publicados por mujeres en revistas científicas y presentados a congresos.

- Relevamiento de las prácticas de "campo" realizadas por diferentes mujeres y las posibilidades de viajar y transitar por las regiones visitadas.

- Mecanismos de formación y circulación de colecciones etnográficas y arqueológicas.

- Reconstrucción de los espacios y las prácticas de divulgación de las ciencias antropológicas.

- Análisis de las membresías en las sociedades científicas y academias nacionales.

El corpus documental utilizado en esta tesis incluyó fuentes éditas e inéditas. Las fuentes éditas consisten en: a) prensa diaria local y de circulación nacional, b) publicaciones oficiales de las instituciones (museos, universidades); Memorias del Ministerio de Justicia e Instrucción Pública. Dichas publicaciones han sido consultadas en diferentes bibliotecas, especialmente se trabajó en la biblioteca de la Facultad de Ciencias Naturales y Museo, del Museo Etnográfico de la Facultad de Filosofía y Letras de Buenos Aires, la central de la Universidad Nacional de La Plata, y la de la Legislatura de la Provincia de Buenos Aires.

Las fuentes inéditas corresponden a diferentes acervos. En los mismos se han consultado fondos privados y fondos administrativos, en los cuales se ha recopilado correspondencia institucional y personal, folletos, recortes y documentos administrativos conteniendo información sobre compra y venta de colecciones, actividades realizadas por el personal de museos y por corresponsales de los mismos, organización y promoción de eventos y actividades científicas, entre otros.

Los acervos consultados son los siguientes: 
1.Archivo Fotográfico y Documental del Museo Etnográfico: Este acervo conserva materiales administrativos y burocráticos, organizados por gestión, es decir, por los sucesivos directores de la institución, y también cuenta con algunos fondos de sus investigadores (Pegoraro, 2013). Se han relevado legajos personales, comunicaciones, correspondencia, relaciones institucionales, libros copiadores, carpetas administrativas, planillas de asistencia de personal, recortes periodísticos e información sobre la adquisición de colecciones, su inventario y catalogación. En este acervo también se conservan algunos documentos provenientes del Museo Argentino de Ciencias Naturales "Bernardino Rivadavia”, que en 1947 traspasó sus colecciones antropológicas y arqueológicas al Museo Etnográfico. También se han consultado los fondos donados por los familiares de Enrique Palavecino y Delia Millán, los cuales contienen correspondencia, cuadernos de campo, libretas con sistematización de sus investigaciones, registros de sus actividades docentes, currículums, folletos, recortes de periódicos, fichas bibliográficas, artículos periodísticos, documentos de su vida familiar, entre otros. Estos materiales están organizados en cuatro fondos distintos: Fondo Enrique Palavecino; Fondo Delia Millán de Palavecino; Fondo Palavecino-Millán de Palavecino y Fondo Fundación Palavecino-Millán (Spoliansky, Roca y Scarafoni, 2011).

2. Archivo Histórico del Museo de La Plata: contiene principalmente documentación de carácter burocrático y administrativo, vinculada con notas, copiadores y distintos registros de la dirección y secretaría de esta institución. En esta investigación se utilizaron los copiadores de las notas enviadas desde la dirección, registros de alumnos y de personal, expedientes de concursos, informes de algunas secciones, notas internas enviadas por el personal a la dirección, correspondencia con otras instituciones y con particulares. Estos materiales permitieron reconstruir prácticas de adquisición de colecciones, de organización 
y actividades del personal y de las relaciones establecidas con el museo y otras instituciones y sujetos 5 .

3. Archivo Histórico de la Provincia de Santa Fe: En este Archivo se consultaron fondos privados vinculadas a familiares de Amelia Larguía. En particular, se consultó el fondo de Jonás Larguía, su padre, y el fondo perteneciente a Juan Carlos Crouzeilles, su esposo. En este último, se incluyen documentos pertenecientes y relacionados con Amelia Larguía, que permitieron relevar algunas de sus prácticas arqueológicas y de coleccionismo: correspondencias, notas de periódicos, homenajes y elogios. Estos documentos permitieron en parte reconstruir el entorno familiar y social de esta coleccionista y aficionada a la arqueología que se analiza en el capítulo 3.

6. Archivo de la Sociedad Argentina de Antropología: La Sociedad no cuenta con un archivo propiamente dicho, pero en el último año se han tratado de reunir y conservar los documentos que han sobrevivido del funcionamiento de esta asociación. Estos materiales incluyen los libros de actas desde su fundación hasta el presente, correspondencia, registros de socios, registros contables y movimientos de caja, folletos de actividades, certificados de envíos e intercambio de la revista Relaciones de la Sociedad Argentina de Antropología, separatas y originales de dicha revista, fotografías, memorias, estatutos, entre otros. La consulta de estos documentos permitió reconstruir los primeros años de la asociación, aportando indicios acerca de cómo se organizaban las actividades y el funcionamiento de la misma tal como se examina en el capítulo 2.

4. Archivo General de la Provincia de Corrientes: Este acervo posee materiales documentales y bibliográficos y cuenta con una importante hemeroteca. En el mismo se consultaron diarios y revistas de la década de 1930, especialmente para reconstruir ciertas prácticas culturales de la época y en relación con los museos científicos e históricos de la

\footnotetext{
${ }^{5}$ Para mayor información sobre las colecciones de este acervo, remitirse a Podgorny Irina y Tatiana Kelly (Editoras) 2012. Los secretos de Barba Azul. Fantasías y realidades de los archivos del Museo de La Plata. Rosario, Prohistoria Ediciones.
} 
ciudad. Asimismo, se consultó el Boletín del Museo Colonial, Histórico y de Bellas Artes de Corrientes, el cual permitió reconstruir algunas de las actividades de Ana Biró en dicho museo. Una gran parte de los documentos en este acervo se encuentran digitalizados y catalogados, lo cual favorece y agiliza su consulta.

\section{Archivo Histórico del Chaco "Monseñor José Alumni": En este acervo se consultaron} diarios y publicaciones culturales de las décadas de 1930 y 1940, especialmente en torno a las actividades de Ana Biró y del "Ateneo del Chaco". También se consultaron libros y otras publicaciones referentes a la historia de la región.

Respecto de las fuentes utilizadas, es preciso señalar que los documentos dan cuenta de la vida y de las prácticas de ciertas mujeres en general de forma fragmentaria. La reconstrucción de las experiencias personales y de las prácticas científicas ha requerido un trabajo de "rompecabezas", que si bien es habitual a la práctica historiográfica en el caso de las mujeres presentó ciertas dificultades: escasos fondos pertenecen a las mujeres, más bien sus documentos deben ser rastreados de forma oblicua, especialmente a partir de los hombres con los cuales se vincularon. Como señala Perrot (2009) suele haber mayor oportunidad de encontrar los rastros de las mujeres en los archivos privados. En ocasiones, los mismos son recibidos en los archivos públicos, nacionales o provinciales, siempre de manera selectiva: escritores, políticos o empresarios traspasan el umbral, pero es mucho más difícil para la "gente común", y más aún para las mujeres. De la mayoría de las mujeres analizadas en esta tesis se ha recopilado información sobre su biografía y desempeño profesional, de algunas los detalles de su vida son escasos. En general, los documentos que dan cuenta de sus tareas y actividades son de tipo institucional, provenientes del ámbito formal y con escasa o nula información personal o subjetiva. A ello se suman algunas publicaciones en diarios y revistas y menciones breves en publicaciones de terceros. En algunos casos, como el de Larguía analizado en el capítulo 3, las colecciones y las descripciones que acompañan a las mismas aportaron otro tipo de fuentes para reconstruir las prácticas científicas. Algunas de las mujeres estudiadas figuran en compilaciones biográficas, como el clásico diccionario de Lily Sosa de Newton (1980), o en compilaciones como la de Gatica de Montiveros (1988). Este tipo de fuentes brinda 
información breve y en general sin mucha especificidad. Estos datos se han podido combinar, en algunos casos, con la información proveniente de diversos repositorios institucionales y mediante la compulsa bibliográfica de diferentes fuentes. Asimismo, para el caso del matrimonio Palavecino-Millán analizado en el capítulo 5, se contó con información proveniente de entrevistas y diálogos personales con una sobrina de Delia Millán y con algunas personas que la conocieron. 


\section{Capítulo 1. Historia de la Ciencia y Género}

Discursos e imágenes recubren a las mujeres como un grueso manto.

¿Cómo alcanzarlas, cómo perforar el silencio, los estereotipos que las envuelven?

(Michelle Perrot, 2009)

\section{Introducción}

Los estudios históricos de las ciencias se han transformado en las últimas tres décadas con la incorporación de nuevos enfoques historiográficos y las investigaciones sobre nuevos temas, sujetos, lugares y procesos vinculados con la actividad científica del pasado (Lightman, 2016). Una parte de estas trasformaciones se relacionó con los aportes que hicieron los llamados estudios de ciencia y género y de mujeres en la ciencia.

Los llamados estudios "de ciencia y género" conforman un amplio campo de saberes y enfoques, los cuales han sido considerados como el resultado de la convergencia entre el feminismo militante y el académico en las décadas de 1970 y 1980; vinculado con lo que se ha llamado el feminismo de la "segunda ola"6 . En esos años se comienza a utilizar

\footnotetext{
${ }^{6}$ Los movimientos feministas a nivel internacional, especialmente en Estados Unidos, han sido descriptos en tres "olas" o momentos: una primera ola feminista o feminismo de la igualdad en los inicios del siglo XX; una
} 
la noción de género como un concepto de utilidad política en los movimientos feministas y como categoría de análisis académico. El uso del término género fue reivindicado en tanto permitía diferenciar "género" de "sexo", donde el primero estaría construido socialmente y el segundo, en cambio, sería parte de la naturaleza humana. Esta distinción también se asociaba a la distinción naturaleza-cultura, vinculándose lo femenino con la naturaleza y lo masculino con lo cultural ${ }^{7}$. Las académicas feministas o interesadas en estos enfoques, comienzan a introducir el concepto de género como forma de análisis y orientan sus estudios hacia temas nuevos, por ejemplo, la desigualdad de género en espacios académicos y de producción de conocimientos, las mujeres como objeto de estudio en el presente y en el pasado, las visiones androcéntricas de la ciencia, entre otros (Kohlstedt y Longino, 1997; Lopes, 1998; Fox Keller, 2006; Maffia, 2007). Varias décadas después, los estudios de género también comenzarán a enfocar en otros sujetos y objetos de estudio; como el hermafroditismo, las disidencias sexuales o las masculinidades ${ }^{8}$.

En este capítulo se presentan de forma sintética algunos aspectos en que la historia de la ciencia incorporó los llamados estudios de género y de mujeres en la ciencia. Asimismo, se revisa cómo la historia de la ciencia argentina ha tratado las cuestiones de género y de la participación femenina en la actividad científica en el país. Por último, se focaliza en la historiografía sobre el desarrollo de las ciencias antropológicas en la Argentina y en cómo se ha considerado la cuestión de género y en especial el tema de las mujeres en esta disciplina.

\footnotetext{
segunda ola o feminismo de la diferencia, especialmente a partir de la década de 1960, y un tercer momento que puede ubicarse a partir de fines de 1980 y que además incluye a movimientos más recientes, como el posfeminismo y el feminismo posestructuralista. Estos momentos no necesariamente deben ser pensados en términos cronológicos, sino más bien en cuanto a las discusiones que implican y a las conceptualizaciones que cada uno reivindica.

${ }^{7}$ Dicho dualismo se ha denominado también como "sistema sexo-género" (Rubin, 1975) o "dualismo sexogénero".

${ }^{8}$ Destacan en este sentido los trabajos de Donna Haraway $(1989,1981)$ y de Preciado (2008). Ver también el dossier de la revista de Historia de la Ciencia Osiris dedicado a las "Scientific Masculinities" (enero de 2015).
} 


\section{La categoría "mujer"}

En las décadas de 1960 y 1970 el llamado "feminismo teórico" generó una serie de discusiones en torno a las diferencias entre sexo y género, permitiendo diferenciar lo biológico (sexo) de lo cultural (género). Algunas críticas posteriores, tales como las de Judith Butler (1998) y Donna Haraway (1989, 1998, 2005), señalaron que la distinción entre sexo y género constituye una ficción, puesto que si el género puede ser construido culturalmente, lo mismo puede hacerse con los significados biológicos del sexo. Haraway (2005) señala que las teorías feministas de género sirvieron para comprender que cualquier sujeto finalmente coherente es una fantasía y que la identidad colectiva y personal es reconstituida socialmente de manera precaria y constante. La identidad de la "mujer" es simultáneamente reclamada y deconstruída. La categoría "género" en sí misma, comenzó a generar problemas semánticos y conceptuales con el tiempo: "ha pasado de ser una categoría analítica a ser una fuerza causal o explanans. Así el término "género" se ha convertido en una especie de comodín epistemológico que da cuenta tautológicamente de lo que ocurre entre los sexos de la especie humana.” (Lamas, 2007: 3)

Sin desconocer estas discusiones, en este trabajo se adopta la definición de género que utiliza Joan Scott ${ }^{9}$ : "el género es una forma primaria de relaciones significativas de poder" (Scott, 1996). El género, siguiendo a esta autora, es un elemento constitutivo de las relaciones sociales basadas en las diferencias que distinguen los sexos y es una de las formas primarias de relaciones significantes de poder, que se se construye a partir de elementos como: los símbolos culturales, los conceptos normativos que generan las interpretaciones de los significados de los símbolos, las nociones políticas y las organizaciones sociales tanto como la identidad subjetiva de cada individuo (Scott, 1996:

\footnotetext{
9 Joan W. Scott (1996) "El género una categoría útil para el análisis histórico” Título original: "Gender: A Useful Category of Historical Analysis” En: American Historical review, 91, 1986, pp.1053-1075. Unos años después, la misma autora revisará su texto de 1986. Esta revisión de la autora estuvo precedida de un suplemento especial en la American Historical Review, en el cual se reúnen una serie de ensayos que reflexionan sobre la influencia del "canónico" artículo de Scott de 1986 en diferentes campos historiográficos.
} 
22-24). Asimismo, sostiene esta autora, debe tenerse en cuenta tanto a los sujetos individuales, y sus bagajes de deseos conscientes o inconscientes, como la organización social, económica y política y la naturaleza de las relaciones interpersonales, para ir más allá de la dicotomía varón-mujer. Se considera que "mujer" no es una categoría "natural", sino que se construye social e históricamente y que debe ser problematizada desde una perspectiva crítica, que considere las tramas de relaciones y la construcción social de esta categoría en cada contexto específico. La categoría "mujeres", entonces, es utilizada de modo crítico, para reconocer su especificidad histórica y sus límites culturales (Haraway, 2005).

En relación con ello, en esta tesis se sostiene que es también necesario pensar en las "mujeres" y las "ciencias" como conceptos plurales para dar cuenta de la diversidad de experiencias individuales que pueden relacionarse al género "femenino" en un determinado momento histórico, derivadas de una multiplicidad de factores que atraviesan la vida de los individuos: su posición social, su estado civil y situación familiar, su personalidad, sus ambiciones e intereses intelectuales y sus recursos económicos, entre otras cuestiones, así como la estructuración y el funcionamiento de las distintas áreas científicas con las que se relacionan.

\section{Historia de la ciencia y los estudios de género}

Para comprender las intersecciones entre la historia de la ciencia y los estudios de género, se deben considerar las investigaciones generadas desde la década de 1980, así como las repercusiones que las mismas suscitaron y las discusiones contemporáneas al respecto $^{10}$. A fines de la década de 1990 , la revista de historia de la ciencia Osiris ${ }^{11}$

\footnotetext{
${ }^{10}$ En forma paralela, desde la década de 1970 los historiadores de la ciencia comenzaron a aceptar de forma gradual un enfoque construccionista social, considerando al desarrollo del conocimiento científico en su relación con las particularidades de las circunstancias locales, la gente, las epistemes y la política; y que no necesariamente conduce hacia una sola verdad (Nyhart, 2016).
} 
dedicaba un número especial al problema "mujeres, género y ciencia". Ese dossier, precedido por un workshop sobre el tema, reunía a un grupo de estudiosos alrededor de una pregunta en común: ¿cuál es la relación entre las investigaciones de mujeres y ciencia y las investigaciones de género y ciencia?. Las cuestiones sobre "mujeres y ciencia" y sobre "género y ciencia" se estaban desarrollando como tradiciones separadas y este dossier se dedicó a analizar la falta de diálogo entre ambas, señalándose la necesidad de intercambio y de colaboración entre los investigadores y las disciplinas que se dedicaban a cada línea de trabajo.

Por otra parte, en el año 2006 la revista de estudios de género brasilera Cadernos Pagu también realizó un dossier sobre "Género en la ciencia”. En la presentación del mismo, Lopes (2006) señala que términos como género, ciencia, feminismos, tecnologías, mujeres y corporalidades se han asociado cada más vez en los trabajos académicos de Brasil y América Latina. La inclusión de estos conceptos ha ampliado el campo de los estudios sociales de la ciencia y el análisis de las culturas científicas locales. En conjunto, los trabajos del dossier muestran que más mujeres de lo que se acostumbra a pensar participaron en las prácticas científicas de Brasil, Argentina y México. En relación con ello, Lopes $(1998,2005)$ señala que la influencia de los estudios de ciencia y género y de epistemología de la ciencia surgidos en la década de 1970 en Estados Unidos llegó más tardíamente a Latinoamérica. Si bien el campo de la historia de las mujeres se desarrolló ampliamente en Brasil y en países vecinos, las cuestiones más específicas de las mujeres en la historia de la ciencia avanzaron lentamente y se desarrollaron principalmente dos áreas de estudios: una dedicada a los indicadores científicos que analizan la participación femenina, y la otra a explicar la ausencia de mujeres en los estudios sobre la historia de la ciencia (Lopes, 2005).

Para revisar los antecedentes sobre estos temas y ofrecer un panorama general de los mismos, en esta sección se focalizaran en dos grandes grupos de trabajos: por un lado,

\footnotetext{
${ }^{11}$ Osiris, 2nd series, Vol. 12, Women, Gender, and Science: New Directions (1997). Editado por Sally Gregory Kohlstedt y Helen Longino.
} 
aquellos dedicados a la reflexión epistemológica de la ciencia desde una perspectiva de género, $y$, por otro los trabajos que se ocupan de las cuestiones referentes a las mujeres y a las relaciones de género en la ciencia.

$\underline{\text { Las reflexiones epistemológicas de la ciencia con perspectiva de género }}$

Los trabajos dedicados a las relaciones entre ciencia y género, parten de la aseveración de que la categoría "género" ha sido generalmente ignorada al estudiar los contextos sociales e históricos de la ciencia. Así, las historiadoras feministas comenzaron a indagar en las implicaciones de género, tanto en el trabajo intelectual de las mujeres como en las formas de investigación científica y sus resultados. Esto implicó un tipo de investigación de orientación filosófica, considerado bajo el título de "epistemología feminista", y dentro del cual, Kohlstedt y Longino (1997) identifican tres áreas temáticas principales.

Una de esas áreas temáticas está conformada por la crítica a las formas de representación de lo masculino y lo femenino, el sexo y las diferencias sexuales en diferentes teorías científicas contemporáneas. Dichas formas de representación se analizaron, por ejemplo, en relación a las formas de recolección y organización de los datos o en términos más generales en relación a la estructura de los programas de investigación. Entre ello, se puede mencionar a Anne Fausto-Sterling (1987) que ha trabajado sobre las formas en que las pautas culturales influencian la construcción de las teorías científicas, especialmente en la biología; analizando casos de estudio como los experimentos de fertilización y desarrollo embrionario realizados con ranas por el italiano Spallanzani en el siglo XVIII. En esta línea, Londa Schiebinger (2004) analiza la representación anatómica de los cuerpos masculinos y femeninos a fines del siglo XVIII, momento que define de “revolución en las opiniones científicas sobre la sexualidad". Entre otras cosas, esta autora muestra cómo las ilustraciones de esqueletos femeninos y masculinos eran utilizadas para reproducir los ideales de la época sobre masculinidad y feminidad. 
Una segunda línea de indagación ha sido el estudio de las imágenes y metáforas "generizadas" en la producción de teorías científicas que se dedican a objetos "sin género". Por ejemplo, Evelyn Fox Keller $(1995,2001)$ ha realizado diversos trabajos que analizan las imágenes y metáforas de la ciencia: “Cuando apodamos «duras» a las ciencias objetivas en tanto que opuestas a las ramas del conocimiento más blandas (es decir, más subjetivas), implícitamente estamos invocando una metáfora sexual en la que por supuesto «dura» es masculino y «blanda» es femenino.” (2001: 149). También Carolyn Merchant (1980, 2006) ha analizado las implicaciones de la metáfora de la naturaleza como femenina.

Por último, la tercer área temática corresponde a los cuestionamientos acerca de cómo han afectado las relaciones de género las concepciones del conocimiento. Estos estudios más bien conceptuales sobre el género han puesto en cuestión aspectos de la ciencia tales como su objetividad y neutralidad, así como el papel del sujeto cognoscente y su relación con el conocimiento producido. La "epistemología feminista" abarca un grupo variado de posiciones teóricas, tanto en relación a la epistemología como al feminismo. El punto en común entre las distintas posturas reside en la crítica a la epistemología "tradicional" y en la adopción de los desarrollos postkuhnianos de la filosofía de la ciencia que propiciaron el abandono de la visión de la ciencia como objetiva, neutral, racional e intersubjetiva (González García y Pérez Sedeño, 2002). Así, desde diferentes áreas y temas de investigación las científicas feministas ampliaron el ámbito de la crítica constructivista social de la ciencia (Fausto-Sterling, 1987, 1992). Algunas de ellas, como Sandra Harding (1986) y Donna Haraway (1988) plantearon discusiones epistemológicas acerca del/los sujeto/s productores de conocimiento, proponiendo respectivamente la epistemología de los puntos de vista y de los "conocimientos situados". Haraway (1988), en particular, defendió la "perspectiva parcial", que otorga autoridad y agencia a individuos que antes no la tenían, mostrando, además, el esfuerzo comunitario para llegar a un conocimiento compartido y fiable (Nyhart, 2016). Estas cuestiones se retoman en parte en esta tesis, especialmente para considerar la forma en que se han construido los discursos canónicos sobre la historia de las ciencias antropológicas en la Argentina. Dichas historias han omitido en gran parte la 
presencia femenina en la historia disciplinar, lo cual permite discutir su objetividad y neutralidad en la elección y producción de objetos de estudio.

\section{Mujeres y relaciones de género en la ciencia}

Los trabajos históricos dedicados a las mujeres en ciencia, también llamados la "cuestión de la mujer en la ciencia" (González García y Pérez Sedeño, 2002) se dedicaron inicialmente a "recuperar" diferentes experiencias femeninas, generalmente ignoradas por las historias convencionales de la ciencia, basadas en "los grandes hombres" y sus teorías o en la reconstrucción de los linajes y aportes de las figuras consagradas (Kohlstedt, 1995; García, 2011b). En esta línea, se desarrollaron estudios que intentaban comprender la "escasez" de mujeres que se dedicaron y dedican a la ciencia. Por un lado, se produjo un conjunto de investigaciones que analizan los sistemas de investigación, desarrollo e innovación examinando el número de mujeres que se dedican a la tarea científica y su posición en el sistema jerárquico científico; considerando discriminaciones, diferencias en las carreras y la feminización de algunas disciplinas. Por otro lado, se ha estudiado la "invisibilización" de las mujeres en la ciencia a lo largo de la historia (González García y Pérez Sedeño, 2002; Maffia, 2007). En líneas generales, estos estudios se ocupan de tres grandes problemas: la ausencia de la mujer en la historiografía del desarrollo científicotecnológico; las estrategias institucionales y educativas que excluyeron a la mujer del mundo de la ciencia y la tecnología; y la dominación androcéntrica en la investigación científica y sus implicaciones sociopolíticas. Los trabajos en esta línea tuvieron un aporte fundamental en las décadas de 1980 y 1990, generando una enorme cantidad de investigaciones sobre biografías individuales, así como diccionarios de mujeres científicas, cátedras y seminarios de posgrado sobre las mujeres en la ciencia, comités y espacios específicos en asociaciones y eventos científicos, entre otros (Kohlstedt, 1995; Lopes, 1998, 2005). Así, la "existencia" de mujeres en la historia y sus contribuciones a la ciencia

fue ampliamente documentada. Este tipo de investigaciones también contribuyó a discutir y 
transformar el lugar de las mujeres científicas en las últimas décadas y a crear políticas científicas orientadas a la igualdad de género en diferentes instituciones (Fox Keller, 2006).

Con el tiempo, surgieron propuestas de análisis más complejas, con nuevas preguntas, las cuales han sido de gran aporte para esta investigación: estudios que comenzaron a ampliar su mirada analizando las circunstancias personales y externas que permitieron desarrollar las carreras científicas de las mujeres, así como los factores que inhibieron sus logros o el reconocimiento de sus aportes. En este sentido, muchos trabajos se han dedicado a la reconstrucción biográfica individual y colectiva de diferentes mujeres, adoptando perspectivas críticas. Ello permitió reconstruir prácticas femeninas en lugares y momentos específicos, más allá de las “grandes mujeres", poniendo en discusión las miradas más clásicas sobre la sub-representación o invisibilidad de las mujeres en la historia. Investigaciones como las de Rentetzi (2008), Schiebinger (2004) y Fox Keller (1983) aportaron nuevas formas de entender los entornos académicos, sociales, políticos e intelectuales, con detalles del trabajo y la vida privada de sus protagonistas: "No se trata solo de acumular nombres de mujer sino de analizar cómo sus historias de vida configuran en cada momento histórico las prácticas científicas y con ellas la ciencia misma.” (Santesmases, Cabré i Pairet y Ortiz Gómez; 2017:400). También estos trabajos analizan las dinámicas del trabajo femenino y las formas de colaboración que necesitaron las mujeres para acceder a la información y a los instrumentales científicos. Al posicionarse desde un enfoque crítico a la historiografía tradicional de mujeres y ciencia centrada en el "rescate" de las "precursoras" o "pioneras", estos trabajos señalaron las barreras y obstáculos de analizar biografías aisladas de factores tales como las prácticas científicas, los cambios en la organización social e institucional de trabajo científico -entre otros- que posibilitaron la presencia femenina en ciertos espacios (García, 2006).

Otro aspecto desarrollado son los papeles de género en la profesionalización de la ciencia y la tecnología, a partir del cual se ha buscado identificar lo que se considera ciencia en un momento y lugar determinados y cómo intervienen las expectativas para mujeres y hombres en dicha clasificación (Shteir, 1996; Kohlstedt, 1995; Kohlstedt y Longino, 1997). También se han llevado a cabo un conjunto de estudios que discuten cómo 
el género ha sido un factor significativo en la estructuración de las instituciones y las prácticas científicas. La inclusión de las categorías género y mujeres en los estudios sociales de la ciencia permitió una renovación que trajo nuevos desafíos y que retomó antiguas discusiones, gestadas en distintas disciplinas y migrados de un campo a otro (Lopes, 2006).

En este sentido, los trabajos realizados por Margaret Rossiter sobre las mujeres en las ciencias norteamericanas constituyen una referencia clásica y fundamental, puesto que sus trabajos rompen con el enfoque habitual de señalar la "excepcionalidad" de las mujeres. Rossiter (1982, 1995, 1997) examina las experiencias particulares de mujeres, en determinados lugares y disciplinas, mostrando cómo cada especialidad en la ciencia tiene sus propias tradiciones y sus propias dinámicas de incorporación de personal, entre otros aspectos. Asimismo, analiza las diferentes proporciones de mujeres en cada especialidad o disciplina científica ${ }^{12}$. Con ello, propone una revisión de saberes y categorías, con la intención de ubicar los casos de estudio en una escala mayor, una "taxonomía de las disciplinas y de las experiencias femeninas dentro de ellas" (Rossiter, 1997: 183). Lo que muestra la autora son patrones ${ }^{13}$ en los sub-campos o especialidades, los cuales tienen una condición histórica que, de modo reciente, se ha ido modificando en algunos campos de saber gracias a la aplicación de políticas específicas de equidad de género. A partir de esta "taxonomía" señala las diferencias de distribución de la proporción femenina al interior de cada campo y que las mismas varían históricamente, considerando la variabilidad entre estos espacios como un fuerte indicador de diferencias en las oportunidades de formación para las mujeres. Las diferencias y variaciones son interpretadas como el resultado de

\footnotetext{
${ }^{12}$ De hecho, afirma: "the single most important indicator or predictor of a woman's experiencie in science is the proportion, though changing over time, of women in her field or subfield." (Rossiter, 1997: 169)

${ }^{13}$ Los patrones surgen de la comparación de proporciones femeninas/masculinas y de su correlación con otras variables, como el prestigio social o el acceso a recursos económicos y sociales de cada campo de saberes. Así, Rossiter señala patrones vinculados con la feminización de ciertas especialidades científicas, con la presencia de asociaciones femeninas específicas, las posibilidades de acceso a cargos de mayor jerarquía para las mujeres, entre otros (Rossiter, 1997).
} 
patrones vinculados a tradiciones tanto institucionales como personales: aquello que parece el patrón de un subcampo puede ser el reflejo de un patrón institucional, que a su vez podría reducirse a un conjunto de redes personales de "protectores" (personal protégée networks) (Rossiter, 1997). Por último, Rossiter defiende la necesidad analítica de romper o subdividir esa "entidad agregada" llamada "ciencia" en singular; para entender las particularidades de cada campo y subcampo disciplinar, estudiando intensivamente sus características, pero sin perder de vista las cuestiones que refieren a cómo cada campo difiere, o no, de los otros (Rossiter, 1982, 1995).

En una línea de trabajo similar, Des Jardines (2010) muestra cómo a principios del siglo XX en Estados Unidos los efectos "masculinizantes" de la profesionalización de las ciencias redefinen la relación de las mujeres con las mismas. Esta autora considera que la definición de "ciencia profesional" se basa en un concepto antitético: la ciencia del aficionado, definida en sus métodos y orientación como "doméstica". Así, las mujeres que se desempeñaban en entornos científicos profesionales lo hacían en una relativa "oscuridad", o se dedicaban a nichos como la pedagogía y la popularización de la ciencia. Y cuando hacían incursiones en los laboratorios de hombres era casi siempre como asistentes, técnicas y ayudantes (Des Jardines, 2010). Pomata (2013) ha relativizado esta mirada, al señalar cómo muchas mujeres "eligieron" dedicarse de forma amateur en la primera mitad del siglo XX, para poder contar con menos restricciones y reglamentaciones en la escritura o en los temas elegidos, o como forma de evitar la segregación o las oportunidades más limitadas de ciertos espacios académicos.

También en esta línea de análisis se ha trabajado acerca de la participación de las mujeres en instituciones tales como museos y laboratorios. En este sentido, destacan los trabajos de Leslie Madsen-Brooks $(2009,2013)$ sobre la participación femenina en museos de historia natural y en dependencias científicas estatales en Estados Unidos; y de Natalie Pigeard Micault (2013) sobre el laboratorio de Marie Curie en Francia y la fuerte presencia de mujeres en el mismo. En esta línea también se encuentran las investigaciones que se dedican a la participación o admisión de mujeres en las asociaciones científicas (Petrovich, 1999; Schiebinger, 2004; Higgit y Whiters, 2008; Terral, 2015). En relación con ello, 
Lothar y Helga Sprung (1996) proponen modelos femeninos de incorporación a la actividad científica, considerando que la participación de mujeres en lugares "masculinos" comúnmente se articuló en relación a papeles "femeninos tradicionales" como el de esposa, amante, compañera o discípula. Muchas veces, las conexiones familiares y personales favorecieron la entrada de las mujeres: muchas de las primeras mujeres fueron hermanas, hijas, esposas o amigas de hombres que ya estaban en el campo (Rossiter, 1997).

Este conjunto de trabajos muestran las dinámicas específicas de incorporación y de participación de las mujeres en la ciencia en distintos contextos y épocas históricas. Justamente, al enfocar en las prácticas específicas de ciertos campos de saberes, disciplinas o espacios institucionales, se corren de los trabajos más tradicionales de "visibilización" de figuras aisladas y se dedican al estudio de las mujeres de una forma más relacional, vinculada a espacios concretos. En ese sentido, algunos recientes trabajos tratan de evitar la tentación de analizar la vida y obra de un científico o una científica como si fueran resultados de la voluntad de agentes individuales, separados de sus aliados, colaboradores y localizaciones institucionales y culturales (García, 2006). Por otra parte, muchos trabajos de historia de la ciencia, en vez de centrarse en "los grandes figuras" o los practicantes consagrados de la ciencia, han seguido a una serie de actores casi invisibles en las historias convencionales de cada disciplina, pero ineludibles para entender la dinámica de la producción del conocimiento y de la circulación de objetos, ideas y saberes en el mundo de la ciencia y fuera de él (García, 2018).

En los últimos años, las perspectivas más contemporáneas de la historia de la ciencia se enfocaron en las mujeres en diferentes ámbitos y prácticas, no solamente en los espacios institucionales más "tradicionales" sino también en las expediciones y trabajos "de campo", en las tareas desarrolladas en ámbitos domésticos, en asociaciones científicas y de aficionados, entre otros espacios.

En relación con ello, aparece la cuestión de los difusos límites entre los espacios "públicos" y los espacios "privados" y el aspecto "doméstico" de la práctica científica, como muestran los trabajos de Schiebinger, 1999; Opitz, Bergwik y Van Tiggelen, 2016, 
entre otros. Así, se discute lo que podría llamarse "la empresa familiar de la ciencia", donde el núcleo familiar -hermanos, hijos, esposos, nietos- colabora en las actividades cotidianas y rutinarias de recolección de muestras, ilustración, etiquetado y registro de colecciones, traducciones, transcripción de notas, fichaje de bibliografía, organización de archivos y correspondencia, entre otras tareas menores y rutinarias pero imprescindibles del quehacer científico.

La vinculación de las mujeres con la ciencia a partir de sus relaciones familiares ha sido una cuestión ampliamente analizada, especialmente en cuanto al trabajo colaborativo entre parejas o matrimonios (Margaret Rossiter 1982, 1995; Mariza Corrêa, 1995; Pycior, Slack y Abir-Am, 1996; Lindsay, 1998; Handler, 2004; Kohlstedt, 2012). En relación con ello, varios trabajos han mostrado el papel de las esposas en el trabajo científico o en las publicaciones firmadas por sus maridos. En varias ocasiones se ha mostrado el trabajo colaborativo en el seno de la pareja, siendo frecuente que esta simetría no se refleje en las publicaciones, firmadas por los hombres. Por otra parte, los miembros femeninos de la familia de un científico, podían participar informalmente de la actividad científica, realizando trabajos como asistentes, secretarias, ilustradoras, organizadoras de colecciones o financiando la compra de materiales o viajes de sus esposos, entre otras tareas ${ }^{14}$. Por ejemplo, Podgorny (2006) muestra cómo Emma Bravard, esposa del paleontólogo y comerciante francés que actuó en la Argentina, Auguste Bravard, le permitió a este tener éxito en su carrera como naturalista. Asimismo, da cuenta de las diferentes tareas que podían realizar las esposas no científicas desde la administración de los fondos de la venta de colecciones de su esposo hasta su participación en las prácticas taxonómicas de la zoología de mamíferos. A partir de este caso, Podgorny -al igual que otros historiadores de matrimonios en ciencia- concluye que algunos personajes femeninos han sido "sepultados" por las biografías de sus esposos, a pesar de haber sido relevantes en la logística de la

\footnotetext{
${ }^{14}$ Como ejemplo de ello, se puede señalar el caso de la antropóloga Jean McWirth Pinkley, la primera y por mucho tiempo la única mujer en el National Park Service, en el cual fue contratada durante la Segunda Guerra como Jefa de Arqueología en el Parque Nacional Mesa Verde, gracias a su padrasto que era oficial en el mismo (Rossiter, 1997).
} 
práctica de disciplinas tales como la paleontología del siglo XIX o las ciencias biológicas del siglo $\mathrm{XX}^{15}$.

Por último, se pueden señalar los estudios de ciencia y género que se dedican a la situación reciente de las mujeres en la ciencia y la tecnología. Los mismos analizan los sistemas de investigación, desarrollo e innovación científica, examinando la proporción de mujeres, su distribución por disciplinas y su posición en el sistema jerárquico científico; teniendo en cuenta discriminaciones y sesgos de género, diferencias en las carreras y la feminización de algunas disciplinas. Estas investigaciones señalan cuestiones como la escasa representación femenina en algunas carreras científicas como las ingenierías, las altas tasas de abandono entre aquellas que ingresan y la subrepresentación de mujeres en los puestos de decisión en el sistema científico (Estebanez, Filippo y Serial, 2003). Estos enfoques sobre problemas contemporáneos de las mujeres en los sistemas de ciencia y tecnología no son contrarios a los desarrollados de forma histórica, y en muchos casos mantienen puntos y perspectivas comunes ${ }^{16}$.

\section{Los estudios históricos de mujeres y ciencia en la Argentina}

La mayoría de los trabajos que analizan a las mujeres en la historia de la ciencia en la Argentina se dedican a estudiar las experiencias de las universitarias o de algunas “mujeres destacadas", en general vinculadas con los museos nacionales y otras instituciones

\footnotetext{
${ }^{15}$ En el capítulo 5 se verán en detalle estos aspectos de las prácticas familiares en la empresa científica.

${ }^{16}$ Los estudios realizados en los últimos veinte años sobre "género, ciencia y tecnología" han señalado la escasez de trabajos sistemáticos o sostenidos en el tiempo que se dediquen a analizar la participación diferencial de hombres y mujeres en las actividades de investigación, así como las especificidades en el desarrollo de las carreras científicas femeninas en la Argentina (Estebanez, Filippo y Serial, 2003; Estebanez et al, 2007). En esta línea, es destacable la labor de la Red Argentina de Género, Ciencia y Tecnología (Ragcyt) creada en 1994 y también de los informes realizados por la UNESCO, especialmente aquellos surgidos de la Cátedra Regional "Mujer, Ciencia y Tecnología en América Latina" y del Proyecto GenTEC, Proyecto Iberoamericano de Ciencia, Tecnología y Género.
} 
científicas de Buenos Aires y a Plata. Poco se conoce sobre las trayectorias de mujeres en otros lugares del país u otros espacios de producción y/o circulación del conocimiento, como parte de los diversos sujetos que intervienen en las prácticas cotidianas de las ciencias.

Un importante conjunto de trabajos se enfoca en las primeras mujeres que alcanzaron estudios superiores. Así, Palermo (2006) señala cómo dicho acceso estuvo marcado desde el inicio con elecciones diferenciales, acorde con una división "socio sexuada" del saber, donde las primeras egresadas a fines del siglo XIX estuvieron vinculadas a las ciencias de la salud: farmacia, obstetricia, medicina, odontología. Aunque estas carreras, especialmente la farmacia que era considerada como una carrera menor, constituyeron una "puerta de entrada" a los estudios universitarios para las mujeres, muy pronto las posibilidades y elecciones comenzaron a diversificarse. En 1896 se creó la Facultad de Filosofía y Letras en la Universidad de Buenos Aires (Buchbinder, 1997, 2005) y se permitió a las maestras matricularse sin más requisito que su título. De acuerdo con Denot (2007), la integración de la mujer a la vida universitaria fue particular en Filosofía y Letras, puesto que la distribución de los graduados por sexo muestra que las mujeres fueron durante sus primeras tres décadas de existencia, alrededor del 50\% de la población de graduados $^{17}$. Por su parte, Lorenzo (2016) analiza algunas fuentes estadísticas sobre ingreso y matriculación en términos de género. Según esta autora, las universitarias de la primera mitad del siglo XX tuvieron que enfrentar sucesivas trabas y prejuicios en distintas instancias de la formación y ejercicio profesional.

Las mujeres médicas de la Argentina de fines del siglo XIX y principios del siglo $\mathrm{XX}$ han sido las más estudiadas desde la historia de la ciencia y desde la historia de las mujeres, en parte por sus vínculos con los movimientos feministas de principios del siglo XX. En 1885 Élida Passo se recibió de farmacéutica y luego presentó un recurso judicial

\footnotetext{
${ }^{17}$ La mayoría, sin embargo, señala la ausencia de datos para ciertos períodos y la fragmentación de las estadísticas universitarias discriminadas por sexo. Ver, entre otros: Bonder, 1987; Palermo, 1998, 2000; García, 2011b; Lorenzo, 2016.
} 
para inscribirse en Medicina, carrera que no pudo finalizar porque falleció antes de graduarse en 1893. En 1889, Cecilia Grierson (1859-1934) terminó el doctorado en Medicina y Cirugía, siendo la primera egresada universitaria del país. La segunda médica recibida en Buenos Aires fue Elvira Rawson (1867-1954). Ambas mujeres, junto a otras profesionales que estudiaron en el extranjero y otras universitarias que se fueron sumando, tuvieron una acción política destacada en la lucha por los derechos civiles de la mujer y en la creación de diferentes agrupaciones y espacios institucionales, como el Consejo Nacional de Mujeres ${ }^{18}$ y la Agrupación de Universitarias Argentinas ${ }^{19}$.

A su vez, desde la cátedra de Historia de la Medicina (Facultad de Medicina, UBA) se han preocupado por el estudio generacional y prosopográfico de las primeras médicas argentinas, desde fines del siglo XIX hasta mediados del XX; profundizando en las biografías de cada médica, sus trabajos de investigación y espacios de inserción laboral y teniendo en cuenta los cambios y tendencias que se observan en cada generación (Kohn Loncarica y Sánchez, 1996, 2000) ${ }^{20}$. Como muestran esas investigaciones, a partir de la década de 1930 se incrementa la especialización en las áreas de inserción profesional y los cargos y espacios profesionales ocupados por las mujeres. En general, a partir de 1930 accedieron a cargos como profesoras en diferentes universidades y carreras, aunque se

\footnotetext{
${ }^{18}$ Esta asociación se creó en 1900, con la participación activa de Grierson y con el apoyo de la "matrona" Alvina van Praet de Sala, quien había sido presidenta de la Sociedad de Beneficencia de Buenos Aires. Con estas dos mujeres presidiéndolo, el Consejo reunió a un amplio espectro de mujeres, desde la elite porteña y provincial, a las representantes de asociaciones de inmigrantes, educadoras y profesionales; una alianza que se generaba por primera vez en el país bajo el lema "en pro de la elevación de la mujer" (Vasallo, 2000). Grierson se alejó del Consejo en 1910, disgustada por el "rumbo conservador" que tomó, entre otras cosas, al patrocinar el "Primer Congreso Patriótico de Mujeres" en 1910. Este congreso, se "enfrentó" al Primer Congreso Femenino Internacional, organizado por la misma época en Buenos Aires, donde se encontraban las feministas más vinculadas a la reivindicación de derechos políticos y que solicitan reformas sociales, educativas y políticas (Barrancos, 2010).

${ }^{19}$ Creada en 1901 por un grupo de mujeres universitarias. Esta agrupación es una de las que organiza el Primer Congreso Femenino Internacional en mayo de 1910.

${ }^{20}$ Sobre las primeras mujeres médicas, ver también: Barrancos, 2002; Lorenzo, 2016; Ramacciotti y Valobra, 2011 y Valobra, 2012.
} 
presentan algunos matices si se consideran las características e historias propias de cada facultad y universidad (Kohn Loncarica y Sánchez, 1996, 2000; Lorenzo, 2016).

En cuanto al análisis de la participación femenina en otros campos científicoacadémicos, se pueden mencionar los trabajos de Susana García (2006; 2011b) sobre las ciencias naturales, quien considera una serie de aspectos relacionados al ámbito científicoacadémico; tales como los criterios de reconocimiento y selección del personal en las instituciones, los contactos personales y vínculos familiares de las mujeres, los estereotipos sobre el trabajo femenino de la época, las disputas de poder; entre otros. A través de estas cuestiones, la autora da cuenta de las posibilidades laborales y las modalidades de ingreso a las instituciones científicas de comienzos del siglo XX. Según García (2006), la poca concurrencia de estudiantes en las carreras de ciencias naturales, tanto en La Plata como en Buenos Aires, pareció favorecer la situación femenina dentro de las mismas, pudiendo obtener becas, distinciones y premios y accediendo también a cargos de ayudante en museos y oficinas de investigación del gobierno. Muchas de ellas se destacaron por sus altas calificaciones, con lo cual pudieron acceder rápidamente a las becas y ayudantías disponibles y mantenerse en esos cargos o ser ascendidas a la siguiente categoría de jefes de trabajos prácticos o de laboratorio. En La Plata, las alumnas de ciencias cursaron en paralelo los estudios de profesorado, carrera que ofrecía mejores oportunidades laborales. Las egresadas en ciencias naturales no podían acceder a la docencia universitaria como profesoras. Al respecto, García señala que las mujeres permanecieron, al menos en un primer momento, en los estratos inferiores de las jerarquías académicas e institucionales; a pesar de que podían presentar las mismas credenciales y habilidades que sus colegas masculinos. El acceso a la posición superior de profesor universitario, fue mucho más difícil y en un proceso más lento que en el caso de los varones (García, 2006: 169).

Hacia finales de la década de 1920, existían un par de cargos de ayudantes y cuatro puestos de jefe de trabajos prácticos en el Museo de La Plata, tres de ellos ocupados por mujeres: el de Botánica, el de Paleontología y el de Mineralogía. García señala que en esa época persistían ciertas ideas sobre la adecuación de un sexo $u$ otro para realizar determinadas tareas, especialmente lo relativo al trabajo "de campo". Este criterio había 
servido de excusa para no tener en cuenta a las egresadas a la hora de analizar posibles candidatos y confeccionar una terna para el nombramiento de un profesor de zoología y jefe de Departamento en Biología, un cargo que comprendían reunir colecciones, explorar y realizar "trabajo de campo" en diferentes lugares. Para el entonces director del Museo, las naturalistas no podían aspirar a jefe de departamento y profesoras porque: "su condición de mujeres no les permite cumplir con todas las obligaciones inherentes al cargo, tales como salir a expedicionar en los diferentes Territorios de la República” (García, 2011b: 98).

En este caso, como sostiene García (2010) apelar a cierta “condición femenina” para desacreditar la postulación de las egresadas a cargos de mayor jerarquía en la institución, tenía como trasfondo la disputa entre grupos universitarios. Pocos años después, y tras el cambio en la dirección del museo, las expediciones por distintas zonas del país formaron parte de las tareas de botánicas y zoólogas de la institución (García 2011). Algunas de ellas realizaron viajes de campaña junto a su esposo, como la zoóloga María Hylton Scott quien viajó junto al zoólogo Max Birabén, y sus hijos. Para ello acondicionaron una camioneta Ford como laboratorio para recorrer la Patagonia en la década de 1930 (Birabén, 1938; García, 2004). Como se analiza en el capítulo 5, el trabajo de campo formó parte de las tareas compartidas en los matrimonios científicos de la época.

Las trayectorias femeninas y las posibilidades de inserción profesional dentro de las ciencias geológicas argentinas, disciplinas con una "larga historia de hegemonía masculina", han sido analizadas por Silvia Ametrano (2008). Las “escasas" interesadas en la geología a comienzos de siglo, se dedicaron a la investigación en Mineralogía y Petrografía, áreas de trabajo de laboratorio que se fueron conformando como "territorio geológico" para las mujeres ${ }^{21}$ (Ametrano, 2008).

\footnotetext{
${ }^{21}$ Como ejemplo, se puede mencionar el caso de Juana Cortelezzi, egresada en 1909 del Museo de La Plata, donde se formó como farmacéutica y como profesora de enseñanza secundaria en ciencias naturales y química. Desde 1906, el Museo ofrecía estudios en ciencias naturales, farmacia, química y geografía y dibujo; carreras que atrajeron un porcentaje importante de mujeres. Cortelezzi fue docente en el Colegio de Señoritas de la Universidad de La Plata desde 1908 y a partir de 1920 trabajó como profesora de práctica pedagógica de
} 
Las primeras egresadas en las ciencias químicas también han sido tratadas en algunas publicaciones ${ }^{22}$, sobre todo desde una perspectiva biográfica. Susana Barberis (2009) señala las características de las primeras alumnas del Doctorado en Química de la Universidad de Buenos Aires, tomando como referencia distintas trayectorias de vida, basadas en entrevistas y memorias escritas de algunas protagonistas. Entre otras cuestiones, resalta cómo algunas de las egresadas tuvieron que conjugar el ejercicio de la profesión con el matrimonio y la crianza de sus hijos, teniendo que trabajar a veces en laboratorios domésticos; situación que es común a otras mujeres dedicadas a la ciencia a lo largo del siglo XX. Además, Barberis señala la separación entre mujeres y hombres en algunos espacios de la Facultad de Ciencias Exactas, Físicas y Naturales de Buenos Aires. Por ejemplo, hasta 1931 cuando se reformó el edifico, dicha facultad tenía una sala especial para las alumnas (llamada el "gineceo") para su tiempo libre fuera de clase. Lorenzo (2016) encuentra situaciones de segregación de género similares al analizar a las pocas mujeres que estudiaron ingeniería en la primera mitad de siglo $\mathrm{XX}^{23}$. Al respecto, la autora señala que la poca elección de las ingenierías se vincula con las valoraciones previas sobre esta carrera y afirma que la formación técnica que las jóvenes recibían antes de ingresar a la universidad era deficiente y que el campo profesional no atraía a las estudiantes por diversas razones, entre otras por la construcción de ciertas nociones que consideraban al

Mineralogía y Geología en el profesorado de la Facultad de Humanidades y Ciencias de la Educación. En 1928 fue nombrada Jefa de Trabajos Prácticos de la cátedra de Mineralogía y Geología del Museo. En esta institución ganó, en 1933, el concurso para el cargo de Profesor Titular en la cátedra de Mineralogía y Petrografía; siendo así la primera mujer en acceder a este puesto en la Universidad de La Plata (García, 2010, 2011b, 2016).

${ }^{22}$ En 1896 se creó en la Universidad de Buenos Aires la carrera para acceder al título de Doctor en Química, en la cual se egresó en 1901 el primer graduado y cinco años más tarde la primera doctora, Delfina Molina y Vedia (1879-1961). En la Facultad de Química y Farmacia de la Universidad de La Plata, se aceptaron desde los inicios como estudiantes regulares a los egresados de escuelas normales, lo cual facilitó que ingresaran las mujeres, destacándose además por sus altas calificaciones (García, 2006).

${ }^{23}$ Entre 1921 y 1940, el porcentaje de mujeres egresadas de las carreras de ingeniería de la Universidad de Buenos Aires no llega al 1\% del total. Para tener una referencia, en Medicina el porcentaje de mujeres egresadas en ese período es entre 30 y $38 \%$ y en Filosofía y Letras es entre 12 y 16\% (UBA) (Lorenzo, 2016:36). 
trabajo en las obras de construcción, en los talleres y las fábricas como poco apto para las mujeres (Lorenzo, 2016).

Por otra parte, se pueden señalar algunas investigaciones que se dedican a analizar casos específicos de mujeres que se desempeñaron en diferentes disciplinas e instituciones. Entre otros, se encuentran los trabajos de Hunter y Pyenson (2005) sobre la físico-química danesa Margrete Heiberg de Bose (1865-1952) ${ }^{24}$ quien se desempeñó como profesora adjunta de la Universidad Nacional de La Plata en $1909^{25}$, de Buschini (2007) sobre la médica italiana Eugenia Sacerdote de Lustig (Buschini, 2007) y de Gavrila (2016) sobre la Escuela de Visitadoras de Higiene Social de La Plata, creada en $1937^{26}$. Las primeras abogadas argentinas también han sido objeto de trabajos biográficos ${ }^{27}$.

Otros trabajos se nutren de los debates contemporáneos en la historia de la ciencia, mostrando un amplio espectro de espacios y actividades en las que participan las mujeres de diferentes formaciones, intereses y clases sociales. Entre ellos, cabe destacar los de Alejandra Pupio, quien se focaliza en el sur bonaerense y muestra las prácticas de coleccionistas, periodistas y maestras que fomentaron museos y colecciones locales y

\footnotetext{
${ }^{24}$ García $(2006,2011)$ menciona cómo su caso ha pasado no se ha tenido mucho en cuenta en los relatos sobre las primeras universitarias. Ver también: Von Reichenbach, Cecilia, "Margrete Heiberg-Bose: a Danish Chemist Pioneer of Physics in Argentina". En: Rodríguez-Sala, María Luisa y Zubieta García, Judith. (comp.) Mujeres en la ciencia y la tecnología: Hispanoamérica y Europa. México, 2005.

${ }^{25} \mathrm{Su}$ incorporación a cargo de un curso práctico de física experimental fue parte de las condiciones de trabajo exigidas por su marido, Emil Bose, quien fue contratado para la reorganización de los estudios en ciencias físicas y promover las investigaciones científicas en la universidad (García, 2011).

${ }^{26}$ En su trabajo incorpora y reflexiona el uso de algunas categorías propias del feminismo, como el "régimen político de la heterosexualidad", el "sexage" y la "división sexual del trabajo"; para reflexionar sobre sus posibilidades, límites y alcances en el estudio de la historia de las mujeres (Gavrila, 2016).

${ }^{27}$ Estas fueron María Angélica Barreda (1887-1963), egresada en la Universidad Nacional de La Plata en 1910 (García, 2006; Suárez, 2012; Arias, 2017); Celia Tapias (1885-1964) quien se recibió en la Facultad de Derecho de la Universidad de Buenos Aires en 1911 (Kohn Loncarica, Sánchez y Agüero, 1998; Suárez, 2012) y Elisa Ferreyra Videla (1895-1979) quien egresó en 1929 de la Universidad Nacional de Córdoba.
} 
actuaron a su vez como corresponsales e intermediarias entre los vecinos y los arqueólogos de instituciones nacionales entre las décadas de 1930 y 1950 (Pupio, 2005, 2011).

\section{La historiografía sobre las ciencias antropológicas en la Argentina}

Las publicaciones y ponencias dedicadas a revisar el pasado de la antropología argentina se han incrementado en las últimas décadas, observándose una proliferación de estudios desde diferentes enfoques y aproximaciones. Desde posiciones teóricas como la Sociología de la Ciencia (Hidalgo 1997-1998; Althabe y Schuster, 1999) y la Antropología de la Antropología (Guber, 2006, 2008), las investigaciones se ocupan de analizar trayectorias de figuras o personalidades de labor significativa ${ }^{28}$, de "grupos académicos" al interior de diferentes instituciones y de las instituciones mismas (Arenas, 1989-1990; Perazzi; 2003; Soprano 2006, 2011). Otras indagaciones han focalizado en los viajes científicos y las prácticas y relaciones en "el campo" (Guber, Bonnin y Laguens, 2007; Visacovsky y Guber, 2002; Bonomo y Farro, 2014; Córdoba, 2015), los espacios de enseñanza universitaria (Zabala, 2010; Bonnin y Soprano, 2011; Carrizo, 2015, Ballestero y Sardi, 2016; Davila, 2018), y las diferentes "corrientes" teóricas que influenciaron en las ciencias antropológicas de la Argentina y sus desarrollos locales (Farro, Podgorny y Tobías, 1999; Podgorny, 2001, 2002; Politis, 2006; Luco, 2010; Gil, 2010; Perazzi, 2013). Algunos trabajos se dedican a temáticas particulares o a las subdisciplinas, como el folklore (Blache, 1991-1992; De Jong, 2005; Dupey, 2012; Abduca, 2014; Escolar, 2014), la antropología física y biológica (Carnese y Pucciarelli, 2007; Soprano, 2008), la antropología social (Bartolomé, 2007; Guber, 2006, 2009a, 2010), la arqueología (Fernández, 1982; Ramundo, 2007, 2010; Saletta, 2010; Podgorny, 2001, 2002, 2004), las colecciones vinculadas a culturas o espacios específicos (Guber y Visacovsky, 1998; Bonnin, s/f; Núñez Camelino,

\footnotetext{
${ }^{28}$ Estos son quizás los más abundantes. Se pueden citar, entre otros: Arenas, 1998, 2002-2003, 2005; Babot, 1998; Ballestero, 2011; Ballestero y Sardi, 2016; Bravo, 2013; Carrizo, 2007, 2010; Córdoba, 2017; Dávila, 2015, 2018; Silla, 2012; Ramundo, 2017; Soprano, 2011.
} 
2005; Benedetti, 2006; Lindskoug, 2008; Biasatti, 2016), los desarrollos particulares de la antropología en diferentes regiones y localidades (Boschín, 1991-1992; Garbulsky, 2004; Bonnin, 2008; Berón, 2013; Heider y Curtoni, 2016), entre otros. En menor medida, se han generado reflexiones sobre el desarrollo de la historia de la antropología argentina como un campo de estudios, donde se discuten las formas predominantes a partir de las cuales se ha construido el pasado de las ciencias antropológicas y las posiciones teóricasepistemológicas de diferentes trabajos (Guber, 2009b; Name, 2012, 2013, 2015).

Otros trabajos que se nutren de los aportes y debates contemporáneos en la historia de la ciencia, han profundizado en las prácticas concretas y la cultura material que subyace al funcionamiento de estas disciplinas que combinan las prácticas de gabinete con el trabajo "de campo" (Podgorny, 2009, Podgorny y Lopes 2008), en la detección de los distintos niveles de coleccionistas (Pupio, 2005, 2011) y el relevamiento de las "instrucciones" institucionales y de las redes jerárquicas que organizaban la recopilación de la información de campo (Pegoraro, 2003), en los ámbitos de sociabilidad y las redes científicas nacionales e internacionales (Podgorny, 2000, 2005, 2007; Podgorny y Lopes, 2008; Farro, 2009), entre otras cuestiones. Desde hace más de dos décadas, se vienen analizando los museos argentinos, examinando las diferentes estrategias para la formación de sus colecciones y el funcionamiento de redes -nacionales e internacionales- de intercambio de objetos y de recolectores en diferentes territorios (Podgorny y Lopes, 2008; Farro, 2009). Estas redes funcionaron mediante instrucciones enviadas desde los museos y solicitando la colaboración de distintos miembros del gobierno nacional y provincial, de funcionarios escolares, profesores y coleccionistas particulares, entre otros. También se organizaron expediciones oficiales desde los museos, se estimularon las donaciones de particulares, se nombraron "corresponsales" en el campo y se compraron objetos a coleccionistas y a comerciantes de especímenes de historia natural, de objetos etnográficos y arqueológicos (Pegoraro, 2003, 2009; García 2007, 2011; Pupio, 2011). En esta tesis se retoman especialmente estos temas vinculados con los debates contemporáneos en la historia de la ciencia, para profundizar en las prácticas científicas, las redes de intercambio y de 
compilación de datos y los círculos de sociabilidad en los cuales participaron diferentes mujeres.

Todos estos trabajos muestran que durante la primera mitad del siglo XX, la antropología argentina -así como otras disciplinas científicas- atraviesa por ciertos procesos de ampliación institucional y de profesionalización. Si en el siglo XIX tuvo en los museos y en las colecciones argentinas un lugar privilegiado de institucionalización, en los primeros años del siglo XX, la universidad se presentó como el locus ideal para la producción de conocimiento y la formación de científicos locales (Podgorny, 2005). A comienzos del siglo XX las ciencias antropológicas se organizan en un conjunto de cargos docentes y científicos, nucleados principalmente en instituciones de Buenos Aires y La Plata. Cabe señalar que la antropología se había desplegado en distintos escenarios de la cultura: los museos, las sociedades eruditas, las colecciones y las bibliotecas privadas (Lopes, 2000; Podgorny, 2004). En las ciencias del hombre, en particular, en las primeras décadas del siglo XX la práctica de la arqueología, la etnografía y la antropología en la Argentina se articulaba a través de dos formas (Podgorny, 2004). Por un lado, los ámbitos privados, tales como las sociedades eruditas, las asociaciones, los vínculos de parentesco, la comunidad de origen, los grupos políticos y los clubes. Por otro lado, las instituciones estatales, tales como las cátedras universitarias y museos.

A partir de 1930 en las ciencias antropológicas se produce un recambio de quienes ocupaban los cargos docentes y científicos de las instituciones de Buenos Aires y La Plata, tras la jubilación y/o la muerte de las figuras que ocuparon esas posiciones desde principios del siglo sin formar discípulos ni consolidar grupos de trabajo (Podgorny, 2004b, García, 2010).A ello confluye también el fomento de las instituciones académicas y museos en las provincias argentinas (García, 2011a) y la promoción del estudio de las culturas regionales, incentivando el estudio de nuevas localidades y temáticas junto con el estímulo a estas disciplinas a través de la formación docente y cursos. En 1930 Milcíades Alejo Vignati reemplaza a Lehmann-Nitsche en la sección Antropología del Museo de La Plata. En la misma institución, Fernando Márquez Miranda ocupa de forma interina el lugar de Jefe de la Sección de Arqueología y Etnografía, dejado por Luis María Torres (1878-1937) en 
1932. En el Museo Etnográfico fallece su director Salvador Debenedetti y su cargo es ocupado por Félix Outes.

Por otra parte, en las décadas de 1920 y 1930 se observa un crecimiento en la edición de trabajos dedicados a la síntesis de discusiones y teorías de las ciencias antropológicas $^{29}$, también aumenta la realización de encuentros nacionales e internacionales y el reconocimiento público de la disciplina (Podgorny, 2002, 2004). Sin embargo, Podgorny señala que será determinante "la imposibilidad de reproducción de los arqueólogos argentinos a través de la cátedra y la universidad" (Podgorny, 2004: 166). Recordemos que desde el establecimiento de la Universidad Nacional de La Plata en 1906, se ofrecían los cursos de Arqueología y Etnografía Americana en el Museo de La Plata, aunque la presencia de estudiantes en la misma era escasa o nula (García, 2010) ${ }^{30}$. Con la excepción del caso de Ambrosetti/Debenedetti en el Museo Etnográfico de la Buenos Aires, "los cargos en las cátedras argentinas no se reemplazan por los discípulos (inexistentes) del profesor saliente, sino por profesores formados en otras disciplinas e instituciones, circunstancia que ayudaría a crear las condiciones para la discontinuidad de las tradiciones y temas de investigación" (Podgorny, 2004: 167).

Muchas investigaciones sobre la historia disciplinar han tomado las ya clásicas periodizaciones ${ }^{31}$ del desarrollo disciplinar, sin profundizar en otros aspectos o cuestiones

\footnotetext{
${ }^{29}$ Se pueden señalar, entre otros: Epítome de Culturología (1936) de Imbelloni, "Esquema de las áreas culturales del territorio argentino" (1932) de Palavecino, Los primitivos habitantes del territorio argentino (1930) de Serrano y el volumen sobre los tiempos prehistóricos y protohistóricos que publicó en 1936 la Academia Nacional de la Historia como parte de la obra Historia de la Nación Argentina (Podgorny, 2002).

30 "Arqueología" estuvo a cargo de Debenedetti entre 1912 y 1930, dictándose para un alumno por primera y única vez en 1915. En el plan de estudios vigente desde 1926, la asignatura de Etnología y Arqueología Americana se dictaba para los estudiantes de cuarto año inscriptos en la orientación antropología, cosa que nunca sucedió hasta 1934 (Podgorny, 2004; García, 2010).

${ }^{31}$ Las periodizaciones más utilizadas son las de Guillermo Madrazo (publicado en 1985 por el Instituto de Antropología de Tilcara), de Edgardo Garbulsky (publicada en 1991 en la Revista Runa del Instituto de Ciencias Antropológicas de la UBA) y la de Hugo Ratier y Roberto Ringuelet (presentada en el panel "La
} 
vinculadas con las ciencias antropológicas. En los últimos años las periodizaciones se pusieron en discusión, desarticulando las asociaciones establecidas entre las ideas teóricas y la afiliación política-ideológica de los principales representantes de la época ${ }^{32}$. En estos cuestionamientos, se ha señalado el fuerte vínculo entre la historia disciplinar y los cambios políticos a nivel estatal, desconociendo las características propias del campo y de las diferentes instituciones de cada provincia (Guber, 2009, Soprano, 2007). A ello habría que sumar que estas reconstrucciones históricas contribuyeron a reproducir una historia basada en las "grandes" personalidades e instituciones. Asimismo, se ha señalado que entre 1930 y 1950 las ciencias del hombre tuvieron una fuerte presencia de las orientaciones históricoculturales. Este "período" se ha entendido como un momento intermedio y de "detracción”, una etapa oscura de la antropología asociada al "aislamiento disciplinar" (Garbulsky, 2000) y concebida como autoritaria, lo cual se habría puesto de manifiesto en el "ascenso" de la escuela histórico-cultural y de la figura de José Imbelloni (1885-1957). Estas interpretaciones han sido poco discutidas y los antecedentes que trabajen desde una perspectiva crítica las prácticas antropológicas de estos años son escasos. En este sentido, los temas que se trabajan en esta tesis permiten ampliar o discutir algunas construcciones históricas sobre la conformación de las ciencias antropológicas en estos años. Así, se intenta mostrar que al contrario de ser un momento de "detracción" u "oscuridad" en las ciencias antropológicas, en las décadas de 1920 a 1940 se observa la creación de museos e instituciones en las provincias, el surgimiento de sociedades específicas como la Sociedad Argentina de Antropología, la promoción de estas disciplinas y la proliferación de actividades destinadas a la difusión y al intercambio de diferentes investigaciones y saberes.

Estos antecedentes muestran cómo ha crecido el interés en analizar la historia de la antropología en la Argentina, especialmente en los últimos veinte años. Sin embargo, pocos

construcción de la Antropología en el Cono Sur”, en la Reunión de Antropología del Mercosur, 1995). Ver el artículo de Guber (2009) para mayores detalles sobre estos trabajos.

${ }^{32}$ Ver especialmente sobre este tema el trabajo de Guber (2009), donde se analizan comparativamente algunas de las periodizaciones más utilizadas. 
trabajos se han ocupado de las intersecciones entre historia de la disciplina y género. Por lo general, las figuras de la historia antropológica que han sido trabajadas, tanto en relación a sus aportes teóricos y metodológicos como en sus posiciones institucionales, son masculinas y las mujeres son mencionadas ocasionalmente. La mayoría de las mujeres de "renombre" en la historia disciplinar son aquellas que contribuyeron con la antropología a partir de las décadas de 1950 y 1960. Sin embargo, la participación femenina, si bien no ha sido mayoritaria, puede registrarse desde comienzos de siglo XX, como ha mostrado Barrancos (2000) en relación a las pocas mujeres que presentaron sus trabajos en el XVII Congreso Internacional de Americanistas, celebrado en Buenos Aires en 1910.

Algunos de los estudios sobre la historia de la antropología, al analizar los contextos institucionales de la disciplina mencionan la participación o presencia de las mujeres, sobre todo de aquellas que alcanzaron mayor reconocimiento a partir de la década de 1960. En la mayoría de las ciencias en las décadas de 1950 y 1960 la situación femenina cambia respecto de las primeras décadas de siglo $\mathrm{XX}$, registrándose mayor presencia $\mathrm{y}$ reconocimiento hacia su trabajo (Rossiter, 1997). En este sentido, resultan un antecedente importante los trabajos de Rosana Guber (2006), quien señala cómo hacia mediados del siglo XX algunos estudiantes provenientes del Profesorado de Historia de Buenos Aires llegaban a interesarse por temas antropológicos, entre ellos ciertas figuras femeninas. Asimismo, Guber $(2006,2013)$ ha desarrollado varios trabajos que centran su análisis en la figura de María Esther Álvarez de Hermitte (1921-1990) 33; pero los mismos no han profundizado sobre la situación femenina en las ciencias antropológicas.

Entre las décadas de 1920 y 1940 se detecta la participación de mujeres en diferentes espacios vinculados con las ciencias antropológicas. Por un lado, dentro del ámbito universitario, es posible identificar a un grupo de estudiantes y egresadas de diferentes carreras universitarias que orientan sus intereses hacia estas temáticas. En

\footnotetext{
${ }^{33}$ Hermitte cursó el profesorado de Enseñanza Media, Normal y Especial en Historia de la Facultad de Filosofía y Letras de la Universidad de Buenos y en 1958 consigue una beca externa del reciente CONICET para realizar sus estudios de posgrado en la Universidad de Chicago, Estados Unidos (Guber, 2013).
} 
general, provienen de los Profesorados ofrecidos por la Facultad de Filosofía y Letras de la Universidad de Buenos Aires y por la Facultad de Humanidades y Ciencias de la Educación de la Universidad Nacional de La Plata. Algunas pocas cursaron sus estudios en el Museo de La Plata, donde optaron por la orientación antropológica. Las clases acercaban a los estudiantes a diferentes actividades como conferencias y charlas, permitiendo también el contacto con las colecciones y con el trabajo cotidiano de los pocos "especialistas". Las estudiantes solían desempeñarse como técnicas o asistentes en los museos, dedicándose a la ilustración científica, el fichaje de bibliografía y el ordenamiento de las colecciones. Por otro lado, se observa una activa participación femenina en espacios de asociacionismo científico y cultural. En el siguiente capítulo se profundiza en un conjunto de mujeres que integraron la Sociedad Argentina de Antropología, así como otras sociedades científicas de la época. Por otra parte, muchas de las mujeres identificadas en este período desarrollaron sus actividades en espacios privados y domésticos o en ámbitos escolares y en instituciones regionales y locales de diferentes provincias de la Argentina. En los capítulos 3 y 4 son tomados algunos casos que permiten dar cuenta de las prácticas llevadas a cabo por las mujeres en dichos ámbitos. 


\section{Capítulo 2. Espacios institucionales y asociacionistas. La Sociedad Argentina de}

Antropología (1936-1945)

\section{Introducción}

Entre las décadas de 1920 y 1940 se detecta la participación de mujeres en diferentes espacios vinculados con las ciencias antropológicas. En torno al ámbito universitario, es posible identificar a un grupo de estudiantes y egresadas de diferentes carreras universitarias que orientan sus intereses hacia estas temáticas, como se observa en la membresía y entre el público que asistió a las actividades de la Sociedad Argentina de Antropología, creada en 1936. Otras mujeres identificadas en este período desarrollaron tareas vinculadas a las ciencias antropológicas, ya sea de forma privada o en instituciones regionales y locales de diferentes provincias de la Argentina. En este período, además, se amplía la participación femenina en espacios de asociacionismo científico y cultural.

En este capítulo se presenta un panorama general de los ámbitos institucionales de las ciencias antropológicas en ese periodo, mencionando las cátedras e institutos universitarios, los espacios de los museos y la expansión de las instituciones regionales y de los espacios asociativos. En relación con esto último, se presta especial atención al funcionamiento de la Sociedad Argentina de Antropología, por ser la primera asociación especializada en las ciencias del hombre en el país. Asimismo, se examina la afíliación femenina y las trayectorias científico-académicas de algunas de sus primeras socias activas. Con ello se busca mostrar parte de las posibilidades (y también limitaciones) que tuvieron las mujeres en los espacios de sociabilidad científica, de intercambio y de difusión de ideas y de formación y entrenamiento en las prácticas científicas. 


\section{Los espacios institucionales de las ciencias antropológicas}

\section{Cátedras y espacios de enseñanza de las ciencias antropológicas}

Las primeras cátedras universitarias dedicadas a las ciencias antropológicas en la Argentina surgieron entre fines del siglo XIX y comienzos de siglo XX, para la formación humanística y también para los estudiantes de ciencias naturales. En 1898 se creó la cátedra de Arqueología Argentina a cargo de Samuel Lafone Quevedo y en 1905, la de Antropología dictada por el antropólogo alemán Robert Lehmann-Nitsche, quien antes había dictado un curso libre de antropología (1903) y de paleoantropología (1904). Ambas cátedras pertenecían a la Facultad de Filosofía y Letras de Buenos Aires, y formaban parte de la sección de Letras e Historia (Buchbinder, 1997). A partir de 1907, el curso de Antropología también era cursado por los alumnos de ciencias naturales de la Facultad de Ciencias Exactas y Naturales de Buenos Aires (García, 2003, 2010). Paralelamente, en la Universidad Nacional de La Plata, la formación de naturalistas en el Museo de La Plata incluyó cursos de Antropología, que fueron dictados por Lehmann-Nitsche a partir de 1907 y hasta su jubilación en 1930, y en los distintos planes de estudios también se incluyeron cursos de arqueología, etnología y lingüística (Podgorny, 2005b, García, 2003, 2004, 2010).

Asimismo, desde 1906 la asignatura Antropología, a cargo del profesor normalista Rodolfo Senet hasta 1920, formó parte de los planes de estudio de los distintos profesorados de enseñanza secundaria organizados por la Sección Pedagógica de la Facultad de Ciencias Juridicas y Sociales de La Plata, Sección que será trasformada en la Facultad de Ciencias de la Educación en 1914 y luego en la Facultad de Humanidades y Ciencias de la Educación (García, 2010).

En las primeras décadas del siglo XX, los egresados universitarios que se doctoraron con una tesis vinculada a alguna temática de las ciencias antropológicas fueron muy pocos. Entre ellos, Carlos Marelli (1909, Facultad de Ciencias Exactas, Físicas y Naturales de Buenos Aires), Juliane Dillenius (1911, Facultad de Filosofía y Letras de 
Buenos Aires), Teodoro de Urquiza (1912, Instituto del Museo de La Plata), Abelardo Gallo (1928, Instituto del Museo de La Plata). En la década de 1930 no se registran doctorados en Antropología, meintras que en la década de 1940 se doctoran María de las Mercedes Constanzó (1940, Facultad de Filosofía y Letras de Buenos Aires) y Manuela García Mosquera de Bergna (1944, Escuela Superior de Ciencias Naturales de La Plata).

Otro espacio importante de formación superior en aquellos años, fue el Instituto Nacional del Profesorado Secundario, creado en 1904. Organizado inicialmente por un cuerpo de docentes y científicos alemanes, competía en la formación científica con las universidades nacionales (García, 2010). Allí se dictaron cursos de arqueología americana. Los alumnos y egresados, tanto varones como mujeres, de este institutito inclinados por las ciencias naturales y antropológicas fueron incorporados como adscriptos y ayudantes en el Museo Argentino de Cienciass Naturales durante la dirección de Martín Doello Jurado entre 1923 y 1946, quien también era docente en esa casa de estudios (Camacho, 1971; García, 2010, 2018).

Entre las décadas de 1930 y 1940, la Escuela de Ciencias Naturales del Museo de La Plata contó con dos profesores titulares y jefes de departamento. Milcíades Alejo Vignati, dirigió la cátedra y el Departamento de Antropología entre los años 1930 y 1955, mientras Fernando Márquez Miranda estuvo a cargo de la enseñanza y del área de Arqueología y Etnografía. Este profesor también dictó la materia "Disciplinas auxiliares de la Historia" en el Instituto Nacional del Profesorado Secundario de Buenos Aires, entre 1932 y 1944 y fue profesor de Prehistoria Argentina y Americana en la Facultad de Humanidades y Ciencias de la Educación de La Plata, como suplente entre 1922 y 1933 y como titular entre 1933 y $1944^{34}$. Las estudiantes que en estos años optaron por la orientación antropológica fueron Manuela García Mosquera de Bergna (doctorada en 1944), Delia Esther Dorato (inscripta en 1938), María Eva Eberle (inscripta en 1939) y María Elena Villagra de Cobanera (inscripta en 1941). Muchas de estas estudiantes fueron ayudantes en la cátedra y en la sección de Antropología: Manuela García Mosquera de

\footnotetext{
${ }^{34}$ También dicto clases de Historia en el Colegio Nacional de La Plata (1921-19033) y en el Colegio Nacional de Buenos Aires (1933-1950).
} 
Bergna ${ }^{35}$ fue ayudante alumna en 1941 y Eva Eberle de Gilardoni y Lilia Esther Chávez de Azcona $^{36}$ fueron ayudantes de laboratorio entre 1938 y 1944 (Soprano, 2009).

Por otra parte, en la Facultad de Filosofía y Letras de la Universidad de Buenos Aires se modificaron los planes de estudios a fines de 1920 y nuevamente en 1928. De acuerdo a Buchbinder (1997) estos planes aspiraban a mantener una formación integral, en una orientación vinculada con la tradición clásica. El primer año era común a todas las carreras y en la formación en Historia se incluían las cátedras de Antropología y Etnografía General y de Arqueología Americana, ambas en el segundo año. Arqueología Americana estuvo a cargo de Francisco de Aparicio a partir de 1930 (Guber, 2006) ${ }^{37}$. En 1933 José Imbelloni era profesor extraordinario de Antropología y Etnología General y en 1937 profesor titular de Antropología (Carrizo, 2014). En 1943, Imbelloni elaboró una propuesta de programa de estudios, publicada en el apéndice del libro Concepto y praxis del Folklore

\footnotetext{
${ }^{35}$ Manuela Carolina García Mosquera (1903-2001) se doctoró en Ciencias Naturales en el Museo de La Plata con la tesis "Indice cefálico, talla y proporciones en escolares de La Plata" defendida en 1944. En 1945 solicitó la adscripción a la cátedra de antropología a cargo de Vignati, la cual dos años después fue "reprobada" y rechazada por Vignati, luego de evaluar el trabajo de investigación y las dos clases dictadas por la aspirante, de acuerdo a la normativa de adscripciones vigente desde octubre de 1945. Finalmente, en 1948 y luego de este rechazo expresado por Vignati, Mosquera solicita que se cancele la solicitud de adscripción (Carpeta C, n 55, 1942-1944, AHMLP). Mosquera era directora de escuela en La Plata y también colaboró con su esposo, Luis Bergna en sus investigaciones antropométricas.

${ }^{36}$ Lilia Chávez de Azcona (1917-1986), egresó de la Facultad de Ciencias Naturales y Museo de La Plata en 1945, con orientación en Biología. Antes, en 1941, se había recibido de Profesora de Enseñanza Secundaria, Normal y Especial en Ciencias Biológicas en la misma universidad. Se desempeñó como ayudante alumna de la cátedra de Antropología en el Museo de La Plata entre 1938 y 1947 y entre 1948 y 1956 fue Jefa de Trabajos Prácticos en la misma cátedra, siendo también Ayudante de la Sección de Antropología (Fichero personal del personal del Museo, AHMLP). Se dedicó principalmente a temáticas vinculadas con el crecimiento y el desarrollo humano desde una perspectiva antropológica (Marcellino, 1985).

${ }^{37}$ El profesorado de Historia contaba con dos materias "antropológicas": Antropología (predominantemente física) y Arqueología (orientada a la Prehistoria). Las mismas se dictaban en el Museo Etnográfico. Al respecto, Guber señala la proximidad universitaria entre Geografía Humana o Antropogeografia, Antropología y Arqueología, la cual "se debía ya no sólo a su origen estatal-territorial en el avance sobre tierras indígenas (1850-1900), sino también a su lugar como disciplinas auxiliares de la Historia" (Guber, 2006: 9).
} 
como Ciencia $^{38}$, donde señala "este programa permitirá que se funde sobre bases firmes el currículum profesional de arqueólogos, etnólogos y folkloristas, lo que es de suma importancia para el futuro del país" (Imbelloni, 1943: 134). Con una intención similar, en 1945 Antonio Serrano destacó la conveniencia de organizar un Patronato de Investigaciones Arqueológicas e insistió sobre la urgente necesidad de contemplar la fundación de una Escuela Nacional de Antropología y de un Museo Nacional de Antropología. Para la Escuela propuso las carreras de Antropología, Etnografía, Arqueología, Lingüística y Folklore ${ }^{39}$. Estos proyectos no tuvieron éxito en lo inmediato. Hubo sin embargo un intento poco exitoso en 1947, cuando en la Universidad Nacional de Tucumán se creó la carrera de Ciencias Antropológicas. La misma fue cerrada en 1952 y de ella sólo egresaron dos personas: Miguel Ángel Torres y Graciela Soledad Nieto (Arenas y Carrizo, 2010) $)^{40}$. En La Plata, también se separaron las carreras del Museo de La Plata, estableciéndose la especialidad en Antropología en los últimos dos años de formación, a partir del cambio de plan de estudios aprobado en 1940.

En la Facultad de Filosofía y Letras de Buenos Aires, ya desde 1952 se podía realizar el grado en Filosofía, Letras e Historia con la posibilidad de optar por la especialización en Antropología. Asimismo, se creó una Licenciatura en Folklore en 1954 (Visacovsky, Guber y Gurevich, 1997). Luego en 1957 se reformó el plan de estudios de la carrera de Historia de la Facultad de Filosofía y Letras de la Universidad Nacional del Litoral. El mismo entró en vigencia en el año 1959 y contaba con opción de elegir la orientación "antropología” (Garbulsky, 2004). Finalmente, en 1958 se creó un programa de Licenciatura en Antropología en el Museo de Ciencias Naturales de la Universidad

\footnotetext{
38 J. Imbelloni, Concepto y praxis del Folklore como ciencia. Buenos Aires, Editorial Humanior, 1943,136 págs.

39 “Actividades Antropológicas en Argentina, 1945”, por Osvaldo L. Paulotti. En Boletín Bibliográfico de Antropología Americana (1937-1948), Vol. 8, No. 1/3 (enero-diciembre, 1945), pp. 14-18.

${ }^{40}$ Sobre la organización curricular de la carrera, ver: Revista del Instituto de Antropología, UNT, vol. 3, n³3, 1947.
} 
Nacional de La Plata y en 1959, en la Facultad de Filosofía y Letras de Universidad de Buenos Aires (Guber y Visacovsky 1999; Guber 2002; Ratier 2010).

$\underline{\text { Museos e institutos }}$

En las décadas de 1930 y 1940 se produce una ampliación institucional de las ciencias antropológicas, con la creación de museos, institutos y otros espacios de investigación y docencia en distintas provincias. Los museos provinciales creados en la década de 1910, de carácter educacional, como los de Mendoza, Paraná y Santa Fe se transformaran en museos de ciencias naturales y antropológicas (García, 2011). Estos museos regionales mantenían intercambios frecuentes entre sí y con los centros científicos de Buenos Aires y La Plata, mediante el envío de materiales para su clasificación y el canje de publicaciones, entre otras actividades (García, 2011; Pupio, 2011; Núñez Camelino, 2013). También en la década de 1930 se promueve la creación de museos históricos, junto con la promoción de legislación para el resguardo y protección de bienes históricos y la creación de la Comisión Nacional de Museos, Monumentos y Lugares Históricos en 1938 (Blasco, 2012). Los museos regionales y provinciales, como otros, utilizaron las circulares y las estructuras jerárquicas de la administración burocrática para recopilar muestras de la naturaleza y objetos históricos y arqueológicos (García, 2011).

Los museos y secciones antropológicas dentro de museos creadas en estos años son: el Museo Arqueológico Provincial de Santiago del Estero, reorganizado por los hermanos Emilio (1868-1949) y Duncan Wagner (1864-1937) ${ }^{41}$ en 1927 a partir de las colecciones

\footnotetext{
${ }^{41}$ Emilio Roger Wagner se dedicó a la entomología y al coleccionismo de flora y fauna en sus numerosas expediciones por el continente sudamericano, además de sus intereses arqueológicos. Él y su hermano mayor Duncan Ladislao Wagner llegaron por primera vez a la Argentina a fines del siglo XIX acompañando a su padre en un viaje diplomático y en 1898 Emilio se instaló en Santiago del Estero, comenzando un emprendimiento agropecuario en Mistol Paso, región de Icaño, donde también realizará numerosas expediciones arqueológicas. Duncan se instala en la provincia en 1927, cuando su hermano lo invita a colaborar con sus trabajos arqueológicos como vicedirector del Museo Arcaico creado en 1916 gracias a la donación de la colección particular de un aficionado, el intendente Alejandro Gancedo (h). Este museo en
} 
que pertenecían al Museo Arcaico; el Museo Arqueológico de Catamarca, anexo al Convento de San Francisco y dirigido por el padre Narváez, creado en 1936 (Caillet-Bois, 1947); la Sección de Arqueología y Etnografía del Museo Histórico Colonial y de Bellas Artes de Corrientes, creada en $1938^{42}$; y el Museo del Departamento de Estudios Etnográficos y Coloniales de Santa Fé, iniciado en 1943 con la dirección de Agustín Zapata Gollán (1895-1986) ${ }^{43}$. Asimismo, algunas provincias contaban con museos “generales”, los cuales ya venían funcionando y tenían colecciones antropológicas, como el museo de Mendoza y el de Paraná (García, 2011).

Museos como el de Santiago del Estero o el de Corrientes, aprovecharon el sistema escolar para facilitar la colaboración en la conformación de colecciones y para el trabajo en el campo. Por ejemplo, el Museo Arqueológico Provincial de Santiago del Estero organizaba conferencias sobre arqueología santiagueña en las escuelas locales y en el

1930 pasó a denominarse Museo Arqueológico Provincial y luego de 1950 Museo Arqueológico Provincial Emilio y Duncan Wagner (Martínez, Taboada y Auat, 2011).

${ }^{42}$ El Museo Histórico Colonial y de Bellas Artes fue fundado en el año 1928, teniendo como precursor al Museo Regional de la Provincia dirigido por el Profesor Valentín Aguilar desde 1920 (García, 2011; Núñez Camelino, 2013). El mismo era dirigido por una Comisión Honoraria que presidía el Ministro de Gobierno, Justicia y Culto, Pedro Bonastre. El Secretario de esa Comisión y Director del Museo era el escribano Víctor M. Claver.

${ }^{43}$ En 1940 se creó el Departamento de Estudios Etnográficos y Coloniales, por Ley n ${ }^{\circ} 2902$ de la Legislatura de la Provincia de Santa Fe con las siguientes finalidades: a) Realizar investigaciones originales de carácter etnográfico, histórico, arqueológico y folklórico, vinculadas con esta provincia; b) Reunir y organizar el material etnográfico, lingüístico, folklórico, toponímico, arqueológico e histórico necesario para esas investigaciones; c) Procurar por todos los medios la colaboración popular para reunir y coleccionar el acervo folklórico de la Provincia; d) Publicar los estudios e investigaciones que realice este Departamento; e) Establecer vinculaciones con instituciones de la misma índole, en especial con las instituciones científicas y universitarias . La iniciativa estaba ligada a la figura de Agustín Zapata Gollán un abogado y profesor de historia, que hacia fines de las década de 1930 comenzó a dedicarse a la arqueología, especialmente a la llamada arqueología histórica, siendo su principal proyecto la antigua ciudad colonial de Santa Fe. En 1941, en el marco del mencionado Departamento se creó el Museo Etnográfico por medio del decreto ${ }^{\circ} 38$ del Ministerio de Instrucción Pública, "para que el Departamento de Estudios Etnográficos y Coloniales realice eficazmente y en toda su amplitud los fines que inspiraron su creación, debe contar con los medios necesarios para formar un Museo Etnográfico" (Busso y Aimini, 2008). 
museo se dictaban talleres de alfarería y tejido en los que se usaban motivos decorativos de la alfarería arqueológica (Martínez, Taboada y Auat, 2011) ${ }^{44}$.

Muchas de estas instituciones tuvieron su origen en las figuras de coleccionistas y amateurs que cedieron o vendieron sus colecciones privadas, al igual que en los grandes museos creados a fines del siglo XIX, como el Museo de La Plata. Así sucede, por ejemplo, con la colección arqueológica de Enrique Amadeo Artayeta, que fue comprada por el Estado nacional para conformar la base del Museo de la Patagonia en 1939 (Pupio y Piantoni, 2016). También por esos años hubo coleccionistas y científicos que con menor o mayor éxito buscaron insertarse en puestos estables en diferentes instituciones, como se verá en el capítulo 4 al analizar las actividades de Wanda Hanke. También se puede mencionar al alemán Jorge von Hauenschild quien estableció un museo privado en Santiago del Estero y luego de varias negociaciones, consigue vender su colección a la Universidad de Córdoba, obteniendo un cargo en la misma (Lindskoug, 2008).

La ampliación institucional de espacios dedicados a las ciencias antropológicas surge en ese contexto de proliferación de museos provinciales y privados y de redes de intercambio, en un momento que algunos han definido de "consolidación universitaria" (Fernández, 1982), debido a la creación de cátedras e institutos dedicados a las disciplinas antropológicas en el interior del país. Entre los espacios vinculados a las universidades, se crean: el Instituto de Etnología de la Universidad Nacional de Tucumán, iniciado en 1928 con la dirección del etnólogo francés Alfred Métraux (1902-1963) ${ }^{45}$; el Instituto de

\footnotetext{
${ }^{44}$ Pegoraro (2017) ha trabajado sobre la utilización de las colecciones del Museo Etnográfico J.B. Ambrosetti por parte de grupos escolares y estudiantes universitarios, quienes dibujaban motivos o diseños de las cerámicas y tejidos indígenas. Esta autora muestra los múltiples usos que tenían las colecciones, tanto como objetos científicos para el estudio de las sociedades prehispánicas de la Argentina y de América del sur, como para relevar diseños y vincularlos con una dimensión artística.

${ }^{45}$ Si bien Métraux promueve publicaciones y realiza estudios etnográficos en la región, en noviembre de 1933 parte hacia Francia sin dar aviso a la Universidad y a pedido del etnólogo francés Paul Rivet (1876-1958), en 1934, se enrola en la expedición franco-belga a la Isla de Pascua junto con Henry Lavachery. Luego, retorna a París con la idea de buscar un nuevo puesto de trabajo, renuncia al Instituto de Etnología de Tucumán en 1935 realiza una estadía en el Museo Bishop de Honolulú hasta 1937 (Córdoba, 2017). Ese año, el instituto tucumano queda a cargo de Enrique Palavecino, quien crea el Departamento de Investigaciones Regionales (Califano, Pérez Diez y Balzano, 1985). Entre 1938 y 1942, el instituto fue dirigido por Radamés Altieri hasta
} 
Etnografía Americana de la Universidad Nacional de Cuyo, creado en 1940 y desde 1947 Sección de Arqueología y Etnología del Instituto de Historia y Disciplinas Auxiliares ${ }^{46}$; el Instituto de Arqueología, Lingüística y Folklore de la Universidad Nacional de Córdoba, iniciado con la dirección de Antonio Serrano (1899-1982) en 1941; el Instituto de Antropología de la Facultad de Filosofía y Letras de la Universidad de Buenos Aires (1947) y el Instituto de Antropología (1951/1952) de la Universidad Nacional del Litoral ${ }^{47}$. Por último, en el año 1946 se conformó el Instituto Étnico Nacional, dependiente del Ministerio del Interior de la Nación, el cual permaneció en funciones hasta 1955 y tuvo algunas dependencias provinciales (Lazzari, 2004; Soprano, 2009).

Algunas mujeres se vincularon con las instituciones mencionadas a través de distintas actividades, realizando donaciones de piezas, como asistentes a cursos, organizadoras de actividades, ilustradoras, asistentes, colaboradoras, encargadas de secciones y directoras de museos. También hubo mujeres que conformaron museos a partir de colecciones personales y que ofrecieron piezas y otros materiales como donación o venta a diferentes museos. Los coleccionistas de provincia formaron redes de intercambio de información, piezas, consejos, opiniones y apoyos (Pupio, 2011). Así, los datos ofrecidos por los maestros y por diferentes coleccionistas y aficionados formaron parte constitutiva de las prácticas científicas, participando de diferentes maneras en las redes de circulación y en la producción de datos científicos.

Como ejemplo de ello, se puede mencionar el caso de Olimpia Righetti (19101989), una maestra normal que en la década de 1930 empezó a colaborar en el museo

su fallecimiento. Luego, vuelve a ser dirigido por Enrique Palavecino y en 1946 es convocada como directora interina María de las Mercedes Constanzó (Arenas y Carrizo, 2010).

${ }^{46} \mathrm{Su}$ primer director fue Salvador Canals Frau, hasta 1946. Entre 1940 y 1950 impulsó la revista Anales del Instituto, dando a conocer "valiosos trabajos y comentario sobre la antropología (en su sentido amplio) del área americana en general y argentina en particular." (Schöbinger, 1960-62). En esta revista la participación de mujeres en sus artículos es frecuente. En 1947, este instituto pasó a ser la Sección Arqueología y Etnología del Instituto de Historia y Disciplinas Auxiliares, bajo la dirección del húngaro Dr. Miguel de Ferdinandy.

${ }^{47}$ El 13 de septiembre de 1951 se dicta una resolución por la que se crea el Instituto de Antropología, el que recién entra en funcionamiento el 28 de abril de 1952 con la designación de su primer director, Antonio Serrano. A raíz de su renuncia, el 21 de junio de 1954 es reemplazado por Alberto Rex González (Garbulsky, 2004). 
Arqueológico Provincial en Santiago del Estero -ubicado en un salón de la Escuela Normal donde estudió Righetti-, dedicándose a la ilustración y a la clasificación de piezas. Allí se formó con los mencionados hermanos Wagner y fue nombrada vicedirectora del museo luego de la muerte de Duncan Wagner en 1937 y directora tras el fallecimiento de Emilio en 1949, puesto que conservó hasta 1967. Righetti dictó conferencias y escribió varios artículos, así como un libro junto a Emilio Wagner: “Arqueología comparada. Resumen de prehistoria" (1946). Siendo directora del museo, entre 1950 y 1960 dirigió una misión arqueológica por los departamentos Banda y Robles (área del río Dulce), zona en la que exhumó bastante material. Righetti utilizó las redes escolares para obtener colaboración durante el trabajo de campo, especialmente en la clasificación de piezas y fragmentos cerámicos. Según recuerda una maestra: "a medida que se iban extrayendo, de acuerdo con las indicaciones que nos daba la Srita. Righetti, nosotros íbamos haciendo la clasificación de lo que se iba encontrando"48. Este ejemplo remite al papel de los maestros como colaboradores en las prácticas arqueológicas y a su intermediación entre los arqueólogos y "el campo", especialmente en las zonas rurales o alejadas de los museos. La actuación de Righetti ha sido escasamente documentada, así como la participación de los maestros en las redes de recopilación de materiales científicos. Estos temas merecen mayor atención y estudios futuros.

También destaca el caso de la húngara Ana Biró (1903-?), quien entre 1938 y 1944 estuvo a cargo de la sección Etnografía y Arqueología del Museo Histórico Colonial y de Bellas Artes de Corrientes y luego de la dirección del Museo de Ciencias Naturales de la misma ciudad, entre 1944 y 1946. Ana Biró nació en Oradea (Nagyvárad) en la región de Transilvania de la actual Rumanía, en ese entonces parte de Hungría. Realizó estudios universitarios en Filosofía y Letras en Budapest y luego emigró a la Argentina, donde fue adscripta en el Museo de Ciencias Naturales Bernardino Rivadavia de Buenos Aires. Luego, acompañando a su marido el ingeniero Emilio José Stern, se mudó al Chaco en

\footnotetext{
48 Relato de Adelina Roldán, en el Documental "Santiagueños: Olimpia Righetti”, producido por Canal Encuentro, 2017.
} 
$1937^{49}$. Escribió una gran cantidad de artículos en revistas científicas, participó en congresos nacionales e internacionales y publicó notas en La Prensa y en revistas culturales. Perteneció también a la Sociedad Argentina de Americanistas y a la Sociedad Argentina de Antropología. Biró se vinculó a las élites intelectuales y artísticas de la región chaqueña, dando conferencias y participando de diversas actividades culturales. Tanto ella como su esposo fueron miembros fundadores del "Ateneo del Chaco", una asociación cultural creada en Resistencia en 1938, destinada a cumplir con los fines "espirituales" del arte y la ciencia (Leoni de Rosciani, 1999). La primera conferencia pública de esta entidad consistió en una conferencia que estuvo a cargo de Biró y trataba sobre "El concepto del mundo en el indio del Chaco". Durante los años que pasó en Corrientes y en la región chaqueña, realizó excavaciones y prospecciones de sitios arqueológicos e históricocoloniales, así como una serie de trabajos de campo etnográficos, realizados sobre todo en las misiones anglicanas de la región. Sus principales temas de interés estuvieron vinculados al arte popular, a las artesanías y a las ilustraciones y arte indígenas, tanto en sus aspectos etnográficos como arqueológicos. Como se observa en los diferentes trabajos publicados por Biró, una gran parte de los materiales arqueológicos que ella investiga provienen de colecciones particulares, o de hallazgos fortuitos de peones o pobladores de distintos pueblos. También supo aprovechar las obras de caminos que se impulsaron en la década de 1940 en la región del Chaco, consiguiendo materiales e informaciones por parte de los peones que trabajaban en las mismas. Asimismo, la ampliación de caminos posibilitó el descubrimiento de algunos sitios arqueológicos, entre los cuales destaca el hallazgo de la ciudad hispano-indígena de Concepción del Bermejo, sitio conocido como "Ruinas del kilómetro 75". El hallazgo del sitio es relatado por ella de la siguiente manera:

"En los últimos meses del año pasado de 1943, la prensa del país se ocupó del descubrimiento de una población hispano-indígena en las cercanías de la ciudad

\footnotetext{
${ }^{49}$ Probablemente la mudanza a la región chaqueña estuvo vinculada con el trabajo de Emilio Stern en la National Lead's Company, una empresa siderometalúrgica instalada en 1938 en la localidad de Puerto Vilelas, sobre el Brazo Barranqueras del Río Paraná.
} 
chaqueña de Presidente Roque Sáenz Peña, dándole naturalmente, un tinte sensacional y a veces fantástico. Y es para despojar al hecho de las leyendas que a su derredor se van tejiendo, salvaguardando la seriedad científica, que relataré la historia del descubrimiento." (1945: 103)

La Dirección de Vialidad se encontraba abriendo un camino desde la localidad chaqueña de Sáenz Peña hacia el norte (actualmente Ruta Nacional 95). Mientras el camino se encontraba en obra, algunos miembros del Club de Pescadores y Cazadores del pueblo se encontraron -durante una excursión de caza- entre la "espesura" del monte con un suelo accidentado, con montículos de diversos tamaños y extensión. Creyendo haber encontrado un cementerio indígena, se comunicaron con Biró, invitándola a visitar el sitio "para verificar” tal suposición. Así, se organizó una pequeña expedición con Biró a la cabeza, donde ella pudo observar los diferentes montículos y la gran cantidad de fragmentos de alfarería diseminados por todo el sitio. Para resolver las dudas que planteaban estas estructuras, se decide "efectuar unas excavaciones a modo de cateo, en procura de datos arqueológicos, que arrojaran luz sobre el gran interrogante que significaba para mí este hallazgo.” (Biró de Stern, 1945: 105).

Posteriormente, Biró se orientó hacia temas vinculados con la artesanía, la cultura popular y la imaginería, formando una colección privada de esta última. Realizó numerosos viajes por el interior del país y por Centroamérica con el auspicio del Fondo de las Artes, de la OEA y de la Comisión Permanente de Artesanías de la UNESCO, de la cual fue presidenta hacia 1957. En la década de 1950 volvió a instalarse en Buenos Aires. Entre 1955 y 1960 ofreció conferencias en Radio Nacional y en la Sociedad Hebraica Argentina y se desempeñó como docente en la Universidad Popular de Belgrano. Sus prácticas dan cuenta de una red de provisión y circulación de datos y objetos, que vinculan a los ciudadanos de distintos poblados, a los misioneros anglicanos y a los "expertos" de diferentes museos e instituciones. También dan cuenta de las posibilidades de acceso de una mujer extranjera a ciertos circuitos científicos y culturales provinciales, en los cuales logró cierto prestigio como científica. 
Las experiencias de Righetti y de Biró no constituyen casos aislados, sino que muestran cómo en los espacios que se expandían las mujeres tenían posibilidades de insertarse y de acceder a puestos directivos. Los institutos y museos que se crearon en las décadas de 1920 y 1930 diversificaron las posibilidades de inserción institucional en las ciencias antropológicas y las mujeres supieron aprovechar las nuevas ofertas de las diferentes provincias.

\section{$\underline{\text { Sociedades científicas vinculadas con las ciencias antropológicas }}$}

Desde las últimas décadas del siglo XIX, las investigaciones antropológicas se desarrollaron y promovieron en relación con diferentes asociaciones: Inicialmente tuvieron un papel relevante la Sociedad Científica Argentina, fundada en 1872 y la Junta de Historia y Numismática Americana, en $1893^{50}$. La Sociedad Científica Argentina, se esgrimía entonces como una institución madre de la cual se desprendieron paulatinamente distintas sociedades científicas del país (Babini, 1961; Farro, 2016) ${ }^{51}$. En las primeras tres décadas del siglo $\mathrm{XX}$ se suman otras asociaciones de ciencias naturales, geográficas y americanistas: la Sociedad Physis (Sociedad Argentina de Ciencias Naturales), la Sociedad Geográfica Argentina "GAEA" (1922), la Sociedad Científica Alemana y la Sociedad de Americanistas de Buenos Aires (1927), entre otras. En 1936 surgirá la primera asociación especializada en las ciencias antropológicas.

Aunque la Sociedad Científica Argentina continuará sus actividades en el siglo XX, en las primeras décadas del siglo comienzan a aparecer otras asociaciones más específicas a

\footnotetext{
${ }^{50}$ Luego Academia Nacional de Historia.

${ }^{51}$ En esta asociación las mujeres participaron minoritariamente: En 1930 solo se eran miembros cuatro mujeres (representando el 0.83\% del total de socios): Lucía Negrete, Carmen B. de Díaz y Lola Ubeda. Para el año 1936 la cantidad de mujeres es casi la misma: Lucía Negrete y Clotilde Molle como socias activas, Atilia A. Arbechi como socia adherente y Amelia Larguía de Crouzeilles como socia activa de la Sección Santa Fe. Una década después, el numero de afiliadas se había duplicado. En 1940 tenia 8 socias activas, lo que representaba un $1.2 \%$ de la membrecía, compuesta por un total de 661 miembros.
} 
cada grupo disciplinar, Según Sábato (2002) esta proliferación de asociaciones profesionales y científicas se enmarca en un contexto de cambios en las concepciones acerca de las características de la formación científica, en el papel de la ciencia en la sociedad y de cierta movilidad social que permitió el ascenso de las capas medias a la educación superior y contribuyó a renovar el perfil social de los profesionales y científicos. En 1911 se fundó la Sociedad Physis, compuesta por estudiantes y naturalistas de la Facultad de Ciencias Exactas Físicas y Naturales de Buenos Aires y estudiantes y egresados de ciencias naturales de La Plata. La asociación se definía por un perfil netamente científico antes que profesional o gremial y se ocupó de promover la enseñanza universitaria de ciencias naturales, gestionando premios y becas de estudio en la Universidad de Buenos Aires. Como otras asociaciones, realizaba reuniones periódicas donde se presentaban avances de investigación y publicaba la revista Physis desde 1912. En 1916, en el marco de la primera guerra mundial y en disputa con la Sociedad Científica Alemana por la “tradición científica nacional”, la asociación comenzó a denominarse Sociedad Argentina de Ciencias Naturales (García y Podgorny, 2000; García, 2016). Esta asociación contemplo temas de ciencias antropológicas incluso luego de la creación de la Sociedad Argentina de Antropología. En las reuniones organizadas por esta asociación y en la revista se publicaron artículos de antropología, aunque estos dejarán de tener presencia hacia 1942. Hasta ese año, la Revista Physis incluyó entre sus secciones la sección de Antropología, Etnografía y Arqueología.

En 1922 se fundó la Sociedad Argentina de Estudios Geográficos "GAEA”, cuyo propósito consistía en el estudio de la geografía general en sus variadas disciplinas, incluyendo la etnografía, geodesia, la topografía, la cartografía, la biogeografía, la geología, la geofísica y la climatología. Entre sus primeros miembros había naturalistas, ingenieros, antropólogos, médicos, docentes, escritores, miembros de la armada y geólogos (García, 2016). Fue la primera asociación científica argentina presidida por una mujer, Elina 
González Acha de Correa Morales ${ }^{52}$. En 1922, la Sociedad comenzó a editar los Anales de GAEA, Sociedad Argentina de Estudios Geográficos, donde predominaron los trabajos geológicos, junto con otros temas relacionados con la geografía física, la cartografía, la toponimia y la antropogeografía. Desde 1934 editó un Boletín de GAEA, Sociedad Argentina de Estudios Geográficos y otras publicaciones (Curto et al., 2008; García, 2016). Esta asociación tuvo estrechas vinculaciones con las ciencias antropológicas y con la Sociedad Argentina de Antropología, puesto que ambas compartían una gran cantidad de miembros y un conjunto de intereses científicos. Elina González Acha de Correa fue una de las primeras socias de la Socciedad Argentina de Antropología, lo cual es un síntoma de las afinidades entre la asociación que ella presidía y la Sociedad Argentina de Antropología ${ }^{53}$.

${ }^{52}$ Formada como maestra en la Escuela Normal de Profesoras, desde 1907 dictó cátedra de Geografía y Ciencias Naturales en el Liceo Nacional de Señoritas $\mathrm{N}^{\circ}$ 1, realizando trabajos de investigación sobre estos temas. En 1922 fundó la Sociedad Argentina de Estudios Geográficos (GAEA). Realizó cursos para embalsamar aves y coleccionar insectos con Eduardo L. Holmberg y se vinculó de distintas formas al Museo Público de Buenos Aires. Escribió diferentes obras de investigación y de divulgación, entre ellos libros de geografía para la enseñanza primaria; recibiendo premiaciones internacionales por esta labor. Participó en sociedades nacionales e internacionales, siendo la primera mujer como miembro correspondiente de la Sociedad Geográfica de Berlín en 1924. También formó parte de la Sociedad de Americanistas de París, de la Sociedad Geográfica de Würzburg (Alemania) y de la Sociedad de Mujeres Geógrafas de Washington, entre otras (Curto, Susana y Marcelo Lascano, 2014). González Acha estaba vinculada con asociaciones feministas, como el Consejo Nacional de Mujeres creado en 1900, siendo muy cercana a Cecilia Grierson. De hecho, al fundarse GAEA, se incluyeron algunas profesionales que formaban parte de dos instituciones feministas sumamente relevantes a comienzos de siglo XX: la Asociación de Universitarias Argentinas y la Unión Feminista Nacional. Asimismo, Elina Gonzáles Acha y su esposo el escultor Lucio Correa Morales (18521923), junto a seis hijos -entre ellos Cristina Correa Morales- formaban parte de los círculos de sociabilidad científica y artística de Buenos Aires y realizaban asiduos encuentros culturales en la casa familiar

${ }^{53}$ Lascano y Curto (2013) hablan de una "expansión de la antropología" hacia la Sociedad Argentina de Estudios Geográficos: En 1938, el geógrafo italiano Romualdo Ardissone, Francisco De Aparicio y el geógrafo Federico Daus, reciben de GAEA subsidios para viajes de estudio, en el marco de los fondos otorgados por el Gobierno Nacional, para la confección de la "Geografía de la República Argentina". En el Boletín de esta asociación de enero de 1945, se destaca la contribución de los miembros del Museo Etnográfico de Buenos Aires durante la VI Semana de Antropología. La sociedad también dedica dos sesiones de la IX Semana de Geografía-Congreso Nacional de Geografía, a las investigaciones del Museo relacionadas con el descubrimiento de Tolombón. En 1945 GAEA financia, junto con el Comité Nacional de Geografía, una expedición en el Norte del país, enmarcada en las líneas de trabajo del Museo Etnográfico de Buenos Aires, con instrumentos facilitados por éste. 
Por otra parte, en 1927, el director del Museo Etnográfico de Buenos Aires, Salvador Debenedetti, junto a algunos historiadores e intelectuales impulsaron la creación de la Sociedad de Americanistas de Buenos Aires, en el Museo Etnográfico y destinada al estudio científico de América y sus habitantes desde el punto de vista americanista (Pegoraro, 2009). La mayoría de sus miembros eran también integrantes de la Société des Américanistes de París, creada en 1895.

\section{La Sociedad Argentina de Antropología}

En 1936, se funda la primera asociación especializada en las ciencias antropológicas del país: la Sociedad Argentina de Antropología: “con el objeto de coordinar la labor de los especialistas en las ciencias del hombre, realizar investigaciones en el terreno de acuerdo con planes orgánicos y normas precisas, y promover, asimismo, una intensa penetración cultural tendiente a difundir y divulgar los resultados científicos obtenidos" ${ }^{\text {"5 }}$.

Según el acta de fundación, la sociedad definió como Antropología "cualquiera de las disciplinas que constituyen las ciencias del hombre (Antropología física, Etnología, Etnografía, Lingüística, Arqueología, etc.)" y como “especialistas” a aquellas personas "que se dedican a la investigación en alguna de las ramas de la Antropología, como objeto principal de su actividad, y que además de haber producido obras meritorias, han seguido estas actividades con carácter profesional" ${ }^{, 55}$.

Así es como quedó conformada la primera corporación de antropólogos del país, habiendo transcurrido más de veinticinco años de una propuesta semejante en el país ${ }^{56}$ y

\footnotetext{
${ }^{54}$ Copiador de la SAA 1936-1943, AFDME.

${ }^{55}$ Acta de fundación de la Sociedad, 24 de abril de 1936 (Libro de Actas, 1936, s/n, f. 4). Archivo SAA.

${ }^{56}$ La propuesta fue realizada durante el Congreso Científico Americano celebrado en Buenos Aires en 1910 (Podgorny, 2004b).
} 
sumándose a un conjunto de 68 asociaciones análogas existentes en el resto del mundo (Podgorny, 2004b). En Chile se había fundado en 1878 la Sociedad Arqueológica de Santiago, la cual permanece solo unos años. En 1909 se fundó la Sociedad del Folklore Chileno y más adelante se crearon la Sociedad de Arqueología e Historia "Francisco Fonck" de Viña del Mar (1937) y la Sociedad Arqueológica de La Serena (1944) (Gänger, 2014; Mora Nawrath, 2016). Uruguay contaba con una asociación de aficionados, la Sociedad de Amigos de la Arqueología desde 1927, la cual se creó con el fin de "agrupar en torno suyo todos los elementos que en el país se sintieran inclinados al culto de las cosas arcaicas" $"$, abarcando tanto la arqueología como la paleontología. En 1930 se creó la Sociedad Arqueológica de Bolivia, por iniciativa del ingeniero militar austro-húngaro Arthur Posnansky (1874-1946) junto con 11 selectos socios (Browman, 2007). En 1937 se creó la Sociedad Mexicana de Antropología, conformada por antropólogos, lingüistas, etnólogos, arqueólogos e historiadores ${ }^{58}$. En 1941, en la Facultad Nacional de Filosofía de la Universidad del Brasil, tuvo lugar la creación de la Sociedad Brasilera de Antropología y Etnología ${ }^{59}$.

La Sociedad Argentina de Antropología se fundó con siete socios y su primera reunión fue en el Museo Mitre de Buenos Aires. Sus fundadores eran los profesores de las cátedras universitarias de las ciencias antropológicas de Buenos Aires y La Plata y del Instituto Nacional del Profesorado, quienes también se desempeñaban en los museos de

\footnotetext{
${ }^{57}$ Sobre la creación de la sociedad, agregan: "Había llegado, pues, la hora de que se prestara a la Arqueología toda la importancia que le concede el mundo civilizado, y es su primer paso el llamado a reunión de la Sociedad, de todos sus amigos, para hacer el recuento del material existente, de defenderlo de saqueos que de tiempo atrás los expatriaban sin esperanzas de retorno, hacer la clasificación inteligente de sus valores, anotar sus procedencias, comparar las colecciones actuales, fomentar las nuevas y poner al alcance de todos los elementos conocidos, para su ilustración recíproca." "Nuestro Programa" en Revista de la Sociedad de Amigos de la Arqueología, Tomo I, 1927, pp. 5-6, Montevideo.

${ }^{58}$ Boletín Bibliográfico de Antropología Americana (1937-1948), Vol. 1, No. 4 (octubre a diciembre, 1937), pp. 199-202.

${ }^{59}$ Boletín Bibliográfico de Antropología Americana (1937-1948), Vol. 5, No. 1/3 (enero a diciembre, 1941), pp. 9.
} 
Buenos Aires y La Plata. Estos primeros socios fueron Francisco de Aparicio ${ }^{60}$, Eduardo Casanova $^{61}$, José Imbelloni ${ }^{62}$, Fernando Márquez Miranda ${ }^{63}$, Enrique Palavecino ${ }^{64}$, Félix

${ }^{60}$ Francisco de Aparicio (1892-1951) era miembro de la Academia Nacional de Bellas Artes por designación del Poder Ejecutivo, crítico de arte y arqueólogo autodidacta. Colaboró como crítico literario en la revista Ideas, donde se contactó con Juan B. Ambrosetti y Félix F. Outes. Se desempeñó como profesor de Historia y Geografía Americana en la Facultad de Ciencias de la Educación de la Universidad del Litoral en Paraná (1920-1930). Entre fines del 1930 y 1947 fue profesor de Arqueología Americana en Filosofía y Letras en la UBA, director del Instituto de Arqueología del Museo Etnográfico hasta 1939; profesor de Historia en el Colegio Nacional de Buenos Aires entre 1933 y 1946, y director del Museo Etnográfico entre 1937 y 1947 (Guber, 2006).

${ }^{61}$ Eduardo Casanova (1902-1977). Nació en España y luego se naturalizó argentino. En 1929 egresó de la Facultad de Filosofía y Letras de la Universidad de Buenos Aires, como Profesor de Enseñanza Secundaria y Especial en Historia. Ejerció la docencia en los niveles medio y superior, se desempeñó como profesor titular de la cátedra de Arqueología Americana de la Facultad de Filosofía y Letras de la Universidad de Buenos Aires, también fue Director de la sección arqueología y director del Instituto de dicha Universidad. Asimismo, fue Jefe de la Sección de Arqueología del Museo Nacional de Historia Natural y Secretario de la sección de yacimientos arqueológicos y paleontológicos del Ministerio de Justicia e Instrucción Pública. Entre 1966 y 1968 actuó como Decano sustituto para esa casa de estudios. En 1959 integró el claustro docente de la Facultad de Historia y Letras de la Universidad del Salvador. En 1964 fundó el Instituto de Arqueología y lo presidió hasta 1970, dos años antes obtiene el título de profesor emérito de la misma Universidad. "Casanova, Eduardo", en Quién es en quién en la República Argentina. Biografias contemporáneas, 1955, Buenos Aires: Editorial Guillermo Kraft Ltda., pp. 147. Ver también: "Eduardo Casanova" en las fichas del Archivo Histórico de la USAL.

${ }^{62}$ José Imbelloni (1885-1967). Nacido en Italia, Imbelloni estudió Medicina en la Facultad de Perugia. Pasó unos años en la Argentina durante su juventud, regresando a Italia para unirse como voluntario en la Primera Guerra Mundial. En esos años estudia Ciencias Naturales y Antropología en la Universidad de Padua, donde en 1920 se doctora con la tesis "Introducción a nuevos estudios de craneotrigonometría". En 1921 retorna a Argentina, donde obtiene el puesto de profesor suplente de Antropología en la Facultad de Filosofía y Letras (UBA), además de estar vinculado al Museo Etnográfico desde 1922, como encargado de investigaciones antropológicas. Entre 1921 y 1930 se desempeña como profesor de Historia antigua en la Universidad de Paraná. Desde 1939 es Profesor Titular en la cátedra de Antropología de la Facultad de Filosofía y Letras de la UBA. En 1946 ocupará el puesto de director del Museo Etnográfico, tras la exoneración de Francisco de Aparicio. Al año siguiente, el Gobierno Nacional lo nombra Director del recientemente creado Instituto de Antropología, también dependiente de la Facultad de Filosofía y Letras, desde el cual publica la Revista Runa, Archivo para las ciencias del hombre (iniciada en 1948). En 1955 es apartado de sus cargos. Sus últimos años los dedicó a la enseñanza en la Universidad del Salvador, como profesor de la cátedra de Antropología y etnología general, en la Facultad de Historia y Letras. Ver, entre otros: CAEA (1985), Carrizo (2014), Mailhe (2016).

${ }^{63}$ Fernando Márquez Miranda (1897-1961) fue un antropólogo argentino que trabajó sobre diferentes temas de arqueología y etnología de poblaciones indígenas. De forma discontinua, se desempeñó en diferentes 
Outes $^{65}$ y Milcíades Vignati ${ }^{66}$. Como primer presidente fue elegido Outes, quien dirigía en ese momento el Museo Etnográfico; y como secretario Casanova, Jefe de la Sección de Arqueología del Museo Nacional de Historia Natural. La tesorería fue cubierta por Vignati, y como director de publicaciones se nombró a Imbelloni, profesor titular de Antropología y Etnografía de la Universidad de Buenos Aires. Todos los socios fundadores integraron el primer consejo directivo de la asociación, al cual se agregaron tres socios incorporados

instituciones como la Facultad de Filosofía y Letras de la Universidad de Buenos Aires y la Facultad de Humanidades y Ciencias de la Educación y el Instituto del Museo/Facultad de Ciencias Naturales de la Universidad Nacional de La Plata (Soprano, 2014).

${ }^{64}$ Enrique Palavecino (1900-1966) era "autodidacta", realizó estudios de bachiller en el Colegio Nacional Mariano Moreno de Buenos Aires, pero no los concluyó. Desde joven se acercó al Museo Bernardino Rivadavia, donde comenzó realizando trabajos anatomico-antropológicos para luego orientarse hacia temas lingüísticos, etnográficos y folklóricos (Morínigo, 1968; Soprano, 2006). Su trayectoria es analizada con mayor profundidad en el capítulo 5 .

${ }^{65}$ Félix Outes (1878-1939). Nacido en Buenos Aires, cursó sus estudios en la Facultad de Derecho y Ciencias Sociales de la Universidad de Buenos Aires (1896-1899) y en la Facultad de Medicina de la misma Universidad. Fue profesor adjunto de Etnografía en la Facultad de Ciencias Naturales de La Plata (19061911); profesor suplente de Antropología en la misma facultad; profesor Adjunto de Arqueología; profesor de Antropología en la Facultad de Filosofía y Letras de Buenos Aires; profesor interino de Geografía Humana en esa facultad -luego titular de la materia-; director del Instituto de Investigaciones Geográficas; director y jefe de expediciones arqueológicas del Museo Antropológico y Etnográfico de esa Facultad (1930-1938); profesor suplente de Antropología en la Facultad de Ciencias Exactas, Físicas y Naturales de la Universidad Nacional de Buenos Aires; miembro del Consejo Superior Universitario (1921); profesor en el Colegio Nacional de Buenos Aires y miembro de su Comisión Directivo. Identificado por Márquez Miranda como perteneciente a la segunda generación de arqueólogos argentinos, junto a Luis María Torres, Salvador Debenedetti, Roberto Lehmann-Nitsche, Eric Boman e Imbelloni, Outes desarrolló paralelamente trabajos sobre toponimia, cartografía histórica, geografía histórica, arqueología, antropología física e historia. Outes sucedió a Debenedetti (1917-1930) en la dirección del Museo Etnográfico de Buenos Aires, y encaró una serie de transformaciones en el mismo (CAEA, 1985; Guber, 2006)

${ }^{66}$ Milcíades Alejo Vignati (1895-1978) egresó en 1915 como Maestro y en 1918 como Profesor de Ciencias de la Escuela Normal de Profesores n ${ }^{\circ}$ 2. Estudió en el Doctorado de Facultad de Ciencias Exactas, Físicas y Naturales de la (UBA) sin finalizarlo. Fue docente de la Facultad de Filosofía y Letras de la UBA hasta 1930 y a partir de ese momento se hizo cargo del Departamento y la cátedra de Antropología en la Facultad de Ciencias Naturales y Museo en la UNLP. Se ocupó de temas relativos a antropología física, arqueología, prehistoria, etnología y lingüística. Su presencia en el Museo se extendió hasta 1955 (Soprano, 2009b; Pupio, 2013). 
poco después: Antonio Serrano, Duncan L. Wagner y Emilio R. Wagner ${ }^{67}$. Tres meses luego de la fundación -el 24 de julio de 1936- se realizó una reunión inaugural a la cual se invitó a los representantes de las principales instituciones científicas de la época: Agustín Mercau de la Academia Nacional de Ciencias Exactas, Físicas y Naturales; Elina González Acha de Correa Morales de la Sociedad Geográfica Americana "GAEA"; Carlos Storni de la Sociedad Argentina de Ciencias Naturales; Nicolás Besio Moreno de la Sociedad Científica Argentina; Ricardo Levene de la Junta de Historia y Numismática; Martín Doello Jurado del Museo Argentino de Ciencias Naturales y a Roberto Levillier, por entonces embajador de la Argentina en México. Ello muestra cómo la Sociedad Argentina de Antropología desde su fundación buscó relacionarse con diferentes instituciones y asociaciones eruditas.

La organización de esta Sociedad se fue ajustando año a año a la mayor o menor participación de socios y a las propuestas que surgieron en su seno. Así, en el primer estatuto (1936) se establecieron varias categorías de socios. Por un lado, la de "socio activo", que se reservaba a los llamados “especialistas”. Esta categoría estuvo integrada por los antropólogos profesionales, aquellos dedicados a la enseñanza e investigación como empleados de algún museo o universidad. El segundo tipo de membresía era el de "socio adherente" que correspondía a "todas las personas que se interesen por las actividades de la Sociedad" $"$.

En mayo de 1937 se publica el primer balance anual de la asociación y se propone la elaboración de un nuevo estatuto, en el cual se agregan nuevas categoría de socios:

\footnotetext{
${ }^{67}$ En la primera sesión, el 4 de mayo de 1936, por decisión unánime se invitó a incorporarse como socios activos y como parte de la Comisión Directiva a Serrano, Emilio y Duncan Wagner y Héctor Greslebin. Este último fue el único que no aceptó la invitación, por "razones de índole particular". Memoria de la SAA 193637, en Relaciones Tomo I, 1937, pp. 201.

${ }^{68}$ Libro de Actas, 1936, pp: 4, ASAA
} 
"estudiantes", "honorarios", "correspondientes" y "protectores"69. De acuerdo al nuevo estatuto, podían ser socios estudiantes los alumnos de los institutos superiores en los que se impartía enseñanza relacionada con la Antropología. Los mismos no pagaban cuota, recibían el Boletín y podían asistir a los actos organizados por la asociación. A su vez, se redefine la categoría de socio activo, ampliándola a cualquier persona que se "interese" por las actividades de la Sociedad (y que abone la respectiva cuota). Con ello, se ampliaba la base social de los miembros activos, la cual además ocurrió en paralelo a la reducción del importe de la membresía. Mientras en 1936 se había establecido una cuota de treinta pesos anuales, en 1937 pasó a ser de diez pesos anuales. Con el pago recibían sin cargo las publicaciones de la Sociedad (la Revista Relaciones y el Boletín) y podían concurrir a todos los actos que la misma organice. El cambio se debió a las limitaciones para asociarse de modo "activo" en el reglamento inicial, las cuales resultaron un "serio inconveniente para el progreso de la Sociedad" ${ }^{, 70}$. El nuevo estatuto de 1937 permitió ampliar la cantidad de miembros y obtener mayor ingreso de dinero gracias al incremento del número de afiliados a pesar de la reducción de la cuota anual. A su vez, el aumento de la membresía permitía mostrar públicamente una mayor consolidación de la asociación y solicitar subsidios a distintos organismos. Con esta transformación ingresaron más mujeres a la sociedad, como socias activas y estudiantes, cuyo aumento progresivo se analiza en el próximo apartado.

El aumento de los afiliados garantizó el funcionamiento de los espacios de exposición e intercambio de saberes, tanto en cuanto a quienes exponían sus trabajos, como en cuanto al público presente, que en general estaba compuesto por una mayoría de estudiantes. Así lo demuestran diferentes registros de eventos en el Boletín o en las Memorias Anuales de la sociedad. Por ejemplo, en una exposición en 1943 sobre "relevamiento de pinturas y grabados aborígenes" Vignati aclara que la disertación es "de

\footnotetext{
69 Podían ser socios honorarios personas o instituciones con "destacada" actuación en los estudios antropológicos; socios correspondientes personas o instituciones residentes en el extranjero que se dedicaran a la investigación antropológica; y socios protectores personas o instituciones que contribuyeran al sostenimiento de la Sociedad con una cuota mínima de 100 pesos anuales, o que hicieran una donación superior a 1000 pesos. Crónica oficial, en Relaciones Relaciones, Tomo I, 1937, pp. 198.

${ }^{70}$ Memoria de la Sociedad Argentina de Antropología, 1937-38. En Relaciones, Tomo I, 1937, pp. 203.
} 
carácter didáctico dirigida especialmente a los alumnos que generalmente asisten a estas conferencias" (Boletín de la SAA, 1943: 56). Cabe señalar, como se verá en el apartado siguiente, que la mayoría de los socios estudiantes eran mujeres.

Las actividades de la asociación propuestas desde sus inicios estuvieron dedicadas a la "intensificación de los estudios antropológicos". Para ello se organizaron sesiones científicas de comunicaciones y la "Semana de la antropología", así como la publicación de una revista y un boletín. Las "sesiones científicas" fueron la principal actividad en los comienzos, que "llevan de inmediato a la práctica uno de los propósitos más elevados de penetración cultural"71 de la sociedad. Estas reuniones se realizaron desde 1937 con una frecuencia, que por lo general, fue mensual, entre los meses de abril y diciembre ${ }^{72}$. En algunas ocasiones se distanciaban más de un mes al intercalarse con la Semana de la Antropología. En las disertaciones participaban por lo general los socios activos y en ocasiones los socios estudiantes. Los participantes debían comunicar el tema de su exposición con una semana de antelación a la Secretaría, indicando el tiempo que estimaban para la misma. Varios socios participaron más de una vez, generando un grupo reducido y reiterativo de expositores ${ }^{73}$. A estas reuniones podían concurrir los socios, sus familiares y personas invitadas especialmente por el Consejo Directivo.

La "Semana de la Antropología" estuvo también entre las primeras propuestas de la asociación. En mayo de 1936 Palavecino propuso la realización de unas "Jornadas Antropológicas" y la Comisión Directiva le encargó que realizara "los sondeos previos y la preparación de un anteproyecto de estructuración de las mismas"74. Unos meses después se

\footnotetext{
${ }^{71}$ Crónica Oficial de la SAA, en Relaciones n² $2,1942$.

${ }^{72}$ En 1937 se realizaron cuatro sesiones de comunicaciones (julio, agosto, septiembre y noviembre), en 1938 se realizaron 5 sesiones (mayo, junio, julio, septiembre y octubre), en 1939 se realizaron 6 sesiones (abril, mayo, agosto, octubre, noviembre y diciembre), en 1940 se realizaron 7 sesiones (abril, mayo, junio, julio, agosto, septiembre y octubre) y 4 sesiones en 1941 (abril, junio, agosto y septiembre).

${ }^{73}$ Aspecto que se observa en la Tabla 1 del Anexo I.

${ }^{74}$ Memoria de la Sociedad Argentina de Antropología, 1937-38. En Relaciones, Tomo I, 1937, pp. 200.
} 
contaba con una veintena de propuestas de trabajos y se creó una comisión para la organización y propaganda de las jornadas, conformada por Palavecino, Vignati y Aparicio. Luego de posponerse la fecha de las jornadas durante varios meses, en septiembre de 1937 Aparicio -recientemente electo como Presidente de la asociación- planteó efectuar una "Semana de la Antropología"75. Así, la primera "Semana" se realizó en el Museo Etnográfico de Buenos Aires, entre el 29 de noviembre y el 4 de diciembre de 1937 y las disertaciones fueron sobre diferentes temáticas ${ }^{76}$. La segunda Semana también se realizó en Buenos Aires, entre el 26 de junio y el 1 de julio de 1939, y tuvo como tema único de discusión "Los Primitivos Habitantes de Santiago del Estero". Los expositores de estas jornadas debían ser autorizados por la Comisión Científica de la Sociedad. La "Semana" se proyectó de modo anual, aunque no todos los años logró concretarse. En algunas oportunidades se llevó a cabo en otras ciudades: en Mendoza se realizó la tercera semana (1941), en La Plata (1945) y en Santa Fé (1951), entre otros, para “estimular la labor que en el campo de las ciencias antropológicas" desarrollan ciertas universidades ${ }^{77}$.

Otra de las actividades propulsadas por la Sociedad fueron las publicaciones. Como señala Lopes (1999) el emprendimiento editorial constituyó una labor esencial en las actividades de las instituciones y asociaciones científicas, dándoles visibilidad pública y más allá de los espacios locales donde actuaban. La edición, distribución y canje de publicaciones permitía tanto a las instituciones como a sus investigadores el ingreso a los circuitos internacionales de canje de bibliografía y a distintas redes de intercambio en el ámbito local e internacional (García, 2010). Los resultados de trabajos de campo y de

\footnotetext{
${ }^{75}$ Cabe señalar que en septiembre de 1937 se eligió una nueva Comisión Directiva, de la cual Palavecino no formó parte, quizás por este motivo quienes propulsaron la Semana fueron otras personas. Palavecino se vuelve a incorporar en las elecciones de Comisión Directiva realizadas en septiembre de 1938. Asimismo, hay que recordar que la Sociedad Argentina de Estudios Geográficos realizaba desde 1931 la "Semana de la Geografía”.

${ }^{76}$ Presentaron trabajos en esta primera ocasión: F. de Aparicio, R. Pardal, M. A. Vignati, E. Palavecino, J. Imbelloni, S. Canals Frau, J. Cáceres Freyre, R. Ardissone, F. Márquez Miranda, A. Älvarez, A. F. Bordas, E. Casanova, E. Wernicke, E. Iribarne y J. A. Carrizo.

${ }^{77}$ Crónica Oficial de la SAA, en Relaciones n 2, 1942.
} 
laboratorio, así como las colecciones y catálogos, cobraban mayor valor si eran publicados y puestos en circulación, permitiendo compartir y circular universalmente la producción de conocimientos (Pyenson y Sheets-Pyenson, 1999; Podgorny, 2002).

Los trabajos presentados tanto en la Semana como en las sesiones eran resumidos y comentados en el Boletín, y una parte de ellos fueron luego publicados en diferentes tomos de la revista Relaciones. El Boletín fue proyectado como una publicación "que ha de difundir los diversos aspectos de la obra cultural realizada por la Sociedad". En el mismo se publicaban resúmenes de las reuniones de comunicaciones, avisos a los socios, noticias de varias instituciones, hallazgos científicos y otras novedades en torno a las ciencias antropológicas y a las actividades de la asociación. Si bien el Boletín estuvo proyectado desde la fundación, se publicó por primera vez en 1942, continuando en sus primeros años de forma regular hasta 1945 y con un único ejemplar en el año 1963.

Por su parte, la Revista Relaciones tuvo su primer número en $1937^{78}$, los siguientes serán en los años 1940, 1942 y $1944^{79}$. La misma contaba con una tirada habitual de 500 ejemplares y se distribuía de forma gratuita a los socios activos. La venta al público general tenía un valor de 20 pesos en 1938 y de 5 pesos para los socios estudiantes. En 1943 el valor de los tomos era de 15 pesos. Los temas tratados en los trabajos incluyen relatos de excavaciones y discusiones sobre objetos arqueológicos de diferentes regiones del país y de países vecinos, estudios sobre documentos históricos y etnohistóricos, hallazgos de cráneos y esqueletos, trabajos sobre grupos sanguíneos y taxonomía humana. Los temas y discusiones plasmados en la revista permiten comprender algunas discusiones dentro de las ciencias antropológicas en estos años. Por ejemplo, en el segundo tomo de Relaciones (1940) se publicaron los trabajos expuestos en la Semana de la Antropología de 1939 sobre

\footnotetext{
${ }^{78}$ En el primer número publicaron sus trabajos Aparicio, Casanova, Imbelloni, Vignati, Villegas Basavilbaso, Canals Frau, Cáceres Freyre, Ardissone, Márquez Miranda, Wernicke e Iribarne.

${ }^{79}$ Luego será retomada en 1970, publicándose hasta el presente con números por lo general anuales.
} 
los habitantes de Santiago del Estero ${ }^{80}$. Específicamente, se discutió sobre la interpretación de los hallazgos arqueológicos realizados en dicha provincia por los hermanos Wagner. Frente a un tema en el cual habían intervenido "hombres de letras, estudiosos de disciplinas heterogéneas, periodistas, políticos y turistas”, la Sociedad Argentina de Antropología daba a conocer "la opinión de los especialistas argentinos" (Aparicio, 1940:2). El espacio de la publicación contribuía con la definición del universo de saberes y prácticas socialmente legítimos que contribuyeron a producir y reproducir programas de pensamiento; y con la creación de un público inmediato, formado por estudiantes y futuros docentes, que posibilitan la reproducción ampliada de la práctica científica y su divulgación (Lopes, 1999; García, 2010).

Para poder concretar las actividades, especialmente las publicaciones, la Sociedad solicitó diversos subsidios a diferentes reparticiones públicas. En 1936, se solicitó un subsidio para las publicaciones a la Comisión Nacional de Cultura, indicando problemas económicos por la escasez de sus miembros: "como la sociedad, dado el limitado número de sus socios y adherentes, tropieza con dificultades insalvables para iniciar sus publicaciones que han de exteriorizar su obra, ha creído que tal vez la comisión que Ud. tan dignamente preside podría prestar su valioso apoyo a nuestra acción cultural" ${ }^{\text {}}$. Una carta similar fue enviada al Presidente de la Comisión de Presupuesto de la Cámara de Diputados de la Nación, esta vez solicitando una suma específica de tres mil pesos. Finalmente, a fines de 1937 se logra una asignación en el presupuesto correspondiente al Ministerio de Relaciones Exteriores y Culto, el cual se mantuvo hasta $1944^{82}$. Luego se gestionaron

\footnotetext{
${ }^{80}$ Este número de la revista contó además con una tirada especial de 30 ejemplares del tomo I y 30 ejemplares del tomo II, editados en papel especial y distribuidos entre los socios fundadores, los socios honorarios Paul Rivet, Wilhelm Schmidt y Max Uhle, y a un conjunto de instituciones: Biblioteca Nacional, Museo Etnográfico, Museo "Bernardino Rivadavia”, Museo de La Plata, Museo Británico, Smithsonian Institution y American Museum of Natural History. ASAA, Libro copiador n²1, p. 60.

${ }^{81}$ 1/9/1936 Copiador SAA 1936-1943, AFDME.

${ }^{82}$ En 1944, el subisidio era de 2000 pesos anuales y no alcanzaba a pagar los costos totales del Boletín más la revista Relaciones. Ello generaba deudas con las imprentas y reiteradas solicitudes a los socios que enviaban
} 
publicidades y otros pedidos de ayuda económica para el accionar de la Sociedad, especialmente para financiar las publicaciones ${ }^{83}$.

Otras actividades realizadas incluyeron visitas y viajes a localidades que "pudieran ser de interés desde el punto de vista antropológico" ${ }^{\$ 4}$, cenas de camaradería y cursos prácticos para los socios, por ejemplo de fotografía científica ${ }^{85}$. También se ofrecieron cursos breves para profesores de enseñanza secundaria, a través del Ministerio de Justicia e Instrucción Pública, motivados por las "frecuentes comunicaciones solicitando bibliografía e informaciones acerca de las culturas de los aborígenes de América" y con el fin de "colaborar al mejor conocimiento de las culturas de los aborígenes de nuestro territorio"

Por otra parte, en el año 1940 se solicitó a la Comisión Nacional de Cultura que incluya a la Antropología entre las disciplinas que premiaba. También se le pidió que modifique la forma en que se conformaban los jurados para los premios regionales. En vez de seleccionar los jurados por su vinculación con la región, quienes no siempre estaban capacitados para juzgar las obras cuando las mismas eran "de carácter histórico", se insistía que debían ser seleccionados y agrupados por temáticas o por especialidades ${ }^{87}$. La sugerencia fue tomada por la Comisión de Cultura para el nombramiento de jurados del año siguiente $^{88}$.

trabajos para que respeten el número máximo de páginas. En 1944, la sociedad tenía una deuda con la Imprenta Plantié que sumaba 6.349 pesos. ASAA, Libro de Actas nº 1, p. 98, 99, 101.

${ }^{83}$ Por ejemplo, el Boletín publicado en 1944 fue costeado gracias a una publicidad de la Editorial Emecé. ASAA, 25/8/1944, Libro de Actas n 1, p. 99.

${ }^{84}$ Memoria de la SAA, 1937-38, en Relaciones, tomo II, 1940, pp. 257.

${ }^{85}$ Este último fue solicitado para su dictado al Foto Club Argentino.

${ }^{86}$ Carta a Jorge E. Coll, Ministro de Justicia e Instrucción Pública, 24/8/1938. Copiador SAA 1936-1943, AFDME

${ }^{87}$ Libro de Actas, 1939, pp: 51, Archivo SAA.

${ }^{88}$ Libro de Actas, 1939, pp. 53, Archivo SAA. 
Además, dentro de la Sociedad Argentina de Antropología se formaron comisiones para realizar trabajos específicos, como "precisar y fijar el vocabulario técnico de antropología y ciencias afines", o la realización de comentarios bibliográficos para que "la Sociedad hiciera conocer la bibliografía que, antigua o moderna, fuera poco conocida" ${ }^{89}$. Por otra parte, la Sociedad se presentaba como un espacio para "vigorizar el espíritu de solidaridad entre los que se dedican a estos estudios, y coordinar la investigación, haciéndola más proficua mediante la acción conjunta de los antropólogos y de todos aquellos que se sienten atraídos por los problemas que presentan las Ciencias del Hombre." 90 Sin embargo, en su seno se dieron debates y discusiones, desacuerdos respecto de la interpretación de ciertos hallazgos.

Al respecto, destacan dos cuestiones ampliamente debatidas: los hallazgos arqueológicos del Arroyo Leyes, que generaron dudas acerca de la clasificación de las piezas cerámicas y discusiones sobre ciertas piezas falsificadas ${ }^{91}$, y los hallazgos realizados por los hermanos Wagner en Santiago del Estero, que alcanzaron amplia difusión y debates a través de la publicación de su libro "La civilización Chaco-Santiagueña y sus correlaciones con las del Viejo y Nuevo Mundo" $(1934)^{92}$.

La Sociedad Argentina de Antropología se posicionó como una voz autorizada para debatir y resolver ciertas problemáticas científicas, buscando constituirse como la referencia de un campo disciplinar en conformación, con prácticas aún heterogéneas y débilmente reguladas y con un conjunto poco denso de sujetos interesados, aficionados y

\footnotetext{
${ }^{89}$ Ambas propuestas fueron realizadas en mayo de 1938.

${ }^{90}$ Relaciones, tomo II (1940: 248), Discurso de Casanova en homenaje a Ambrosetti y Outes.

${ }^{91}$ El debate sobre dichos hallazgos es analizado con mayor detalle en el capítulo 3.

92 El libro propone que la provincia de Santiago del Estero había sido poblada, en una lejana época por pueblos de una "civilización adelantada", servidores de una deidad constituida por la trinidad hombre-aveserpiente. Además, aquellos primeros habitantes habrían sido los constructores de grandes túmulos en los cuales habitaban, formando pueblos que se extendían sobre centenares de hectáreas. Las cerámicas eran correlacionadas por los Wagner con otras de Eurasia y América, tanto en sus formas peculiares como por su simbolismo, evidenciando según ellos el paralelismo entre Troya y Santiago del Estero (Arenas, 2005).
} 
especialistas. Precisamente, uno de las cuestiones que se discuten en estos años es la práctica ocasional de la arqueología, con fines comerciales o como una distracción turística, la cual resulta perjudicial para las investigaciones sistemáticas:

"la mayoría de los yacimientos arqueológicos del noroeste argentino adolecen de la falla común de haber sido vandalizados por manos ignaras de buscadores de tesoros, de arqueólogos ocasionales y de turistas. Estas tres plagas obran de consumo, para lograr un efecto final: la inutilización del yacimiento para toda investigación sistemática y exhaustiva." 93 .

La Sociedad Argentina de Antropología buscó posicionarse en un papel central en la distinción entre especialistas y no especialistas, así como en la promoción de investigaciones acordes a sus propios parámetros de sistematicidad y profesionalismo. Asimismo, en su seno de la asociación se dieron discusiones respecto de los cambios políticos ocurridos a nivel estatal y su relación con el funcionamiento de la Sociedad. Recordemos que en 1943 se inició un proceso que comenzó con el golpe militar de junio y que tuvo impactó algunos meses después en el ámbito académico, cuando se decretó la intervención de la universidad de Buenos Aires y se impusieron nuevas tendencias políticoeducativas a nivel nacional (Halperín Donghi, 1962; Buchbinder, 1997). Un porcentaje significativo de profesores fue cesanteado $\mathrm{u}$ obligado a renunciar, se modificaron las estructuras de investigación y los planes de estudio se pusieron en revisión o reforma. A comienzos de 1945, los conflictos entre grupos reformistas y católicos se agudizaron y si bien las autoridades universitarias intentaron limitar las polémicas de carácter político en el

\footnotetext{
${ }^{93}$ Boletín de la SAA, agosto de 1943: 61-62. El 9 de junio de 1943 se realizó una reunión de comunicaciones donde F. de Aparicio presentó un plan de investigación intensiva de los Valles Calchaquíes, el resumen de la misma fue publicado en el citado Boletín de agosto de 1943. Además, la noticia señalaba que se buscaba realizar un "trabajo científico, sistemático y colectivo, en el cual trabajarían a la par alumnos y profesores." El verano anterior se habían realizado expediciones de modo preliminar, por parte de personal del Museo: junto a Aparicio, viajaron los profesores Augusto Raúl Cortazar, Alberto M. Salas, Lía Raquel Sanz de Arechaga y el estudiante Juan Antonio Güemes. En este viaje hallaron una "ciudad indígena intacta", en Tolombón, Valle de Santa María, Salta.
} 
interior de las instituciones, "no hubo forma de sustraerse al conflictivo proceso político que se inició entonces" (Buchbinder, 1997:157).

En relación con esta situación, en la sesión del Consejo Directivo del 12 de septiembre de 1945 se decidió postergar la realización de la Semana de la Antropología y el entonces Presidente de la asociación, Francisco de Aparicio propuso el siguiente comunicado para dar a publicidad:

"La Comisión Directiva de la Sociedad Argentina de Antropología, en vista de las manifestaciones repetidas de sus miembros más conspicuos que aclaran no poder participar en certámenes científicos porque la intranquilidad reinante en las horas angustiosas que vivimos les niega la calma indispensable para toda labor de estudio e investigación, y teniendo en cuenta que este estado de ánimo se manifiesta asimismo en el público que concurren habitualmente a reuniones científicas, el cual ha faltado casi en absoluto en diversos actos celebrados últimamente en sociedades afines, resuelve suspender la Semana de la Antropología que debía celebrarse en el próximo mes de octubre y todas sus actividades públicas durante el corriente año"94.

Esta declaración fue objetada por el "carácter político" de la misma. Casanova propuso modificaciones a la declaración, e Imbelloni manifestó que "la sociedad era de carácter científico y que nada tenía que ver con hechos políticos", declaración apoyada por Romualdo Ardissone ${ }^{95}$. Por último, la secretaria María de las Mercedes Constanzó ${ }^{96}$ señaló que no sería necesario dar noticia de la suspensión del evento puesto que aún no se había anunciado la realización del mismo. Estas diferencias, y por supuesto el clima político y de incertidumbre de la época, contribuyeron con la disminución de actividades de la Sociedad Argentina de Antropología.

\footnotetext{
${ }^{94}$ Libro de Actas n 1, 1945, pp:106-107, ASAA.

${ }^{95}$ Op. cit.

${ }^{96}$ Se hará mención con más detalle de su labor en la asociación más adelante en este capítulo.
} 
A comienzos de 1946 se realizó una nueva intervención sobre las universidades decretada por el Poder Ejecutivo Nacional. Entre 1946 y 1947 la oposición reformista fue confrontada en todas las universidades nacionales por medio de la cesantía de 423 docentes, al tiempo que se generaron las condiciones para que otros 823 renunciaran voluntariamente o en solidaridad con los primeros, oponiéndose a la limitación de funciones en las tareas de docencia e investigación y/o como crítica al recorte de la autonomía. Los debates frente a las intervenciones tuvieron expresión parcial en las diferentes instituciones y espacios académicos (Buchbinder, 1997; Soprano, 2009a). En el caso de la Sociedad Argentina de Antropología, a este contexto académico y político problemático se le sumaron dificultades económicas, especialmente la escasez de recursos para afrontar las publicaciones

En abril de 1947, el decano interventor de la Facultad de Filosofía y Letras de Buenos Aires dispuso que las reuniones de la Sociedad Argentina de Antropología en el Museo Etnográfico debían comunicarse con cinco días de anticipación, expresando también los temas que serían tratados en las mismas. Asimismo, toda noticia enviada a los periódicos desde la asociación debía realizarse por vía de la Secretaría de la Facultad. Estas disposiciones fueron entendidas como "tutoría" y "censura" por los miembros del Consejo Directivo de la Sociedad y se propuso el traslado de su sede a la Sociedad Argentina de Estudios Geográficos GAEA ${ }^{97}$. Las siguientes reuniones del Consejo Directivo se hicieron allí, aunque se fueron espaciando en el tiempo, disminuyendo la frecuencia a dos o tres reuniones por año en lugar de los habituales encuentros mensuales. En un Boletín de noticias antropológicas publicado en 1947 se señala la "escasez" de actividades y la disminución de la vitalidad de la Sociedad Argentina de Antropología ${ }^{98}$. Asimismo, durante este año no se editó ninguna publicación, aunque se celebraron algunas reuniones de comunicaciones. Las comunicaciones serán en el siguiente año la única actividad que la Sociedad estuvo en condiciones de organizar, invitándose "aún a aquellos que no tengan

\footnotetext{
${ }^{97}$ Libro de Actas, ${ }^{\circ} 1$, p. 114, 10 de abril de 1947, ASAA.

98 “Noticiario argentino". Por Antonio Di Benedetto. En Boletín Bibliográfico de Antropología Americana (1937-1948), Vol. 10 (enero-diciembre, 1947), pp. 9-15.
} 
antecedentes" y a "personas ajenas a la Sociedad"99. Las reuniones del Consejo Directivo, además de distanciarse cada vez más en el tiempo, tendrán cada vez menos participantes. En diciembre de 1948 se reunieron cinco personas que decidieron convocar una asamblea extraordinaria para la renovación de las autoridades, la cual ocurrió en julio de 1949, con poca presencia de $\operatorname{socios}^{100}$. En 1950 se retoman algunas actividades, con la intención de volver a publicar el Boletín, lo cual no ocurrió hasta 1963.

De forma paralela al decaimiento de actividades de la Sociedad hacia mitad de la década de 1940, surgen otras asociaciones donde también participan miembros de la Sociedad o interesados en las ciencias antropológicas. En 1943 se creó un "círculo de alumnos" "101 llamado AKIDA, siendo su significado una flexión de AKIS -en griego: estímulo y punta de proyectil o acicate-, pero también remitía a las iniciales de los profesores referentes de segundo año de la carrera de Historia en Buenos Aires: Ardissone, Constanzó, Imbelloni, Daus, Aparicio (Guber, 2011). AKIDA proponía una labor colectiva, de "unidad en el trabajo, servicio a la ciencia y asociación con suma de valores"102 y se presentaba como una iniciativa de profesores y alumnos de Historia. Su propósito era el estímulo para quienes quisieran "intensificar la investigación en el campo de las ciencias

\footnotetext{
${ }^{99}$ Libro de Actas $n^{\circ}$ 1, p. 119, 12 de abril de 1948, ASAA.

${ }^{100}$ Libro de $\operatorname{Actas}^{\circ}$ 1, p. 122, 123, 12 de abril de 1948, ASAA.

${ }^{101}$ En este círculo, "Los propósitos que se persiguen son los siguientes: a) Fomentar la amistad y colaboración entre los estudiantes del Doctorado de Historia y cuantos aspiren a realizar obra original en el campo de las "Ciencias del Hombre". b) Mantener el contacto con los profesores transcurrido el periodo escolar, esta vez como consejeros y amigos. c) Estimular la realización de trabajos de investigación. d) Proporcionar la oportunidad de exponer trabajos monográficos, obteniendo con ello, a la par de una justa satisfacción personal, la fluidez y soltura necesarias para la enseñanza. e) Realizar sesiones de comentario bibliográfico para mantener a los asociados al tanto de los trabajos recientemente aparecidos. f) Organizar viajes de estudio." Para ser parte del círculo, debían comunicarse con la estudiante Olga Mingo, quien también formaba parte de la Sociedad Argentina de Antropología. Ver "Constituyose el Centro AKIDA, Estudiantes de Historia”, en AMICITIA, Año III, N 16, Agosto de 1943, pp. 20.
}

102 “AKIDA, círculo de estudiantes de Historia”, por Beatriz Gredenberg, en AMICITIA, Año III, n 18, noviembre y diciembre de 1943, pp. 16. 
del hombre, prefiriendo temas argentinos y americanos, sin apartarse de la concepción universal.” En una nota sobre la fundación, la estudiante Beatriz Gredenberg señala:

"Ya vemos en pléyade a los iniciados en Historia, Arqueología, Geografía Humana, Antropología o Geografía Física, dar los primeros pasos que le permitirán la marcha hacia Ateneos y Congresos de mayor profundización. Ya los vemos, pala en mano, buscar en los perdidos tiempos de la antigüedad los restos de alguna ciudad que fué. Quizás, esa flecha dibuje en el tiempo la trayectoria de alguna de nosotras que logre descollar. Quizás, al paso de los años alguna tarde brumosa y fría con la vista fija en algún documento de archivo o en los restos denunciadores de una civilización pasada recuerden los alumnos de Historia y sus profesores de aquella tarde de 1943 en que se comprometieron sobre su firma a sostener un círculo de investigación, estudio y camaradería." 103

Esta asociación estudiantil contribuyó a recaudar fondos para viajes de entrenamiento organizados en conjunto con los profesores de la Facultad y tenía su sede en el Museo Etnográfico. Por otra parte, en 1946 se creó la Sociedad Argentina de Americanistas ${ }^{104}$, la cual se definió como una "entidad de carácter exclusivamente cultural, cuyos socios realizan una labor desinteresada, sin otra finalidad que el adelanto de la Americanística en general y de las ciencias particulares predilectas por cada uno de ellos" (Di Benedetto, 1948: 9). Esta asociación realizaba sus sesiones plenarias y sus conferencias en el Instituto de Arte Americano de la Facultad de Arquitectura de la Universidad de Buenos Aires. Muchos de los miembros fundadores de la Sociedad Argentina de Antropología participaban de éstas y de otras sociedades, al igual que las socias como se examina a continuación.

\footnotetext{
${ }^{103}$ Op. Cit. El subrayado me pertenece.

104 Al parecer, esta Asociación no tiene vínculos con la mencionada anteriormente en este capítulo, la Sociedad de Americanistas de Buenos Aires.
} 


\section{Las primeras socias: proporciones, actividades y sociabilidad cientifica}

A los pocos "especialistas" que fundaron la Sociedad Argentina de Antropología, se sumaron los "interesados" en estas disciplinas, incluidas varias mujeres que participaron activamente en la misma. En esta asociación, como en otras sociedades científicas argentinas, las mujeres fueron admitidas sin que se establecieran criterios diferentes en las membresías para socios masculinos o femeninos. Cabe recordar, que en Estados Unidos inicialmente las mujeres no fueron admitidas en la American Anthropological Association de Washington. Esto llevó, a fines del siglo XIX, a que las mujeres crearan su propia asociación antropológica: la Women's Anthropological Society of America (WASA), creada en 1885 para promover profesionalmente a las mujeres (Tarducci, 2015). En 1902, esta asociación femenina se fusionó con la mencionada American Anthropological Association, dando lugar a una nueva asociación: la American Anthropological Association, la cual aceptó la membresia femenina activa y en 1903 tuvo como presidenta a Alice Fletcher $(1838-1923)^{105}$. Con estos antecedentes, hacia 1920 y 1930, las mujeres formaban una parte significativamente de los asociaciones y de los espacios de formación antropológica en dicho país (Schumaker, 2008).

En la Sociedad Argentina de Antropología la proporción de mujeres que se incorporó a la misma fue aumentando con el paso de los años, llegando a ser más del 50\% en la membresía estudiantil a partir del período 1938-39 (Ver Tabla 2). Cabe recordar que en las primeras décadas del siglo $\mathrm{XX}$, la mayoría de los alumnos de los cursos de antropología y arqueología, tanto en la Universidad de Buenos Aires (Buchbinder, 1997) como en La Plata (a partir de 1920) pertenecían a las carreras de profesorado, con un alto

\footnotetext{
${ }^{105}$ Nacida en Cuba pero criada en Nueva York, viajó de joven por Europa donde enseñó en varias escuelas privadas. Vivió en Boston, donde tuvo una intensa vida social como activista por los derechos de las mujeres. Fue una de las fundadoras, en 1873, de la Association for the Advancement of Women, de la cual fue secretaria muchos años. Alrededor de 1878 conoció a Frederick Putnam, entonces director del Museo de Etnología y Arqueología Peabody, en Harvard. En 1878, a sus cuarenta años, inició sus actividades como antropóloga, realizando excavaciones arqueológicas para el Museo Peabody, donde fue la primera mujer en obtener un cargo permanente en esa institución privada. También realizó trabajo de campo con los Omaha y desarrolló en simultáneo con Franz Boas una teoría del totemismo (Tarducci, 2015).
} 
porcentaje de mujeres (García, 2010). La incorporación de socios puede observarse en la tabla 1, elaborada a partir de las comunicaciones publicadas por la Sociedad en el período 1936-1943 ${ }^{106}$. Como se observa en la misma, hay dos momentos donde se incorporan gran cantidad de miembros, uno en 1936-1937 y otro en 1941-1942. El primer pico en la curva corresponde con el cambio de estatuto y con la ampliación de las categorías de socios. El segundo podría vincularse con un momento de auge de la asociación, en el cual se vienen desarrollando diferentes actividades y se promueve activamente el ingreso de nuevos miembros, junto con la promoción de las ciencias antropológicas en todo el país.

Tabla 1: Incorporación de socios/as activos y estudiantes

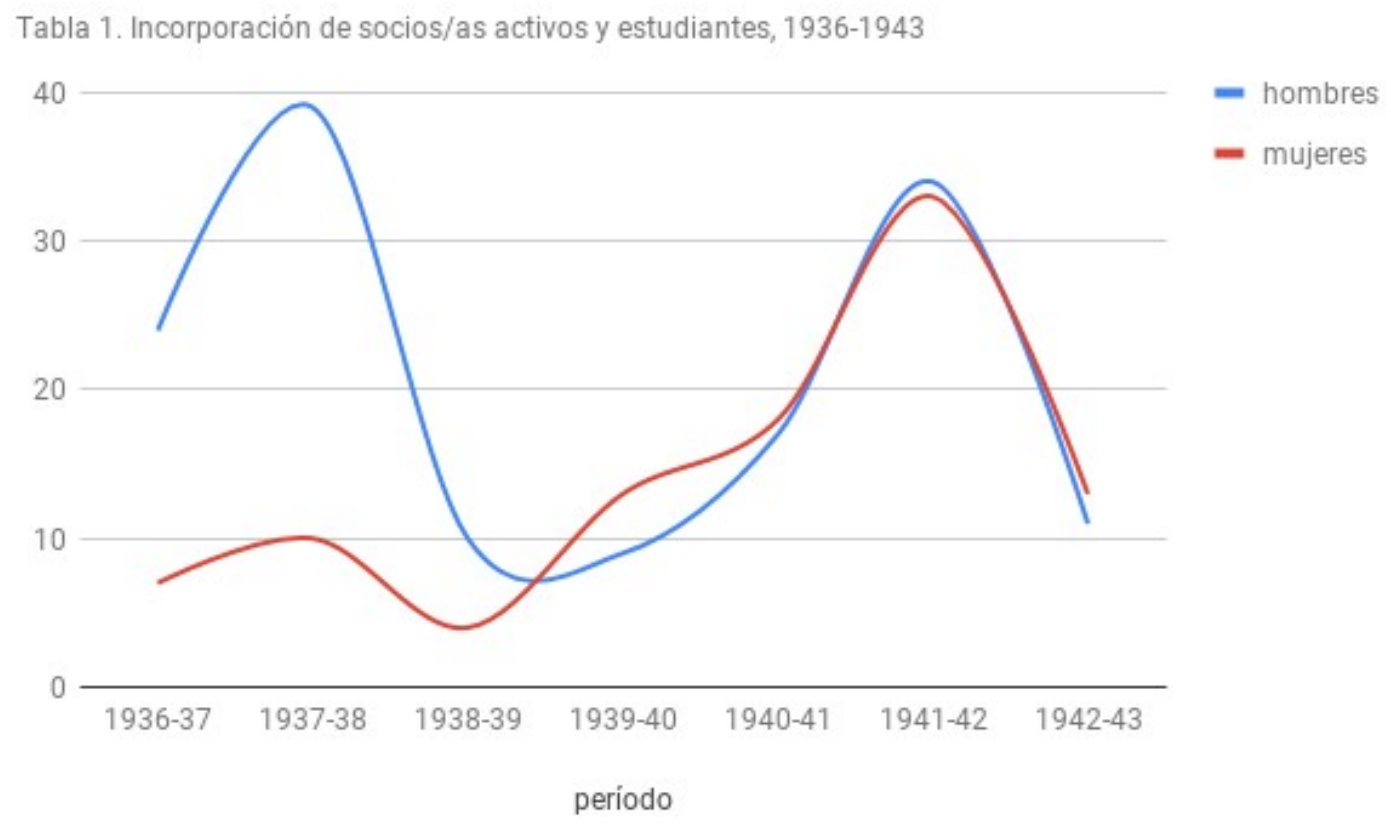

${ }^{106}$ En el Anexo I puede observarse las cantidades de socias y socios incorporados por categoría y por año. 
Tabla 2. Incorporación de socios/as activos y estudiantes, 1936-1943

\begin{tabular}{|c|c|c|c|c|c|c|}
\hline & socios activos & & & socios estudiantes & & \\
\hline Período & hombres & mujeres & total & hombres & Mujeres & total \\
\hline $1936-37$ & 10 & & & 14 & 7 & 21 \\
\hline $1937-38$ & 31 & 5 & 36 & 8 & 5 & 13 \\
\hline $1938-39$ & 9 & 1 & 10 & 1 & 3 & 4 \\
\hline $1939-40$ & 6 & & 6 & 3 & 13 & 16 \\
\hline $1940-41$ & 8 & 1 & 9 & 9 & 17 & 28 \\
\hline $1941-42$ & 15 & 6 & 21 & 19 & 27 & 46 \\
\hline $1942-43$ & 3 & 1 & 4 & 8 & 12 & 20 \\
\hline
\end{tabular}

Aunque la membresía es reducida en la Sociedad Argentina de Antropología, el porcentaje de membresía femenina es elevado al compararse con otras asociaciones. Así por ejemplo, mientras esta Sociedad tenía en 1936, un 22.5\% de socias, de un total de 31 miembros, la Sociedad Científica Argentina contaba con un total de 622 afiliados, de los cuales un 0.6\% eran mujeres. En 1937, el porcentaje de membresía femenina de la Sociedad Argentina de Antropologia desciende al 20\%. Ese mismo año, la Sociedad Argentina de Ciencias Naturales tiene un porcentaje de 13\% de socias de un total de 84 afiliados, siendo once mujeres, pertenecientes al campo de la botánica, zoología, paleontología y mineralogía, las que participan activamente en esta sociedad. Estas cantidades y porcentajes pueden observarse en la tabla 3. En proporción, la Sociedad Argentina de Antropología es la que mayor cantidad de mujeres presenta, aunque en valores absolutos, las socias activas fueron pocas en comparación con la categoría 
estudiantil. En total, entre 1936 y 1942, se vincularon a la Sociedad catorce mujeres como miembros activos, mientras que en ese mismo periodo 69 hombres se adhirieron como socios activos. En la categoría de estudiantes, se registran más mujeres en ese lapso: 65 alumnas $^{107}$.

Tabla 3: Cantidad de socias y socios activos en diferentes asociaciones científicas

\begin{tabular}{|l|l|l|l|l|}
\hline sociedad/año & socios & Socias & Total & $\begin{array}{l}\text { socias en } \\
\text { Sociedad Argentina de Antropología / 1937 }\end{array}$ \\
\hline $\begin{array}{l}\text { Sociedad Physis de Ciencias Naturales } \\
\text { /1937 }\end{array}$ & 73 & 10 & 49 & $20.4 \%$ \\
\hline Sociedad de Americanistas de París/ 1937 & 515 & 11 & 84 & $13 \%$ \\
\hline Sociedad Científica Argentina / 1936 & 619 & 4 & 622 & $0.64 \%$ \\
\hline
\end{tabular}

Si se analiza la proporción de hombres y mujeres en algunas actividades específicas, encontramos que la proporción del 20,4\% de mujeres en la Sociedad Argentina de Antropología no se corresponde con una igual participación en la comunicación y en la publicación de trabajos. De hecho, la cantidad y frecuencia de mujeres en las reuniones científicas donde se presentaron comunicaciones entre 1936 y 1944 es menor que la cantidad de socias activas y estudiantes del período. De las 52 personas que exponen su trabajo en estos años, 7 son mujeres ${ }^{108}$. Entre ellas, María de las Mercedes Constanzó y Ana

\footnotetext{
${ }^{107}$ En términos porcentuales, en este período de 8 años las socias activas conforman casi el $16 \%$ y las socias estudiantes el $51.6 \%$ del total de asociados.

${ }^{108}$ Estas son: Constanzó, Biró de Stern, C.M. de Aparicio, Sanz de Arechaga, Iribarne, Millán de Palavecino y Vidal de Battini.
} 
Biró son las que presentaron comunicaciones más veces, con 7 y 5 trabajos respectivamente ${ }^{109}$. La proporción de mujeres que publicaron artículos en la revista de la Sociedad entre 1937 y 1944 es aún menor. Solamente cinco mujeres publicaron en la misma: Eva Iribarne, Berta Elena Vidal de Battini, María de las Mercedes Constanzó (con dos trabajos, uno en el tomo 3 y otro en el 4), María Delia Millán y Ana Biró (con dos trabajos en el número 4). El porcentaje es bajo y aumenta levemente con el paso de los años. Estas proporciones evidencian diferencias en la distribución de las posibilidades de acceder o potenciar una carrera científico-académica para las mujeres, siendo que del conjunto total de socias, solamente siete participaron de las comunicaciones y publicaciones. Dichas actividades eran fundamentales para el diálogo, la discusión y la difusión de los avances y resultados de las investigaciones.

Entre 1936 y 1945 se registran dieciocho mujeres que estuvieron vinculadas a la Sociedad Argentina de Antropología como socias activas. Las primeras en incorporarse fueron: Elina González Acha de Correa Morales (1861-1942), su hija Cristina Correa Morales de Aparicio (1897-1984), Ada Pastore (1906-1952), María Delia Millán (19021994) ${ }^{110}$, Berta Elena Vidal de Battini (1900-1984), María de las Mercedes Constanzó (n. 1909), Ana Biró (n. 1909), Eva Arminda Iribarne (n. 1913), Elena Scolni de Kliman y María Elena Villagra Cobanera. En 1938 ingresa Amelia Larguía de Crouzeilles y dos años después María Cambiaggio. En 1941 ingresan Luisa B. Vignale de Ardissone, Blanca P. de Bordas, Elvira H. de Casanova, Livia L. Corsini, Sara de Mundo y Daisy Rípodas Ardanaz $^{111}$. En promedio, las edades de las primeras socias rondan los 36 años, siendo la más joven Eva Iribarne quien tenía 23 años en 1936 y la mayor Elina González Acha con 75 al momento de asociarse. Varias de estas asociadas también participaban en otras

\footnotetext{
${ }^{109}$ Ver Tabla 1, Anexo I.

${ }^{110}$ Millán no aparece en las publicaciones como socia, pero de acuerdo al Archivo de la SAA fue incorporada en 1937. Su trayectoria académica es analizada en el capítulo 5.

111 De algunas de ellas no se han podido consignar sus fechas de nacimiento o muerte. Hay escasa información acerca de la biografía de muchas de estas mujeres y la reconstrucción de las mismas excede los intereses del presente capítulo.
} 
asociaciones científicas y compartían el interés por otros campos de saber, como la geografía, la historia, la botánica y la ornitología. Es decir, estaban insertas en ciertas tramas de sociabilidad científica de la época.

Asimismo, muchas de estas primeras asociadas mantenían vínculos personales con otros miembros de la Sociedad, siendo familiares, colaboradoras o alumnas de ellos. Entre las que mantenían vínculos familiares, están Elina González Hacha y su hija Cristina Correa Morales. Ambas formaron parte de un amplio círculo de sociabilidad, siendo la casa de Elina González Hacha y de su marido, el escultor Lucio Correa Morales (1852-1923), un espacio de reuniones entre científicos e intelectuales (Curto y Lascano, 2014) ${ }^{112}$. Cristina Correa Morales estaba casada con Francisco de Aparicio, con el cual colaboró durante treinta años. De hecho, Guber (2006) considera que ese matrimonio le facilitó a Aparicio el acceso a redes sociales vinculadas con el humanismo y las artes porteñas. Ella presentó algunos trabajos en las reuniones de comunicaciones de la Sociedad Argentina de Antropologia sobre "dibujo y arqueología", "los escritos de Frank Paddington", entre otros. También publicó artículos en revistas de divulgación como la Revista Geográfica Argentina. Luego del fallecimiento de Aparicio, en 1951, conformó la Fundación Francisco de Aparicio para ayudar al conocimiento de la arqueología y la geografía. Así como Cristina Correa Morales, varias mujeres se unieron a la Sociedad Argentina de Antropología acompañando a sus esposos, tales como Luisa B. Vignale de Ardissone, Blanca P. de Bordas, Elvira H. de Casanova y Emilia G.B. de Imbelloni ${ }^{113}$. También la botánica Ada Pastore se vinculó a la Sociedad Argentina de Antropología, a través de sus

\footnotetext{
${ }^{112}$ Lucio Correa Morales era primo de Francisco Moreno y de Eduardo Holmberg. Lucio Correa Morales acompañaba las excursiones como fotógrafo. También trabajó como administrador en el zoológico de buenos Aires, gracias a las gestiones de su primo Holmberg (Guber, 2006; Curto y Lascano, 2014).

${ }^{113}$ Como solamente se han encontrado registros con sus apellidos de casadas, el apellido de solteras de la mayoría de estas mujeres no ha sido identificado, más allá de su letra inicial. Esto era habitual en la época y es lo que Correa (1995) ha llamado "renombre" en el sentido de ser nombradas de una forma nueva a partir del matrimonio.
} 
relaciones familiares, siendo cuñada de $\operatorname{Vignati}^{114}$ y como discípula del bótanico Lorenzo R. Parodi, quien estaba en la primera nómina de socios. Otras mujeres tenían vínculos a través del contexto universitario: Entre las alumnas están María Elena Villagra de Cobanera, que fue ayudante alumna de la cátedra de Milcíades Alejo Vignati en el Museo de La Plata (Soprano, 2009); Elena Scolni de Kliman, quien realizó su tesis bajo la dirección de Imbelloni; María de las Mercedes Constanzó que también trabajó junto a Imbelloni como estudiante y luego de egresada como técnica en el Museo Etnográfico.

De estas 18 socias, al menos 8 habían completado una formación universitaria: Cristina Correa Morales, Ada Pastore, Berta Elena Vidal de Battini, María de las Mercedes Constanzó, Ana Biró, Eva Arminda Iribarne, Elena Scolni de Kliman y María Elena Villagra Cobanera. Otras, como Elina González Acha y María Delia Millán se formaron como maestras. Todas las socias universitarias tuvieron algún tipo de vínculo con los museos: el Etnográfico, el Argentino de Ciencias Naturales y el de La Plata. Estas socias activas se involucraron en un amplio espectro de actividades, realizando trabajos en la Sociedad y en espacios vinculados a la misma como secretarias, expositoras, ayudantes técnicas en los museos, docentes, estudiantes, público y como colaboradoras en expediciones y en los eventos de la asociación.

Como ejemplo de la actuación institucional de alguna de las socias activas se puede mencionar la labor de Eva Iribarne como técnica en el Museo Etnográfico, donde realizó tareas de clasificación materiales arqueológicos, contribuyendo con la misma labor en otras instituciones, como el Museo Nacional de Arte Decorativo, donde "examinó las piezas precolombinas que se exhiben al público en la biblioteca del museo y realizó anotaciones correspondientes." "115 Iribarne participó brevemente como secretaria de la Sociedad en el

\footnotetext{
${ }^{114}$ Los hermanos de Ada Pastore, Franco Pastore y Victoria Pastore, estudiaron en la Facultad de Ciencias Exactas, Físicas y Naturales de la Universidad de Buenos Aires junto a Milcíades Alejo Vignati, quien no terminó la carrera y luego se casó con Victoria Pastore.

${ }^{115} 7 / 9 / 1938$, Carta del Museo Nacional de Arte Decorativo a Aparicio. Fondo Aparicio, Carpeta "Colecciones. relaciones institucionales" 1937-38, AFDME.
} 
período 1937-38 ${ }^{116}$, realizó exposiciones en las sesiones de comunicaciones y también publicó, como se mencionó, en la Revista Relaciones. Por su parte, María Elena Villagra de Cobanera fue ayudante alumna de la cátedra y Sección de Antropología del Museo de La Plata, entre 1936 y 1947. Fue de los escasos alumnos que se inclinaron por esta orientación en el doctorado de ciencias naturales ofrecido en esta institución. La información sobre su trayectoria es escasa. Por los registros que se guardan en el AHMLP, estudió entre 1930 y 1935. Publicó algunos trabajos sobre craneología de los "primitivos habitantes" de la Provincia de Buenos Aires. También participó durante un breve período como secretaria de la Sociedad Argentina de Antropología en la segunda mitad de 1943.

Otra de las asociadas fue Elena Scolni de Klimann quien se dedicó a temas de antropología biológica, junto con otras estudiantes dirigidas por José Imbelloni. Su tesis, dirigida por este profesor, se tituló "Sobre las características del fémur en los varios grupos de indígenas argentinos" y fue publicada en Physis en $1938^{117}$. La tesis analiza 165 fémures, pertenecientes a nueve localidades indígenas que de acuerdo con la clasificación de Imbelloni reúnen 3 grupos raciales: Andidos, Pámpidos y Fuéguidos. La misma fue considerada "de verdadero interés y muestra de la excelente orientación de la escuela antropológica argentina" (Comas, 1940). Luego se desempeñó como maestra, dictando clases de Física, Química y Mineralogía, Petrografía, y Geología en la Escuela Industrial de la Nación "Otto Krause" de Buenos Aires.

Entre las socias activas más involucradas con las actividades de la Sociedad, podemos mencionar a María de las Mercedes Constanzó, quien se asoció en 1936 y en 1940 fue electa para desempeñarse como secretaria de la Sociedad Argentina de Antropología, cargo que ejerció hasta 1945. Constanzó era santafecina, se había recibido en 1932 de profesora de Historia en la Facultad de Filosofía y Letras de Buenos Aires, donde luego se doctoró en Filosofía y Letras en 1940 con una tesis titulada "Antropología

\footnotetext{
${ }^{116}$ Iribarne ingresa primero como vocal y tras la renuncia de Jorge Cranwell como secretario en mayo de 1938 ocupa su puesto. Cranwell fue electo como vocal en reemplazo de Iribarne.

${ }^{117}$ Physis n XII, pp. 197-227, Buenos Aires.
} 
Calchaquí: La colección Zavaleta del Museo Argentino de Ciencias Naturales "Bernardino Rivadavia". Este trabajo se dedicaba a "situar racialmente" a los indígenas del Valle Calchaquí, en relación con los demás aborígenes americanos (Constanzó, 1942:214). A partir del estudio de un conjunto de materiales óseos, provenientes de la Colección Zavaleta $^{118}$, comparó los resultados obtenidos con las taxonomías establecidas por Imbelloni para la clasificación del "Hombre Americano" (Constanzó, 1942:269). En su conclusión, la tesis afirma que la región Calchaquí estuvo habitada por individuos de una unidad racial, que según los datos osteométricos, debe ser considerada como una de las ramas más meridionales de los llamados pueblo-ándidos (Constanzó, 1942:280).

Constanzó ejerció la docencia en colegios secundarios y como Jefa de Trabajos Prácticos de Antropología en la Facultad de Filosofía y Letras de Buenos Aires. Asimismo, se desempeñó como técnica del Museo Etnográfico desde 1940. Dichas actividades se articulaban con su participación en la Sociedad Argentina de Antropología. Ese año asumió como secretaria de la misma, encargándose de la redacción de las memorias de las reuniones internas de la Comisión Directiva como de los eventos públicos, de las sesiones de comunicaciones y de la Semana de la Antropología. También se desempeñó como secretaria del Boletín de esta asociación, y como tal estaba encargada de redactar las crónicas de cada encuentro, los resúmenes de obras de diferentes antropólogos y las novedades. Hacia 1945, Constanzó y Vidal de Battini ${ }^{119}$, intentaron gestionar un nuevo subsidio para las publicaciones, siendo que ese año había dejado de ser otorgado el subsidio de 2000 pesos con el cual contaba la Asociación en años anteriores.

\footnotetext{
118 Esta colección contaba con un conjunto de piezas arqueológicas y osteológicas provenientes de yacimientos en el Valle Calchaquí. El material óseo consistía en 242 cráneos, 164 mandíbulas y algunos huesos largos. La colección había sido adquirida por el Museo Nacional de Ciencias Naturales -luego Museo Argentino de Ciencias Naturales- en 1907. Los materiales que estudió Constanzó no contenían información sobre las condiciones de hallazgo, solo estaban acompañados por un "somero" catálogo realizado por Zavaleta y algunas fotografías (Constanzó, 1942:215).

119 en 1944 fue electa como Tesorera de la Comisión Directiva.
} 
Su principal área de trabajo era la antropología física, especialmente la craneología. Como técnica en el Museo Etnográfico de Buenos Aires, se dedicó a estudiar restos antropológicos de esta institución. Hacia mediados de 1940 se encontraba a cargo del Departamento de Antropología Física y Paleontología Humana y de la Sección de Etnografía de este museo. Sus investigaciones fueron publicadas en revistas científicas especializadas ${ }^{120}$, así como en periódicos y revistas de divulgación ${ }^{121}$. También realizó análisis y descripción de colecciones en otros museos ${ }^{122}$. En 1943 visitó los museos Histórico y de Historia Natural de Santiago de Chile donde estudió colecciones procedentes del norte de Chile (Arica, Punta Pichalo, Chiu-chiu, entre otros), realizando alrededor de trescientos dibujos de piezas arqueológicas del norte y centro de Chile ${ }^{123}$. Ese mismo año, a pedido de la Junta de Historia de la Provincia de San Juan, realizó un viaje a dicha provincia para examinar una momia hallada en Hilario, localidad del departamento de Calingasta. Constanzó también formó parte de la Misión a Tolombón (Salta), organizada por el Museo Etnográfico en enero de $1944^{124}$, ayudando a "los alumnos en sus estudios" 125 . Estos viajes tenían por objeto "subsanar una deficiencia de los actuales planes

${ }^{120}$ Entre otras: Acta Americana, Anales del Instituto de Etnología Americana de la Universidad Nacional de Cuyo, Relaciones de la Sociedad Argentina de Antropología, Boletín del Instituto de Investigaciones Históricas de Buenos Aires, Boletín del Museo Nacional de Historia Natural de Santiago de Chile.

${ }^{121}$ Por ejemplo, en el diario La Nación, en la Revista Geográfica Americana y revista del ACA. Algunos trabajos de divulgación fueron realizados a pedido del Colegio de Graduados de Filosofía y Letras y de la Biblioteca Joaquín V. González, y a veces eran difundidos por Radio del Estado. Los temas tratados eran diferentes: leyes biológicas en Antropología, la sangre como elemento para el diagnóstico racial (1944), antropología cultural, impresiones de su viaje por Chile con datos folklóricos sobre Chile, entre otros.

${ }^{122}$ Posiblemente colaboró también con las investigaciones sobre talla e inmigración de Juan Severino López, su esposo, quien era profesor de historia y jefe de la sección Demografía Histórica del Instituto Étnico Nacional.

${ }^{123}$ En el Museo de Historia Natural estudió una colección de cráneos procedentes de Arica, provenientes de un yacimiento explorado por la arqueóloga Grete Mostny, concluyendo que los restos pertenecían al tipo denominado ándido.

\footnotetext{
${ }^{124}$ Ver más adelante en este capítulo.

125 4/7/1945, AFDME, Fondo Institucional.
} 
de estudio que dan sólo un conocimiento teórico del país y no ponen al futuro profesor en condiciones de desempeñarse desde la cátedra, con toda la eficacia que sería de desear" (Constanzó, 1945: 55). Los mismos fueron realizados por estudiantes varones y mujeres junto a los profesores de distintas materias y contaban con el apoyo de la asociación estudiantil AKIDA ${ }^{126}$. Parte del material reunido en estos viajes ingresó a las colecciones del Museo Etnográfico y fue luego utilizado por Constanzó en sus investigaciones. En 1944 estudió, por pedido de Imbelloni, las órbitas de cráneos indígenas de la Provincia de Río Negro, Argentina. También por encargo de este profesor realizó una investigación bibliográfica sobre la antropología física de los indígenas de la República Argentina y países limítrofes, “con el fin de reunir de una manera definitiva los datos existentes tanto los que se refieren a las parcialidades desaparecidas como a las vivientes ${ }^{127}$.

En 1946 Constanzó fue convocada para "reestructurar" el Instituto de Antropología de la Universidad de Tucumán (en reemplazo de Enrique Palavecino), asumiendo interinamente la dirección hasta 1947. Allí se desempeñó como profesora de Prehistoria y Etnografía en la Facultad de Filosofía y Letras de la misma universidad, entre 1946 y 1947. En 1947 su cargo no es confirmado y la dirección del Instituto quedó a cargo de Osvaldo Paulotti (Guber, 2006; Arenas y Carrizo, 2010; Perazzi, 2014).

Las prácticas asociadas a la trayectoria de Constanzó son compartidas por otras mujeres de la época: las tareas docentes ad-honorem, la participación en comisiones directivas o espacios de toma de decisiones como secretarias y el desempeño de cargos institucionales en distintos escalafones, el fichaje bibliográfico, la ilustración de objetos

\footnotetext{
${ }^{126}$ De hecho, la asociación "AKIDA" contribuyó con la recaudación de fondos para posibilitar los viajes. De su participación, señala Constanzó: "el mayor mérito de AKIDA consiste pues en predicar con el ejemplo, ya que no es suficiente pregonar la necesidad de un conocimiento inmediato de la realidad argentina en sus múltiples aspectos: geográfico, económico, histórico, social, etcétera; es preciso demostrar la posibilidad de acceder a ese conocimiento, poniendo la realización del viaje al alcance de todo el estudiantado sin excepción, siempre que reúna el único requisito de haber aprobado determinadas materias que pueden contribuir al mayor aprovechamiento del mismo." (Constanzó, 1945: 56)

${ }^{127}$ 4/7/1945, AFDME, Fondo Institucional.
} 
arqueológicos o antropológicos, la asistencia en la organización e inventariado de colecciones, la colaboración con sus esposos, entre otros. Estas actividades no les fueron exclusivas ni tampoco asignadas con argumentos relativos a su género. Las diversas ocupaciones y tareas más bien remiten a una caracterización más compleja de la sociabilidad y de las prácticas antropológicas, a las diferentes estrategias disponibles para acceder a las colecciones en los museos, a las bibliotecas y a los espacios de discusión y difusión de saberes. Por otra parte, el caso de Constazó muestra que para mediados del siglo $\mathrm{XX}$, las antropólogas argentinas podían ser elegidas para dirigir y reorganizar instituciones, pero, al igual que los hombres y los espacios académicos, estarían a merced de los avatares político-institucionales de la época.

\section{Asociacionismo y participación femenina}

Considerando las actividades e investigaciones realizadas por las mujeres dentro de la Sociedad Argentina de Antropología y considerando los cambios en la membresía analizados en este capítulo, se observa que las mujeres accedieron a puestos de diferentes jerarquías, integrando la Comisión Directa de la asociación como secretarias, vocales y tesoreras y asumiendo responsabilidades como la edición del Boletín. El aumento proporcional de socias entre 1936 y 1943 se dio principalmente en la categoría de estudiantes y la proporción femenina aumenta con el tiempo en términos de exposición de trabajos y de publicación de trabajos en la revista Relaciones y en el Boletín. Las socias estudiantes participaban especialmente como público en las sesiones de comunicaciones científicas, en las cuales los concurrentes más continuos son los estudiantes, siendo la sociedad "como una prolongación amable de la cátedra" (Márquez Miranda, 1943). En suma, si consideramos las proporciones presentadas de mujeres y hombres, éstas ofrecen un indicador de algunas diferencias en la participación dentro de la Sociedad Argentina de Antropología. Dicha participación se vincula también con diferentes oportunidades de 
formación y de realización de una carrera académica y con la conformación y delimitación de las ciencias antropológicas en las décadas de 1930 y 1940.

La asignación de tareas y la segmentación de las posibilidades de trabajo en relación a una idea de habilidades o condición "femeninas" fue la primera hipótesis que se propuso al comenzar a elaborar este capítulo. Sin embargo, no es posible determinar que efectivamente ocurrió una división sexual de tareas dentro de las actividades de la Sociedad Argentina de Antropología en sus primeros años. Tanto mujeres y hombres realizaban tareas en las divisiones y secciones de distintos museos, analizando muestras, catalogando materiales y haciendo fichas bibliográficas. Cuando en 1943 se organizaron los viajes de estudios a Tolombón, liderados por Aparicio, tanto hombres como mujeres -estudiantes y profesores/as- participaron de las mismas. Guber (2006) señala que en la época del viaje "la segregación de género estaba a la orden del día en la Universidad de Buenos Aires" y que las mujeres que viajaron tuvieron recomendaciones respecto de la vestimenta: "Por instrucción de Aparicio, las mujeres debían vestir camisa de manga larga y pantalónbombacha, para prevenir quemaduras y heridas por los espinillos; debido a estos recaudos, particularmente al pantalón, el cura de la parroquia a cargo del museo arqueológico de Santa María, no les permitió el acceso.” (Guber, 2006: 15) ${ }^{128}$. La vestimenta recomendada por Aparicio era la que habitualmente llevaban otras mujeres al campo. Por ejemplo, en 1936, cuando los etnólogos Jules Henry (1904-1969) y Zunia Henry viajaron a la región chaqueña para realizar trabajo de campo y estudiar a los Pilagá, Eva Spiro, entonces esposa de Métraux, envió recomendaciones especiales para Zunia: le sugiere comprar bombachas de gaucho, no vestir pantalones en la ciudad o bien la conveniencia de las alpargatas para soportar el clima cálido de la región (Córdoba, 2017).

Las experiencias analizadas en este capítulo permiten una aproximación al funcionamiento y a los primeros años de la Sociedad Argentina de Antropología, que

\footnotetext{
${ }^{128}$ Los viajes "mixtos" no eran una novedad, en el Museo de La Plata se realizaban viajes de campaña que contaban con estudiantes varones y mujeres desde las primeras décadas del siglo XX (García, 2010). En 1907 un grupo de estudiantes de ciencias naturales organizó una excursión a Tandil a la cual asistieron varones y mujeres (García, 2010: 207).
} 
permiten también comprender ciertas características de las ciencias antropológicas en las décadas de 1930 y 1940. La participación de las mujeres en la sociedad no fue menor, y fue especialmente amplia entre estudiantes y público. Sus actividades y temáticas dan cuenta de la primera década de la asociación, conformada de forma heterogénea por diversos sujetos, intereses y saberes: la historia, la geografía, la arqueología, el folklore, la etnografía, la etnobotánica, la enseñanza en diferentes niveles, entre otros.

Como señala Podgorny (2005), el estudio de los modos particulares de sociabilidad científica implica también atender a su relación con cierta definición institucional y su contexto material y social, teniendo en cuenta que tanto las ideas como las instituciones son producto de las acciones, elecciones y estrategias de actores concretos en el marco de contextos específicos. En este sentido, la Sociedad Argentina de Antropología constituyó un espacio de sociabilidad, de intercambio y difusión de conocimientos y prácticas; que desarrolló y promovió estrategias para el fortalecimiento de las ciencias antropológicas como disciplinas científicas. Asimismo, esta asociación se articuló con diversas instituciones, especialmente las universidades, generando relaciones entre los espacios de cátedra, de sociabilidad y camaradería y de investigación, tanto en los museos como en los viajes y expediciones de campo. 


\section{Capítulo 3. Coleccionismo y prácticas privadas en la ciencia}

\section{Introducción}

Numerosos trabajos sobre la historia de los museos se han ocupado de analizar las prácticas asociadas a la colección de objetos etnográficos, arqueológicos y antropológicos; así como las relaciones que median entre el campo, el gabinete y los poseedores de un conocimiento local sobre las cosas; considerando también las formas de ordenar estos materiales y ubicarlos en un lenguaje universal (cf. Kuklick y Kohler, 1996; Penny 2002). Como señalan Podgorny y Lopes (2013), la historia de estas instituciones comenzó a comprenderse a partir de un mundo de dimensiones que exceden las salas de exhibición y los depósitos. Esta mirada sobre los museos remite a varias cuestiones, entre ellas las redes de intercambio y de provisión de datos y artefactos que tendieron los científicos y las administraciones de los mismos. En forma paralela al estudio de la cultura material y a los nuevos enfoques que la historia de la ciencia, proliferaron los trabajos sobre coleccionismo (cf. Jardine, Secord y Spray, 1996; Penny, 2003; Alberti, 2005; Gänger, 2014; Hynes, 2018) y sobre la circulación y las formas del conocimiento (cf. Secord, 2004; Podgorny y Lopes, 2013).

Vinculado con estas perspectivas, también se ha trabajado sobre el funcionamiento de redes de contactos y de provisión de datos más "informales" y sobre el papel de los coleccionistas privados en estas redes de acopio de materiales y datos y en la producción de 
conocimientos (cf. Kohler, 2007). Pupio (2005, 2011, 2012) ha mostrado cómo los aficionados y coleccionistas de las provincias formaban una red de relaciones entre ellos, favoreciendo la creación de museos municipales y la institucionalización de las colecciones arqueológicas. Los coleccionistas ponían a disposición sus datos para el estudio de los arqueólogos de Buenos Aires y La Plata, actuando como intermediarios entre ellos y los vecinos. Asimismo, desde los museos de Buenos Aires y La Plata les enviaban recomendaciones de bibliografía y apoyaban su "entrenamiento" a través de correspondencia con instrucciones sobre las formas de registro, excavación, recolección, documentación y traslado de los materiales (Podgorny, 2009; Pupio, 2011). Estas cuestiones remiten a las prácticas amateur en las ciencias y al papel de los aficionados en la conformación de los saberes científicos (Stebbins, 2001; Charvolin, Micoud y Nyhart, 2007). Si bien se suelen establecer diferencias entre las categorías "coleccionistas" y “aficionados" en la arqueología, las fronteras entre ambas se han definido como arbitrarias y borrosas (Pupio, 2011).

El objetivo de este capítulo consiste en el análisis de las prácticas de coleccionismo privado llevadas a cabo por una sexagenaria santafesina, Amelia Larguía de Crouzeilles (1875-1952). Entre 1930 y 1950 hubo un creciente interés arqueológico por la región del Arroyo Leyes en Santa Fe y Amelia Larguía participó de las discusiones e intercambios que suscitaron las piezas cerámicas encontradas en este "paradero". Asimismo, en este capítulo se muestra cómo diferentes aficionados e interesados en la arqueología participaron de una serie de hallazgos y debates científicos. Larguía formó parte de este conjunto variado de sujetos que se involucraron con la promoción de sitios y materiales arqueológicos, actuando como mediadora entre los científicos de Buenos Aires y La Plata y los pobladores locales. Su caso además ilustra otra de las modalidades y posibilidades a través de las cuales las mujeres pudieron participar de las ciencias antropológicas de la época. 


\section{Las cerámicas del Arroyo Leyes y el interés de los coleccionistas}

A inicios de la década de 1930, los hallazgos realizados en las zonas aledañas a la ciudad de Santa Fe, especialmente en el paraje llamado Arroyo Leyes ${ }^{129}$, generaron un amplio interés arqueológico. Las piezas cerámicas halladas suscitaron amplios debates en torno a la clasificación y a la autenticidad de las mismas (Bonin, 2008; Ceruti, 2012; Podgorny, 2014). Estas discusiones involucraron a científicos, aficionados y coleccionistas; entre ellos, a Amelia Larguía, una señora de la élite local.

Larguía nació en Santa Fe el 5 de enero de 1875, en el seno de una familia numerosa $^{130}$ y destacada de la élite santafesina. Hija de Mauricia Mercedes Descalzo Gómez (1842-1876) y de Jonás Larguía (1832-1891) ${ }^{131}$, ingeniero encargado de varias obras públicas en la provincia y de una prolífera actividad política e intelectual. En 1899 se casó con Juan Carlos Crouzeilles (1869-1917), periodista, diputado y miembro del gobierno provincial $^{132}$, con quien tuvo seis hijos ${ }^{133}$. Tras la muerte de su esposo, obtuvo una pensión

\footnotetext{
${ }^{129}$ La localidad del Arroyo Leyes se ubica a 11 kilómetros de la ciudad de Santa Fe, siendo actualmente parte del conglomerado urbano de esa ciudad.

${ }^{130}$ Puesto que era una de nueve hermanos: Francisco Tomás, Mercedes E., Jonás Isaac, Lucrecia, Constancio F. J., Eduardo A., Eduarda Adelaida, Pedro Regalado y Francisco.

131 Jonás Larguía realizó numerosas obras públicas en la provincia de Santa Fe y en el país. Su actividad política e intelectual fue prolífera, intercambió correspondencia con Diego de Alvear, Nicolás Avellaneda, Bernardo de Irigoyen y con Dardo Rocha; entre otros. Escribió ensayos sobre la "Educación del pueblo", redactó el proyecto de ley de creación del departamento de ingenieros de la provincia de Santa Fe y publicó diversas notas periodísticas. También actuó como Jefe de la Oficina de Estadística provincial y estuvo vinculado a la compañía francesa de ferrocarriles de Santa Fe (Fondo Jonás Larguía, AHPSF).

${ }^{132}$ Crouzeilles fue diputado en la legislatura provincial entre 1894 y 1904, en 1904 asumió como Ministro de Hacienda y Obras Públicas del gobernador M. Freyre. En 1907 fue miembro de la Convención reformadora de la Constitución de la Provincia; asesor letrado de la provincia en la Capital Federal y diputado nacional. (Fondo Juan Crouzeilles, AHPSF).

133 Estos eran: Amelia (n. 1898), Flora María Teresa (n. 1900), Juan Carlos (n. 1902), Pedro (n. 1904), Lucrecia Eugenia (n. 1907) y María Acha (n. 1910).
} 
del gobierno provincial ${ }^{134}$. De acuerdo con sus escasas biografías, en 1931 cuando sus hijos ya habían crecido, comenzó a interesarse por los "misterios insondables" de la región (López Rosas, 1993) y a conformar una colección arqueológica que continuo hasta su muerte en 1952. Su inclinación por la arqueología comenzó de forma paralela al interés local generado por los hallazgos y debates de las piezas provenientes de la zona del Arroyo Leyes.

Se ha señalado que el "paradero" de Arroyo Leyes fue dado a conocer por el viajero Fernando R. Mántaras en 1930, quien encontró de casualidad algunos restos de alfarería y desde entonces se dedicó a buscar "más prolijamente" (Podgorny, 2014). Mántaras, además, se constituiría en guía de "campo" de otros coleccionistas como Larguía, a quien acompañaría en la visita a este sitio arqueológico y otros de la región. Tal como ella relató en 1934: "debo el conocimiento de la mayoría de los sitios visitados al señor Fernando R. Mántaras, con quien hemos realizado frecuentes excursiones que nos han permitido reunir un interesante material arqueológico" (Larguía de Crouzeilles, 1934: 217). Larguía, a su vez, escribió a los arqueólogos de Buenos Aires y La Plata, dando noticias sobre los hallazgos de este sitio e insistiendo en su importancia arqueológica. Inicialmente se contactó con Francisco de Aparicio, por entonces profesor de arqueología en la Universidad de Buenos Aires y encargado del Departamento de Arqueología del Museo Etnográfico, quien anteriormente había residido en Santa Fe y había sido profesor de Arqueología americana en la Universidad Nacional del Litoral entre 1920 y 1930.

\footnotetext{
${ }^{134}$ Tras la muerte de Crouzeilles, en abril de 1917, el senado santafesino propuso un proyecto de ley sobre tablas para apoyar a sus herederos, considerando que "la familia ha quedado en la mayor indigencia". El senador Gerardo Costanti manifestó que "le han quedado a la señora viuda varios hijos cuya educación se hace indispensable". El proyecto fue sancionado sin discusión. En reiteradas ocasiones, Larguía de Crouzeilles tuvo que pedir la prórroga de la pensión, así como el aumento del monto (Fondo Juan Crouzeilles, AHPSF).
} 
Por su parte, el agente de seguros Manuel B. Bousquet también se atribuyó el "descubrimiento" del yacimiento de Arroyo Leyes. En una entrevista publicada por un periódico santafesino, señaló:

"en una de mis recorridas en busca de elementos arqueológicos, visité la región de Santa Rosa (Departamento de Garay), y al pasar por el Arroyo Leyes, a donde me dirigí por indicaciones del señor Leandro Sosa, comprobé la existencia de fragmentos de alfarería indígena. En mis primeras exploraciones en el mencionado paraje pude obtener únicamente algunos trozos de alfarería sin mayor valor; pero a medida que avanzaba en las excavaciones iba hallando fragmentos con borde y otros pintados, pipas, instrumentos de hueso labrado, hermosos ejemplares de cabeza de loros, ejemplares que se conocen únicamente en la colección del Sr. Francisco de Aparicio, y obtenidas en Malabrigo. Continuando las excavaciones di con un gran número de vasijas y de piezas que representan la fauna de esa zona." 135

Frente al interés que despertaron los objetos cerámicos del Arroyo Leyes entre distintos coleccionistas y visitantes, los pobladores locales comenzaron a realizar recolecciones -y quizás algunas falsificaciones- para ofrecer en venta. La proliferación cerámica levantó sospechas y varios estudiosos cuestionaron la autenticidad de las piezas, generándose debates sobre su antigüedad y clasificación. En la discusión sobre estos materiales, intervinieron diferentes arqueólogos, coleccionistas y aficionados, entre ellos, Francisco de Aparicio, Antonio Serrano, Félix Outes, los sacerdotes jesuitas Raúl Carabajal y Guillermo Furlong, Amelia Larguía, Manuel Bousquet, Fernando Mántaras, entre otros. Las exploraciones arqueológicas fueron muy difundidas en la prensa local, a través de la

\footnotetext{
135 “Cómo se dió con el Yacimiento Arqueológico de Arroyo de Leyes, según Manuel A. Bousquet”, El Orden, Santa Fe, domingo 7 de julio de 1935.
} 
publicación de los hallazgos, de las comisiones de científicos que iban a estudiarlos ${ }^{136}$, así como de los debates que se generaron sobre los objetos.

En 1937, Francisco de Aparicio publicó un artículo titulado "Excavaciones en los paraderos del Arroyo Leyes" donde menciona que "a comienzos de 1934, la Sra. Amelia Larguía de Crouzeilles, mediante una copiosa correspondencia, consiguió convencerme de la importancia arqueológica de la zona adyacente al Arroyo de Leyes" (Aparicio, 1937:7). También el director del Museo Etnográfico de Buenos Aires, Outes, reconoció la asistencia prestada por Larguía en el reconocimiento de ese sitio arqueológico, gracias a la información y objetos “de belleza singular" enviados por la coleccionista al museo ${ }^{137}$. Por su parte, Larguía en su correspondencia daba aviso de que dicho yacimiento "era objeto de una destrucción tenaz y desatentada (sic) por parte de los pobladores, quienes extraían objetos con el propósito de venderlos a curiosos y aficionados" ${ }^{\prime 138}$.

A partir de estas noticias y piezas recibidas, Aparicio realizó dos excursiones al Leyes, una en 1934 y otra en 1936. En la primera, acompañado por el geógrafo Federico Daus $^{139}$ y el Director del Museo de La Plata, Joaquín Frenguelli, quien había vivido en Santa Fe entre 1911 y 1934 y conocía la arqueología y la geología de la región ${ }^{140}$. Los

\footnotetext{
136 Especialmente de las dirigidas por Aparicio en 1934 y en 1936 y de la proyectada por la Sociedad Argentina de Antropología en 1940, de la cual se habla más adelante en este capítulo. Ver, entre otros: "Hallazgos arqueológicos en las márgenes del Arroyo Leyes" en EL LITORAL, 31 de Marzo de 1935; "Se proyecta una investigación arqueológica en el arroyo Leyes” en EL ORDEN, 11 de Noviembre de 1940.

${ }^{137}$ AFDME, 2/10/1938.

${ }^{138}$ AFDME, 2/10/1938.

${ }^{139}$ Federico Daus, adscripto a la sección de Antropogeografía del Museo Etnográfico. Sobre su trayectoria, ver: Quintero (2002); Lascano y Curto (2015).

${ }^{140}$ Joaquín Frenguelli (1883-1958). Médico graduado en la Universidad de Roma, había nacido en esa ciudad en 1883. En la Argentina actuó desde 1920 como profesor de Geología y Paleontología en la Facultad de Ciencias de la Educación de la Universidad del Litoral (Santa Fe). Especializado en invertebrados y paleobotánica, fue desde 1934, secretario, luego director, del Instituto del Museo de la Universidad de La Plata (García, 2016; Riccardi, 2013).
} 
expedicionarios encontraron dificultades para excavar sobre la zona de los campos, ya que los mismos estaban sembrados y los pobladores locales no les permitieron hacer "pozos". No obstante, pudieron excavar en los alrededores, aunque la zona ya había sido socavada por vendedores de "tesoros":

"solo en una pequeña franja, comprendida entre el camino carretero y la costa, es posible excavar, pero esta zona se encuentra totalmente removida por los lugareños, que realizan búsquedas continuas con propósitos de lucro. Es de allí de donde han salido -según testimonios de los propios recolectores- las numerosas piezas que se han dado a conocer últimamente" (Aparicio, 1937:8-10).

Luego de estas exploraciones, Aparicio visitó la colección de Manuel A. Bousquet en la ciudad de Santa Fe, la cual contenía objetos

"procedentes de los yacimientos del Leyes, que diferían fundamentalmente de todos los restos arqueológicos del litoral paranaense conocidos hasta la fecha. El efecto de esta colección fue, francamente, desconcertante. Algunas piezas denunciaban muy a las claras la existencia de una superchería; otras, en cambio, abrían un interrogante que aún hoy no tiene respuesta satisfactoria. Desde entonces hasta hoy, la cuestión del Leyes ha estado sobre el tapete, apasionando a especialistas y aficionados, y adquiriendo, por momentos, caracteres de escándalo, poco frecuentes en nuestro mundo científico" (Aparicio, 1937).

En este comentario, Aparicio advertía sobre las diferentes cuestiones que giraban en torno a los hallazgos de la región. Una de ellas es la presencia de objetos cerámicos que eran de dudosa autenticidad y que fueron calificados como "supercherías" o "seudocacharros". De igual manera, Frenguelli denunciaba una "industria de seudocacharros", promovida por coleccionistas desconocedores de la arqueología o guiados por otros intereses: "tuve la ingrata sorpresa de comprobar que la mayor parte de las noticias sensacionales carecían de veracidad" (Frenguelli, 1935:3). 
En una segunda excursión en mayo de 1936, Aparicio solicitó la compañía de Bousquet a fin de "obtener la colaboración de los pobladores, indispensable para el éxito de la empresa" (Aparicio, 1937:12). Al llegar, encontraron que la costa del Arroyo Leyes estaba totalmente removida y que "sólo conservaba su virginidad el campo que circundaba las casas, virginidad guardada con celo femenino por los tenaces competidores de la ciencia oficial" (Aparicio, 1937:12). Excavaron cerca de la costa del arroyo y recorrieron las barrancas de la zona, obteniendo gran cantidad de "tiestos", vasos, figuras y otros rastros de ocupación humana, como comida, valvas de moluscos y huesos. Asimismo, consiguieron el “anhelado permiso para cavar en una sección del terreno absolutamente virgen. Una parte del campo que no había sido roturada nunca con ningún propósito"141 (Aparicio, 1937:15). De estos hallazgos, Aparicio aclara:

\begin{abstract}
"todas las piezas exhumadas en el curso de las investigaciones de que doy cuenta en esta breve comunicación, han sido extraídas por mis propias manos, extremando el análisis en cada caso. Tengo el convencimiento de que todas estaban in situ y, por lo tanto, no abrigo la menor sospecha de que pudieran haber sido introducidas en el terreno con propósitos de engaño o de especulación.” (Aparicio, 1937:18).
\end{abstract}

A partir de la experiencia de la excavación en una zona "virgen", se constataba que "la superchería y el charlatanismo se han mezclado, desgraciadamente, al asunto, pero esta circunstancia no amengua, en modo alguno, el interés estrictamente científico del problema" (Aparicio, 1937: 19). Con esta afirmación, Aparicio recurría a sus saberes y prestigio como arqueólogo para atestiguar la autenticidad de las piezas obtenidas.

Junto al problema de la autenticidad de las piezas, se encontraba el del comercio de piezas falsificadas. Frenguelli consideraba que "Bousquet, en el deseo de acrecentar sus colecciones con piezas extraordinarias, había casi monopolizado la adquisición de los

\footnotetext{
141 Aparicio aprovecha esta oportunidad para realizar una excavación "sistemática", encontrando diferentes objetos a medida que profundizaban las "punteadas", en un primer nivel poco aparecía, en un segundo nivel abundantes tejas y restos de comida y en un tercer nivel -entre 80 y $90 \mathrm{~cm}$ de profundidad- hallaron algunas piezas cerámicas (Aparicio, 1937).
} 
materiales ofrecidos en venta", sugiriendo que ello habría fomentado las falsificaciones y la fabricación de objetos por los pobladores de la zona (Frenguelli, 1937, p. 62-63; Podgorny, 2014). Sobre esta cuestión, el sacerdote Carabajal, profesor de historia y encargado del Museo Histórico del Colegio "La Inmaculada Concepción” de Santa Fe, denunció también el negocio generado alrededor de los “descubrimientos arqueológicos de la zona":

"Una advertencia que debe servir de voz de alerta para directores de Museos, es el hecho de que anda en circulación y se ofrece en venta, y por desgracia en gran cantidad, cierta alfarería que nada tiene de indígena, pues ha salido de las manos de los actuales lugareños y que presenta un aspecto tan reciente, que solamente un profano en estudios arqueológicos puede ser sorprendido en su buena fe. La avidez de coleccionistas ingenuos ha despertado la avaricia de gente inescrupulosa y ha brotado la industria de los seudocacharros." (Carabajal, 1936:56)

Las críticas apuntaban entonces a los coleccionistas inexpertos que buscaban acrecentar su patrimonio y con ello favorecían la producción de malas imitaciones y la circulación de piezas, algunas consideradas de origen dudoso. Frente a este tipo de cuestionamientos, coleccionistas como Bousquet buscaron validar "científicamente sus colecciones, buscando el apoyo de arqueólogos reconocidos y permitiendo su estudio. Bousquet atesoraba en su casa en Santa Fe y luego en su casa en Buenos Aires "un verdadero museo de cosas nuestras: piezas arqueológicas, armas y documentos de los próceres del panteón nacional" (Podgorny, 2014:29). También tejía alianzas, promoviendo sus hallazgos mediante donaciones y ventas de piezas a diferentes museos e instituciones (Podgorny, 2014) ${ }^{142}$. Entre ello, buscó el apoyo de Antonio Serrano, quien se ocupó del

\footnotetext{
${ }^{142}$ En 1935, entregó dos piezas al sacerdote jesuita Miguel Ramognino, quien a su vez las donaba al "Museo de Antigüedades" del Colegio del Salvador de Buenos Aires. En 1937 entregó piezas en depósito al Museo Argentino de Ciencias Naturales de Buenos Aires y vendió una veintena de piezas de su colección al Ministerio de Justicia e Instrucción Pública de la Nación con destino al Museo Antropológico y Etnográfico de la Facultad de Filosofía y Letras de la Universidad de Buenos Aires. En 1945 se registra la donación de un conjunto de piezas al Museo de Antropología de la Universidad Nacional de Córdoba (Podgorny, 2014; Bonnin s/f).
} 
estudio de sus colecciones, validándolas “científicamente". En una entrevista, al relatar la forma en que dió con el "paradero" de Leyes, señaló la relación establecida con los arqueólogos de Buenos Aires y cómo Aparicio “comprobó” la autenticidad de sus piezas:

"Una vez convencido de que me hallaba en presencia de un "paradero" indígena de importancia, intensifiqué la búsqueda y pude así obtener un elevado número de piezas de alfarería que llamaron justamente la atención de los peritos argentinos. A raíz de ciertos rumores malevolentes sobre mis hallazgos, y luego de comprobada por el arqueólogo Francisco de Aparicio, en el propio "paradero", la autenticidad de la cerámica de mis descubrimientos, recibí la ayuda moral del Dr. Félix Outes, sabio conocido mundialmente." (Bousquet, $1935^{143}$ ).

La ayuda moral y la verificación por parte de estos "peritos" corrieron de forma paralela al crecimiento de la "industria de seudocacharros", la cual estuvo presente tanto en las discusiones como en el circuito de materiales provenientes del Arroyo Leyes. Al respecto, Mantarás describió un conjunto de piezas adquiridas a un "vendedor" local, entre las cuales algunas cerámicas mostraban con claridad su confección reciente, puesto que las impresiones de los dibujos mostraban las huellas de tapas de hojalata de bordes ondeados, objetos de hierro en forma de cuña y una moneda o pieza circular con un número dos de imprenta en su centro (Mántaras, 1936).

Otra de las cuestiones discutidas sobre los hallazgos del Arroyo Leyes fue la clasificación de los mismos. Las piezas halladas poseían diferentes técnicas y ornamentaciones, tipos de manufactura, variaciones en el uso de materiales, en el espesor de pasta, entre otros atributos. También se postularon diferentes interpretaciones sobre la pertenencia cultural de las piezas y sus posibles correlaciones con culturas de otras regiones, así como la antigüedad de las mismas. Sobre esta cuestión, dice Frenguelli:

\footnotetext{
143 “Cómo se dió con el Yacimiento Arqueológico de Arroyo de Leyes, según Manuel A. Bousquet”, El Orden, Santa Fe, domingo 7 de julio de 1935.
} 
"el carácter de los nuevos hallazgos modificaba de una manera fundamental y sorprendente nuestros conocimientos sobre la cultura de los indígenas que poblaron los bordes y el complejo insular del río Paraná, desde el delta hasta Corrientes. El acervo industrial y cultural de poblaciones que (...) se habían definido como de cazadores y pescadores seminómades y primitivos, adquiría características elevadas, comparables con el acervo de las poblaciones americanas más adelantadas, como las que construyeron ciudades famosas y prolijamente cultivaron campos" (Frenguelli, 1935: 3).

Por su parte, Aparicio, luego de sus excursiones, consideró que el tipo de cerámica encontrado en el paradero de Leyes era nuevo "un tipo de cerámica desconocido hasta el momento, en la forma no usual de vasos enteros" en relación a los yacimientos "clásicos" del litoral paranaense (Aparicio, 1937:19). La principal discusión sobre la clasificación de estos objetos estaba centrada en resolver si los artefactos constituían una "unidad cultural" o varias. Tanto Bousquet, como Serrano y Furlong, entre otros, sostenían la unidad cultural del conjunto de restos cerámicos hallados en la región del Arroyo Leyes y la asociaban a la cultura Mocoví.

Frenguelli, quien realizó tres visitas al yacimiento de Leyes (una vez solo, otra, con Larguía y la tercera, ya mencionada con Aparicio y Daus en 1934), insistió en el aislamiento del Leyes y en que las piezas "verdaderamente" indígenas estaban desconectadas de todo intercambio histórico (Frenguelli, 1937; Podgorny, 2014). La misma hipótesis fue presentada unos años después por el sacerdote Carabajal, quien realizó 28 excavaciones durante tres años en la región. Carabajal diferencia los "seudocacharros" del resto de los materiales de Leyes, a los cuales clasifica en tres "zonas" o "culturas". Las mismas estaban escalonadas de norte a sur, siguiendo el margen del Arroyo Leyes. Esta separación explicaría la diversidad técnica, de los motivos decorativos y la antigüedad de los objetos hallados. La zona norte comprendía la cerámica antigua, predominando las vasijas ornamentadas con incisiones punteadas sobre un surco continuo, o sobre superficies lisas. La zona central era la más antigua y la alfarería que se encontraba ahí era lisa y policromada al rojo vivo y ocre, y de técnica sencilla. La zona sur, presentaba las piezas de 
técnica más "perfecta", abundando las formas muy bien estilizadas. Carabajal consideraba que el material de estas tres zonas correspondía a cerámica post-hispánica, de fines de siglo XVIII y comienzos del XIX (Carabajal, 1936: 54). Así como Furlong, Bousquet y Serrano, Carabajal vinculó la cerámica de la región con la cultura mocoví, aunque coincidía con Frenguelli y Aparicio en separar dos tipos de cerámicas, calificando a las más "recientes" como supercherías y falsificaciones, como ya se mencionó. Por otra parte, tanto Carabajal como Larguía $(1934,1936)$ identificaron relaciones de la alfarería de Leyes con aquella de la llamada Civilización Chaco-Santiagueña estudiada por los hermanos Wagner.

Larguía realizó diversas visitas a la zona del Arroyo Leyes y a otros "paraderos" indígenas, acompañada inicialmente, como ya se mencionó, por Mántaras e intervino en las discusiones arqueológicas de la época. Esta coleccionista publicó algunos trabajos, donde describió diferentes sitios, su localización y materiales hallados en los mismos, con la finalidad de "poner en conocimiento de los estudiosos y especializados, estos paraderos que constituyen páginas reveladoras, donde el arqueólogo puede reunir elementos para el estudio de la prehistoria, siempre renovado y atrayente" (1936: 22).

Hacia 1940, las discusiones sobre las cerámicas del Arroyo Leyes habían disminuido (Podgorny, 2014), aunque seguían obsesionando a algunos arqueólogos. Con la creación del Departamento de Estudios Etnográficos y Coloniales de Santa Fe en 1940, Aparicio, por entonces presidente de la Sociedad Argentina de Antropología, le escribió a Agustín Zapata Gollán (1895-1986) ${ }^{144}$ para poner en práctica el “anhelo” de colaboración

\footnotetext{
${ }^{144}$ Se egresó como abogado en la antigua Universidad de Santa Fe, ejerció también el periodismo y participó en actividad política desde la democracia progresista llegando a ser Intendente de la ciudad durante el gobierno de Luciano Molinas (1932-1936). Ejerció como Profesor de Sociología en la Facultad de Ciencias Jurídicas y Sociales y como Profesor de Bellas Artes. En 1938 fue enviado por el Gobierno de la Provincia a realizar investigaciones históricas en los archivos del Perú; fruto de esas investigaciones es el trabajo «Caminos de América» que presentó en el XXVII ${ }^{\circ}$ Congreso Internacional de Americanistas en Lima. Desde 1940 hasta su muerte, en 1986, dirigió el Departamento de Estudios Etnográficos y Coloniales (Benzi, Busso y García, 2011).
} 
entre las dos instituciones ${ }^{145}$, con el propósito de explorar conjuntamente los yacimientos próximos al Arroyo Leyes, que "plantean el dilema arqueológico de mayor interés en nuestro país" ${ }^{146}$. Asimismo, el Director del Museo Etnográfico de Buenos Aires, le aclara a a Zapata Gollán que "las colecciones que se reunieron en el curso de estos trabajos, una vez estudiadas, quedarían de propiedad del departamento a su cargo" $" 147$.

Al año siguiente, Aparicio vuelve a insistir con la idea de una exploración conjunta entre ambas instituciones y le envía un plan de investigaciones a realizar ${ }^{148}$ :

1. establecer si a lo largo del Paraná, en esa región, han existido diversas culturas indígenas y si han tenido alguna relación entre sí,

2. determinar el límite septentrional de la cultura caracterizada por representaciones plásticas cuyos restos sólo se han señalado hasta la Laguna Brava, en las inmediaciones de Resistencia, y

3. establecer las relaciones culturales entre los aborígenes precolombinos y protohistóricos del Paraná, con los pueblos chaqueños históricos y contemporáneos.

Estos tres puntos sintetizaban los debates que se dieron en los años previos, dejando de lado esta vez las "supercherías" y "seudocacharros". En octubre de 1941, la Sociedad Argentina de Antropología consigue un cheque por 3 mil pesos del Gobierno de la provincia de Santa Fe, pero la realización de la anhelada exploración se postergará por

\footnotetext{
${ }^{145}$ Carta de Aparicio a Zapata Gollán, 28/10/1940, libro copiador de la SAA, AFDME.

${ }^{146}$ Op. Cit.

${ }^{147}$ Op. Cit.

${ }^{148}$ Carta de Aparicio a Zapata Gollán, 04/04/1941, libro copiador de la SAA, AFDME.
} 
años, sin concretarse en la forma en que fue prevista $^{149}$. Por diversos desacuerdos para fijar una fecha entre los científicos de Buenos Aires y de Santa Fe, el proyecto de la expedición se irá desarmando. Por su parte, Larguía, informada de la posibilidad de una exploración arqueológica en el Arroyo de Leyes, en tanto socia de la Sociedad Argentina de Antropología, había ofrecido su colaboración al Departamentos de Estudios Etnográficos y Coloniales $^{150}$. Sin embargo, los meses pasaron sin resultados, y la contaduría general de la provincia de Santa Fe reclamará en varias oportunidades, entre 1942 y 1950, la rendición del subsidio otorgado. La Sociedad Argentina de Antropología, cambiando de presidentes y de comisiones directivas, aclarará en todas las ocasiones, que la exploración aún no se había realizado, esgrimiendo diferentes motivos ${ }^{151}$.

Mientras tanto, Zapata Gollán se abocó casi completamente a la localización y excavación de las ruinas de Santa Fe La Vieja en Cayastá ${ }^{152}$, iniciada en 1944 por su cuenta y luego por encomendación del gobierno de la Provincia en $1949^{153}$. Finalmente, el 6 de septiembre de 1950 el Consejo Directivo de la Sociedad Argentina de Antropología autoriza a su Presidente, Salvador Canals Frau, para iniciar una gestión extraoficial ante el Gobierno de Santa Fe que procure "variar el destino de los fondos dados por esta

\footnotetext{
${ }^{149}$ Desde la sociedad, se enviarán misivas y solicitudes diversas a Zapata Gollán solicitando acuerdo para la fecha de tal empresa y su colaboración para la contratación de peones, transporte y demás gestiones previas a las excavaciones.

${ }^{150}$ 3/5/1942 Carta de Larguía a Zapata Gollán, Museo Etnográfico y Colonial de Santa Fe.

${ }^{151}$ La mayoría de las veces será Zapata Gollán quien rechazará las excavaciones, debido a la creciente del río Paraná (1942), "por falta de medios de locomoción, aún de propiedad particular, que estuvieran en condiciones de hacer los viajes diarios entre Santa Fe y el yacimiento de Leyes" y porque los terrenos han sido sembrados recientemente y eso impediría los trabajos (1945) y por haber sido desalojado el local que ocupaba el Departamento de Estudios Etnográficos y Coloniales (1947). Copiador de la SAA, AFDME.

${ }^{152}$ sitio donde la tradición localizaba la ciudad vieja de Santa Fe, fundada por Juan de Garay en 1573

153 Estas excavaciones suscitaron debates en la sociedad santafesina, y muchos pobladores y religiosos acudían a Cayastá para prender velas a las tumbas "profanadas". Zapata Gollán tuvo que fortalecer su tarea mediante la ayuda de diversas personalidades, historiadores y aficionados miembros de la Sociedad Científica Argentina quienes iniciaron una Sociedad de Amigos de Santa Fe la Vieja para promover el interés científico, cultural y turístico del sitio.
} 
provincia" ${ }^{\text {"154 }}$. Así, los fondos destinados a las investigaciones en el Arroyo Leyes serán utilizados en las actividades de la octava Semana de la Antropología, que se realizó en 1951 en dos sesiones, una en Buenos Aires y otra en Santa Fe. La sesión en Santa Fe incluyó una "visita" al yacimiento de Leyes y a las ruinas de Cayastá. Los pasajes y gastos de traslado a los miembros de la Sociedad fueron pagados con el subsidio de 3 mil pesos solicitado por Aparicio seis años antes. Las discusiones sobre las cerámicas halladas en el Arroyo Leyes y en las regiones aledañas fueron desapareciendo del escenario de la arqueología. La mayoría de las colecciones quedaron guardadas en los museos hasta los estudios que hará Alberto Rex González en 1980 (Podgorny, 2014).

\section{Las prácticas y colecciones de Amelia Larguía}

Coincidiendo con la publicidad y los debates iniciales sobre los hallazgos en el Arroyos Leyes, Larguía comenzó la formación de una importante colección arqueológica privada, que se siguió acrecentando hasta su muerte en 1952. La misma alcanzó un volumen de más de cinco mil piezas, conformada especialmente por cerámicas regionales aunque también por materiales líticos y restos óseos humanos. Además de coleccionar una gran cantidad de objetos, escribió varios trabajos sobre sus hallazgos y realizó exposiciones en eventos científicos, considerando su propia clasificación de los materiales y la vinculación de los mismos con otras colecciones e interpretaciones sobre su origen y pertenencia cultural. Asimismo, fue socia activa de la Sociedad Argentina de Antropología y de la Sección Santa Fe de la Sociedad Científica Argentina ${ }^{155}$, constituida en 1934, donde

\footnotetext{
${ }^{154}$ Libro de Actas, Archivo de la SAA.

${ }^{155}$ A fines del siglo XIX se promovieron y se crearon algunas filiales en las provincias, que poco después desaparecieron. Esto quedo como anhelo y se volvió a impulsar en la década de 1930. En esa época, la primera sección en instalarse fue la de Córdoba el 3 de agosto de 1934 y pocos días después, el 10 de agosto de 1934, celebró su primera reunión la sección santafesina. Luego se sumaron secciones en Mendoza y en Tucumán.
} 
en su primera reunión Larguía presentó la comunicación “Algunos datos arqueológicos sobre paraderos indígenas en la provincia de Santa Fe”.

Larguía estableció vínculos e intercambió correspondencia con los arqueólogos y con los directores de diferentes museos de Buenos Aires, La Plata, Santiago del Estero, Paraná y Santa Fe; promocionando los sitios de la zona, proveyendo datos, fotografías, objetos e intercambiando opiniones sobre la interpretación de las piezas. Luego de haber comenzado su colección, empezó a enviar informes a la Sociedad Científica de Santa Fe, comunicando sus hallazgos y dando a conocer sus colecciones. Además, comenzó relaciones epistolares con "los estudiosos de la materia", Entre otros, mantuvo correspondencia con los hermanos Wagner $^{157}$ y con Olimpia Righetti del museo santiagueño, con profesores de la Universidad del Litoral como Horacio Damianovich y Agustín Zapata Gollán, con miembros del museo de Paraná, como Victor Badano, con el director del museo de La Plata, Joaquín Frenguelli y con los arqueólogos del Museo Etnográfico de Buenos Aires, como ya se mencionó. Por ejemplo, a Aparicio le envió algunas piezas de su colección, ofreciendo el resto para su estudio. Asimismo, envió noticias sobre los sitios al Director de la Biblioteca de Antropología del Museo Nacional de Lima (Perú) y al Director de la Biblioteca Nacional de Buenos Aires, Gustavo Martínez Zuviría, entre otros.

Larguía se dedicó a la reconstrucción de las piezas a partir de fragmentos y a su posterior análisis e interpretación. Antes de ir al campo, se dedicaba a leer, clasificar y

\footnotetext{
${ }^{156}$ Wapnir, Salomón. “Doña Amelia”, en La Prensa, 23/octubre/1960. Wapnir (1904-1971) trabajaba para la firma Bunge y Born - Molinos Río de La Plata, que lo trasladó a distintos lugares del país hasta su jubilación en 1956. Fue crítico literario en La Prensa y escribió más de diez obras, entre las que se destacan ensayos sobre crítica literaria y relatos de viajes. También se desempeñó como periodista en las secciones literarias de los diarios La Prensa, La Nación y La Razón, y en la revista El Hogar, entre otros. Ver más en: Lanzillotta, María de los Ángeles. 2011. Con la pluma y la palabra. Los grupos intelectuales emergentes del Territorio Nacional de La Pampa (1910-1943). Tesis de Maestría en Estudios sociales y culturales Facultad de Ciencias Humanas, Universidad Nacional de La Pampa.

157 Véase, por ejemplo, el artículo de Larguía de 1936, donde cita las "comunicaciones particulares" con Emilio Wagner, con quien intercambió correspondencia, piezas arqueológicas y calcos.
} 
documentarse, para poder conocer el valor y el origen de las piezas. Los sitios arqueológicos señalados por ella se ubicaban en las orillas y en islas de los ríos cercanos a la ciudad de Santa Fe: Paraná, Saladillo, Leyes, entre otros: “allí a diversas profundidades y por el natural desgaste que producen las corrientes quedan al descubierto fragmentos de alfarería con impresiones y grabados, huesos humanos, algunas bolas arrojadizas de piedra, asas y cabezas estilizadas, en su mayoría ornitomorfas.” (Larguía, 1934: 218) ${ }^{158}$. Estas descripciones muestran la importancia de la observación en las barrancas y riveras de los ríos y barrancas para el hallazgo de piezas arqueológicas o fósiles en la región, una tradición que ya se remontaba por lo menos a inicios del siglo XIX, confirmada con los recorridos de naturalistas europeos como el joven Charles Darwin y el francés Alcides D’Orbigny y otros posteriores, a lo que se sumaron profesores de la región (García y Podgorny, 2010).

Los coleccionistas santafecinos participaron de esa tradición de recorrer las orillas de los arroyos en busca de "descubrimientos". Larguía se sumó al auge de esas excursiones, facilitadas por los automóviles: "conservando siempre su atuendo y el aspecto natural de una dama, cubierta la cabeza con su invariable sombrero y provista de una pequeña pala" ${ }^{\prime 59}$. A diferencia de las recomendaciones de vestuario que se daban en la época, como el uso de pantalones, para que las mujeres realizaran expediciones y trabajos científicos en el campo, ella mantuvo su atuendo de viuda. Según los relatos de quienes la conocieron, siempre usaba un vestido o falda oscura y su infaltable "pamela", un tipo de sombrero que

\footnotetext{
158 Algunos de los sitios que menciona son "El Simbolar" al noreste de la Laguna de Guadalupe, "Añapiré” o "Rincón de Santo Domingo" en un campo sobre el Saladillo, "San Guillermo" sobre el mismo río Saladillo más al norte, "Los Zapallos" sobre la barranca que bordea al arroyo de Leyes cerca del límite sur del departamento Garay, "Rincón de Mota" hacia el noreste también sobre el arroyo Leyes, "Isla Periquillo" sobre la costa del Saladillo y al noreste del sitio "Añapiré”, "Los Ubajays" al sur de la localidad de Helvecia en el departamento de Garay en un brazo del río San Javier y "Sauce Viejo", al sur de Santa Fe en las inmediaciones del pueblo de Sauce Viejo sobre la margen derecha del río Coronda. En este último, se encuentran "esparcidos abundantes fragmentos de alfarería, evidentemente, algunos de ellos, coloreados con ocre, lo que demuestra la anterior existencia de un paradero indígena de características semejantes a los descubiertos en distintos puntos del mismo río.” (Larguía, 1936: 27).

${ }^{159}$ Wapnir Op. Cit.
} 
usaban las señoras de la época. Así lo cuenta el historiador López Rosas cuando describe sus "excursiones":

"Vestida de oscuro, zapatos de tacones bajos y una sencilla pamela -artefacto sin el cual una señora no podría salir a la calle- lleva en su mano un bolso de regular tamaño (...) El Ford $T$ atraviesa la ciudad y toma rumbo al norte, por el arenoso camino que lleva a Monte Vera y el pueblo de Arroyo Aguiar y tuerce por fin por un sendero que conduce a la costa." (López Rosas, 1993: 420)

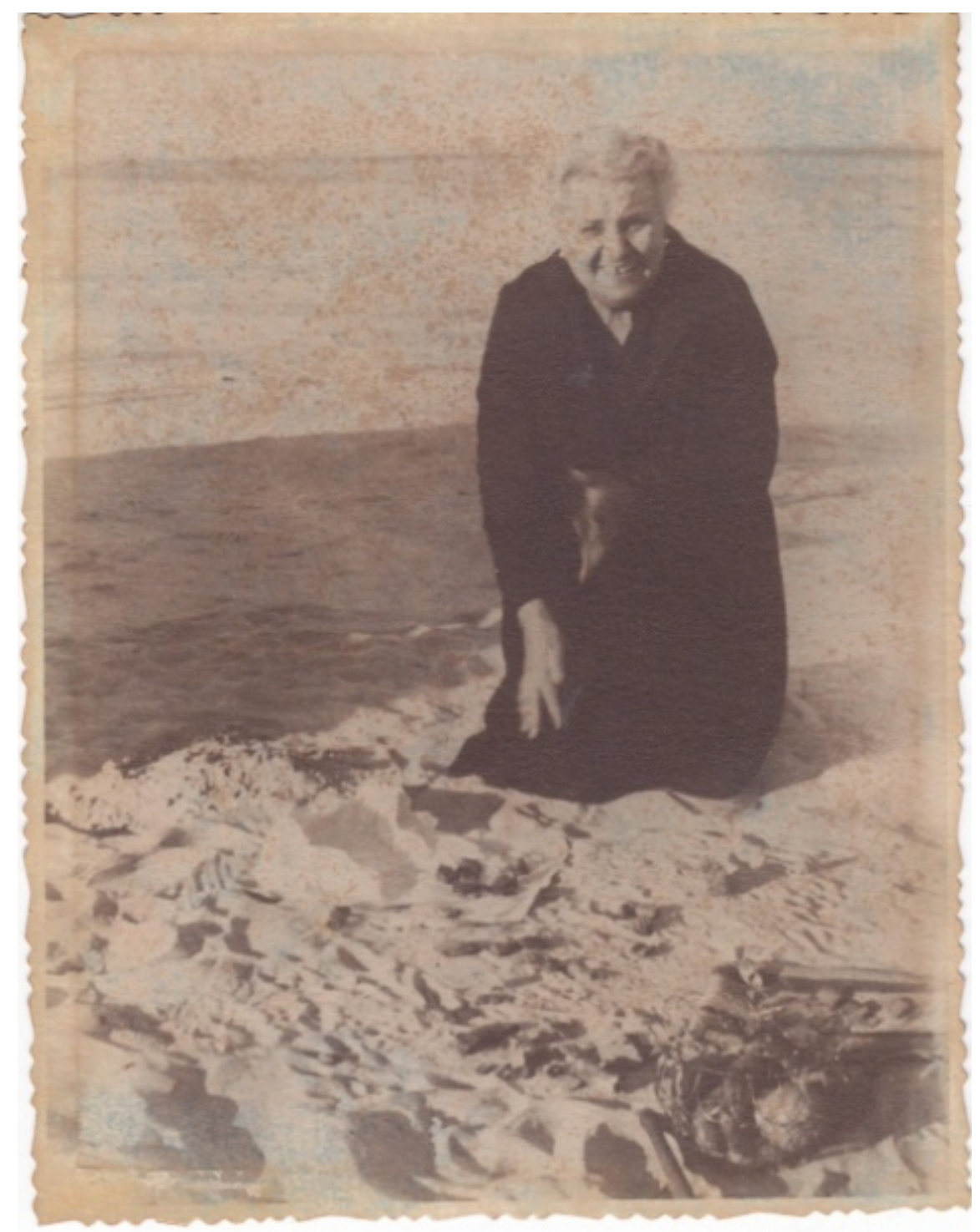

Ilustración 1: Amelia Larguía junto a un conjunto de piezas. Archivo General Provincial de Santa Fe s/f 
Una vez que llegaba al "paradero", Larguía dialogaba con los pescadores y los vecinos del lugar, buscando identificar los mejores lugares para excavar. Luego se dedicaba a realizar "prolijas excavaciones" a lo largo de la costa, lugares en los cuales aparecían la mayoría de las piezas, "dejando la arenosa playa tal como si hubiera andado por la misma una familia de vizcachas, es decir llena de pozos.” (López Rosas, 1993: 420). De esta forma, esta señora se ocupaba de recopilar un conjunto de datos, los cuales eran ofrecidos a los “especialistas". Como señala Pupio (2011) esta información aportada por coleccionistas y aficionados locales contribuía con la conformación de un "mapa arqueológico" que era utilizado para conocer nuevas regiones, para confirmar datos o para continuar el trabajo en un yacimiento determinado. Con estas prácticas, Larguía al igual que otros coleccionistas, actuó como mediadora entre los lugareños y los arqueólogos.

Esta coleccionista, también realizó comparaciones entre las piezas de su colección y otras cerámicas de distintas regiones del país. Por ejemplo, realizó correlaciones con las cerámicas del noroeste argentino descritas por el arqueólogo sueco Eric Boman su obra “Antigüedades de la región andina de la República Argentina y del desierto de Atacama" (1908). Asimismo, entre los hallazgos de la "Isla del Periquillo", encontró una "pequeña cabecita antropomorfa" la cual asoció a la "divinidad sin boca" definida por los hermanos Wagner (Larguía, 1936: 24). De forma similar, encontró en el paradero San Guillermo variedades cerámicas, entre ellas "una cabeza de loro estilizada y que vierte dos largas lágrimas", la cual mostraría un vínculo con la "Civilización Chaco-Santiagueña”, definida por los Wagner.

Como ya se mencionó en el capítulo anterior, Emilio y su hermano Duncan Wagner, habían desarrollado numerosas excavaciones arqueológicas en la provincia de Santiago del Estero (Martínez, Taboada y Auat, 2011). Sus hallazgos e interpretaciones generaron ciertos conflictos en la arqueología de la época, especialmente luego de la publicación en 1934 de su libro La civilización chaco-santiagueña y sus correlaciones con las del Viejo y Nuevo Mundo (Arenas, 2005; Martínez, Taboada y Auat, 2011; García, 2011). Esta obra se 
volvió muy popular y coleccionistas como Larguía comenzaron a intercambiar correspondencia, interpretaciones y piezas con los Wagner. Sin embargo, la existencia de una civilización Chaco-Santiagueña y su interpretación del origen de las culturas fue discutida por los arqueólogos de Buenos Aires y La Plata (Martínez, Taboada y Auat, 2011), que en 1939 organizaron la segunda Semana de la Antropología en torno a los "Primitivos habitantes de Santiago del Estero", como ya se mencionó en el capítulo anterior. A pesar de las críticas de parte de los sectores científicos, los materiales arqueológicos trabajados por los hermanos Wagner alcanzaron una gran difusión en el país, especialmente en el sistema escolar (García, 2011), y entre especialistas extranjeros.

Probablemente, como señala Suárez (2008) el contacto entre Larguía y los estudios de los hermanos Wagner se potenció en una visita que hizo Duncan Wagner a Santa Fe en 1937, donde ofreció una Conferencia en la Sociedad Científica local titulada "La migración de los símbolos" ${ }^{\prime 60}$. La interpretación de Larguía de las relaciones entre la civilización Chaco-Santiagueña propuesta por los Wagner y las piezas de la región santafesina fue confirmada mediante correspondencia con los encargados del Museo Arqueológico de Santiago del Estero, quienes le señalaron:

“...hemos dividido en tres ramas la alfarería perteneciente a las naciones cuyos restos encontramos en el subsuelo del Chaco de Santiago del Estero, y provincias colindantes, y que practicaban una misma religión, rindiendo culto a una misma divinidad, antropo-ornitomorfa, íntimamente ligada con la serpiente a tal punto que se la debe más bien llamar antropo-ornito-ofídica. Son los rastros del culto de esta divinidad representada amenudamente vertiendo lágrimas, que vamos rebuscando incansablemente a través del tiempo y de las tierras de América y demás

\footnotetext{
${ }^{160}$ La conferencia versó sobre "Qué debe pensarse, de las hipótesis que afirman que la América es la cuna de todas las civilizaciones prehistóricas" (Informe anual de la Sección Santa Fé de la Sociedad Científica Argentina, en Anales de la Sociedad Científica Argentina, 1938). La misma tuvo lugar el 4 de mayo de 1937 y contó con el apoyo de la Sección «Extensión Universitaria» del Instituto Social de la Universidad Nacional del Litoral, bajo la dirección del Ingeniero José Babini.
} 
continentes." (Carta de Emilio Wagner a Larguía, 12/01/1934. Citada en Larguía, 1934).

Así, el hallazgo que realizó Larguía en el paradero San Guillermo, permitía corroborar la hipótesis planteada por los hermanos Wagner sobre la llamada civilización Chaco-Santiagueña. Las interpretaciones de la coleccionista santafecina sobre las piezas se orientaron hacia la unidad cultural de las mismas y a la influencia que éstas habrían recibido de otras regiones, especialmente la andina y la santiagueña. Es decir, los diferentes hallazgos realizados en los sitios aledaños a la ciudad de Santa Fe pertenecían, según Larguía, a una misma cultura que habría recibido influencias de la región andina y de Santiago del Estero. En su trabajo de 1936, concluye que los "documentos arqueológicos" hallados por ella en distintos paraderos indígenas "conservan la tipología general, evidencian el contacto con otras culturas lejanas y la coexistencia con otras civilizaciones" (Larguía, 1936:28).

El contacto con "civilizaciones lejanas" es verificado por Larguía gracias al hallazgo de una pequeña "huaica" en turquesa "de igual forma y dimensión que la encontrada por el Dr. Frenguelli en años anteriores" (Larguía, 1936:28) y otra pieza similar hallada a orillas del Arroyo Leyes. Estas semejanzas son interpretadas por ella como una manifestación de las migraciones "de las que nos hablan extensamente los cronistas, y los historiadores contemporáneos dedicados a esta clase de investigaciones.” (Larguía, 1936: 28). Su activa participación en los principales debates surgidos en torno a las cerámicas de Leyes y otros sitios permite observar cómo se vincularon diferentes sujetos con los espacios y las discusiones de la arqueología. Su caso también muestra el interés por la ciencia de una mujer madura, educada, viuda y con ciertos recursos sociales y económicos que le permitieron reunir una colección de abundantes piezas, informarse sobre la bibliografía sobre el tema, escribir artículos, presentar charlas y participar en asociaciones científicas. Sus prácticas se inscriben en un contexto de proliferación de aficionados, coleccionistas y arqueólogos que se interesaron por el paradero de Arroyo Leyes y las cerámicas encontradas allí. 
Por otra parte, Larguía se dedicó a la organización, clasificación y reconstrucción de las piezas que conformaban su colección ${ }^{161}$. Tras su fallecimiento en 1952, los hijos donaron su colección al Museo Etnográfico y Colonial de Santa Fe, creado en 1943, formando parte actualmente de la División de Arqueología de dicho museo. Los objetos y registros de su colección conservados actualmente ahí, permiten un acercamiento a las prácticas museológicas de esta coleccionista ${ }^{162}$. Cada pieza posee una etiqueta original, con un número romano que la identifica y otros datos, como sus medidas o el número que referencia el lugar del hallazgo ${ }^{163}$. Se acompañaban, además, de un inventario manuscrito, donde se listaban los artefactos definidos por tipos de piezas o sus partes. Las denominaciones más frecuentes eran: vasija, urna, vaso, fragmento, bordes, asas, torteros, apéndices. También aparecen objetos registrados como: "esponja de rio usada como antiplástico", fragmento de borde, silbatos, cráneos y otros materiales óseos. En ese inventario de Larguía, cada pieza posee una información descriptiva breve (color, forma irregular, presencia de asas y apéndices, etc.), las dimensiones (diámetro, altura, circunferencia) y el lugar de procedencia ("paraderos", que en ocasiones toman los nombres de la zona geográfica). Dentro de la misma carpeta hay una sección de "ejemplares de correlaciones entre la alfarería indígena de Santa Fe y la de Santiago del Estero". Dichos objetos pertenecen en su mayoría al sitio Saladillo, aunque también hay dos calcos provenientes de Santiago del Estero. Es probable que haya intercambiando algunas cerámicas o calcos con los hermanos Wagner y con otros coleccionistas privados y museos. Por ejemplo, en La civilización chaco-santiagueña se reproduce la imagen de una vasija de la colección "Larguía de Crouzeilles".

\footnotetext{
${ }^{161} \mathrm{Al}$ respecto, dice Wapnir: “Ahora, y a medida que el tiempo avanza, las piezas reunidas van cubriendo las habitaciones de la casa, los pasillos y las galerías, en cajones y canastos, pero doña Amelia encuentra cómo reunir pacientemente, con sus manos diestras y atrayentes, los pequeños trozos que encontrara, hasta dar la forma original a sus hallazgos." (Wapnir, 1960)

162 Durante casi cuarenta años este museo contó con una vitrina especial para esta colección. Sobre las colecciones actuales en el Museo, remitirse a María Rosario Feuillet Terzaghi y Sandra Escudero, 2013.

${ }^{163}$ Asimismo, las piezas tienen la numeración actual del Museo Etnográfico y Colonial de Santa Fe.
} 
El inventario de esta coleccionista también contiene el detalle de la cantidad de piezas halladas en cada sitio, algunos de la región santafesina y otros de La Rioja, Catamarca y Santiago del Estero: El “Aromal” Guadalupe (119), Saladillo (1957), Saladillo Añapiré (1554), Arroyo Leyes (280), Isla Periquillo (775), Laguna del Capón (685), Ombú Basualdo (172), Desvío Arijón (105), Las Tejas (7), Gaboto (5), saladillo Quiroga (7), Cuatro Bocas (3), Los Ubajays-Helvecia (33), Santiago del Estero (75) y El Remanso.
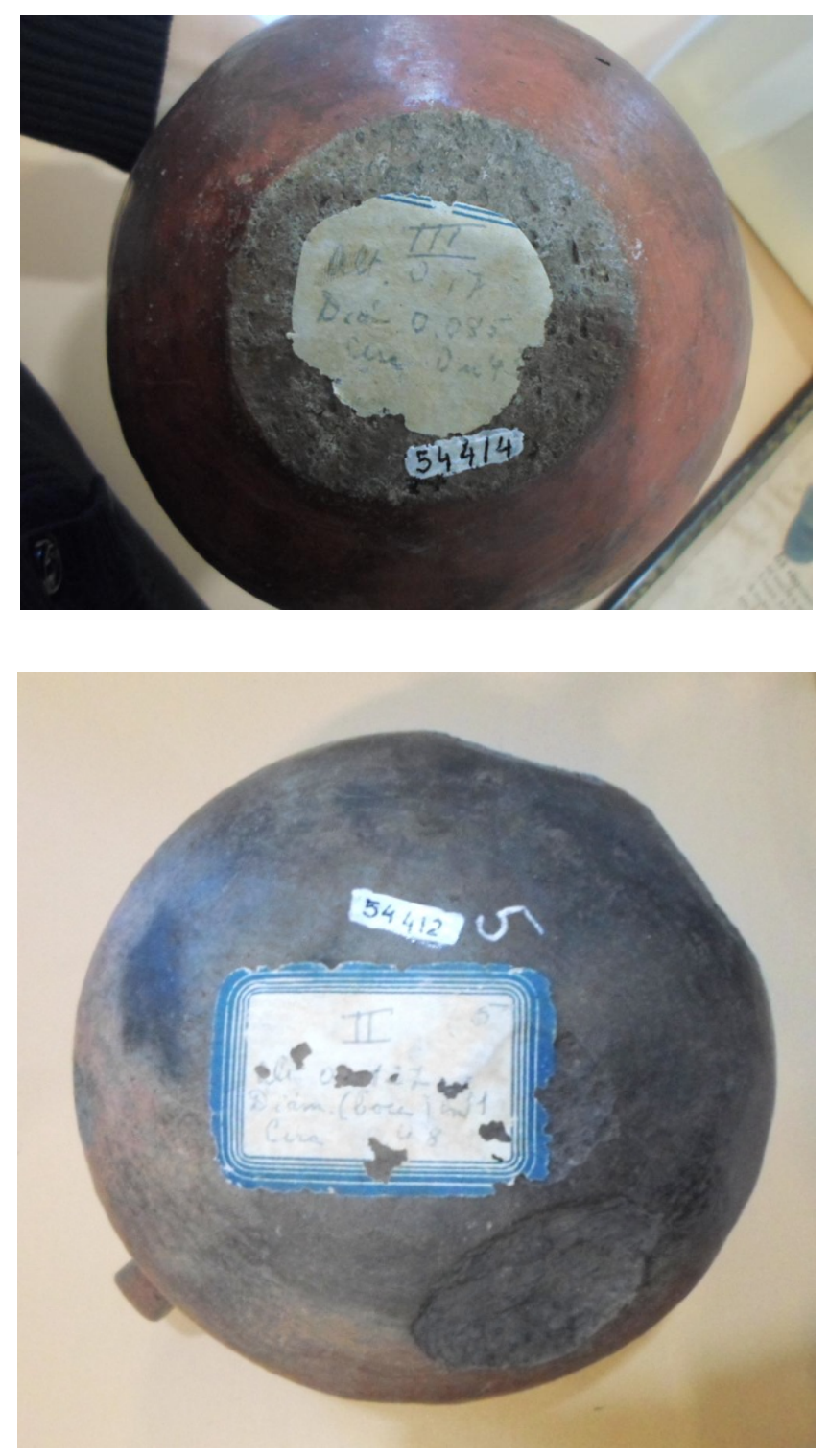

Ilustraciones 2 y 4: Piezas de la Colección Amelía Larguía de Crouzeilles, División Arqueología del Museo Etnográfico y Colonial de Santa Fe 


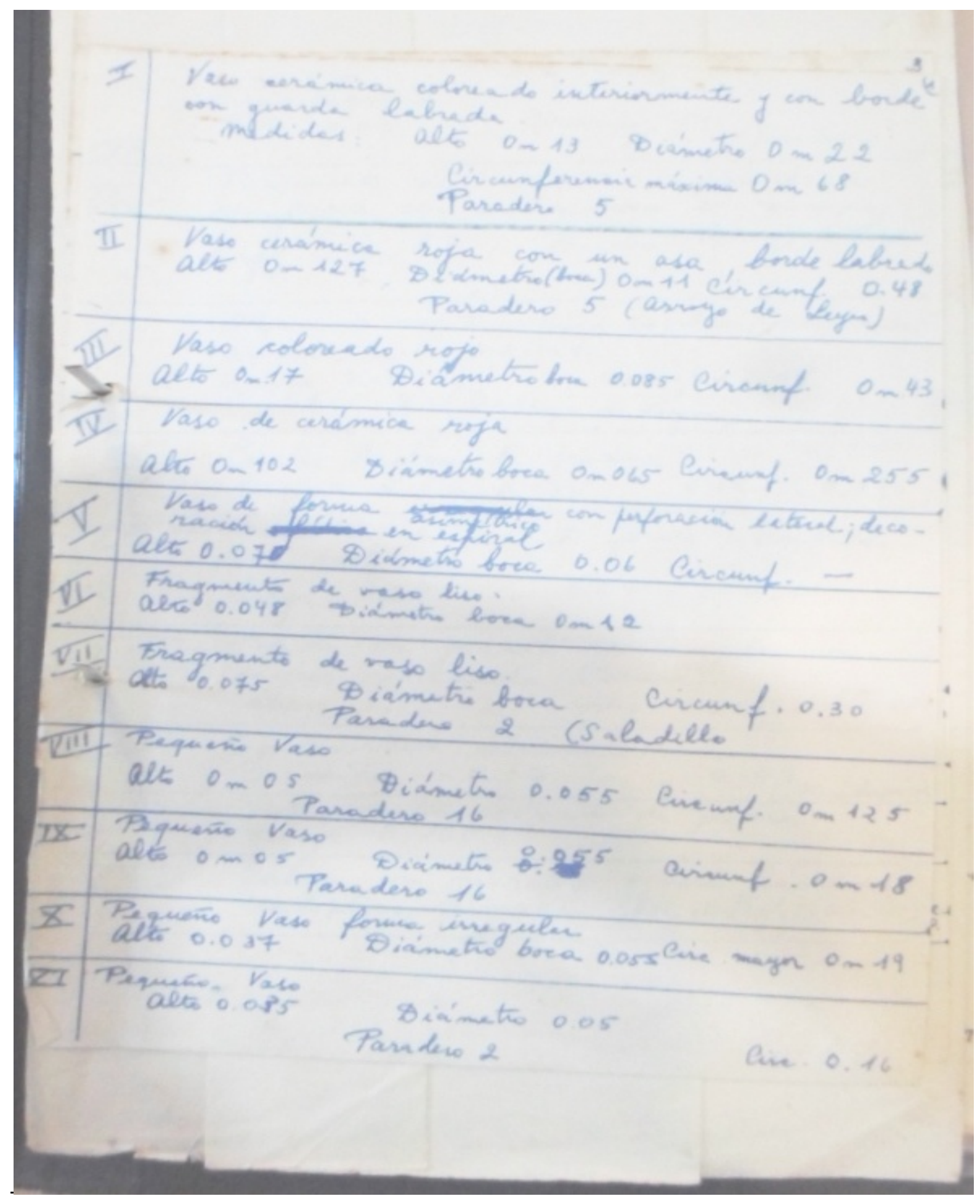

Ilustración 3: Primera hoja del inventario de Amelia Larguía de Crouzeilles 


\section{Coleccionismo privado, prácticas amateur y redes de circulación de objetos}

$y$ datos

El acopio de colecciones a través de distintas redes de contactos fue un aspecto común de las prácticas vinculadas a la arqueología en el período estudiado en esta tesis, donde un conjunto diverso de coleccionistas y aficionados se vincularon personalmente o epistolarmente con arqueólogos de diferentes instituciones provinciales y nacionales. Las redes establecidas y la formación de colecciones estimularon las investigaciones regionales y locales y permitieron el desarrollo de conocimientos sobre el pasado de los territorios provinciales, entre ellos la arqueología. A partir del caso de Amelia Larguía y de los debates surgidos en torno a las cerámicas halladas en la región del Arroyo de Leyes en las décadas de 1930 y 1940, se muestra cómo coleccionistas del interior del país formaron parte de las prácticas de la arqueología, recolectando materiales y proponiendo interpretaciones sobre las mismas, dialogando y discutiendo con los arqueólogos de los grandes museos de Buenos Aires y La Plata.

El papel desempeñado por las mujeres en la formación de colecciones privadas en la Argentina aún merece mayores investigaciones, pero a partir de algunos documentos relevados en el transcurso de esta investigación, han aparecido nombres y actividades de diferentes mujeres que se dedicaron a través de diversas formas y recursos a la arqueología y a otras disciplinas científicas, formando colecciones privadas y participando de los amplios circuitos de intercambio de materiales y de datos. Como se verá en el capítulo siguiente, algunas de estas mujeres hicieron de las colecciones su modo de subsistencia, otras, como esta viuda de la élite santafesina, lo hicieron como una "excursión" de fin de semana y un pasatiempo erudito con el que llenar los últimos años de vida. Más allá de las motivaciones personales y de las diferentes posiciones económicas y sociales, este capítulo contribuye a mostrar los aportes que algunas mujeres han hecho a determinados saberes científicos y a las colecciones de diferentes museos desde espacios y prácticas privadas, los cuales muchas veces no han sido considerados en los relatos históricos de las ciencias antropológicas. 
Como se observa en este capítulo, la participación de aficionados y coleccionistas en los debates y en las prácticas de la arqueología constituyó parte de las ciencias antropológicas por lo menos hasta mitad de siglo XX, como muestran diferentes trabajos, especialmente los de Pupio para el sur de Buenos Aires (2011), aunque también los de García (2011), Bonnin (2008), Lindskoug (2008), entre otros. Asimismo, este capítulo buscó demostrar cómo una mujer viuda y de la élite social santafesina, se vinculó a una red de intercambios de objetos y de informaciones sobre la arqueología de la región, contribuyendo con el conocimiento y difusión de los sitios y objetos arqueológicos. La colección privada de Larguía actualmente es parte del acervo del Museo Etnográfico y Colonial de Santa Fe y constituye un aporte al conocimiento del pasado indígena de la provincia y con material para diversas investigaciones contemporáneas ${ }^{164}$. Asimismo, es importante destacar cómo la experiencia de Amelia Larguía forma parte de la historia de las ciencias antropológicas, en tanto la misma sea pensada como una "práctica colectiva", teniendo en cuenta las intervenciones de diversos sujetos, los debates científicos, las redes de contactos, apoyos y de circulación de saberes y objetos. Asimismo, implica también atender a la movilización de informaciones y cosas entre diferentes espacios: el "campo", los museos, las colecciones locales, las casas familiares, las asociaciones y otras instituciones-culturales y científicas. Como se intenta mostrar en los diferentes casos tratados en esta tesis, las mujeres no estuvieron ausentes en esos espacios y prácticas, "ni solas ni resignadas" (García, 2006), participaron como pudieron y quisieron de la actividades científicas.

${ }^{164}$ Entre otros, ver Ceruti, y González, 2007; Bonomo, Politis y Gianotti, 2011 


\title{
Capítulo 4. Prácticas científicas y comerciales
}

\author{
Introducción
}

En In 1926: living at the edge of time, Gumbrecht menciona el establecimiento de una geografía de la autenticidad, opuesta a la artificialidad de los países y ciudades del hemisferio norte. En esa geografía, determinadas regiones aparecían como reservorios de tradiciones no contaminadas por el progreso (Gumbrecht, 1997; Podgorny, 2008, 2014). Desde esta perspectiva, Sudamérica, más precisamente su centro e interior selvático, se volvió un "campo" de especial interés para las investigaciones etnográficas. Recordemos, que la idea de "santuario" o la existencia contemporánea de "mundos perdidos", o la noción de ritmos de evolución diferente o la mera posibilidad de territorios olvidados por la evolución, no fueron ajenas a las ciencias naturales y antropológicas a fines de siglo XIX y principio del $\mathrm{XX}^{165}$. En la década de 1930 estas mismas cuestiones seguían vigentes, especialmente en torno a la "pequeñas tribus" silvícolas del interior sudamericano, que parecían poco afectadas por la civilización. Por ello, viajeros y etnógrafos intentaban contactar directamente con estos grupos, para observarlos, formar colecciones y poder "rescatar" lo que la sociedad occidental estaba transformando.

Como analizan diferentes trabajos, las mujeres no estuvieron por fuera de los viajes y del trabajo de campo. En las décadas de 1920 y 1930 la presencia de mujeres estudiantes

\footnotetext{
${ }^{165}$ Véase entre otros: Bowler, 1996; Podgorny, 2005.
} 
de antropología en diferentes universidades fue un aspecto común en países como Estados Unidos, Francia, Inglaterra, Alemania, entre otros (Schumaker, 2008). En estos espacios se promovía el trabajo "en el campo" tanto de hombres como de mujeres, y como se verá en el capítulo siguiente se proponían formas de trabajo colaborativo y complementario. Pero no sólo las estudiantes realizaban viajes, otras mujeres movidas por sus propios intereses o por sus temas de trabajo también realizaron investigaciones en el "terreno", realizando diferentes tareas y aprovechando estratégicamente redes personales a institucionales, contactos con científicos y con pobladores y nativos (cf. Correa, 1997; Lopes, 2008 b, 2008c; Sombrio y Lopes, 2011 y Sombrio, 2013, 2014).

Como parte del objetivo de esta tesis de mostrar las diversas experiencias de mujeres en las ciencias antropológicas de la Argentina, en este capítulo se examina la actuación de la médica austríaca Wanda Hanke (1893-1958), devenida en exploradora en sus viajes por Sudamérica desde 1934 hasta su muerte en el interior de Brasil. Su caso muestra a una mujer que pudo viajar casi de forma permanente por Argentina, Brasil y Paraguay durante 24 años, estableciendo diversas redes de apoyo pero sin contar con cargos permanentes en ningunas institución. Hanke se internó en esos "mundos auténticos", entrando en contacto directo y en el medio natural de esas poblaciones con la intención de estudiarlos, pero también obteniendo colecciones para venderlas y así poder subsistir y continuar sus viajes. La trayectoria de esta exploradora da cuenta de un personaje ambiguo, que "vivía de la ciencia" y que también subsistió gracias a los favores conseguidos a cambio de sus actividades, aunque también se puede pensar como un aprovechamiento "estratégico" de su condición de "mujer que (supuestamente) viajaba sola".

Los trabajos de Hanke son mencionados dentro de los antecedentes de las investigaciones etnográficas y lingüísticas de varios grupos indígenas sudamericanos. Sombrio y Lopes (2011), analizando diversos documentos sobre los vínculos de Hanke con las instituciones brasileñas, mencionan la relevancia de este caso para problematizar la participación de las mujeres en las prácticas científicas y en la formación de colecciones etnográficas en la primera parte del siglo XX. Tal como señalan estas autoras, esto lleva a 
considerar la circulación de objetos, personas e información y a entender las prácticas científicas como forma de comunicación y comercio.

En particular, en este capítulo se examinan las publicaciones y los relatos de los primeros viajes de Hanke por los territorios sudamericanos y las cartas conservadas en los archivos del Museo Etnográfico de Buenos Aires y el Museo de La Plata, instituciones a las cuales ofreció diversas colecciones en venta entre los años 1934 y 1944. Estos documentos permiten indagar en torno a las prácticas comerciales ligadas a la formación de colecciones etnográficas y a las interacciones con miembros de diferentes comunidades y regiones ${ }^{166}$. Por otra parte, las fuentes analizadas muestran los problemas suscitados en la recopilación de objetos e información y en el manejo de las lenguas indígenas, los escenarios de los contactos y de los intercambios a los que éstos daban lugar. Y en como las mujeres se movían y realizaban trabajo de campo etnográfico.

\section{De médica a exploradora}

Wanda Theressia Leokadia Hanke nació el 9 de diciembre de 1893 en Troppau (población de la actual República Checa), por entonces parte del Imperio Austrohúngaro. En 1918, se doctoró en Filosofía en la Universidad de Munich. Dos años después, terminó los estudios de medicina en Wurzburgo y en 1926, los de abogacía en Marburgo. Trabajó como médica en Alemania y Austria hasta que decidió hacer un viaje de estudio etnológico (Liener, 2010). A los cuarenta años dejó sus actividades en Viena y a su hijo con su madre,

\footnotetext{
${ }^{166}$ Las regiones y comunidades que visita Hanke son innumerables, a modo de ejemplificar, se pueden mencionar algunos grupos con los cuales establece contacto (utilizando su terminología): Ashluslays, Botocudos, Cainguá, Guaraníes, Guayaquíes, Lenguas (del norte y del Sud), Matacos, Carijos, Chacaes, Chiriguanos, Coroados, Guarayos, Macaes, Mbyaes, Pilagá, Sanapaná, Siriono, Tereno, Cadivens, Tobas, entre otros. Liener (2010) proporciona una lista de procedencia de todas las colecciones reunidas por Hanke.
} 
para embarcarse hacia Sudamérica y estudiar los grupos indígenas de la floresta ${ }^{167}$. No son del todo claros los motivos por los cuales esta médica dejó sus ocupaciones y familia para dedicarse a la exploración, a la formación de colecciones y al registro de las lenguas indígenas de Sudamérica.

Entre los años 1933 y 1940 Hanke gestionó, sin éxito, permisos ante el Consejo de Fiscalización de Expediciones Artísticas y Científicas de Brasil ${ }^{168}$ para realizar exploraciones en el territorio de dicho país ${ }^{169}$. Sin permiso para investigar en Brasil, Hanke igual se embarcó para Sudamérica aunque modificó su itinerario: en agosto de 1934 desembarcó en Buenos Aires, donde pasó un mes aprendiendo los rudimentos del español. Luego permaneció casi dos años en el territorio de Misiones, en la región chaqueña de Paraguay. Volvió a Buenos Aires en 1936, donde dictó conferencias en la Unión Germánica. Ese año regresó a Viena, donde vendió algunas colecciones ${ }^{170}$ y buscó apoyo financiero para su siguiente viaje. En septiembre de 1937 regresó a América del Sur, donde permaneció por 18 años, recorriendo parte del Noroeste y Noreste argentino, Paraguay, Bolivia y Brasil.

\footnotetext{
${ }^{167}$ Liener (2010) señala que Hanke había estado internada en diferentes hospitales austriacos y alemanes por problemas psíquicos y es posible que la partida hacia Sudamérica estuviera motivada por el miedo a ser sometida a otra internación.

${ }^{168}$ El Consejo funcionó entre 1933 y 1968 y se ocupaba de controlar y fiscalizar las expediciones realizadas por extranjeros y particulares (sin vínculos a instituciones científicas) por los territorios de Brasil. Sobre la historia de este organismo véase: Grupioni (1998). Por su parte, Sombrio (2014) analiza la documentación de este organismo para detectar la presencia de mujeres expedicionarias y analizar sus trayectorias, considerando especialmente sus actividades vinculadas al trabajo de campo a mediados de siglo XX.

${ }^{169}$ El viaje que proyectó en 1933 tenía como objetivo realizar una expedición en las regiones desconocidas de los ríos Xingu, Tapajós y sus afluentes, en compañía de un etnólogo y un geógrafo y según la carta de Hanke contaba con el financiamiento de la Fundación Rockefeller (Sombrio 2014: 161). Aunque las negativas de este Consejo implicaron algunas dificultades para Hanke, no le impidieron realizar expediciones y juntar materiales en ese país, incluso contando con la ayuda de otras reparticiones estatales como el Servicio de Protección a los Indios o del ejército, que tenían más presencia en el territorio que el Consejo de Fiscalización de Expediciones Artísticas y Científicas (Sombrio, 2014).

${ }^{170}$ Las colecciones provenían principalmente de los grupos Ashluslay, Matako, Lengua y Chiriguano. (Liener, 2010)
} 
Hanke estableció vínculos con los museos y otros establecimientos científicos de las ciudades que visitaba, ofreciendo materiales etnográficos en venta, pero también sus servicios como exploradora, recolectora de objetos e información, como conferencista o para escribir artículos para las revistas científicas de esas instituciones. A medida que fue moviéndose, estableció diferentes redes de intercambio, y actuó muchas veces en función de los intereses de adquisición de cada museo o de los investigadores con los cuales intercambió correspondencia ${ }^{171}$. Con el tiempo y la suma de experiencias exitosas y fallidas, perfeccionó sus habilidades comerciales y científicas (Arias, 2017). Sus formas de trasladarse, trabajos y recursos variaron a lo largo de los veinticuatro años que recorrió América del Sur. En este capítulo se profundiza en una parte de su de su estadía en el territorio sudamericano (1934-1949), a partir del análisis de la correspondencia que mantuvo con antropólogos y otros científicos de la Argentina y de otros documentos relacionados con el ingreso de las colecciones en los museos de Buenos Aires y La Plata. También se utilizan las publicaciones científicas y de divulgación y otros escritos de Hanke.

Durante el período examinado, esta médica austriaca realizó trabajos etnográficos y reunió colecciones sin contar con un puesto regular en algún museo. Sin embargo, informalmente recibió distintos tipos de ayudas, tanto de museos como individuos particulares, con los que se contactaba y se ofrecía como recolectora y/o colaboradora en el "campo". Como se puede observar en la documentación guardada en el Archivo Fotográfico y Documental del Museo Etnográfico de Buenos Aires y en el Archivo Histórico del Museo de La Plata ${ }^{172}$, esa ayuda podía consistir en el pago de gastos de pasajes, alojamiento, revelado de fotografías, traslado de colecciones. En otras ocasiones, recibió asistencia para publicar artículos y corregir el español en sus textos. También la

\footnotetext{
${ }^{171}$ En Brasil, se contacta principalmente con el director del Museo Paranaense en Curitiba, primero Loureiro Fernandes entre los años 1941 y 1946, y luego Carlos Stellfeld, director hasta 1949 (Sombrio, 2014).

${ }^{172}$ En adelante, AFDME y AHMLP respectivamente.
} 
ayudaron para contactarse con otras instituciones científicas y gubernamentales o con investigadores de lengua alemana y las embajadas en los países vecinos ${ }^{173}$.

Al igual que otros viajeros y exploradores, esta exploradora se movió entre los contactos provistos por las redes de connacionales o con los que compartía el mismo idioma materno. En su caso, se vinculó sobre todo con germano-parlantes, tanto colonos como científicos, que le permitieron establecer relaciones con ciertas instituciones. En el Museo de La Plata, por ejemplo, contó con la ayuda del geólogo alemán Walter Schiller, quien le proveyó contactos con otros científicos alemanes en Bolivia. Asimismo, al iniciarse la segunda guerra mundial se movió a través del apoyo de las redes consulares, como la establecida a través de la delegación alemana en el territorio de Misiones. Durante los años de la Segunda Guerra, para trasladar las piezas vendidas a los museos entre diferentes países, como en el caso del Museo de La Plata, recurrió a los contactos y el amparo provisto por las delegaciones diplomáticas argentinas en los países vecinos (Arias, 2017).

Para subvencionar sus viajes y actividades, implementó diferentes estrategias que muestran el amplio rango de posibilidades -e ingenio- que tuvieron las mujeres para actuar en el ámbito de las ciencias antropológicas. La formación y venta de colecciones etnográficas, junto a algunos objetos arqueológicos y especímenes zoológicos de los sitios visitados constituyeron una parte importante de los ingresos de Hanke ${ }^{174}$. Esto se complementó ofreciendo artículos y fotografías a revistas turísticas, de divulgación científica y periódicos. Entre ellos el diario La Prensa, la revista femenina Vosotras y la

\footnotetext{
${ }^{173}$ Las embajadas fueron un recurso al que recurrió Hanke especialmente cuando tuvo algunos problemas por sus actividades durante los años de la segunda guerra mundial.

${ }^{174}$ Las colecciones y otros objetos de las primeras expediciones de Hanke son adquiridos por diferentes museos, entre ellos el Museo Argentino de Ciencias Naturales "Bernardino Rivadavia", el Museo Etnográfico de la Facultad de Filosofía y Letras de la Universidad de Buenos Aires, el Museo de La Plata, el Museo Paranaense de Curitiba (Brasil) y el Museo Etnológico de Viena (Museum für Völkerkunde).
} 
Revista Geográfica Americana ${ }^{175}$. En esta última publicó dieciséis artículos entre 1937 y 1949, relatando las particularidades de diferentes grupos indígenas y sobre ciertas ciudades, sobre todo aquellas de interés turístico ${ }^{176}$. Además, en esos años, escribió para los Arquivos do Museu Paranaense y para varias publicaciones de lengua germana, como las revistas argentinas Phoenix y Lasso y la alemana Zeitschrift für Ethnologie. También realizó conferencias y publicó varios artículos en los organismos de la Sociedad Científica Alemana de la Argentina.

\section{Intercambios epistolares: favores, negociaciones y aprendizaje}

Uno de los objetivos de Hanke al internarse por primera vez en Sudamérica era estudiar a los "esquivos" Guayaquíes ${ }^{177}$. El 6 de octubre de 1934, llegó a la colonia Leandro Alem, en el territorio de Misiones, gracias al servicio de vapores que recorría el Paraná. En esa localidad la recibió un amigo austríaco. Desde allí, recorrió diferentes territorios y se contactó con colonias y "tolderías" indígenas, en su mayoría del grupo denominado Cainguá. También visitó algunos poblados en la costa paraguaya del río Paraná y a principios de 1935 fue a la ciudad de Asunción. Mientras se familiarizaba con la

\footnotetext{
${ }^{175}$ La Revista Geográfica Americana se editó entre 1933 y 1956 con entregas mensuales. Estaba destinada a una amplia audiencia y se financiaba a través de las suscripciones y de la publicidad. En sus páginas se publicaron numerosos trabajos etnográficos y de divulgación de investigaciones científicas, en convivencia con notas orientadas a la promoción del turismo nacional y al conocimiento de la cultura en general (Zusman 2012). José Anesi encabezó la iniciativa de esta revista, que contó con la colaboración de varios naturalistas y antropólogos del país.

${ }^{176}$ Algunos de los que grupos que describe en esta revista son: Ashluslays, Lenguas, Chacaes, Chiriguanos, Cainguaes, Guayaquies, Macaes, Toba, Pilagá, Guaraníes y "tribus guaranizadas", Guarayos, Mbyaes, Sanapaná, Botocudos y Coroados. También describe ciudades en artículos como "Sierras y Ciudades del Sud de Brasil" (agosto de 1946) y algunas costumbres populares de las regiones visitadas, como la fiesta de la Virgen de Caacupé en Paraguay (octubre de 1946).

${ }^{177}$ Se toman las denominaciones de los pueblos visitados por Hanke tal cual ella los menciona en sus cartas y publicaciones.
} 
vida en el monte y el lenguaje guaraní, proyectó algunas expediciones para intentar encontrarse con los indígenas llamados "Guayaquíes",178.

Los Guayaquíes eran poco conocidos "científicamente" y sus miembros se presentaban como "esquivos" y "hostiles" a la mirada de los antropólogos y exploradores. Como se ha señalado, desde fines de siglo XIX permanecían "casi desconocidos aún por aquellas personas que se interesan por la suerte de las razas autóctonas" (La Hitte, 1895, en Martínez, 2012). A principios de siglo XX, distintos misioneros, científicos y la prensa local, se habían ocupado de describir y brindar noticias sobre este grupo. En el Congreso Internacional de Americanistas celebrado en Buenos Aires en 1910, el alemán Federico Mayntzhusen presentó una colección "Guayakí" ", a raíz de la cual se extendió el interés y las discusiones sobre lo que podría llamarse la "cuestión Guayaquí,, especialmente en relación a su clasificación lingüística ${ }^{180}$. Este grupo se transformó, según Pegoraro (2009) en un "problema etnográfico" en tanto se consideraba como una tribu interesante por sus rasgos físicos y su cultura material "en estado neolítico", según las definiciones de Ambrosetti, Vogt y Mayntzhusen, entre otros. Los artefactos de la cultura Guayaquí eran considerados como un "testimonio de una sociedad renuente a la civilización" (Pegoraro, 2009: 218). Por otro lado, aparecía el problema de su estudio, la obtención de informaciones sobre los mismos y la posibilidad de hacer trabajos "de campo" con ellos.

\footnotetext{
178 Actualmente, este pueblo se autodenomina aché, considerándose el término "guayaquí" como despectivo ya que significaría "ratón de monte" (Martínez, 2012). Sin embargo, se usa el término Guayaquí por ser el utilizado por Hanke y otros investigadores de la época.

179 Mayntzhusen (1873-1949) había creado en su propiedad, en la Colonia Capitán Menza, Paraguay; una reducción de indígenas Guayaquíes. Conocido entre sus colegas como etnógrafo, historiador y colonizador de tierras en el Paraguay. Los objetos exhibidos en el Congreso eran parte de su colección particular y habían sido en su mayoría obtenidos en las ocho expediciones que el mismo había realizado entre 1903 y 1910 en búsqueda de campamentos guayakíes (Pegoraro, 2009).

${ }^{180}$ Este tema es tratado por Hanke en un artículo de 1938. Ella señala que el problema de clasificación de los Guayaquí es lingüístico y racial, y que según Mayntzhusen y Vogt son Guaranies. Otros los ubican entre los Gês, Shoklengs o Sirionos. Ehrenreich los considera una raza aparte, con lo cual concuerda Hanke. La autora señala también que fueron guaranizados "desde los tiempos históricos" y por eso se conservan pocas palabras y algunos restos de costumbres y creencias (Hanke, 1938).
} 
Observarlos y menos aún fotografiarlos en su vida cotidiana no era sencillo, tal como reconoció el explorador francés Albert-Jehan Vellard (1901-1996), quien entre febrero y octubre de 1932, poco tiempo antes que Hanke, intentó contactarlos (Vellard, 1933). La mayor parte de los objetos e información obtenidos por Vellard provenía de "rastros"181 en la selva y de campamentos abandonados, algo similar a lo que va a reunir Hanke dos años después. El francés observa a los Guayaquí a la distancia, “a escondidas” observa su campamento y desde allí describe algunos comportamientos de su vida cotidiana (Vellard, 1939). Cuando intenta un acercamiento, es atacado en su tienda durante la noche y luego, al quedarse sin sus baqueanos, termina la expedición. Algunos datos más sobre este grupo los obtiene de historias que le cuentan los indígenas de otras etnias, como los Mbwiha ${ }^{182}$. Hanke, por el contrario, consiguió establecer algunos contactos directos, especialmente con algunas mujeres. Esta exploradora publicitó ese "logro" en varios artículos, entre ellos, en una nota publicada en La Prensa en 1936, donde relató cómo había logrado contactarlos en las cercanías de Villarica, Paraguay (Hanke, 1936). Para Hanke, quien apenas se iniciaba en el campo de la etnografía, escribir sobre ellos o investigarlos en su "estado natural" adquiría un valor fundamental, tanto para reforzar su prestigio como exploradora como para obtener mayores beneficios en la transacción de materiales e informaciones.

\footnotetext{
181 Vellard (1939) señaló la dificultad para estudiarlos en su "hábitat natural”. Junto a sus guías, Vellard recorría la selva intentando el contacto directo, pero frecuentemente hallaban campamentos abandonados, a partir de los cuales Vellard podía deducir algunas actividades. Al ser un grupo nómade, sus campamentos eran difíciles de ubicar y los guías "rastreaban" los movimientos como si siguieran a un animal de caza. Incluso cuando los encontraban, era difícil entrar en relación con ellos, siendo común que al ver a los exploradores abandonaran todo y salieran huyendo.

182 Mediante ciertos “avistamientos" de estos indios, Vellard remarcaba su lugar como uno de los tantos proveedores de datos en la empresa colectiva de observación del mundo y de la naturaleza. Sin embargo, al haber podido observar a pueblo tan esquivo, se destacaba como un recolector más calificado que otros, un reconocimiento que podía traducirse en nuevos encargos y mejores recompensas (Martínez, 2012:14).
} 


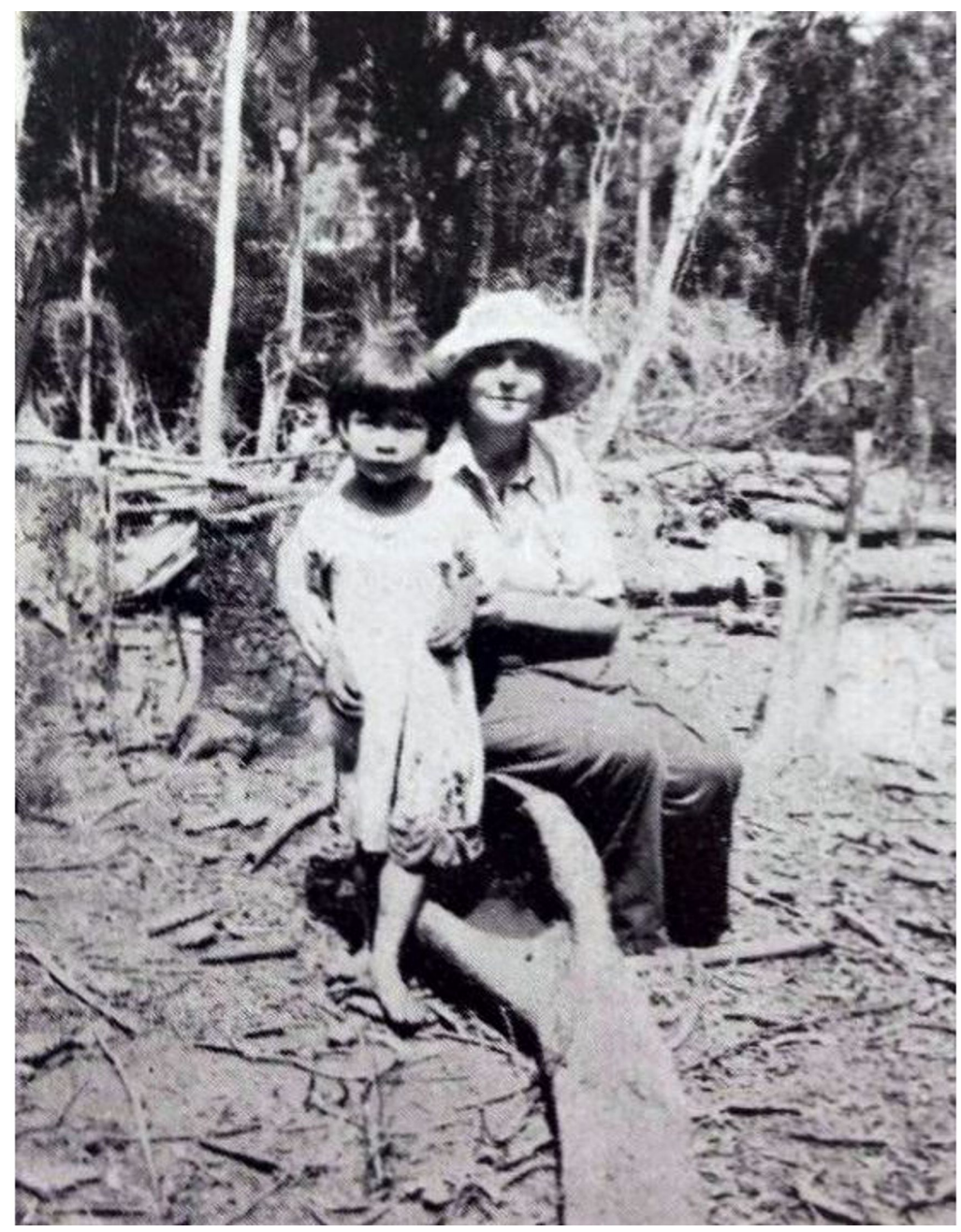

Ilustración 4: Fotografía publicada en la Revista Geográfica Americana, agosto de 1938. La leyenda original de la foto dice "La autora con Elsita"

En 1937, nuevamente en Sudamérica tras una estadía en Europa, Hanke retomó el interés por algunos grupos ya visitados, como los mencionados Guayaquíes. Asimismo, recurrió a algunas relaciones y correspondencias establecidas en su primer viaje con diferentes investigadores y funcionarios pertenecientes a museos y otras instituciones. Uno de sus intercambios más asiduos fue el realizado con el encargado de la Sección de Antropología del Museo Argentino de Ciencias Naturales "Bernardino Rivadavia”, José Imbelloni, quien la orientó respecto de los materiales y temas de interés del momento, colaborando con sus envíos de materiales a dicho museo así como al Museo Etnográfico de la Universidad de Buenos Aires. 
El trato directo con Imbelloni fue muy provechoso para la exploradora austríaca, puesto que este va a actuar como intermediario entre ella y una serie de contactos vinculados a las ciencias antropológicas, a los museos y a otros circuitos culturales. Entre ello, se puede mencionar la mediación de Imbelloni entre ella y el italiano José Anesi ${ }^{183}$, director de la Revista Geográfica Americana donde se publicaron diferentes trabajos de Hanke. Imbelloni recibía sus manuscritos y los enviaba a algún ayudante de su área para la corrección del español antes de ser enviados a la revista. Estos favores permitieron sortear algunos problemas a esta austríaca con el lenguaje español, el cual -como se señala adelante- no manejaba bien. Así, las negociaciones que rodeaban la compra y venta de objetos etnográficos involucraron el intercambio de distintos tipos de favores. Por su parte, Hanke, durante sus exploraciones, le buscaba a Imbelloni materiales de especial interés para sus investigaciones, como restos óseos o dibujos hechos por los indígenas ${ }^{184}$.

Los objetos que Hanke ofrecía en venta eran clasificados principalmente como "etnográficos": artefactos indígenas de uso cotidiano para la elaboración y cocción de alimentos, para el transporte de objetos, adornos, instrumentos, armas, entre otros. También reunió restos óseos humanos y en ocasiones especímenes zoológicos (chanchos de monte, escarabajos, arañas, onza, caracoles, nidos de avispa, entre otros). A esto se sumó la recopilación de idiomas nativos, fotografías e ilustraciones realizadas por los indígenas. También realizó mediciones antropométricas de individuos pertenecientes a los grupos Chiripá, Cainguá, Baticola y Guayaquí; y tomó algunas muestras de cabellos de los

\footnotetext{
${ }^{183}$ José Anesi (1881-1963) era italiano, se había graduado en estudios clásicos y era editor y representante en la Argentina de las más importantes firmas cartográficas italianas, inglesas, francesas y del Instituto Geográfico De Agostini. Poseía una editorial cartográfica desde 1918 y desde 1945 se vinculó a la casa Peuser, quedando asociado a la producción de mapas y atlas (Cicalese, 2008; Zusman, 2012).

${ }^{184} \mathrm{Al}$ parecer, los dibujos fueron un pedido de Imbelloni y Hanke en diferentes cartas y envíos al museo se ocupa de ellos: "En éste cajón hay unas cosas para usted primeramente algunos cantaros o mate con dibujos y después animales de cera, que me hicieron los indios. Es mucho más fácil de conseguir animales de cera que dibujos. Y con dibujos es así que más fácil dibujan encima de un mate o un cántaro. Con papel y lápiz no quieren trabajar y dicen que no saben, que no se acostumbra entre ellos y otras cosas más. Donde no pude conseguir dibujos en papel, les hice dibujar mates o cántaros y le mande estos." Carta de Hanke enviada desde El Dorado, 7/4/1938 a Imbelloni, AFDME.
} 
mismos. Por lo general enviaba listados describiendo los materiales (con precios incluidos) y con comentarios acerca de los usos nativos de los objetos y del lugar de procedencia. Como ejemplo, se transcribe parte de una carta de ella reportando el envío de una caja con materiales obtenidos de los Guayaquíes y de los Cainguás en 1935 al Museo Argentino de Ciencias Naturales, junto con insectos y muestras de alfarería. Hanke estimaba que los materiales etnográficos tenían un valor de $25 \$ \mathrm{~m} / \mathrm{n}$ y contenía los siguientes objetos:

"De los indios Cainguá:

- $\quad 1$ rebenque, 1 carretel y 1 pipa de una toldería en el monte atrás de Paso Yobai (febrero, 1935).

Indios Guayaquíes:

- $\quad 1$ cuchillo y 1 piedra para abrir las frutas, de un campamento abandonado en el monte, a 2 leguas de Ñuverá (marzo, 1935).

- $\quad 3$ agujas de hueso de una mujer escapando de nosotros, en el monte, 7 leguas de Ñuverá (Marzo de 1935)

- 1 bandallo

- $\quad 1$ cántaro

- $\quad 1$ cadena de dientes

- $\quad 1$ canasto (los últimos cuatro, regalados de dos mujeres, con las cuales yo tenía relación en el monte, mayo 1935)

Colección de los indios Guayaquíes:

- $\quad 1$ hacha de piedra

- 1 canasto de hilo

- $\quad 1$ soga de cabellos de mujer

- $\quad 2$ huesos de animales usados de instrumentos 
cosas destacadas:

- $\quad$ muestra de la tierra excavada
- $\quad 1$ pedazo con dibujo" 185

Gracias al intercambio epistolar con Imbelloni y con otros encargados de colecciones o jefes de sección en los museos, Hanke fue aprendiendo ciertas formas "apropiadas" (según los parámetros de los museos) de ofrecer objetos en venta, incorporando los pasos necesarios para esas transacciones y el envío de las piezas, así como para el registro de los datos que debían ser consignados, las condiciones de hallazgo y otras descripciones pertinentes al uso u origen de los objetos. En la institución receptora un especialista emitía su opinión respecto a la tasación de los objetos en función de su "valor científico". El valor monetario asignado debía ser luego aprobado por la dirección y finalmente se le enviaría el pago al vendedor ${ }^{186}$. En función de esas tasaciones "expertas", Hanke se fue inclinando hacia la recolección de aquellos objetos mejor valuados, es decir, aquellos materiales que resultaban ser más valiosos -en términos científicos o simbólicospara los compradores, los investigadores y responsables de los departamentos específicos del museo. Estos intercambios epistolares permiten apreciar las interacciones y negociaciones colectivas que conforman el valor de los objetos, donde se intercalan apreciaciones científicas y comerciales.

\footnotetext{
${ }^{185}$ Carta de Hanke a Doello Jurado, 9/9/1935, AFDME.

${ }^{186}$ En el caso de Hanke, se daban dos modalidades de tasación. Por un lado, ella solía sugerir el precio de los objetos o colecciones, el cual luego era aceptado o negociado en función de los criterios de la institución receptora. Por otro lado, hubo envíos en los cuales no se consideraban los valores sugeridos hasta contar con los objetos "a la vista". Como ejemplo se puede señalar un envío de materiales de los "Botocudos" realizado por Hanke al Museo de La Plata en 1940, del cual Márquez Miranda solicita que "el expediente se reserve hasta el momento de la llegada de tales especies. En efecto, es difícil poder informar acerca de su valor venal y del grado de interés que puedan revestir para la sección Etnografía sin haberlos tenido entre manos." (Nota de Márquez Miranda a la Dirección del Museo, 5/10/1940, AHMLP).
} 
Las formas "apropiadas" de realizar estas transacciones no siempre eran respetadas ni tampoco siguieron un patrón único. Hanke en diferentes ocasiones intentó vender materiales sin considerar las pautas establecidas por los museos, resultando exitosa en algunos casos. Así sucedió con unos esqueletos Guayaquíes de 33 vértebras ${ }^{187}$ que ofreció a Imbelloni:

"Cerca de aquí hay un lugar donde se encuentran tres esqueletos Guayaquíes. A mí me parece que tienen 33 vértebras y que son diferentes de otros esqueletos humanos. Pero no puedo escavarlos y llevarlos sin ayuda y para ésta tengo que pagar. [...] Excepcionalmente de los 30 pesos de Anesi no recibí ni un centavo desde me fui de Buenos Aires. En Viena me olvidaron completamente aunque mandé ya una gran colección. Lo mismo me pasó en Tucumán. Ni los diarios de Europa ni éstos de Argentina me pagan para mis colaboraciones. Para el museo de Buenos Aires tengo una colección de los Guayaquí y otra de los Chaqueños; la última está en Asunción donde tenía que enseñarla para recibir un préstamo. Yo creo que a Ud. van a interesar mucho los esqueletos de los Guayaquí y por esto le ruego de hablar también de su parte con el Director para que me mande 100 pesos inmediatamente. Después va recibir los esqueletos y objetos de los Guayaquí y puedo yo continuar mis trabajos científicos.

[...] Como ahora con los esqueletos se trata de una ocasión única le pido de ayudarme muy pronto hablando con el Director." 188

Esta carta expresa claramente cómo Hanke expuso una serie de argumentos para persuadir a Imbelloni de lo urgente que necesitaba el dinero, motivándolo para interferir en la transacción asegurándole el carácter extraordinario de los esqueletos y el posible valor científico de sus exploraciones en la región. Los argumentos esgrimidos eran habituales en

\footnotetext{
${ }^{187}$ Los seres humanos poseen 33 vértebras durante la etapa fetal y en la niñez, y durante la etapa adulta sólo poseen 24 , puesto que los huesos del sacro y el cóccis se unen formando un solo hueso cada uno.

${ }^{188}$ Enviada desde Puerto Victoria (Misiones, Argentina), el 29 de enero de 1938 a Imbelloni, AFDME.
} 
sus correspondencias, falta de apoyo de diferentes instituciones o falta de cumplimiento de acuerdos con algunas personas específicas, préstamos o empeño de sus colecciones, deudas con hoteles o casas de provisión de insumos para su trabajo (rollos fotográficos por ejemplo), entre otros. Es curioso que señale que estos esqueletos tenían 33 vértebras, admitiendo que aún no los había excavado, y para lo cual solicitaba dinero. Su estrategia, sin embargo, fue exitosa: Imbelloni consigue que el Director del Museo, Martín Doello Jurado, compre de forma "anticipada" la remesa de Hanke, sin ver los materiales. El antropólogo italiano aclaró que eso era una situación excepcional y que Doello Jurado adelantaba el pago con su propio dinero ${ }^{189}$. Imbelloni le recomendó a Hanke determinadas conductas para las sucesivas transacciones con el museo:

“[...] Debo hacerle resaltar el hecho que dicho envío ha sido una medida absolutamente de excepción, pues el Museo en este momento no tiene sumas disponibles por gastos, y el Director ha tenido que sacarlo de su peculio particular, por el momento. Algo se debe también a mis oficios, habiéndole hecho resaltar que los materiales que Ud; puede enviar serían de interés para esta sección. Así que sería conveniente que Ud. al acusar recibo de la suma acompañara un agradecimiento personal para el Prof. Doello Jurado. Otra cosa importante, que es oportuno la tenga en cuenta en lo sucesivo, es que el Museo, como toda repartición oficial, no puede de ninguna manera y por ninguna causa hacer entregas de dinero sin haber recibido mercaderías u objetos de colecciones, y este es un particular sobre el cual la contaduría general tiene siempre los ojos bien abiertos. Por eso, cuando Ud. tenga que hacer algún pedido, de carácter pecuniario, en concepto de cesión o venta, tendrá que considerar estas reglamentaciones.

Lo que le he dicho, espero que Ud. entienda, es solo con el afán de ayudarla en esforzada empresa de hacer con la nada lo que pocos se atreverían a hacer con la

\footnotetext{
${ }^{189}$ Esto es una práctica común, puesto que los directores de diferentes museos aseguran la compra cuando no se disponen de más fondos en la partida de gastos, luego recuperan estos gastos en la siguiente ejecución del presupuesto estatal (Farro, 2009).
} 
ayuda pecuniaria de las instituciones. Su estado de necesidad lo comprendo fácilmente aunque espero que ha de recibir ayudas de Viena; ya escribí al Dr. Röck ${ }^{190}$ hablándole de la inmensa miseria de sus recursos.

[...] Cuide que los esqueletos de Guayaquí estén completos y cuidadosamente recojidos, teniendo separados los respectivos huesos; envíeme también un croquis del yacimiento y las circunstancias de su identificación. Yo no he hablado con Anesi, pero si tiene algunas fotografías haga un pequeño artículo que se lo corregiremos en el Museo y podremos hacer la tentativa de hacerlo comprar para remitirle su plata. No olvide mantenerse en contacto y enviar lo que cree oportuno, tanto para el Museo como para mí."191

Con el dinero del museo Hanke pudo excavar y enviar dichos esqueletos a través del vapor de la Compañía "Mihanovich". Mientras esos materiales estaban en camino, Hanke continuó la correspondencia con Imbelloni, informando sobre los esqueletos Guayaquíes que tenían "cabellos y piel y que sin duda eran cadáveres indios". Agregó también que vio una vértebra doblada y que los huesos le parecían más chicos que de otra gente y solicitaba que se le comunique "el valor de un esqueleto, porque quisiera saber si vale la pena escavar más (sic) ${ }^{\prime 192}$. Poco después, Hanke se interna en el monte e intenta contactar con los "indios", para medirlos y hacerlos dibujar, pensando que eso le interesaría a Imbelloni.

Respecto de las excavaciones, Hanke solía contratar peones para las mismas. Estos trabajos son mencionados brevemente en sus cartas o publicaciones, en el caso de estos esqueletos en particular, dice Hanke:

"Son muy importantes para la ciencia no sólo Guayaquí vivos, sino también sus restos óseos. Es difícil encontrar sus esqueletos, y estos hallazgos dependen de

\footnotetext{
${ }^{190}$ Fritz Röck (1879-1953) era entonces Director del Museo de Etnología de Viena (Liener, 2010).

${ }^{191}$ Carta de Imbelloni a Hanke, enviada desde Buenos Aires el 15 de febrero de 1938.

${ }^{192}$ AFDME, carta de Hanke a Imbelloni 6/03/1938
} 
circunstancias fortuitas. Aunque tenía referencia de algunos enterratorios Guayaquí. Tan sólo pude excavar dos esqueletos, que pertenecen a aquellos indígenas de los que hablé antes y que murieron de una fiebre mortal. Los peones del puerto, temblando de miedo a los espíritus, se rehúsan con energía a enseñar los lugares de entierro. Finalmente hicimos venir a un peón de la colonia ${ }^{193}$, un joven argentino, llamado Paiva, que era menos supersticioso y más inteligente que sus compañeros, el cual nos condujo hasta el sitio, nos ayudó a cavar, cobró y se fue. Las tumbas se encuentran en las barrancas del Río Paraná, un tanto alejadas del puerto. Probablemente el agua, durante las crecientes, arrastró algunos esqueletos, pues en lugar del número que me aseguraron únicamente encontré dos, sin contar los restos muy incompletos de una criaturita de 8 días, víctima de la inhumanidad de su madre. Uno de los esqueletos fue hallado a unos dos metros de profundidad y conservaba aún restos de las partes blandas en putrefacción.” (Hanke, 1938: 122).

Los siguientes meses, la exploradora envía materiales al Museo Argentino de Ciencias Naturales de los grupos Baticola y Chiripa, fotografías y escritos para la mencionada Revista Geográfica Americana. También remite algunos cajones especiales para Imbelloni conteniendo dibujos indígenas ${ }^{194}$, mates y cántaros y esculturas de cera representando animales de los Toba y los Cainguá, cabellos Guayaquíes y medidas antropométricas. Asimismo, asegura que conseguirá más colaboraciones para Anesi y muy probablemente más dibujos y medidas y -como es habitual en sus cartas- agrega un comentario sobre sus "desgracias" y su deseo de dedicarse plenamente a la ciencia: "si hay algo más que le interesa pido instrucciones. Aquí me persigue otra vez mi mala suerte. La

\footnotetext{
${ }^{193}$ Se refiere a la colonia de Puerto Victoria, en Misiones.

194 Como señala Ballestero (2013) los dibujos son considerados como un medio de expresión donde la representación gráfica no es más que el lenguaje del pensamiento. Por lo tanto, la expresión gráfica es un claro indicio del estado evolutivo de la mente del autor del dibujo. Este tipo de trabajos se inserta dentro de una serie de estudios previos surgidos a lo largo del siglo XIX y principios del siglo XX como búsqueda de elementos materiales o expresiones culturales que permitieran matizar la supuesta "homogeneidad" biológica de las "razas" gracias al carácter material y simbólico de los dibujos.
} 
lluvia impide mis conferencias y todos trabajos que podría hacer para ganar plata. Ud. va entender que ya no quiero trabajar más en cualquier profesión y quisiera vivir solo para la ciencia". 195

Como en otras ocasiones, Hanke insiste -nuevamente- en su falta de recursos para continuar las exploraciones. Remarca que no ha recibido ayuda de Viena y que su "única esperanza es el Museo Argentino y Anesi”, aunque antes de "pedir al Sr. Director un puesto en el Museo de Buenos Aires, quiero mandar primeramente las colecciones chaqueñas y trabajar algo más"196.

En mayo de 1938, Imbelloni reporta que recibieron en buen estado los diversos materiales ${ }^{197}$, excepto los esqueletos, los cuales

"podrían haber estado más completos (faltan algunas vértebras del adulto, muchos carpos y tarsos y falanges de manos y pies; pero especialmente sensible es la falta de las dos vértebras, una cervical y una dorsal, cuya ausencia no puede de ningún modo atribuirse, como usted alguna vez me ha dicho, a una falta orgánica y fisiológica de aquellos indios, pues la coincidencia de las articulaciones y las costillas, atentamente examinada, nos ha convencido de lo contrario)." 198

Los esqueletos, entonces, no tenían ninguna característica extraordinaria, pero esto se comprobó luego de haber sido comprados por el museo. Estas transacciones e intercambios epistolares en torno a un conjunto de objetos permiten visualizar las prácticas

\footnotetext{
${ }^{195}$ AFDME, carta de Hanke a Imbelloni, 19/04/1938

${ }^{196}$ AFDME, carta de Hanke a Imbelloni, 04/05/1938

${ }^{197}$ Los esqueletos y algunas hojas de dibujos de indios, con algunas "plásticas" en cera, pequeños objetos y una lista de medidas acompañadas por fotografías. También fueron recibidas las colaboraciones para Anesi, las cuales fueron corregidas y pasadas a máquina En esta ocasión, la tarea fue realizada por Luis Alberto Chillida y Adolfo Dembo, ambos empleados del museo que trabajaron junto a Imbelloni. Ellos, junto a Radamés Altieri e incluso el mismo Imbelloni se ocupaban de tipear y corregir los textos de Hanke.
}

198 AFDME, carta de Imbelloni a Hanke, mayo de 1938. 
colectivas y heterogéneas vinculadas a la formación de colecciones etnográficas y antropológicas. Prácticas que, como se ve en los diferentes capítulos de esta tesis, no fueron ajenas a las mujeres. En el caso de Hanke, se combinan actividades de exploración, escritura de textos científicos y de divulgación y actividades comerciales. Asimismo, muestra cómo el estar al tanto de las novedades científicas y mantener contactos con investigadores de los museos ayudaba a la selección de piezas e información y a las formas de su compilación y transporte.

\section{Medicina, trueque, compra y otras estrategias de supervivencia}

Las prácticas científicas y comerciales de Wanda Hanke se enmarcan en una red de relaciones en la cual participan diferentes individuos, como los referentes de las comunidades indígenas, los encargados de las colecciones en los museos nacionales, los pobladores que venden sus vasijas o los peones que ayudan a desenterrar los esqueletos (Arias, 2017). También permiten observar las distintas estrategias desplegadas por estos personajes, tanto hombres como mujeres, que recorren el territorio Sudamericano y devienen en exploradores, "organizadores" de colecciones y que aspiran a vivir de la ciencia o de su discurso (cf Podgorny, 2011, 2012). En el caso de Hanke, se combinaron las exploraciones etnográficas con el ejercicio de la medicina, el periodismo y la venta de colecciones.

En febrero de 1935, habiéndose quedado casi sin dinero y luego de recibir consejos poco favorables para viajar sola ${ }^{199}$ por el Paraguay "para poder ganar dinero con mi

\footnotetext{
${ }^{199}$ En su correspondencia, Hanke siempre se lamenta por "viajar sola", con todas las dificultades que implica ello para una mujer que promedia los cuarenta años. Sin embargo, estos documentos también demuestran que casi nunca está realmente sola, puesto que cuenta con ayudantes que trasladan sus bultos, peones que exhuman restos humanos y objetos arqueológicos, un secretario que traslada colecciones de Misiones a Buenos Aires y diferentes personas en las instituciones con las cuales intercambia materiales, en los puestos aduaneros en la selva o en las delegaciones diplomáticas de diferentes países; por citar algunos ejemplos. Por otra parte, Sombrio (2014) señala que, en cierta forma, los límites menos rígidos de las prácticas científicas en
} 
profesión de médico y continuar así mis estudios" (Hanke, 1995: 19). De la misma forma, en 1938 en los alrededores de Puerto Victoria en Paraguay, tuvo "mucha ocasión para estudios científicos y podría averiguar mucho con un poco de dinero", pero si no recibía ayuda financiera tendría que "trabajar otra vez -como los últimos meses- dando conferencias o como médica en el campo". Por otro lado, aprovechó su saber médico para dialogar e intercambiar informaciones con los curanderos nativos. Así, por ejemplo, en una de sus visitas a la región de los llamados Lenguas en el Chaco Boreal, Hanke cuenta cómo entabló muy buenas relaciones con un médico nativo y una "vieja" de esa tribu, quien le enseñó a emplear diferentes "yuyos" para curar enfermedades. Su "condición femenina" le ayudó a relacionarse con las mujeres de diferentes comunidades, compartiendo algunas actividades y tareas específicas. En la toldería del cacique Saravia, de los Lenguas del Sur, la madre del cacique la acompañó al monte y le enseñó cómo reconocer las hojas de caraguatá y también a preparar sus fibras para los tejidos. Dicha señora le dio "lecciones de hilado, tejido, alfarería y me enseñó su idioma" (Hanke, 1939). También se vinculó con las mujeres que vivían en las estancias de Misiones, ya sean parte de la familia de los propietarios o trabajadoras indígenas, familiarizadas con los idiomas indígenas de la región y con los caminos y ubicación de las tolderías. Estas mujeres le facilitaron el acceso y la permanencia en distintos poblados Cainguás en sus primeros años de viaje.

En la medida en que Hanke fue adquiriendo experiencia en la región y haciéndose conocida por sus exploraciones entre grupos indígenas y en territorios poco accesibles a la civilización, ejercería de "chaperona" o guía de ricas exploradoras, periodistas, investigadores o quienes estuvieran dispuestos a pagar sus servicios para internarse en el interior selvático. Como ejemplo de estas actividades, se puede mencionar la expedición

el campo facilitaron la incorporación de las mujeres en estas actividades. La investigación en el campo fue más difícil de reglamentar que aquella de laboratorio: "por siglos las mujeres viajaron hacia lugares distantes registrando sus observaciones en cartas, diarios y pinturas, lo cual permite la construcción de una historiografía sobre mujeres viajantes y que actuaron como investigadoras de campo.” (Sombrio, 2014: 19). 
proyectada por Hanke en conjunto con la Baronesa Camilla Blanc ${ }^{200}$. En 1940, Camille Blanc se contactó con Hanke para acompañarla en una expedición al Matto Grosso, de la cual se había enterado por los periódicos. La intención de viajar fue difundida por la revista femenina Vosotras en un artículo titulado "Dos mujeres vencerán al Matto Grosso" (28/6/1940): “En compañía de la señora Wanda Hanke, que irá a hacer observaciones etnográficas a la temible selva brasileña, la Baronesa Blanc de Corbieres de 26 años de edad, buscará una nueva aventura para su vida, desafiando la muerte, el clima y la fiebre del Matto Grosso". En este marco, Blanc escribió al Museo de La Plata solicitando que cada Departamento le envíe una lista de objetos que quisieran obtener de las regiones que recorrería. Quizás estas intenciones, que se superponían con las actividades comerciales que Hanke mantenía con el Museo, fueron la causa de la cancelación de la expedición en conjunto. El motivo no es claro, pero la breve relación entre ambas terminó de forma conflictiva, con denuncias y acusaciones mediante. Así, Hanke escribe a Frenguelli, Director del Museo:

"Yo hice la denuncia a la sección criminal de la policía en Buenos Aires, pero temo, que nadie se moverá, para ayudar a mí. La Blanc es linda y joven, además muy galante que por tal razón nadie la quiere perjudicar y se le permite de destruir la existencia y la fama de una persona honrada que se sacrifica para la ciencia. Todos los hombres asienten con ella y todavía piden a mí, de perdonarla.” ${ }^{201}$.

Frente a esta situación el Museo decidió no intervenir y la excursión entre ambas mujeres no prosperó. Además de ofrecer servicios de medicina o guía, el principal recurso de Hanke fue, sin dudas, la comercialización de objetos y colecciones etnográficas y

\footnotetext{
${ }^{200}$ Nacida en el seno de una importante familia en 1913, la suiza Anna Georgette Camille Blanc viajó con su familia a la Argentina en 1933. Hasta 1954 la familia se radicó en Salta, donde su padre Luis Hubert Casimir Blanc estableció una Hacienda y una planta de producción de aceite de oliva.

201 AHMLP, Carta de Hanke a Frenguelli, 31/12/1940. El seguimiento de este desencuentro merece futuras investigaciones. Aprovecho para agradecer a Christian Meyer y a sus hermanos por su generosidad y amabilidad al ofrecer datos sobre su madre Camille.
} 
antropológicas $^{202}$. Esos materiales provenían de distintas personas y poblados y para obtenerlos empleó distintas estrategias, según las pautas de intercambio y las posibilidades de negociación con ciertos individuos o grupos. Muchas veces obtuvo objetos mediante trueque, ofreciendo cigarrillos, géneros y prendas, entre otras cosas "modernas". Así, por ejemplo en 1939, en una carta dirigida al director del Museo Etnográfico de Buenos Aires, Hanke manifiesta que "Para pagar la colección a los indios di casi toda mi ropa, así que Ud. ve, que yo trabajo con muchos sacrificios personales" ${ }^{203}$. En otra ocasión, Hanke describe cómo obtiene algunos cráneos entre los Sirionó de las cercanías de Santa Cruz de la Sierra: “yo vi dos nenas jugando con un cráneo como una pelota y enseguida me lo vendieron por un pedazo de género. Un hombre, asistiendo a este negocio se fue a su casa y volvió con un cráneo gritando de lejos: 'aquí murió otro pariente nuestro, queremos cambiarlo por tabaco'." (Hanke 1942: 93)

En un artículo publicado en diciembre de 1937 en la Revista Geográfica Americana, Hanke relató cómo fue la forma en que consiguió intercambiar objetos con un grupo de $\operatorname{Matacos}^{204}$ residentes en una misión anglicana en el Algarrobal ${ }^{205}$. Primero ofrece cigarrillos, pero se los rechazan por las normativas de la misión. Al respecto, Hanke señala que para "el viajero que tiene interés en comprar algunos objetos etnográficos, encuentra

\footnotetext{
${ }^{202}$ Se registran colecciones reunidas o remitidas por Hanke en varios museos Sudamericanos y de Europa: Museum für Völkerkunde, Viena, Austria; Museum für Völkerkunde Munich, Alemania; Världskulturmuséet, Gotemburgo, Suecia; Museu de Arqueologia e Etnologia, San Pablo y Museu Paranaense, Curitiba, Brasil; Museo Etnográfico Juan B. Ambrosetti y Museo de La Plata, Argentina.

${ }^{203}$ AFDME, carta de Hanke 1/12/39.

${ }^{204}$ Hanke señala que este grupo de matacos ha adquirido, a diferencia de otros grupos, los "rudimentos de la civilización" en gran parte debido a la misión anglicana instalada hace 20 años. Hanke pasa dos semanas allí, "observando las costumbres de la toldería india" pero encuentra muy pocos vestigios de su "propia cultura autóctona", ya que casi todos sus habitantes son cristianos y han olvidado sus mitos, sus leyendas y sus supersticiones (Hanke 1937: 409).

${ }^{205}$ La misión llamada "El Algarrobal" fue fundada entre los Wichí (mataco) en 1914 por los misioneros anglicanos de la South American Missionary Society. Se ubica en el chaco salteño, cerca del límite con la provincia de Formosa, Departamento de General San Martín, Municipio de Embarcación, Argentina (Gómez, 2011).
} 
muchas dificultades para realizar su propósito"(Hanke, 1937: 410), especialmente en relación a las normativas de las misiones religiosas. Sin embargo ella insistía y por lo general lograba realizar los intercambios:

"El primer día, a pesar de muchos esfuerzos, no encontré más que unos cántaros y una bolsa, pero si se sabe tratar a los indios, poco a poco vienen a aparecer las fajas, los ponchos, calabazas de varios tamaños y al final pipas y juguetes. Sin embargo, pese a toda mi diligencia, no pude encontrar arma alguna (...) Una sola flecha vi en el toldo de un anciano y al preguntarle si la quería vender, éste me dijo que si y que tenía otras más (...) parece que mi "armero" había quedado contento con el precio que le pagué, ya que en los días siguientes otros llegaron ofreciéndome armas (...) también se presentaron algunas mujeres, con carreteles y una viuda anciana con un sonajero que encontró en su casa" (Hanke, 1937: 410-412).

La búsqueda de estos objetos "etnográficos" que menciona Hanke remite a la mencionada idea de "autenticidad", a partir de la cual se prefieren ciertos objetos que serían los "verdaderamente" indígenas, como armas, vestimentas o instrumentos. La forma de obtener estos objetos varía: algunas veces se debían pagar con dinero o mediante el trueque de las cosas que llevaba consigo. Esta dependencia monetaria era vista como una pérdida de ciertos "valores tradicionales" de las culturas. Cuando Hanke visitó a los Botocudos 206 de Santa Catarina, Brasil, ofreció una colección de los mismos al Museo de La Plata, aclarando que "lastimosamente" los Botocudos ya se olvidaron de su cultura antigua y las armas de ellos solo se consiguen por los viejos: "Los indios acá viven en un puesto del gobierno y tienen sus precios fijos en dinero. Muy poco se puede hacer con objetos de

\footnotetext{
${ }^{206}$ El término "botocudo" refiere al uso del botoque (también llamado tembetá) y fue utilizado para designar a diferentes sub-grupos del grupo lingüístico Macro-Jê. Izabel Missagia de Mattos (2009) "Da etnoarqueologia à história indígena: os botocudos em seus processos identitários (século xix ao xxi)”, en: Habitus, v. 7, n 1.2, pp: $75-97$.
} 
cambio como lo hice siempre en Paraguay y en el Chaco. Me permito de agregarle los precios, que yo pague en dinero, el resto compre con género nuevo"207.

En una publicación sobre los Lenguas describe una situación similar: "Me recibieron y trataron muy bien, pero exigían el pago de todo lo que me proporcionaban: ni el agua me daban gratis”. Por estos motivos, para Hanke los Lenguas del Sur tienen mucha “degeneración", y cree que es "evidente que el contacto con los blancos contribuye a corromper a los indígenas" (Hanke, 1939). Estas "degeneraciones" o la "pérdida" de valores "tradicionales" no impedían la recolección de los objetos, ni tampoco su posterior venta al museo y su consideración como "etnográficos". Las distinciones entre lo "auténtico" y lo que no lo era aparecen difusas en estas transacciones.

Por otra parte, algunos de los materiales reunidos eran obtenidos de campamentos abandonados o de lugares "dispersos en el monte". Una misma colección podía contener piezas de distintas procedencias, algunas eran obtenidas por intercambio en las tolderías, otras eran recolectadas en campamentos abandonados o de los individuos que huían de ella, como unas agujas que se le cayeron a una mujer en el monte ${ }^{208}$. Otros objetos eran recibidos como regalos de algunas mujeres indígenas. Los conjuntos de piezas ofrecidos a los museos iban acompañados con un listado con la procedencia y otros datos adicionales, como el uso de cada una de las piezas. Con ello justificaba, de alguna manera, la pertenencia a la colección aún de cosas "naturales" cuyo estatus de artefacto era discutible. Así por ejemplo incluyó en una colección de objetos Guayaquíes y Cainguás una "piedra para abrir frutas" y en otra ocasión un palo para sacar la miel de los panales, un objeto que el Museo de La Plata se negó a comprarle por no considerar que era un artefacto de la cultura Guayaquí. No queda claro en los documentos de Hanke si los usos asignados a los

\footnotetext{
207 AHMLP, carta de Hanke 13/08/1940.

${ }^{208}$ Dicha relación es relatada en la nota publicada por Hanke en La Prensa en 1936. En la misma se cuenta cómo contactan ella y su ayudante paraguayo con un pequeño grupo de guayaquíes, un joven y algunas mujeres, intercambiando objetos y compartiendo algunas experiencias en el monte.
} 
objetos recolectados eran registrados a partir de lo relatado por los informantes o vendedores de los objetos, o por sus propias observaciones.

Como se ha analizado en diferentes trabajos, el estudio de la formación de colecciones científicas implica tener en cuenta los diferentes aspectos culturales de las prácticas de la ciencia y el papel de los mediadores e intermediarios y sus efectos en la producción de conocimiento (Kuklick y Kohler, 1996). También remite al carácter transaccional de la ciencia (Podgorny, 2013) y a las instancias de intermediación en la formación de colecciones, donde los informantes y proveedores de objetos en el "campo" tienen un papel activo en la selección de los materiales que conformarán esos conjuntos de objetos etnográficos, incorporadas luego en los museos como las representaciones materiales de los grupos indígenas. Los procesos de adquisición, exposición y catalogación de estos objetos, integrados luego a otros conjuntos para conformar representaciones materiales de las culturas, terminan muchas veces ocultando los diferentes procesos y agentes que participaron en la creación de las colecciones (Penny, 2002, Podgorny, 2002).

Junto a las colecciones de artefactos, Hanke se ocupó de registrar mitos y creencias indígenas", copiar los motivos decorativos de piezas cerámicas, utensilios, tatuajes y otros símbolos y de tomar fotografías de los nativos en su estado "natural". A partir de 1949 incluyó con más frecuencia relevamientos lingüísticos de los diferentes grupos con los cuales estableció contacto. Como señala Farro (2013) las recopilaciones lingüísticas de diferentes grupos contribuyeron con el desarrollo de la antropología, de la historia y de la geografía en la Argentina; siendo la clasificación de las lenguas uno de los "hilos de Ariadna" que posibilitaron internarse en el laberinto de los grupos indígenas del pasado y sus sucesivos desplazamientos geográficos. Los registros lingüísticos también eran colecciones que podían entrar en el circuito comercial de provisión de material de los museos.

El rudimentario manejo del español de Hanke generó desconfianza en la "transcripción" española de los vocabularios y mitos registrados por ella, poniéndose en duda su "pericia" como recolectora de "campo". Su "español aproximativo" constituyó un 
problema en relación a la información recolectada por Hanke, como unos "cantos antiguos" de los botocudos y algunos apuntes gramaticales que remite a La Plata. Al respecto, Márquez Miranda ${ }^{209}$ señala que "su ya citado poco conocimiento de nuestro propio idioma y de la cultura de los indígenas que visita, reducen considerablemente las posibilidades de haber realizado una labor susceptible de utilización directa" ${ }^{210}$. No obstante, para 1940 la exploradora austriaca ya conocía qué piezas y colecciones podían despertar el interés en los museos argentinos. Así, ese año envió armas, canastos y tejidos con fibras vegetales de los Botocudos al Museo de La Plata. El jefe de la Sección de Arqueología y Etnografía encontró "interesante" el material remitido y accedió a pagar el precio requerido por Hanke. Unos meses después, esta colección será utilizada para renovar la Sala de Etnografía del Museo, siendo estos materiales catalogados por Márquez Miranda como pertenecientes a los Bororós.

En sus últimos años, entre 1952 y 1955 Hanke trabajó en la Universidad Mayor de San Simón de Cochabamba, Bolivia (Ocampo Moscoso, 1982). En 1955 regresó a Europa, pasando por España e Italia antes de llegar a Austria y Alemania en diciembre de 1956. En 1957 volvió a Brasil, donde continuó realizando exploraciones hasta su muerte, el 30 de agosto de 1958 en Benjamin Constant, Amazonas. Sus viajes a Europa los aprovechó para vender colecciones, dar conferencias y recaudar dinero para nuevos recorridos e investigaciones ${ }^{211}$. Hasta su muerte, realizó numerosas exploraciones y observaciones sobre

\footnotetext{
${ }^{209}$ Op. Cit.
}

${ }^{210}$ AHMLP, nota de Marquez Miranda a la Dirección, 2/06/1941

${ }^{211}$ La mayoría de los objetos ofrecidos por Hanke en Europa fueron adquiridos por el Museo de Etnología de Viena. En dicho museo se registran actualmente 682 objetos coleccionados por Hanke, recibidos en dos períodos en los cuales estuvo en contacto con el museo, entre 1935 y 1938 y entre 1955 y 1957. El período 1935 y 1938 fue cuando se recibieron la mayor cantidad de objetos (586) provenientes de 10 grupos étnicos diferentes. Aché, Ashluslay, Aymara, Baure, Cainguá, Chiriguano, Lengua, Matako, Siriono y Toba. Algunos objetos son inventariados bajo el epígrafe "cultura popular", otros, principalmente de la región amazónica, no tienen ninguna entrada relativa al origen étnico. Los grupos de objetos más representados son el Ashluslay con 162 objetos de 1936, seguido por el Matako con 140 números (1938), el Lengua (58 objetos) y el 
distintos grupos indígenas de Misiones y el Chaco argentino, Paraguay, las tierras bajas de Bolivia y el interior de Brasil, recopilando dialectos, mitos, dibujos, fotografías y colecciones que ofreció en venta a museos de varios países.

\section{La ciencia como una forma de subsistencia}

Las negociaciones alrededor de las colecciones antropológicas muestran disputas y conflictos e ilustran cómo las mismas son definidas en relación a intereses diversos (Pegoraro, 2003, 2009; García, 2007; Lindskoug, 2008; Podgorny y Lopes, 2008; Farro, 2009; Pupio, 2011; Bonnin 2011; Martínez, Taboada y Auat, 2011; Pupio y Piantoni 2016). Por otra parte, permiten observar la combinación de prácticas científicas y comerciales, donde las actividades de mujeres como Wanda Hanke no fueron una excepción. En ese sentido, este caso se puede comparar con aquellos personajes itinerantes que desde el siglo XIX recorrieron el continente sudamericano adoptando la identidad de explorador, pero también desarrollando prácticas ligadas a la medicina, el periodismo y el mercado del coleccionismo (Podgorny, 2008, 2010 2011). De esta forma, estos individuos, circulando por mundo diferentes, articularon actividades científicas y mercantiles alrededor del conocimiento y de los objetos de pueblos indígenas. Como señala Podgorny (2011) el estudio de este tipo de personajes descartados u olvidados en ciertos relatos de la historia de la ciencia, posibilita mostrar el lado colectivo e híbrido de la ciencia y de la producción del conocimiento.

Las prácticas desplegadas por esta exploradora y médica austríaca, así como las de otros personajes que recorrieron el territorio Sudamericano, pueden ser leídas en el marco de la historia de las "ciencias del terreno", una línea de investigación donde el "trabajo de campo" se define como una actividad compleja, colectiva y que exige la cooperación de un variado conjunto de individuos: estudiosos, directores de las instituciones científicas,

Chiriguano (56 objetos), ambos también de 1938.Esta colección ha sido analizada en profundidad por Liener (2010). 
residentes locales, personal de las reparticiones estatales, entre otros; quienes atribuyen distintos significados tanto a los objetos recolectados como a las tareas llevadas a cabo en el terreno (Kuklick y Kohler, 1996; Podgorny, 2002; Farro, 2009). Como se ha visto en capítulos anteriores, las actividades de las mujeres analizadas -como también de ciertos personajes masculinos- ponen en jaque las distinciones entre profesionales, amateurs, coleccionistas, exploradores o vendedores de colecciones, mostrando la existencia de prácticas y trayectorias que se mueven en los límites no bien definidos del quehacer científico. 


\section{Capítulo 5. Matrimonios y prácticas familiares en la ciencia}

“Isn't it wonderful?

All the women students in my department have found husbands"

G.P.Murdock (cf. Swidler 1989:263)

\section{Introducción}

Como parte del análisis de distintas experiencias de mujeres en la ciencia, este capítulo está dedicado a los lazos de matrimonio y a la organización de tareas científicas entre esposos, también llamados como "parejas creativas en la ciencia" (Pycior, Slack y Abir-Am, 1996) o trabajos en la "intimidad" del matrimonio (Lindsay, 1998). Estos estudios han mostrado cómo diversas parejas científicas en distintos momentos de la historia y en distintos contextos trabajaron de forma colaborativa, muchas veces obteniendo beneficios económicos y sociales por las actividades científicas compartidas, a veces ambas partes y otras solo uno de los miembros, generalmente los hombres aunque en algunas casos las esposas científicas. En relación con ello también se ha señalado cómo los vínculos familiares favorecieron el acceso femenino a los ámbitos científicos, siendo que muchas de las primeras mujeres que se inician en la ciencia eran hermanas, hijas, esposas o amigas de hombres que ya se encontraban dentro del campo (Rossiter, 1997: 171). Asimismo, se pueden considerar diferentes experiencias matrimoniales vinculadas con la ciencia: algunas 
donde los hombres eran científicos y las mujeres acompañaban sus prácticas (o viceversa) y otras donde ambos se dedicaban a la ciencia. En el primer caso, las esposas se ocuparon de un conjunto de actividades que muchas veces quedaron en la "sombra", realizando tareas de "colaboración" como tipeo, corrección de trabajos, fichaje de textos, etiquetado, pasar en limpio las notas, traducciones, atención de la correspondencia y asistencia en el trabajo de campo, entre otras tareas (Rossiter, 1982, 1995; Corrêa, 1995; Handler, 2004; Kohlstedt, 2012). Sin embargo, como señaló Corrêa $(1995,1997)$, no todas las experiencias de esposas encajan en la idea de asistente o "facilitadoras": aunque algunas de ellas se desempeñaron en ese tipo de papeles ${ }^{212}$, hubo otras que trabajaron a la par de sus maridos o incluso estuvieron a cargo de sus propias investigaciones ${ }^{213}$.

En este capítulo se trabaja sobre aquellos matrimonios en los cuales ambos miembros se dedicaban a la ciencia, tomando como caso de estudio el matrimonio conformado por María Delia Millán (1902-1994) y Enrique Palavecino (1900-1966), enfocando especialmente en la organización cotidiana del trabajo científico y en aquellos aspectos vinculados a la investigación etnográfica. A diferencia de muchos casos relatados en la literatura sobre matrimonios científicos, las actividades desarrolladas por estos cónyuges muestran que sus prácticas no estaban organizadas en base a una división sexual de tareas. Aunque se observan diferencias temáticas entre Millán y Palavecino, sus actividades las realizaron de una forma coparticipativa y compartida. Cada uno llevó a cabo sus propias investigaciones, publicando de forma individual una gran cantidad de trabajos, participando en numerosos eventos y actividades y ofreciendo conferencias y cursos.

\footnotetext{
${ }^{212}$ Un ejemplo de ello es Helen Pierson, quien piensa su estadía en Brasil entre 1947-1948 como una "Girl Friday", término que remite a una ayudante, empleada o asistente a la que se le encomiendan una amplia variedad de tareas. Pierson se ocupaba así de dactilografiar la correspondencia de su marido, dar clases de inglés a los alumnos de la Escola do Sociologia e Politica, buscar libros y artículos en la Biblioteca Municipal de San Pablo, hacer levantamientos para las investigaciones de campo y preparar cuestionarios, con sugerencias a los estudiantes para esas investigaciones (Correa, 1995).

${ }^{213}$ En este sentido, los trabajos arqueológicos realizados por Betty Meggers (1921-2012) en la Amazonia junto a su marido Clifford Evans, muestran un ejemplo de un matrimonio que realiza trabajo de campo en equipo, donde Meggers escribe su propio diario y firma sus trabajos sin usar el apellido de casada, algo poco usual en la época (Sombrio, 2014).
} 
Teniendo en cuenta que ambos han tenido una larga trayectoria académica, en este capítulo se enfoca en las primeras décadas de sus actividades y carreras científicas, comprendidas aproximadamente entre los años 1925 y 1950.

\section{El matrimonio Millán-Palavecino}

Delia Millán -“Titú"- como le decían en el ámbito familiar, era la segunda de diez hijas de María Adelina Méndez Funes (1878-1970) y José R. Millán (1869-1962). Había nacido en Mar del Plata en el seno de una familia dedicada a la docencia, al estudio y a las artes; luego se mudó a Temperley junto a sus padres y la mayoría de sus hermanas, donde permaneció hasta su muerte. Su madre fue directora de la Escuela Normal n ${ }^{\circ} 1$ de Mar del Plata y su padre fue docente, inspector de escuela e historiador. Según algunos relatos, Delia Millán había aprendido el arte del tejido en el seno de su familia, con su madre y sus hermanas ${ }^{214}$. Tanto ella como su madre estaban vinculadas con la Liga Patriótica Argentina y ambas participaron de la fundación de la Escuela Industrial de Artes y Oficios de Mar del Plata. Entre las actividades llevadas a cabo por las señoras de la Liga, entre mediados de 1920 y la década de 1930 se desarrollaron eventos de exposición y venta anual de textiles tejidos y bordados en talleres domésticos para mujeres indígenas y criollas (Mc Gee Deutsch, 2003; 2005; Pegoraro, 2017). De forma paralela, los museos y las instituciones educativas promovieron la creación de talleres y escuelas en diferentes regiones del país, dedicados al trabajo con textiles que copiaban los diseños de tejidos y cerámicas prehispánicas (García, 2011). También se instalaron telares en establecimientos educativos y esta actividad se difundió como novedad en revistas de la época (Pegoraro, 2017).

\footnotetext{
${ }^{214}$ Conversación personal con Eloisa Benitez Millán 28/09/2017. “Mi abuela María Adelina (Balala) tenía un enorme telar en la galería y tejía tapices que luego regalaba en las fiestas navideñas. Yo, la recuerdo en la rueca, con las lanas."
} 


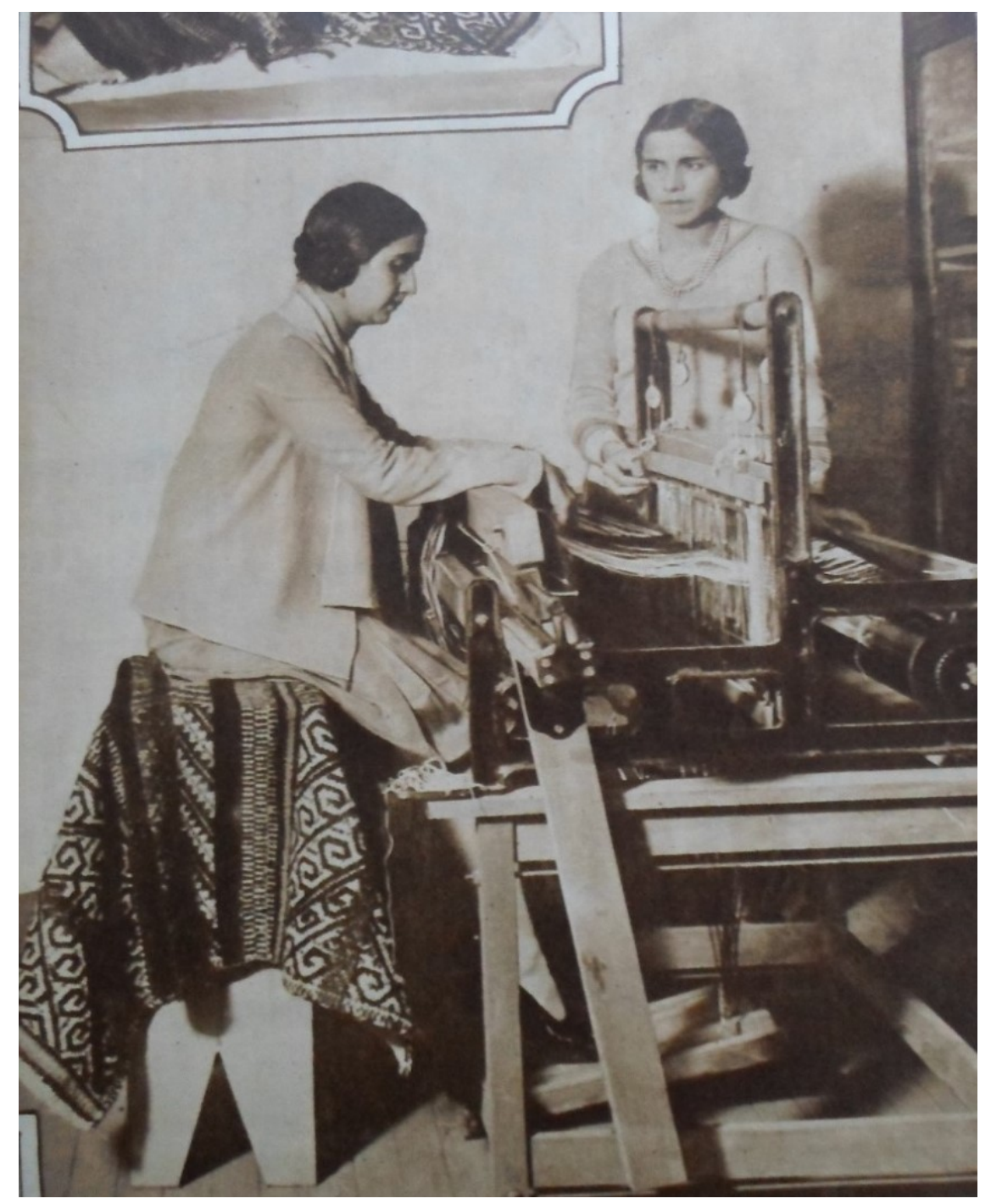

María Delia Millán en el telar y Florencia Brachman en el MACN, La Prensa, 22 de junio de 1930

Millán se especializó en cuestiones vinculadas al folklore y a las artesanías populares. El tema central de su amplia obra fue el arte textil entre los aborígenes prehispánicos, durante la colonia y en los grupos rurales "indígenas" y "criollos" contemporáneos. Sus primeros trabajos se orientaron al análisis de colecciones presentes en diferentes museos, una práctica que era común en esos años como se ha visto en capítulos anteriores. Luego irá incorporando materiales de sus viajes, en general realizados junto a Palavecino. Dentro de esta temática, se ocupó de diferentes cuestiones: las áreas de dispersión del "tejido aborigen” en la Argentina, los tejidos y tintes criollos, la alfarería, los 
adornos personales, la cestería, las fibras textiles y tintóreas utilizadas en los tejidos, la medicina popular, la gastronomía aborigen y la particular de algunas zonas, la vida familiar, las técnicas y motivos decorativos de los tejidos, entre otros.

Al dedicarse a los tejidos, telares, vestimentas, entre otros temas, Millán trabajó muchas veces con mujeres indígenas, observando sus actividades y entrevistándolas. No hay, sin embargo, registros que indiquen una intención explícita de dedicarse al "punto de vista" femenino. Es frecuente en sus trabajos encontrar referencias a la vida cotidiana de las mujeres en relación a la fabricación o al uso de objetos que estudió:

"Las mujeres indígenas entre las cuales documenté el tejido de las fajas -grupo Pilagá, Toba-Pilagá, Mataco, Vilela, Tapiete y Chunupí- eran de comunidades que pertenecían o estaban vinculadas a misiones religiosas y contaban, por lo tanto, con un mayor bagage cultural" (Millán, 1981: 38)

Al estudiar la fabricación textil, tarea que ha sido destinada en diferentes culturas a las mujeres, muchas veces se encontró con actividades que remitían a una división del trabajo por géneros dentro de las comunidades estudiadas. Esto no es aplicable a todas las culturas observadas, ya que también trabajó con hombres tejedores. Si bien no es posible considerar la obra de Millán como un conjunto de investigaciones "habituales" para las mujeres dedicadas a la etnografía, es posible que su interés por los tejidos provenga de su educación previa y de las actividades familiares. Así, los sentidos asociados a lo femenino en su formación personal pueden haber otorgado cierto sesgo de género a la elección de su tema. Millán sin dudas aprovechó su "condición" femenina, como lo hizo Wanda Hanke, para establecer relaciones con otras mujeres, ganar su confianza y obtener información y objetos a los que quizás los investigadores masculinos no tenían acceso. 


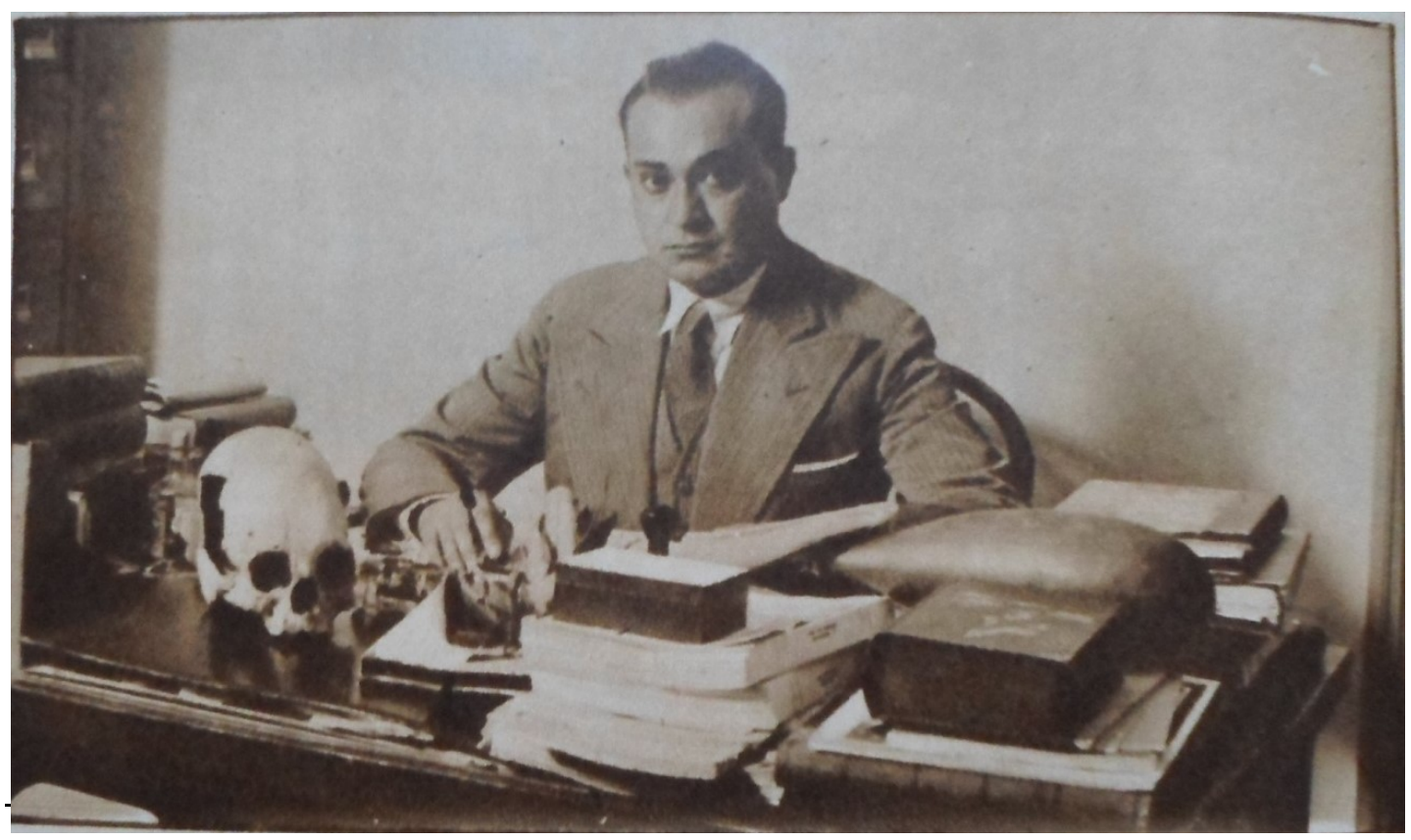

Enrique Palavecino en el MACN, La Prensa, 22 de junio de 1930

Enrique Palavecino, nació en Buenos Aires el 15 de julio de 1970. Fue un antropólogo "autodidacta", cursó en el Colegio Nacional Mariano Moreno de Buenos Aires, pero no concluyó sus estudios. Desde joven se acercó al Museo Nacional de Historia Natural, donde comenzó realizando trabajos anatómico-antropológicos para luego orientarse hacia temas lingüísticos, etnográficos y folklóricos (Morínigo, 1968; Soprano, 2006). Se dedicó a problemas diversos, con el propósito de sistematizar las culturas indígenas a nivel regional y nacional, utilizando el método comparativo e influenciado por el difusionismo cultural (Palavecino 1948; Morínigo, 1968). Desde 1925, desempeñó “funciones de adscripto" en la sección de Arqueología y Etnografía del Museo Nacional de Historia Natural (Doello Jurado, 1929), donde luego ascendería en la jerarquía de empleos de esa institución. La "adscripción” al museo, era una forma de permiso otorgada por la dirección de la institución y una modalidad de vinculación ad-honorem habitual, como se vió en capítulos anteriores, que-permitía a las personas acceder a las colecciones para su estudio y a la biblioteca de la institución (García, 2018). Esto constituyó el primer paso de la trayectoria profesional de varios naturalistas y antropólogos, pero mientras los hombres 
pudieron ascender en las jerarquías institucionales, las mujeres, hasta por lo menos avanzada la década de 1930, permanecieron en los escalafones más bajos (García, 2006).

Tanto Palavecino como Millán comenzaron su carrera científica frecuentando a muchos naturalistas, estudiantes y graduados que pasaban por las secciones de dicho museo. En general provenientes de la Facultad de Ciencias Exactas, Físicas y Naturales y del Instituto Nacional del Profesorado, los estudiantes colaboraron revisando y clasificando algunas colecciones (García, 2018). En 1928 Palavecino fue designado como ayudante técnico y en 1930 como encargado de la sección ${ }^{215}$. Ese mismo año ingresa Delia Millán como adscripta a la sección de Arqueología. En sus comienzos, los pasos en la carrera de cada uno parecen similares. Al poco tiempo, Palavecino logró acceder a un cargo rentado como empleado del Museo, mientras que Delia por un breve tiempo se mantuvo en puestos honoríficos o supliendo los cargos del marido, situación que cambió progresivamente. Esto fue una situación común para las mujeres que se vincularon con los museos científicos en la primera parte del siglo XX (cf. García, 2004, 2006) ${ }^{216}$.

A lo largo de los años tanto Millán como Palavecino formaron parte de diversas instituciones, en las cuales ocuparon diferentes cargos y espacios de trabajo. Por lo general, se movían en conjunto a las ciudades y cada uno se acomodaba en diferentes instituciones. Además del ya mencionado Museo, Palavecino ganó un concurso como profesor suplente de Antropología en el Museo de La Plata en 1934 y luego, en 1947, fue designado como

\footnotetext{
${ }^{215}$ En 1930, Palavecino se refería a la sección de etnología del Museo Argentino de Ciencias Naturales como un espacio donde se realizaban trabajos "de gabinete", que consistían en la catalogación, clasificación, restauración, conservación, descripción de las piezas nuevas e interesantes, entre otras actividades. También desde la sección se realizaban, "dentro de sus posibilidades", excursiones de estudios etnográficos a los territorios nacionales. Las colecciones se acrecentaban con los objetos traídos de esos viajes, y gracias a la donación de particulares, como sucedía en otros museos. En ese momento, las secciones de etnología y de arqueología del museo contaba con varios colaboradores y adscriptos, dedicados a investigaciones especiales. Entre ellos, Carlos Vega, quien trabajaba sobre música indígena americana; Enrique Gandía, estudioso de la etnología histórica; y María Delia Millán, quien se ocupaba de los tejidos indígenas. "Museo Nacional de Historia Natural, parte IV, Sección Etnología” en La Prensa, 22/06/1930.

${ }^{216}$ Con algunas excepciones, como es el caso de Ana Biró mencionado en el capítulo 3.
} 
profesor adjunto de dicha materia ${ }^{217}$. También fue profesor de prehistoria y arqueología y de etnografía y folklore en el Departamento de Filosofía y Letras de la Universidad Nacional de Tucumán entre 1937 y parte de 1938, siendo al mismo tiempo Director del Instituto de Antropología de la misma universidad. Por su parte, Millán, asumió de forma interina el puesto, ocupado antes por su esposo, de jefe de la sección etnografía en el Museo Argentino de Ciencias Naturales entre 1937 y 1939, cuando Palavecino volvió a ocuparlo hasta 1943, quedando su esposa como ayudante de la sección. En 1943 Palavecino fue nombrado nuevamente Director del Instituto de Antropología en Tucumán, en el cual permaneció durante 3 años, dictando clases de prehistoria y etnología. Paralelamente, en 1942 Millán fue adscripta en el Instituto de historia, lingüística y folklore en la Universidad de Tucumán y entre 1939 y 1943 se vinculó al Museo de Folklore de la Provincia de Tucumán, el cual le patrocina un viaje a la región de Río Hondo en Santiago del Estero. Es difícil saber cómo pudieron desempeñar cargos paralelos en instituciones de ciudades distantes como Tucumán y Buenos Aires. Entre 1940 y 1948, Palavecino también tuvo un puesto como profesor adjunto de antropología y etnografía general en la Facultad de Filosofía y Letras de Buenos Aires. En 1948 fue designado como profesor interino de prehistoria y etnografía en el Museo de La Plata, donde permaneció hasta 1950. Su esposa obtiene, en 1948, un puesto interino como conservadora del Museo Municipal de Bellas Artes de Buenos Aires y en 1949 como encargada de colecciones del Museo de Motivos Populares Argentinos José Hernández ${ }^{218}$. También se vincula en estos años con la Sociedad de Amigos del Arte Popular, estando a cargo de la sección dedicada al "vestido, adorno,

\footnotetext{
${ }^{217}$ En la designación se reconoce que Palavecino llevaba "más de doce años en el ejercicio del cargo" $\left(19 / 12 / 1947, \mathrm{C}^{\circ} 53\right.$, AHMLP)

${ }^{218}$ En 1938 la Municipalidad de Buenos Aires recibe la donación de la casa de Félix Bunge, quien dispuso en su testamento que debería estar destinada a la creación de un museo de motivos argentinos. La administración de la casa queda en manos de una entidad privada, la Asociación Folklórica Argentina (creada en 1937). Santo S. Faré, presidente de la asociación, asume como primer director del museo. En 1944 se traslada a la casona la sede del Museo Municipal de Bellas Artes, Artes Aplicadas y Anexo de Artes Comparadas y su director Carlos Abregú Virreira, queda a cargo de la administración de la casa y luego responsable del Museo de Motivos Argentinos y Biblioteca del Folklore Argentino "José Hernández". (Quaranta, 1998; Legislatura de la Ciudad Autónoma de Buenos Aires, s/f).
} 
tejido y canasteria", y al Departamento de Folklore del Instituto de Cooperación Universitaria de los cursos de cultura católica. El acceso a cargos más altos para Millán será a partir de fines de la década de 1950. En 1952 fue profesora en un seminario de la Escuela Nacional de Danzas Folklóricas ${ }^{219}$ dedicado al vestido y al adorno en la República Argentina. En 1957 pasa a dirigir el Museo Folklórico del Noroeste "Manuel Belgrano" y el Instituto de Estudios Folklóricos de Tucumán. Luego en 1968 fue Directora del Museo de Motivos Populares José Hernández. Como se puede observar, cada uno tenía sus cargos en instituciones o dependencias diferentes, compartiendo la residencia en la misma ciudad. Cada uno fue construyendo su propia trayectoria y relacionándose con espacios donde desarrollar y ampliar sus temas de interés. Palavecino y Millán trabajaron en conjunto durante 36 años, hasta el fallecimiento de Palavecino en 1966. Millán, por su parte, seguirá dedicándose a la investigación durante treinta años más.

\section{Viajes y trabajo "de campo"}

La colaboración científica entre María Delia Millán y Enrique Palavecino se prolongó durante 36 años, a través de un conjunto de espacios de formación y enseñanza científica, con una serie de temas de interés, numerosas expediciones y viajes de estudios y la formación de abundantes colecciones etnográficas y arqueológicas que acrecentaron los acervos de distintas instituciones en el país: el Museo Argentino de Ciencias Naturales "Bernardino Rivadavia", el Museo Etnográfico de Buenos Aires, el Instituto de Antropología, Lingüística y Folklore de Tucumán, el Museo de la Plata, el Museo de Folklore de Tucumán y el Museo de Motivos Populares Argentinos de Buenos Aires.

\footnotetext{
219 La Escuela Nacional de Danzas Folklóricas Argentinas fue creada en 1948 y estaba destinada a la formación de un "cuerpo de técnicos capacitados para la docencia de esta materia, a fin de unificar la enseñanza, resguardar la autenticidad y pureza de nuestras expresiones folklóricas y contribuir a que conserven su estilo y características, dentro del más riguroso concepto estético como manifestación del sentir artístico y espiritual". (Blache y Dupey, 2007: 302)
} 


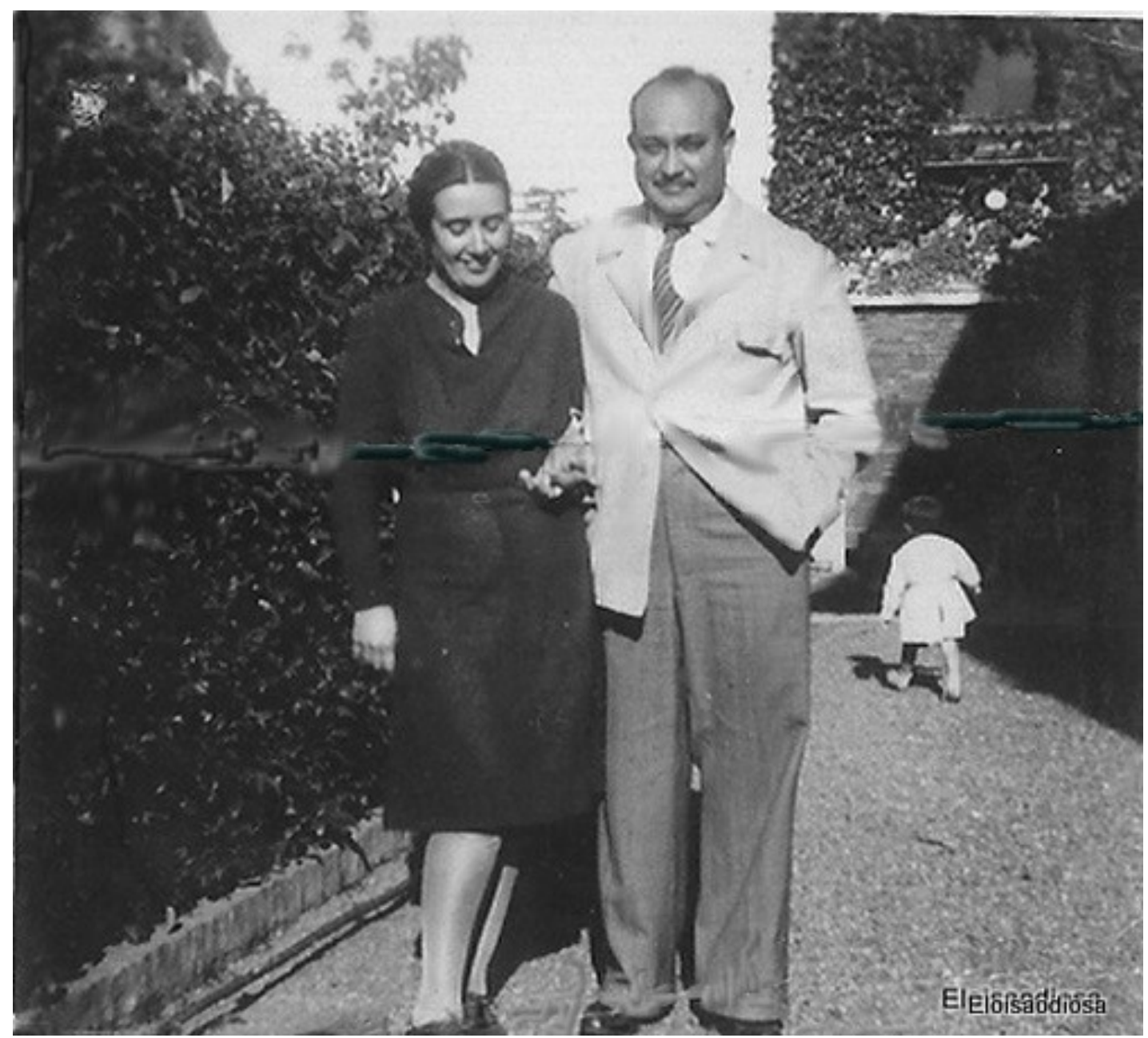

Delia Millán y Enrique en su casa en Temperley s/f. Gentileza de Eloisa Benitez Millán

Los viajes realizados por Palavecino y Millán fueron patrocinados por diferentes instituciones, principalmente por el Museo Nacional de Historia Natural "Bernardino Rivadavia ${ }^{220}$, la Universidad Nacional de Tucumán y el Museo de La Plata, entre otros. Los documentos guardados actualmente en el Archivo Fotográfico y Documental del

${ }^{220}$ A partir de 1933, el museo cambia su nombre a la denominación actual Museo Argentino de Ciencias Naturales "Bernardino Rivadavia". 
Museo Etnográfico de Buenos Aires ${ }^{221}$ permiten reconstruir en parte los viajes de investigación realizados por ambos, tanto en conjunto como por separado. Como parte de esta documentación se encuentran los cuadernos de campo, los cuales están organizados cronológicamente, con un índice al comienzo que indica la fecha y el lugar a donde viajaron. Estos cuadernos contienen anotaciones sobre lenguas indígenas, aspectos de la vida cotidiana, alimentos, formas constructivas, creencias, utensilios, técnicas, remedios, entre otros. También tienen dibujos que describen la decoración de cerámicas y otros objetos, formas constructivas y la organización de los espacios estudiados, como los patrones de asentamiento. Las anotaciones en cada cuaderno están separadas por hojas en blanco, aunque sin indicar si poseen un orden cronológico o temático, tampoco hay fechas o indicaciones respecto al momento en que se tomaron dichas notas. Muchos de estos cuadernos no poseen fecha, mientras que otros tienen algunas referencias en la portada, por ejemplo: “Cuaderno de campo 1940-41. Titú ${ }^{22}$ y Enrique Palavecino. Viaje del Museo de Ciencias Naturales de La Plata. Chanes, Chiriguanos. Río caraparí, Iquira. Capiazuti, Aguaray”, o “Cuaderno Embarcación 1945: Titú y Enrique Palavecino. 11 al 26 de agosto, 1945. Primer viaje de Titu particularmente. Embarcación. Tobas, Toba Pilagá, Matacos”²23. En las anotaciones contenidas en los cuadernos de viaje, no abundan las referencias acerca de cómo dividían y organizaban las tareas "en el campo" y esto es difícil de deducir de estos registros.

En base a la información relevada en estos cuadernos, elaboraron un conjunto de "libretas" en las cuales recopilaron mitos de las distintas culturas visitadas, los cuales estaban mecanografiados y organizados por región. Al respecto, dice Millán (1970: 177178):

\footnotetext{
${ }^{221}$ Fondos Palavecino y Millán de Palavecino, AFDME.

222 Titú es el apodo de Delia Millán, en las cartas, cuadernos y otros documentos personales aparece recurrentemente.

${ }^{223}$ Fondos Palavecino y Millán de Palavecino, AFDME
} 
“En las dos gruesas libretas correspondientes al viaje al Chaco Central están reunidas las observaciones etnográficas, ilustradas muchas de ellas con bocetos, y los diversos mitos tomados en la versión exacta del relator, a veces repetidas por un intérprete, nutridas con voces del idioma aborigen, especialmente cuando se refieren a elementos naturales, de la vegetación o la fauna”.

Estas libretas contienen "notas de la vida material" y "relatos de los mitos de los dos grandes grupos habitantes del Chaco": los Mataco en el área occidental y los Toba en el oriente (Millán, 1970: 178). Aunque el estudio de los mitos y de las lenguas indígenas fue uno de los temas de Palavecino, en los cuadernos y libretas se muestran registros y observaciones de ambos al respecto. Se puede deducir que tanto Millán como Palavecino tomaron notas, dado que se diferencian claramente dos tipografías. Las anotaciones realizadas durante los viajes de campo muestran un alto grado de trabajo coparticipativo. Como han señalado Spoliansky, Roca y Scarafoni (2011), al analizar los cuadernos y otros documentos de Millán y Palavecino resulta difícil distinguir el trabajo de ambos como actividades separadas.

Aunque las anotaciones eran una tarea compartida, cada uno en el campo se dedicó a sus propios temas de investigación. Por ejemplo, en el Boletín Bibliográfico de Antropología Americana se señala que en 1941

"Enrique Palavecino realizó varias excursiones al Chaco salteño, cuyos principales resultados consisten en el estudio completo de las plantas silvestres cuyos frutos, hojas y raíces aprovechan los indígenas en su alimentación. Dentro del orden de las manufacturas, dedicó su atención a la técnica de la alfarería, mientras la Sra. María Delia Millán de Palavecino, se interesó por la preparación de las fibras vegetales y textiles, así como su subsiguiente hilado, teñido y tejido. El Prof. Palavecino recogió asimismo distintas observaciones sobre la organización social y la religión de los indios del Chaco." (Paulotti, 1943-1944).

Así, cuando estaban realizando trabajo de campo las anotaciones se hacían en conjunto, sin una distinción más que la tipografía. Los datos obtenidos eran luego 
aprovechados en función de los temas de cada uno. Años más tarde, en una carta a su marido $^{224}$, Millán recordará el trabajo de campo conjunto:

"he podido tomar bastantes notas de redes, hamacas, chinchorros, habitación y algunas artesanías muy interesantes. ¡Pero cómo me faltabas tu! estamos tan acostumbrados a cambiar ideas y hacer paralelos cuando trabajamos!. Te mandaré las notas que he tomado. Espero habrás recibido las anteriores."225

Si bien las cartas son posteriores al período que se trabaja en este capítulo, estos fragmentos permiten aproximarse a las experiencias de trabajo de campo compartidas. La idea de "cambiar ideas" y "hacer paralelos" mientras trabajan juntos muestra que no sólo se dedicaban a tomar notas en una misma libreta, sino que también discutían y dialogaban sobre sus observaciones y sobre sus interpretaciones de las culturas.

Asimismo, el trabajo de este matrimonio se enmarca en una época en la cual el trabajo de campo etnográfico se consolida como la fuente legítima y privilegiada del estudio de las culturas “exóticas” (Guber, 1991, 2011; Stocking, 1996; Barth, Parkin, Silverman y Gingrich, 2012). En diferentes países, las prácticas de trabajo de campo se promueven y en muchas ocasiones se asocian al trabajo en equipo. Son innumerables los casos de matrimonios científicos que realizaron viajes en conjunto, recopilando información para investigaciones compartidas o individuales. En Francia, Marcel Mauss (1872-1950) en sus clases en la Sorbona y en el Instituto de Etnología proponía una forma

\footnotetext{
${ }^{224}$ Las cartas fueron enviadas en 1960, cuando Millán realizó una estadía de trabajo de tres meses en Caracas, Venezuela. Millán le escribe a Palavecino y le cuenta sobre las diferentes actividades que realiza, especialmente el dictado de clases y la investigación bibliográfica. Parte del trabajo que realizó en Caracas consistía en hacer salidas a lugares cercanos, acompañando a distintas personas. Allí trabajó junto a la etnomusicóloga Isabel Aretz (ver Anexo II) y a su marido músico y escritor Luis Felipe Ramón y Rivera. Ambos estaban vinculados al Instituto Nacional de Folklore de Venezuela en la década de 1960. Isabel Aretz realizó sus primeras investigaciones en la Argentina, formando parte del Instituto de Musicología del Museo Argentino de Ciencias Naturales "Bernardino Rivadavia" en la década de 1940. Seguramente allí conoció a Delia Millán y a Enrique Palavecino.

${ }^{225}$ Carta de Millán a Palavecino. Caracas, 25 de junio de 1960, AFDME. Fondos Palavecino-Millán. Carpeta "Correspondencia".
} 
de trabajo en equipo ${ }^{226}$ y complementaria entre hombres y mujeres. Cuando comenzó a dictar cursos en el Collége de France, en 1930, la asistencia a sus clases aumentó significativamente, con una presencia de mujeres que en ocasiones alcanzaba el 50\% (Grossi, 2006). Mauss promovía la formación de mujeres investigadoras que pudieran mirar el "mundo de las mujeres" para comprender la supuesta universalidad de lo masculino/femenino (Corrêa, 1997; Grossi, 2006). Algunas de las mujeres que estudiaron con Mauss, como Denise Paulme (1907-1998) ${ }^{227}$ y Germaine Tillion (1907-2008), fueron becadas con fondos del Royal Anthropological Institute de Londres especialmente direccionados a la investigación sobre mujeres en diferentes grupos africanos. En 1937 Paulme se casó con el etnomusicólogo y antropólogo francés André Schaffner (1895-1980), con quien continuó realizando trabajos de campo en África. En los viajes en conjunto, como sucedió con otros matrimonios de científicos, se repartían las tareas: Schaffner entrevistaba a los hombres y Paulme a las mujeres (Paulme, 1992; Grossi, 2006).

Por otra parte, hubo parejas donde ambos científicos compartían el trabajo de campo, pero las mujeres publicaban poco o nada al respecto, y no aparecía su autoría en el trabajo de sus maridos. Así sucedió con el francés Lévi-Strauss quien entre 1935 y 1936 realizó un viaje de campo de ocho meses ${ }^{228}$ junto a su esposa Dina Dreyfus (1909-1989). En las publicaciones que resultaron de este viaje, Dreyfus no fue mencionada, aunque había participado en la investigación etnográfica (Ashwell, 2011; Corrêa, 1995). Tampoco tuvo

\footnotetext{
226 "La ventaja de una misión compuesta por varios miembros aparece aquí de manera más clara. El recorte, siempre indispensable, podrá ser fácilmente operado por tres o cuatro colegas que trabajen sobre momentos diferentes de la vida tribal." (Mauss, 2006: 38 [1947])

${ }^{227}$ Denise Paulme dedicó la mayoría de sus investigaciones a ciertas regiones de África, fue asistente en el Museo de Historia Natural de París, entre 1938 y 1961 formó parte del Departamento del África Negra en el Museo del Hombre y fue nombrada directora de estudios en la École Pratique des Hautes Études en 1957, donde ayudó a crear el Centro de Estudios Africanos, siendo también una de las fundadoras de los Cahiers d'études africaines (Corrêa, 1997). Paulme también trabajó junto a Déborah Lifchtiz en su investigación con los dogon en Sanga, en 1935 (Paulme, 1992).

${ }^{228}$ Dicho viaje tenía como objetivo recolectar muestras de cultura material para el Musée de 1'Homme y realizar un estudio etnográfico completo de las tribus nómadas Nambikwara (Ashwell, 2011).
} 
las mismas oportunidades que Lévi-Strauss: al llegar ambos a Brasil, a diferencia de su marido Dreyfus no consiguió un puesto en la universidad, a pesar de que ambos tenían la misma formación $^{229}$ (Valentini, 2010). De forma similar, en la década de 1940 Alicia Dusan y Gerardo Reichel-Dolmatoff, ambos dedicados a la arqueología y a la etnografía en Colombia, realizaron trabajo de campo en conjunto, aunque la mayor parte de los resultados eran publicados por Reichel-Dolmatoff (Echeverri, 1998: 68).

Las tareas de campo compartidas también eran promovidas por Max Gluckman (1911-1974) entre sus estudiantes de la Escuela de Manchester, Inglaterra. El trabajo en equipo en el campo implicaba una división de tareas por género. Por ejemplo, como se dio en otros casos, en el matrimonio entre Víctor Turner (1920-1983) y Edith Turner (19212016) él entrevistaba a los hombres y ella a las mujeres; ocupándose también de tomar las fotografías y de relevar la mayoría de las genealogías ${ }^{230}$. Edith Turner tuvo, según Engelke (2004), un papel importante en la descripción del "punto de vista femenino" de las mujeres Ndembu, el cual resultaba "inaccesible" para los hombres.

Asimismo, se pueden mencionar en esta época a las investigaciones de "campo" realizadas en conjunto por los esposos Margaret Mead (1901-1978) y Gregory Bateson, quienes en las décadas de 1920 y 1930 desarrollaron trabajo de campo en Bali y Nueva Guinea (Grimshaw, 2008). Mead dedicó gran parte de sus investigaciones a las mujeres y las niñas y al estudio comparado de los $\operatorname{sexos}^{231}$ (Darnell, 2008).

Estos casos mencionados, así como muchas otras parejas que se dedicaron a la antropología, muestran la promoción de una forma de organización del trabajo de campo en

\footnotetext{
${ }^{229}$ En su estadía se dedicó a una serie de investigaciones sobre la "mancha mongólica" y a preparar la "Misión Lévi-Strauss". Luego, con la fundación de la Sociedad de Etnografía y Folclore en 1937, y gracias a los vínculos establecidos con el musicólogo y ensayista Mario de Andrade, Dina Dreyfus conseguirá una inserción institucional.

${ }^{230}$ Las cuales fueron fundamentales para la primera disertación y el primer libro de Victor Turner "Schism and Continuity" (1957).

${ }^{231}$ En 1928 publicó su famoso libro "Coming of Age in Samoa".
} 
equipo, utilizando la división de tareas en las parejas o matrimonios como una estrategia colaborativa, una forma de relevar mayor cantidad de información y también como un modo de acceder a distintos "puntos de vista" de las sociedades estudiadas. Por otro lado, algunos de esos casos revelan que la posición o el reconocimiento de las esposas no era equivalente al de sus maridos. Sin embargo, esto no se dio en el matrimonio MillánPalavecino. Si bien realizaban actividades en forma colaborativa, cada uno se dedicó a sus temas de interés y desarrolló sus carreras científicas de forma individual.

Los lugares en los cuales realizaron trabajo de campo se detallan a continuación en la tabla 1. La misma se ha elaborado a partir de un análisis comparativo de los currículums de Delia Millán y de Enrique Palavecino y permite observar los viajes realizados por ambos, en conjunto y por separado, así como las instituciones que patrocinaron los mismos.

Tabla 1: Viajes y trabajo de campo Millán y Palavecino 1927-1950

\begin{tabular}{|l|l|l|}
\hline Año & Enrique Palavecino & Delia Millán \\
\hline 1927 & $\begin{array}{l}\text { Chaco salteño. Patrocinado por el } \\
\text { MACN }\end{array}$ & \\
\hline 1928 & $\begin{array}{l}\text { Famatina, La Rioja. Patrocinado por el } \\
\text { MACN }\end{array}$ & \\
\hline 1929 & $\begin{array}{l}\text { Chaco central-norte. Patrocinado por el } \\
\text { MACN }\end{array}$ & \\
\hline 1930 & $\begin{array}{l}\text { Neuquén. Patrocinado por el MACN } \\
1933\end{array}$ & $\begin{array}{l}\text { Bolivia, Lago Titicaca. Patrocinado por } \\
\text { el MACN }\end{array}$ \\
\hline 1935 & $\begin{array}{l}\text { Chaco central-norte. Patrocinado por el } \\
\text { MACN }\end{array}$ \\
\hline $1936-$ & $\begin{array}{l}\text { Chaco austral. Patrocinado por el } \\
\text { MACN }\end{array}$ & \\
\hline
\end{tabular}




\begin{tabular}{|c|c|c|}
\hline 1937 & $\begin{array}{l}\text { Viaje a Humahuaca y Carapary. } \\
\text { Patrocinado por la UNT }\end{array}$ & Córdoba y La Rioja. Patrocinado por el MACN \\
\hline & & $\begin{array}{l}\text { Tilcara, Quebrada de Humahuaca. Patrocinado } \\
\text { por el MACN }\end{array}$ \\
\hline \multirow[t]{4}{*}{1938} & $\begin{array}{l}\text { Viaje a Cruz del Eje, Córdoba, } \\
\text { Patrocinado por el MLP }\end{array}$ & Chaco salteño. Patrocinado por el MACN \\
\hline & $\begin{array}{l}\text { Segunda etapa del mismo viaje. } \\
\text { Patrocinado por el MACN }\end{array}$ & Tucumán. Patrocinado por el MACN \\
\hline & & Córdoba (NO). Patrocinado por el MACN \\
\hline & & Córdoba (NO). Patrocinado por el MACN \\
\hline 1939 & $\begin{array}{l}\text { Villa Dolores, Córdoba. Patrocinado } \\
\text { por el MACN }\end{array}$ & Córdoba. Patrocinado por el MACN \\
\hline \multirow[t]{2}{*}{1940} & $\begin{array}{l}\text { Beltrán, Santiago del Estero. Comisión } \\
\text { para la medición de un arco meridiano }\end{array}$ & Chaco boliviano. Patrocinado por el MACN \\
\hline & $\begin{array}{l}\text { Indios chané del Itiyuro. Comisión para } \\
\text { la medición de un arco meridiano }\end{array}$ & \\
\hline 1941 & $\begin{array}{l}\text { Chané de Tuyunti. Patrocinado por el } \\
\text { MACN }\end{array}$ & \\
\hline \multirow[t]{3}{*}{$\begin{array}{l}1941- \\
42\end{array}$} & $\begin{array}{l}\text { Borde occidental del chaco. } \\
\text { Patrocinado por el MACN }\end{array}$ & Chaco salteño. Patrocinado por el MACN \\
\hline & & Tucumán. Patrocinado por el MACN \\
\hline & & Región Chaco salteño. Patrocinado por el MACN \\
\hline 1943 & & Región Chaco salteño. Patrocinado por el MACN \\
\hline & & Añayuta, Santiago del Estero. Patrocinado por el \\
\hline
\end{tabular}




\begin{tabular}{|c|c|c|}
\hline & & MACN \\
\hline & & $\begin{array}{l}\text { Río Hondo, Santiago del Estero. Patrocinado por } \\
\text { el Museo de Folklore de la Provincia de } \\
\text { Tucumán }\end{array}$ \\
\hline 1944 & $\begin{array}{l}\text { Catamarca. Patrocinado por el Instituto } \\
\text { de Antropología de la Universidad } \\
\text { Nacional de Tucumán }\end{array}$ & \\
\hline 1945 & $\begin{array}{l}\text { Tinti Salta. Patrocinado por el Instituto } \\
\text { de Antropología de la Universidad } \\
\text { Nacional de Tucumán }\end{array}$ & \\
\hline 1947 & & Mar del Plata. Viaje particular. \\
\hline 1948 & $\begin{array}{l}\text { Goya, Corrientes. Patrocinado por el } \\
\text { MLP }\end{array}$ & $\begin{array}{l}\text { General Belgrano, Provincia de Buenos Aires. } \\
\text { Viaje particular. }\end{array}$ \\
\hline \multirow[t]{3}{*}{1949} & $\begin{array}{l}\text { Salta y Formosa. Patrocinado por el } \\
\text { MLP }\end{array}$ & $\begin{array}{l}\text { Córdoba. Patrocinado por el Museo de Motivos } \\
\text { Populares “José Hernández". }\end{array}$ \\
\hline & Tres Arroyos. Patrocinado por el MLP & $\begin{array}{l}\text { Chaco salteño. Patrocinado por el Museo de } \\
\text { Motivos Populares “José Hernández”. }\end{array}$ \\
\hline & & $\begin{array}{l}\text { Córdoba, zona cuyana. Patrocinado por el Museo } \\
\text { de Motivos Populares “José Hernández". }\end{array}$ \\
\hline 1950 & & Región Tres Arroyos, Provincia de Buenos Aires. \\
\hline
\end{tabular}

Como se observa en la tabla, la institución que más patrocinó viajes de ambos es el Museo Argentino de Ciencias Naturales y la región más visitada es el noroeste del país, especialmente la región chaqueña. Los meses más habituales de viaje eran agosto, octubre, noviembre y diciembre. Como era frecuente en la época, las fechas de trabajo "de campo" 
debían acomodarse a las tareas docentes y a otras actividades institucionales, siendo los meses de vacaciones los más apropiados para viajar. También en esta tabla se puede ver cómo los viajes que coinciden geográficamente se concentran en los primeros años. A medida que pasa el tiempo, cada uno fue avanzando con sus temas y viajando a distintas regiones y localidades.

Considerando en conjunto los diferentes documentos analizados: cartas, informes, registros de viajes y cuadernos de notas; el trabajo que realizaban Millán y Palavecino no parece estar organizado en función de divisiones por género, sino por sus propios temas de investigación. Los temas e intereses los fueron llevando a cada uno a desarrollar su propia carrera, en diferentes instituciones. Como parte de esta “especialización” que cada uno fue construyendo, a medida que avanzaron los años también realizaron más viajes por separado. Los documentos permiten aproximarse a lo que era el trabajo en equipo en este matrimonio: la toma de decisiones, el diálogo, la forma de concebir las culturas con las cuales trabajaban, las prácticas habituales compartidas por ambos. Las actividades desarrolladas en sus viajes compartidos se basaron en la cooperación y en el diálogo e intercambio de ideas mutuo.

\section{$\underline{\text { Los estudios realizados en la región chaqueña }}$}

La región más visitada por el matrimonio Millán-Palavecino fue el chaco salteño, donde fueron conformando una red de contactos personales, con los sacerdotes y maestros en las misiones y con diferentes nativos informantes y referentes de las comunidades. Las primeras investigaciones en esta región fueron realizadas por Palavecino en 1928 y continuaron durante casi cuarenta años.

Al parecer, la relación con los habitantes de esta región cambió drásticamente en 1935 cuando Palavecino, siendo jefe de la sección de etnografía del Museo Argentino de Ciencias Naturales, fue comisionado para acompañar a un grupo de indios Mataco, los cuales habían llegado a Buenos Aires con su lenguaraz para una exhibición en 1935. Ese 
Museo y la Comisión de Protección del Aborigen, gestionaron el regreso de los indígenas a su lugar de residencia, solicitando a Palavecino que los acompañara. Millán (1970) considera este viaje como un momento de apertura en las investigaciones en la región chaqueña:

"Ya llegados a su destino, los indígenas invitaron al delegado que los acompañó en su regreso a presenciar la ceremonia de magia que celebrarían "para devolver su alma a los indígenas que viajaron, pues ésta había quedado en la imagen fotográfica que había aparecido en diarios y revistas de Buenos Aires”. La ceremonia celebrada por 30 brujos que describió entonces el Profesor Palavecino, fue el dique que libró la reserva natural del indígena, iniciando un vínculo amistoso que duraría por décadas entre el estudioso y los relatores, dueños de su pasado tradicional." (Millán de Palavecino, 1970: 177)

Así, a partir de 1935 este "dique" abierto permitió ampliar las investigaciones del matrimonio en la región chaqueña, en la cual conformaron una red de vínculos entre indígenas, mestizos y misioneros. Una de las relaciones que establecieron fue con la misión chaqueña "El Algarrobal” en Embarcación, provincia de Salta ${ }^{232}$, donde también estuvieron otros investigadores y viajeros, como Wanda Hanke, Alfred Métraux y Jules Henry, entre otros.

La red de contactos generada por el matrimonio Millán-Palavecino les permitió profundizar en ciertas investigaciones que requerían de la confianza de los indígenas, especialmente de aquellos que eran "informantes". Los mismos constituían un papel central en el relevamiento de ciertas cuestiones difíciles de conocer, como la mitología antigua de

\footnotetext{
${ }^{232}$ Hacia fines de 1934, el Chaco Argentino contaba con cuatro misiones: Misión Algarrobal o Chaqueña, cuyos misioneros eran el Rey. B.A. Tompkins, Mr. H.C. Grubb, Alfred y Dorothy Tompkins, J. Arnott, la señorita Royce y Phillips y Treby -nativos evangelistas; Misión Selva San Andrés, con C.M. Smith, W.H. White y Juan Julian Rumalda -también nativo evangelista; Misión El Toba, con W.A. Leake, su hermana Olivia Leahe y W.J. Price; y, finalmente Mision San Patricio, con B.L.Treanor y A. Cox. (Torres Fernández, 2006). Sería interesante indagar en futuras investigaciones el papel que desempeñaron las mujeres en estas misiones.
} 
los grupos estudiados y de grupos aledaños: "decía el Profesor Palavecino refiriéndose a la recolección de los mitos que solamente la convivencia, y trato diario son los que permiten la mejor conceptuación del pensamiento aborigen, hasta tanto se rompe la barrera casi infranqueable de su confianza (Millán, 1970: 179).

Palavecino (1948: 463) al hablar del área chaqueña señaló: "fue y es todavía en gran parte morada de un conglomerado de tribus que muy tardíamente entraron en contacto con masas considerables de blancos. Esta circunstancia ha sido un factor de conservación de la cultura original". Como se muestra en el capítulo 4, en la década de 1930 seguían vigentes aquellas ideas que promovían la búsqueda de "mundos auténticos" en los cuales los etnógrafos podían hallar los fenómenos en su estado "original". Esta perspectiva estuvo presente en los trabajos de Millán y de Palavecino, siendo que ambos adoptaron formas de análisis similares en sus investigaciones respecto de las culturas, su clasificación y sus características, y su representación geográfica y estudio a través de mapas, como se verá en el siguiente apartado.

En un trabajo publicado en coautoría -quizás el único-, este matrimonio señala que en los viajes comprendidos entre 1938 y 1949 a esta región, su tarea "más importante" fue la de "completar un cuadro definitivo de la cultura de los Matacos y Tobas" y que el estudio de otras culturas fue emprendido de modo marginal (Palavecino y Millán, 1956). La región fue estudiada por ambos y en sus publicaciones y conferencias se puede deducir o leer explícitamente en algunos casos el trabajo realizado en conjunto durante las investigaciones de campo. Asimismo, a pesar de los intereses particulares de Millán y de Palavecino muchos de sus trabajos poseen cuestiones comunes, tanto por los grupos y regiones estudiados, como por la adopción de bibliografía y esquemas teóricos similares, como se verá en el siguiente apartado. Una vez más, aparece aquí el diálogo y la coparticipación. 


\section{Escritura y temas de investigación}

Tanto Millán como Palavecino escribieron una gran cantidad de trabajos sobre diferentes culturas y problemas vinculados en su mayoría con la región del chaco salteño, aunque también sobre otras regiones del país y de países vecinos como Bolivia, abarcando un conjunto variado de culturas y tradiciones indígenas, mestizas y criollas. Ambos trabajaron con un enfoque teórico-metodológico muy próximo a lo que se ha llamado difusionismo cultural (Bohannan y Glazer, 1993; Barth, Parkin, Silverman y Gingrich; 2012) o culturología $a^{233}$, en estrecha relación con el enfoque que promovía Imbelloni en las décadas de 1930 y 1940, la "Nueva Etnología" (Perazzi, 2003; Guber, 2006; Carrizo, 2014). El "método etnológico" al cual adscribe Imbelloni y del cual uno de los representantes europeos era el alemán Fritz Graebner ${ }^{234}$, consistía en la consideración de los "hechos etnológicos" en su conjunto y en sus relaciones, y no como hechos aislados (Graebner, 1940; Kaplan y Manners, 1979; Bohannan y Glazer, 1993). La cultura en este marco de ideas era posible de ser estudiada a partir de sus bienes: "por esa razón el estudio de las culturas se convierte de una manera didáctica en el estudio de los patrimonios" (Imbelloni, 1953: 35).

Desde este marco, la particularidad de la etnología consistía en su habilidad para comparar los datos etnográficos y clasificarlos, estableciendo áreas y círculos culturales mediante el reconocimiento de relaciones entre "elementos" culturales "homólogos" y "análogos" (Bohannan y Glazer, 1993; Barth, Parkin, Silverman y Gingrich; 2012). Este

\footnotetext{
${ }^{233}$ Con este segundo término la define Imbelloni: "corriente del pensamiento etnológico que procede del método histórico de Graebner y de su peculiar concepción de las culturas. De un modo totalmente material, podríamos decir que el primer trabajo del culturólogo consiste en la construcción del mapa de los elementos culturales homólogos, y de los análogos que se presentan en la tierra." "En lugar de referirnos al método, preferimos el vocablo Culturología, que expresa con suficiente precisión el objeto del nuevo pensamiento metódico." (Imbelloni, 1953: 52 y 53)

234 "Metodología etnológica" de Graebner fue traducido para la colección Teoría de la Universidad Nacional de La Plata y publicado en el año 1940. Su versión original, Methode der Ethnologie había sido publicada en 1911.
} 
tipo de trabajos se vinculó con estudios de tipo cartográficos, con la producción de mapas de las áreas culturales y con una noción de cambio cultural que pretendía discutir con el evolucionismo al incorporar una mirada historicista de las culturas. Las producciones de Millán y de Palavecino están muy influenciadas por esta corriente teórica, aunque sus posturas y enfoques no se pueden encasillar únicamente en el difusionismo y además fueron variando con el paso del tiempo y la emergencia de otras problemáticas y perspectivas de análisis. En la década de 1950 orientaron sus trabajos hacia problemas de cambio y transformación cultural y hacia la delimitación de la "cultura folk" más cercanos a las investigaciones de Robert Redfield y Oscar Lewis (Morínigo, 1968; Soprano, 2006), ambos dedicados a etnografías sobre comunidades mestizas o migrantes en contextos de cambios sociales y nuevas vinculaciones entre los espacios urbanos y rurales ${ }^{235}$.

La recopilación de datos de diferentes culturas para su comparación y síntesis en esquemas y mapas culturales está plasmada en dos obras muy relevantes en las trayectorias de Millán y Palavecino: Áreas y capas culturales en el territorio argentino (Palavecino, 1948) y Arte del tejido en la Argentina (Millán de Palavecino, 1981).

El libro Arte del tejido en la Argentina, consiste en una compilación de 48 años de labor y contiene una organización de los datos en relación a determinadas áreas geográficas, productivas y culturales. Las formas de clasificación de los grupos por áreas geográficas y características socioculturales son similares y en la mayoría de los casos las mismas que utilizaba Palavecino y que se utilizaban ampliamente en las décadas de $1930 \mathrm{y}$ 1940. El libro analiza en particular la mezcla de dos "capas culturales" que han contribuido al desarrollo de la cultura en el territorio argentino: una aborigen prehispánica que se manifiesta a través de "rasgos supervivientes" y otra correspondiente al período hispano (Millán, 1981: 9). Asimismo, este trabajo se nutre de documentos del trabajo de campo y

\footnotetext{
${ }^{235}$ Con el paso del tiempo Palavecino comenzó a preocuparse por la teoría del cambio cultural, el problema de la "aculturación" y el rol de la antropología en la construcción de políticas que permitieran la integración de los pueblos indígenas chaquenses al estado, problemáticas que se ven reflejadas en publicaciones como "Algunas notas sobre la transculturación del indio chaqueño" (1958-59), "Teoría del cambio cultural" (1962) e "Introducción al problema indígena chaqueño" (1965) (Califano et ál. 1985; Perazzi 2003).
} 
documentos de archivo relevados por Millán a lo largo de los años, en los cuales considera el arte textil en sus "fases arqueológicas, etnográficas y comunitarias"236 (Millán, 1981: 12). Si bien el libro es posterior al período que se trabaja en esta tesis, reúne la información que aparece dispersa en diferentes trabajos de Millán desde sus primeras exposiciones y publicaciones a inicios de 1930. El esquema y la forma de análisis e interpretación de las culturas indígenas y criollas es similar en toda su obra, con cierta tendencia a incorporar el cambio cultural como un factor destacado a partir de la década de 1960. Esta consideración no es única de su trabajo, sino que fue una tendencia en la antropología y en la etnografía a nivel internacional.

Por su parte, Áreas y capas culturales es un trabajo que se convirtió en un "clásico" de Palavecino. Fue publicado en 1948, aunque una versión previa del mismo fue presentada en el Congreso Internacional de Americanistas realizado en 1932 en la ciudad de La Plata, bajo el título de Áreas culturales del territorio argentino: "Hace ya catorce años tuve la oportunidad de presentar un pequeño esquema de las áreas culturales del territorio argentino. El tiempo transcurrido desde entonces ha servido para destacar las deficiencias de aquella rudimentaria tentativa y su circulación me obliga a editar este nuevo panorama más ajustado al actual estado de nuestros conocimientos" (Palavecino, 1948: 447) 237 . Este trabajo, influenciado en parte por las ideas "difusionistas" en la antropología y también por la fuerte vinculación entre geografía y ciencias antropológicas en las décadas de 1930 y 1940, ofrece dos esquemas clasificatorios, uno etnográfico y otro arqueológico, para las

\footnotetext{
236 "La utilización de los conocimientos modernos sobre grupos antiguos y actuales permite establecer cuadros comparativos, secuencias culturales y difusiones con el análisis de las protoculturas, de las civilizaciones andinas, de los habitantes de la zona tropical o del Pacífico. Con los rasgos caracterizantes desarrollados de cada área, el conjunto muestra las distintas manufacturas y, de modo muy claro, los tipos de tejidos propios del ámbito sudamericano.” (Millán, 1981: 18)

${ }^{237}$ Asimismo, estos trabajos serán continuados más adelante en relación a la definición y delimitación de las "áreas folk": "Áreas de cultura folk en el territorio argentino (esbozo preliminar)", publicado en una compilación de Folklore argentino (Imbelloni, 1959); "Áreas de cultura folk en Argentina", presentado en las Jornadas Internacionales de Arqueología y Etnografía (Buenos Aires, 1960); y "Regiones folklóricas y regiones económicas en la República Argentina", en Revista de Economía Regional del Consejo Federal de Inversiones (1965) (Soprano, 2006).
} 
áreas y capas culturales de la argentina. Es decir, es un libro en el cual se otorgan pautas para la interpretación de las observaciones etnográficas y del registro arqueológico, definiciones, conceptos y clasificaciones. Asimismo, brinda información resumida de las diferentes "culturas" o "grupos culturales": Economía, Vivienda, Vestido y Adorno, Transporte y Comunicación, Industrias, Armas y utensilios, Sociedad, Religión y magia, Arte, Juegos y Recreaciones, Instituciones, Religión, entre otros. En el libro no hay referencias a las prácticas vinculadas al trabajo de campo y las culturas son organizadas bajo un esquema basado en la economía (cazadores, agricultores, pescadores, etc.) la cual se asocia a diferentes áreas y capas culturales.

La perspectiva analítica de Palavecino y Millán se puede examinar también en el Programa del curso de Etnografía y Arqueología que Palavecino ${ }^{238}$ dictaba en 1949 en el Museo de La Plata. El mismo contiene una parte general donde se enseñan los conceptos de cultura y de ciclos culturales, así como los aspectos de "Ergología sistemática": economía; armas; vida social, familiar y religiosa; vivienda y vestido. Luego se introduce un panorama general de las culturas sudamericanas, para adentrarse en las áreas y capas culturales de la Argentina según la etnografía.

Cuando Millán le escribe a Palavecino desde Venezuela menciona dos libros que "extraña" y que necesita como soporte para sus clases, solicitando a Palavecino que se los envíe. Uno es Áreas y capas culturales y el otro Notes and queries: "mañana lunes iré a la universidad para consultar la Biblioteca. Me afecta mucho, lo extraño a "notes and queries", veré si está aquí, pues no quiero que me mandes!. Si quiero pedirte por avión: Capas y Áreas Culturales, ¡no lo traje!”239. También menciona cómo las observaciones realizadas en este país apoyan las interpretaciones que ellos utilizaban para entender las culturas:

\footnotetext{
${ }^{238}$ AHMLP

239 Carta de Millán a Palavecino. Caracas, 25 de junio de 1960, AFDME. Fondos Palavecino-Millán. Carpeta "Correspondencia".
} 
"No puedo, eso si, dejar de pensar a cada momento, cuánto provecho sacarías tú, porque parecería que pensando en América desde este punto, el panorama, el mapa, cobrara en un sentido mas ¿cómo te diría? impacto, y que las zonas etnográficas tuvieran una explicación más clara." 240

Una vez más, aparece la importancia de los mapas y del análisis geográfico-cultural de las áreas culturales o "zonas etnográficas", las cuales estuvieron presentes en toda la obra de ambos. El segundo libro mencionado por Millán: Notes and Queries on Anthropology fue una guía realizada y distribuida por el Royal Anthropological Institute de Londres. Su primera edición fue en 1874 y continuó editándose, con ampliaciones, hasta 1951. La edición que suele citar Millán en sus trabajos es la quinta, publicada en 1929. La guía fue producida en un momento en el cual las prácticas vinculadas a la historia natural (entre las cuales se incluía la antropología) se organizaban mediante la división entre aquellos que clasifican y sistematizan y aquellos que se relacionan con el terreno, redactando para ello instrucciones, que procuraban educar la vista y los gestos del viajerocolector (Podgorny, 2002). Notes and queries no era una novedad, los datos empíricos proveídos por amateurs y viajeros se remontan a la época victoriana, pero fue significativo para los años posteriores en cuanto a los datos que se debían recopilar especialmente para la antropología (Stocking, 1993). Si bien la guía estuvo ideada como una herramienta de instrucción para la recopilación de datos etnográficos por "amateurs", hacia fines de siglo XIX y comienzos del $\mathrm{XX}$, con la incorporación del trabajo de campo como parte fundamental de la actividad antropológica en la década de 1920 la guía se seguirá utilizando. En el prólogo a la quinta edición (1929) se aclara: “como el libro ha sido diseñado para el uso de aquellos que no tienen entrenamiento en antropología, o para aquellos que no han tenido la oportunidad de leer ampliamente, así como también para el uso de observadores entrenados, (...) de alguna manera, el libro es prácticamente un libro de

\footnotetext{
${ }^{240}$ Op. Cit.
} 
texto así como una guía para la adquisición de información precisa"241. Este tipo de guías funcionaron como manuales, pautando los elementos que era necesario relevar a la hora de realizar trabajo de campo. En tal sentido, las guías han sido un modelo de clasificación, es decir un esquema que eventualmente permitiría acceder a características generales necesarias para conocer cualquier población y que a la vez permitían comparar los mismos elementos en distintas sociedades. A diferencia del libro "Áreas y capas culturales" de Palavecino, en "Notes and queries" si hay referencias específicas a los métodos. Por eso, la combinación de ambos libros por parte del matrimonio Millán-Palavecino resulta interesante para comprender los marcos a partir de los cuales organizaron sus trabajos de campo y los esquemas con los cuales interpretaron y analizaron los datos.

\section{Trabajo matrimonial en ciencia: actividades entrelazadas}

Los estudios sobre las relaciones familiares y matrimoniales han constituido un capítulo importante de la historia de la Antropología de distintos países. En tal sentido, destacan dos cuestiones vinculadas con el trabajo en pareja: el trabajo de campo y la escritura. Respecto de la organización de las actividades en el trabajo de campo, se han analizado diversas experiencias de matrimonios en las cuales las parejas se organizaban de acuerdo a una división generizada del trabajo, donde las esposas científicas se ocupaban de ciertas cuestiones vinculadas con sus supuestas habilidades o afinidades femeninas. Así, muchas se dedicaron a observar y relevar los aspectos relacionados con las mujeres y niños de los grupos estudiados. La división de tareas en la investigación permitía "complementar" las observaciones y la recolección de información de los varones etnógrafos (Corrêa, 1995; Handler, 2004; Lamphere, 2004; Tarducci, 2015).

Por otra parte, la escritura ha sido señalada como un espacio de tareas compartidas por las parejas y matrimonios en ciencia, aunque ello no siempre significaba que ambas

\footnotetext{
${ }^{241}$ Prefacio a la quinta edición, pp. viii, 1929.
} 
partes de la relación obtuvieran el crédito o reconocimiento acorde a sus aportes. En ese sentido, se ha señalado que aunque muchas mujeres realizaron contribuciones significativas para las publicaciones, no siempre se ha reconocido su papel en la autoría de las mismas. Mariza Corrêa (1995) señala al respecto que muchas antropólogas que viajaron a Brasil entre 1930 y 1950 eran designadas como "la esposa de", y sus producciones escritas tenían poca repercusión en el ámbito científico. Sin embargo, muchas "esposas” publicaron trabajos de su autoría o en coautoría con sus maridos, como es el caso de Millán quien aunque realizaba investigaciones en conjunto con Palavecino publicó la gran mayoría de sus obras de forma individual.

En el caso de Millán y Palavecino trabajaron en conjunto en el relevamiento y estudio de diferentes grupos indígenas del país, describiendo y estudiando lenguas, costumbres y aspectos de la cultura material de las mismas, y recopilando una gran cantidad de información y de objetos arqueológicos y etnográficos. A partir de un estudio comparativo de sus publicaciones y documentos, se han podido observar dos cuestiones centrales en las prácticas del matrimonio Millán-Palavecino. Primero, en cuanto a las actividades y prácticas realizadas durante los viajes de campo, la información analizada muestra tareas compartidas y complementarias. A diferencia de otros matrimonios que dividían su práctica etnográfica de acuerdo a una "división sexual" del trabajo que les permitía complementar diferentes aspectos "masculinos" y "femeninos" de los grupos estudiados; en este matrimonio de etnógrafos las tareas no aparecen divididas por criterios “femeninos/masculinos". Luego, el trabajo realizado en conjunto funcionó como un recurso disponible para las investigaciones personales de cada uno. Así recuerda Millán el diálogo e intercambio entre ambos:

“Tendríamos que estar juntos para que el viaje fuera bueno. No puedo escribir más seguido, tengo mucho que leer cada día y que escribir fichas y aun páginas. Te iré mandando cada clase, -para que me critiques y tal vez hacia el final del curso, puedo 
enmendar alguna omisión que resultara verdadera falla-. Me haces una falta terrible". 242

Esta importancia del viaje en equipo para que sea "bueno" parece ir disipándose con el incremento de viajes por separado. Desde 1950 Millán y Palavecino empiezan a realizar viajes por su cuenta, aunque también siguen realizando algunos en conjunto, especialmente a la región del Chaco. A partir de esa época sus carreras se fueron afianzando y si en un momento necesitaron de un apoyo mutuo cada vez será menos necesario para continuar con sus respectivas formaciones y desempeño laboral. En estos años se afianza especialmente la situación de Millán, quien fue Directora del Museo Folklórico del Noroeste de Tucumán y del Museo de Motivos Populares Argentinos José Hernández de Buenos Aires. Asimismo, con la creación del CONICET se desempeñó como investigadora del mismo durante veinte años.

Por otra parte, no hubo problemas de autoría entre ellos, ya que tanto Millán como Palavecino publicaron gran cantidad de trabajos y realizaron investigaciones significativas en sus temas particulares.

Por último, cada uno se dedicó a diferentes temas de investigación, realizando aportes a diferentes campos de saberes, especialmente al Folklore y a la Etnografía. Millán se dedicó casi exclusivamente a los tejidos. Su aporte fundamental fue establecer una clasificación y una descripción detallada de las diferentes técnicas textiles utilizadas en las diferentes regiones de la Argentina, de las materias tintóreas y del instrumental que interviene en la actividad textil (Sulca, 2004). Como se dijo, el trabajo en relación a los telares era una práctica que Millán había aprendido en el seno de su hogar, de parte de las mujeres de la familia, y era además una de las actividades que se impulsaban desde la Liga Patriótica, con la cual Millán estaba vinculada. En este sentido, el trabajo con tejidos podría

\footnotetext{
${ }^{242}$ Carta de Millán a Palavecino. Caracas, 16 de julio 1960, AFDME. Fondos Palavecino-Millán. Carpeta "Correspondencia".
} 
relacionarse con ciertos temas seguidos en general -aunque no de forma exclusiva- por mujeres.

Como otras parejas en la historia de la ciencia y de la antropología, Delia Millán y Enrique Palavecino compartieron y se distribuyeron tareas en sus viajes y en sus investigaciones. Estas experiencias muestran el riesgo de considerar las diferencias de género a priori para comprender prácticas concretas en el pasado, que si bien pueden haber sucedido en contextos sociales donde ocurrían desigualdades vinculadas al género, no son generalizables. Muchas esposas han trabajado en conjunto y con reconocimiento por su trabajo, el problema radica quizás en la forma en que se han relatado estas experiencias, o en la falta de investigaciones que recuperen sus historias en detalle. 


\section{Consideraciones finales}

La historiografía sobre las ciencias antropológicas en la Argentina no ha dedicado mucha atención a la actuación femenina en la época analizada en esta tesis. A partir del análisis de algunos casos particulares, esta investigación se propuso articular cuestiones de los estudios de género, de la historia de las mujeres y de la historia de la ciencia para dar cuenta de las distintas experiencias por las que las mujeres pudieron vincularse al quehacer antropológico argentino en el período comprendido entre las dos guerras mundiales. Por entonces, el "trabajo de campo" se había incorporado a las prácticas de las antropólogas de distintos países, se promovía en los cursos universitarios y además, su realización conjunta por parejas o matrimonios se presentaba como el ideal del trabajo etnográfico. Por otra parte, aunque en esta tesis se ha remarcado el abanico de posibilidades y estrategias de participación que evidenciaron las mujeres en el contexto argentino, ello no opaca las limitaciones que enfrentaron para desarrollar una carrera académica similar a la de sus pares masculinos en las décadas de 1930 y 1940.

La reconstrucción de las prácticas de ciertas mujeres ha sido compleja y dificultosa en muchos casos, debido a la presencia fragmentaria de las actividades y de la vida personal de las mujeres en los acervos documentales. En muchas ocasiones, el camino para recopilar información ha sido oblicuo, a través de las figuras allegadas a estas mujeres, en general hombres: jefes o compañeros de trabajo en los museos y asociaciones, maridos y otros familiares.

Más allá de mostrar que las mujeres formaron parte de la historia de las ciencias antropológicas en la Argentina, esta investigación buscó comprender cómo fue la participación de las mismas en contextos específicos del quehacer científico: ¿Qué actividades realizaban? ¿Sobre qué temas escribían? ¿Cuál fue su trayectoria académica y profesional? ¿Hubo diferencias entre hombres y mujeres? ¿Existían sesgos de género en la asignación o elección de tareas, en la elección de objetos de estudio, en el acceso a puestos 
y cargos? ¿Hubo mecanismos explícitos o implícitos de segregación de las mujeres en las prácticas científicas? Si estos existieron, ¿eran iguales para todas las mujeres, o hubo también distinciones sociales y de clase? A partir del trabajo con los diferentes documentos relevados, estos interrogantes comenzaron a ampliarse, pues muchas de las actividades recopiladas no se vinculaban con cuestiones únicamente de las "mujeres", más bien mostraban una variedad de participantes en las ciencias antropológicas, en su mayoría dejados de lado por los relatos tradicionales sobre el pasado disciplinar.

Las mujeres estudiadas ocuparon posiciones diferentes en el campo (Bourdieu, 1994, 1999) de las ciencias antropológicas y se dedicaron a un amplio espectro de actividades. Eran aficionadas, coleccionistas, exploradoras, universitarias, docentes, técnicas y científicas. Las trayectorias y los casos estudiados, lejos de ser homogéneos, presentan una gran diversidad de modos de ser y hacer y de pensar a las mujeres en la historia de la ciencia. Las mujeres analizadas ocuparon puestos en los museos de Buenos Aires y de La Plata como técnicas, como ayudantes de cátedra o de sección. También en los museos y otras instituciones provinciales y regionales fueron directoras y jefas. Algunas llevaron adelante sus prácticas por su propia cuenta, desde su casa o en permanente movimiento por el territorio Sudamericano. Fueron señoras y señoritas, esposas, hijas, viudas, exploradoras, doctoras, docentes, etnógrafas, arqueólogas. Usando pantalón o vestido, viajaron en auto, en tren, en barco a vapor o a caballo, realizaron trabajo "de campo", excavaciones, observaciones. Recolectaron objetos arqueológicos y etnográficos, tomaron notas de sus observaciones, hicieron apuntes de idiomas nativos, de recetas, de técnicas textiles, sacaron numerosas fotografías y realizaron esquemas, copiaron ilustraciones de vasijas y de telares. La mayor parte de las mujeres que se trabajan en esta investigación y también de aquellas que son mencionadas brevemente publicaron sus trabajos, tanto en revistas especializadas como en diarios y revistas de divulgación, dieron conferencias en salones y en la radio. Sus trabajos contribuyeron a ampliar el patrimonio material de diferentes museos y colecciones privadas, aportando restos óseos, cerámicas, textiles, instrumentos musicales, utensilios de la vida cotidiana, entre otros. También participaron de las discusiones vigentes en el período de estudio, acerca de la clasificación 
de las razas y las culturas indígenas, así como de sus transformaciones y de los vínculos con la sociedad occidental.

Los diversos temas de investigación que trabajaron las mujeres en este período son, por un lado, una muestra del abanico de problemáticas que se incluían dentro del campo de las ciencias antropológicas: antropología física o biológica, etnografía y etnología, arqueología, folklore y geografía, entre otras. Por otro lado, matizan la idea de que las mujeres en la historia de la antropología se han ocupado mayormente de temas "femeninos", producto de "guetos" o de feminización de ciertas actividades profesionales, como la infancia, el sexo y la nutrición (Schumaker, 2008), o como la orientación a la pedagogía y la etnografía en tanto extensiones de sus "atributos innatos como madres" (Echeverri, 2007).

Las trayectorias académicas y profesionales muestran posibilidades diversas, en los museos y en las universidades, así como en las asociaciones, las mujeres participaron activamente, aunque con ciertas desventajas respecto de sus pares masculinos, ya que en la década de 1940 no hubo profesoras titulares. Y aquellas que se ocuparon de la dirección de algunos espacios científicos lo hicieron en las provincias, en instituciones en ocasiones de reciente trayectoria o de menor prestigio que los espacios de Buenos Aires y La Plata. Posiblemente esta presencia tan variada en distintas instituciones estuvo favorecida por la escasa cantidad de "especialistas" en las ciencias antropológicas, que requería de trabajo para organizar las colecciones, fichar bibliografía, organizar espacios de trabajo y recolectar materiales en "el campo". Asimismo, estas diversas "mujeres" y "científicas" supieron aprovechar estratégicamente sus posiciones sociales, sus vinculaciones familiares, las redes de connacionales y el auge por ciertas colecciones o temas, la cercanía a los sitios arqueológicos, sus posibilidades económicas e incluso su condición "femenina". Así, se mostró cómo una señora de la élite santafesina aprovechaba una pensión por viudez para reunir materiales arqueológicos y organizarlos, clasificarlos e interpretarlos, en medio de una "fiebre" por las vasijas de su región. O cómo una exploradora austríaca que sin ningún financiamiento estable logró recorrer diversos "mundos perdidos" y de ese contacto formar colecciones que serían su sustento, generando vínculos con investigadores de diferentes 
museos quienes la instruyeron acerca de ciertos modos "correctos" de coleccionar y quienes la ayudaron a corregir textos, conseguir fondos y gestionar otros favores. Estas observaciones permitieron discutir los usos del concepto "mujer" o "científica" en la época.

Algunas de estas mujeres actuaron como intermediarias entre los científicos de diferentes museos y el "terreno". Tal es el caso de Amelia Larguía quien a través de sus recorridas por los alrededores de Santa Fe formó una importante colección arqueológica, gracias al diálogo y al intercambio con pescadores, con pobladores locales y con otros aficionados y coleccionistas como ella. Desde una situación diferente, Wanda Hanke recopiló una gran cantidad de información etnográfica, arqueológica y antropológica; la cual ofreció en venta a diferentes museos como uno de sus medios de subsistencia. Tanto Hanke como Larguía no contaban con puestos ni cargos institucionales, pero supieron participar en los debates científicos de la época, escribiendo artículos, intercambiando correspondencia con científicos y estudiosos, ofreciendo objetos y divulgando resultados.

Otras de las mujeres trabajadas en la tesis se vincularon a los principales espacios institucionales del período. En este sentido, María de las Mercedes Constanzó y María Delia Millán realizaron investigaciones prolongadas en la antropología y en la etnografía y el folklore. La experiencia de ambas permitió discutir algunos lugares comunes de la historia de las mujeres en la ciencia, matizando la idea de que todas han atravesado por dificultades y discriminaciones vinculadas al género, como el techo de cristal, la discriminación horizontal o el trabajo no reconocido -"en la sombra"- en el seno familiar o en las instituciones. Asimismo, algunas de estas mujeres ocuparon cargos y lugares destacados en su época: Constanzó ocupó un papel fundamental en la Sociedad Argentina de Antropología. La húngara Ana Biró estuvo a cargo de las colecciones de etnografía y arqueología y luego a cargo de un museo en Corrientes.

Por otra parte, al estudiar las prácticas conjuntas del matrimonio Millán-Palavecino, se dió cuenta de las posibilidades de desarrollo de una carrera para las mujeres en el marco de un matrimonio conformado por científicos, donde no siempre la organización del trabajo se dividió por criterios femeninos/masculinos. Es preciso señalar, sin embargo, que también 
se observan limitaciones para estas mujeres: ninguna fue profesora titular ni alcanzó un puesto jerárquico en las instituciones de Buenos Aires y La Plata.

Así, el estudio de las experiencias de algunas mujeres, sus actividades insertas en contextos específicos, permitió reconocer sus aportes a la conformación histórica del campo disciplinar, considerando a la producción de conocimientos en su carácter colectivo. Esto posibilitó adentrarse en algunas cuestiones específicas, poco trabajadas, en la historia de la antropología en la Argentina. La misma se ha ampliado enormemente en los últimos años, pero aún requiere de más estudios que avancen sobre la trama compleja de saberes, prácticas e individuos que contribuyeron en mayor o menor medida a su diversificación y fortalecimiento. A partir de un conjunto de experiencias femeninas, las preguntas planteadas permitieron también indagar en diferentes cuestiones. Por un lado, se pudo mostrar cómo las ciencias antropológicas en estos años se diversificaron y se expandieron institucionalmente en diferentes provincias, con la creación de museos e instituciones donde la participación de mujeres fue amplia. El surgimiento de la Sociedad Argentina de Antropología y de otras sociedades específicas también muestra una activa participación femenina. Asimismo, este crecimiento asociativo mostró la poca cantidad de "especialistas" en las ciencias antropológicas a comienzos de la década de 1930. Ello implicó la promoción de estas disciplinas, el reclutamiento de socios y socias y la proliferación de actividades destinadas a la difusión y al intercambio de diferentes investigaciones y saberes. La Semana de la Antropología y las sesiones científicas organizadas por la Sociedad Argentina de Antropología contaron con la presencia continua de mujeres, que participaron como expositoras, como público y como organizadoras.

Por otra parte, estas cuestiones posibilitan considerar la amplitud y diversidad de espacios, más allá de los museos y las universidades de Buenos y de La Plata, donde se conformaron las ciencias antropológicas. Más que anclarse en instituciones concretas, se observa la circulación de las prácticas, los materiales y los datos entre espacios sociales diversos: los museos metropolitanos, los museos regionales y locales, las cátedras, los laboratorios, los espacios domésticos, el "campo", entre otros. 
Por último, la decisión teórica-metodológica de indagar la historia de la ciencia a partir de sus protagonistas femeninas debe ser revisada. Esto es, repensar la importancia de valorar el aporte de ciertos sujetos a la historia de la ciencia, sin necesidad de contar con un "prejuicio" teórico a priori por su condición de género. Dedicarse a las mujeres como punto de partida, como se hizo en esta tesis, es también asumir el riesgo de que quizás esas mujeres no hayan sido significativas en la ciencia y que sólo se diferencian de otros sólo por ser "mujeres", categoría que en sí misma debe ser constantemente definida, considerada en sus variaciones y en cada contexto sociocultural e histórico. 
Anexos 


\section{Anexo I: Sociedad Argentina de Antropología}

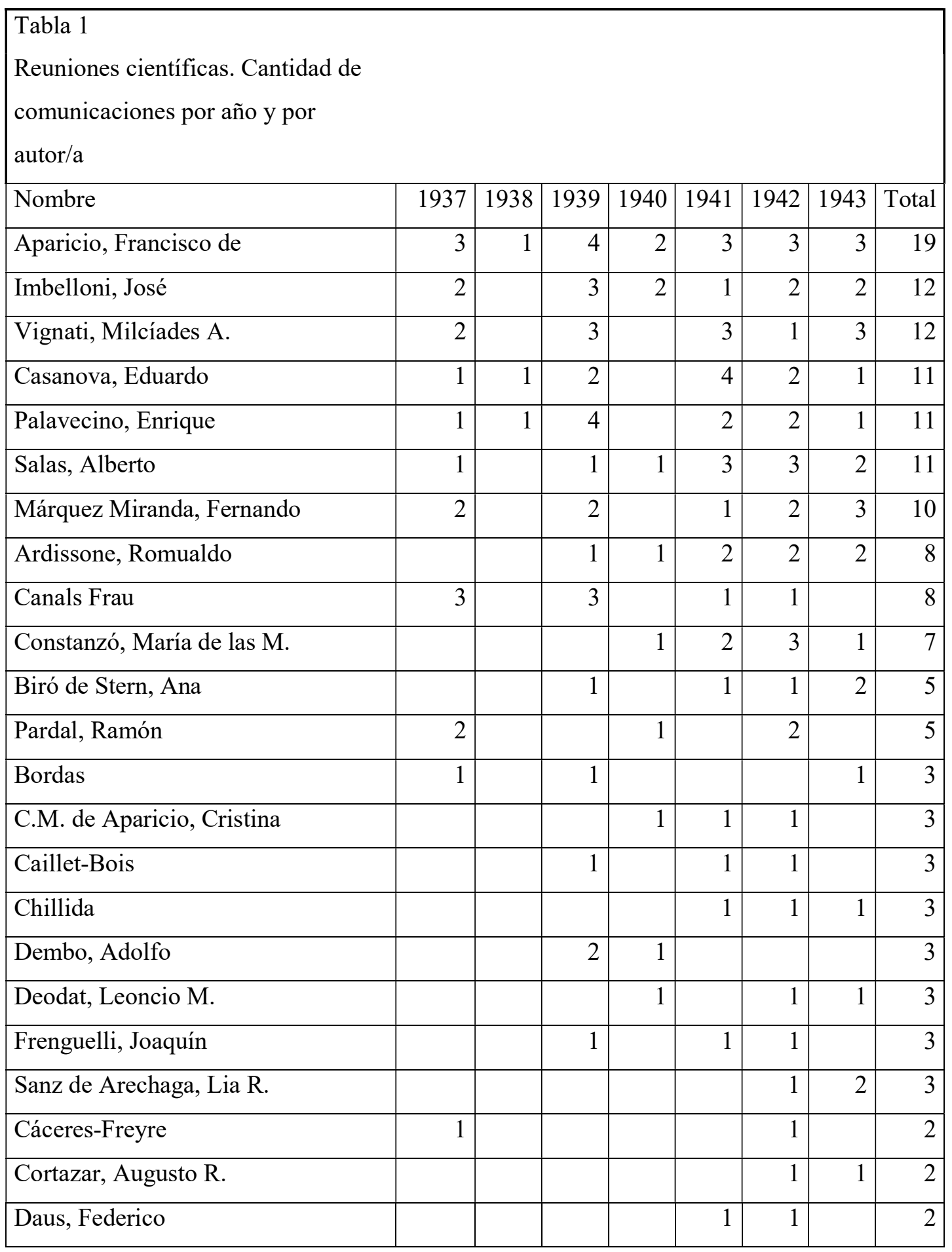




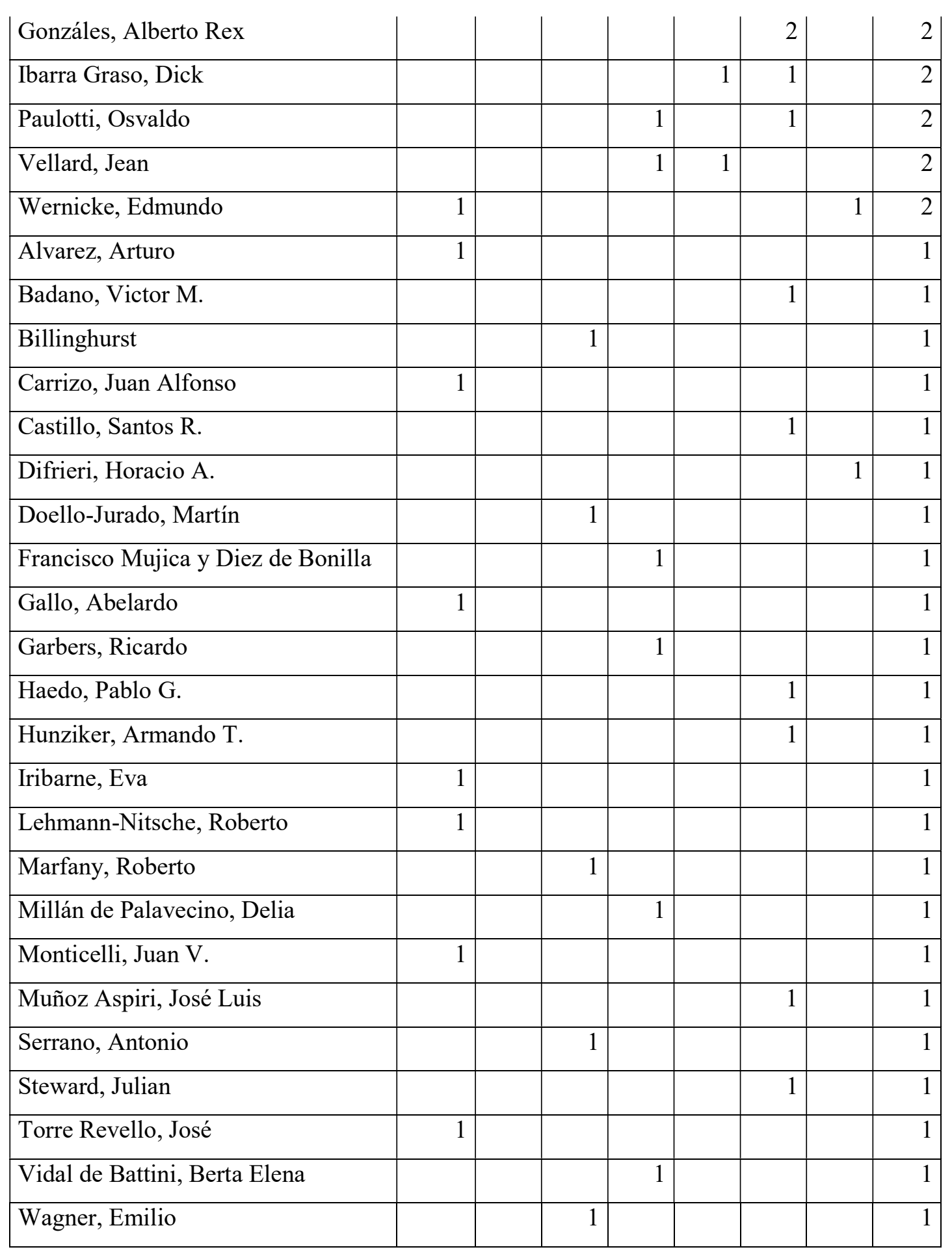




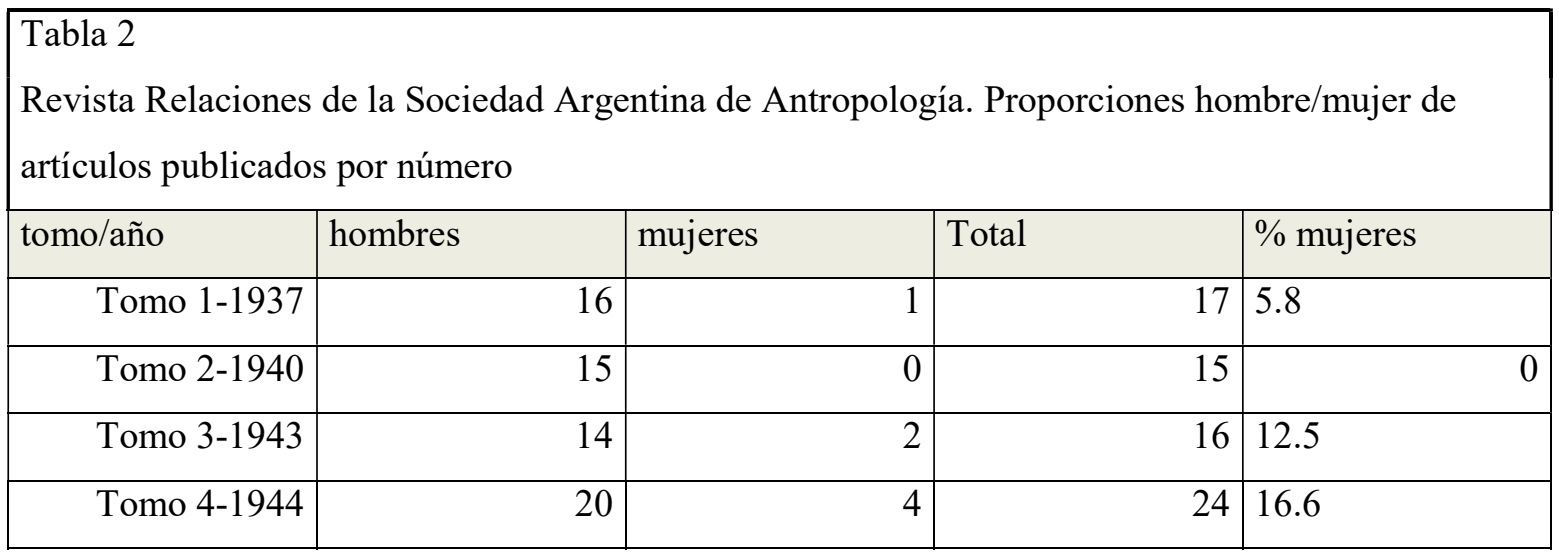

\section{Tabla 3}

Incorporación de socias/os a la Sociedad Argentina de Antropología por año, 1936-1943

\begin{tabular}{|c|c|c|c|c|c|c|}
\hline \multirow[b]{2}{*}{ Período } & \multicolumn{3}{|c|}{ Socios activos } & \multicolumn{3}{|c|}{ Socios estudiantes } \\
\hline & Hombres & Mujeres & Total & Hombres & Mujeres & total \\
\hline $\begin{array}{l}1936- \\
1937[1]\end{array}$ & 10 & & 10 & 14 & 7 & 21 \\
\hline $1937-1938$ & 31 & 5 & 36 & 8 & 5 & 13 \\
\hline $1938-1939$ & 9 & 1 & 10 & 1 & 3 & 4 \\
\hline 1939-1940 & 6 & & 6 & 3 & 13 & 16 \\
\hline 1940-41 & 8 & 1 & 9 & 9 & 17 & 26 \\
\hline $1941-42$ & 15 & 6 & 21 & 19 & 27 & 46 \\
\hline $1942-43$ & 3 & 1 & 4 & 8 & 12 & 20 \\
\hline
\end{tabular}




\section{Tabla 4}

Nombres de socios/as que se incorporan a la Sociedad Argentina de Antropología 1936-1943.

\begin{tabular}{|c|c|c|}
\hline & Socios/as activos/as & Socios/as adherentes/estudiantes \\
\hline período & Francisco de Aparicio & Radamés Altieri \\
\hline \multirow[t]{20}{*}{$1936-37$} & Eduardo Casanova & $\begin{array}{l}\text { María de las Mercedes Constanzó Romualdo } \\
\text { Ardissone }\end{array}$ \\
\hline & José Imbelloni & Elina Gonzalez Acha de Correa Morales \\
\hline & Fernando Márquez Miranda & Juan Arnot \\
\hline & Félix Outes & Eva Iribarne \\
\hline & Enrique Palavecino & Manuel A. Bousquet \\
\hline & Antonio Serrano & Elena S. de Kliman \\
\hline & Milciades Alejo Vignati & Julián B. Cáceres Freyre \\
\hline & Duncan L. Wagner & Ada I. Pastore \\
\hline & Emilio R. Wagner & Jorge A. Cranwell \\
\hline & & Ana Biró de Stern \\
\hline & & Adolfo Dembo \\
\hline & & María Elena Villagra Cobanera \\
\hline & & Gervasio Fernández Madero \\
\hline & & Pablo Gaggero \\
\hline & & Ramón Pardal \\
\hline & & Lorenzo R. Parodi \\
\hline & & Carlos Sodini \\
\hline & & José M. L. Viani \\
\hline & & Florencio Villegas Basavilbaso \\
\hline & José Anesi & Ernesto Annecou \\
\hline \multirow[t]{5}{*}{$1937-38$} & $\begin{array}{l}\text { Cristina Correa Morales de } \\
\text { Aparicio }\end{array}$ & Marta Barrionuevo \\
\hline & Adolfo Arana & Enrique Benítez de Aldama \\
\hline & Carlos F. Barraza & Clotilde Fernández \\
\hline & Berta Vidal de Batini & Roberto Fraboschi \\
\hline & Alejandro Bordas & Carolina Graiño \\
\hline
\end{tabular}




\begin{tabular}{|c|c|c|}
\hline & Ricardo Caillet-Bois & |Eusebia Ibáñez \\
\hline & Alfredo Calcagno & Anibal Nasia \\
\hline & Rodolfo Carcavallo & Justo Pérez Gardel \\
\hline & Juan Alfonso Carrizo & Hugo Rivarola \\
\hline & Federico A. Daus & Raquel Sánz \\
\hline & E. Mansilla Derqui & Roberto Scalabrini \\
\hline & Abelardo Gallo & Juan Manuel Suetta \\
\hline & Anavadro Gnecco & \\
\hline & Pastor Jordán & \\
\hline & Ricardo de Lafuente Machain & \\
\hline & Carlos Lizer y Trelles & \\
\hline & Osvaldo Loudet & \\
\hline & Julio Marc & \\
\hline & Alberto A. Mignanego & \\
\hline & José Luis Molinari & \\
\hline & Francisco Pardo & \\
\hline & Alberto Salas & \\
\hline & Modesto Santillán Robles & \\
\hline & Miguel Solá & \\
\hline & Augusto Tapia & \\
\hline & Alfredo Taullard & \\
\hline & Raúl Ungaro & \\
\hline & Carlos Vega & \\
\hline & Oscar Vigliani & \\
\hline & Raúl Vigliani & \\
\hline & Edmundo Wernicke & \\
\hline & Rómulo Zabala & \\
\hline & Rómulo Zabala (hijo) & \\
\hline & Jorge Argañaráz & Lidia Benítez de Aldama \\
\hline 1938-39 & Amelia Larguía de Crouzeilles & Aurora Rosa Caminos \\
\hline & Alfredo Gargaro & Fernando Chaij \\
\hline
\end{tabular}




\begin{tabular}{|c|c|c|}
\hline & Alfredo Guido & María Celina Griffero \\
\hline & Angel Guido & \\
\hline & Horacio Molinari & \\
\hline & Ernesto Padilla & \\
\hline & Héctor R. Ratto & \\
\hline & Carlos Reyes Fajardo & \\
\hline & Ramón F. Vásquez & \\
\hline & Armando Braun Menéndez & Marta Aldanondo \\
\hline $1939-40$ & José Cortez Martinez & María Adela Carbone \\
\hline & Ricardo Garbers & Ángel Castellán \\
\hline & Rafael Jijena Sánchez & Delia Chianelli \\
\hline & José Marelli & Guillermo Fernández \\
\hline & Alberto Rex González & Isolina Grossi \\
\hline & & Cora Guyer \\
\hline & & María Irene Ilesca \\
\hline & & Dolores Márquez \\
\hline & & Dora Masotto \\
\hline & & Nelly Ons \\
\hline & & Adolfo Rivera \\
\hline & & Nélida Teppa \\
\hline & & Delia Terrén \\
\hline & & Mercedes Terrén \\
\hline & & Hebe Unía \\
\hline & Maria Cambiaggio & Celia Areu Núñez \\
\hline $1940-41$ & Oscar Carbone & Norberto Beggo \\
\hline & Augusto R. Cortazar & José Blanco \\
\hline & Rogelio Diaz Costa & Livia Corsini \\
\hline & Segundo Fernández & Elena Chiozza \\
\hline & Dick. E. Ibarra Grasso & Horacio Difrieri \\
\hline & Andrés Millé & María Cristina Dominguez \\
\hline & José María Saénz Valiente & Cesáreo C. García \\
\hline
\end{tabular}




\begin{tabular}{|c|c|c|}
\hline & Agustín Zapata Gollán & Lorenzo J. González \\
\hline & & Beatriz Gredenberg \\
\hline & & Raquel Gutiérrez \\
\hline & & Jorge Irurzun \\
\hline & & Graciela Lapido \\
\hline & & Juan S. López \\
\hline & & Carmen Luna \\
\hline & & Irma Martinez \\
\hline & & María Nélida Moisá \\
\hline & & José Luis Muñoz Aspiri \\
\hline & & Ernesto L. Olivier \\
\hline & & Osvaldo Paulotti \\
\hline & & María Esther Pisano \\
\hline & & Clara Rodriguez \\
\hline & & María Angélica Ruiz Mingo \\
\hline & & María Irma Ruiz Moreno \\
\hline & & Héctor Schenone \\
\hline & & Helen Scheuss \\
\hline & & Aída Torres \\
\hline & & Tatiana Voiculescu \\
\hline & Víctor M. Badano & Angel Bianchi \\
\hline $1941-42$ & Luisa B. Vignale de Ardissone & Raquel Avila Pietranera \\
\hline & Ergasto Cordero & Guillermo Billoch \\
\hline & Blanca P. de Bordas & María Rosa Bustos \\
\hline & Santos R. Castillo & Cesar Corte Carillo \\
\hline & Elvira H. de Casanova & Helena Beristain \\
\hline & Leoncio S.M. Deodat & Horacio Cuello \\
\hline & Livia L. Corsini & Marina Cullell \\
\hline & Alfredo Dornheim & Luis Chillida \\
\hline & Sara de Mundo & Matilde Castello \\
\hline & Guillermo Fernández Vidal & Eduardo Dolhagaray \\
\hline
\end{tabular}




\begin{tabular}{|c|c|}
\hline Daisy Rípodas Ardanaz & Orlanda Caputo \\
\hline Pablo G. Haedo & Servando Dozo \\
\hline Roberto Levillier & Virginia Catanesi \\
\hline Rodolfo Maldonado Bruzzone & Pedro D. Ferraro \\
\hline Benigno Martinez Soler & María L. Castro \\
\hline Manuel M. Romain & Jose Antonio Guemes \\
\hline Enrique Revol & Susana Ensinck \\
\hline Amadeo R. Sirolli & Miguel A. Gregori \\
\hline Ernesto Sourrouille & Elsa Ecker \\
\hline León Strube Erdmann & Francisco Gancedo \\
\hline & Celia Ferreres \\
\hline & Jose Santos Gollan \\
\hline & Zunilda González \\
\hline & Armando T. Hunziker \\
\hline & Dolores Gomez Omil \\
\hline & Antonio Imperiale \\
\hline & Elsa Labanchi \\
\hline & Rogelio López \\
\hline & Olga Mingo \\
\hline & Ciro René Lafón \\
\hline & Ofelia Moscatelli \\
\hline & R. Manfredi? \\
\hline & Amalia Maldonado \\
\hline & Luis Narvaiz \\
\hline & Elvira Orella \\
\hline & Horacio Zapater \\
\hline & Elena Pérez Jofré \\
\hline & Raúl Remonda \\
\hline & Dora Púrpura \\
\hline & Carlota G. Paulsen \\
\hline & Josefina Ragau \\
\hline
\end{tabular}




\begin{tabular}{|c|c|c|}
\hline & & Celia Squessini \\
\hline & & Natalia A. Sogni \\
\hline & & Aurelia Yannucci \\
\hline & & Rosa M. Zuluaga \\
\hline & Iván Hernandez & De la FFyL, UBA: \\
\hline $1942-43$ & Daniel Hammerly Dupuy & Vicente Baena \\
\hline & Maria Eva Eberle & Juan M. Biedma \\
\hline & Juan Alberto Vellard. & María Josefina Codda \\
\hline & & Jorge Cassani \\
\hline & & Esther Nélida Costa \\
\hline & & Roberto Federici \\
\hline & & María M. García Santamarina \\
\hline & & Nelly Giannatoni \\
\hline & & Ofelia Luque \\
\hline & & Leonor Maestre \\
\hline & & Nélida Manso \\
\hline & & Dolores J. Maciel \\
\hline & & Néstor H. Orsi \\
\hline & & María Ignacia Pérez \\
\hline & & Sara Perticarari \\
\hline & & Salvador Storni \\
\hline & & Esther A. Tesone \\
\hline & & María L. Taboada \\
\hline & & José A. Zullo \\
\hline & & De la FaHCE, UNLP: \\
\hline & & Arón Embon \\
\hline
\end{tabular}




\section{Anexo II: Datos biográficos de algunas mujeres vinculadas a las ciencias antropológicas argentinas durante primera mitad del siglo $\mathrm{XX}^{243}$}

\section{Aguirre, Victoria (1860-1927)}

Pintora y coleccionista de arte. Hija de Manuel Aguirre Ituarte y Mercedes Anchorena Ibañez, nació en Buenos Aires el 6 de junio de 1868, en el seno de una familia adinerada y bien posicionada en la sociedad porteña. Apasionada por las obras de arte y poseedora de medios de fortuna, realizó numerosos viajes por distintos países formó una colección de antigüedades, así como de libros raros en ediciones de lujo. Armó un museo particular, cuyas pizas donó a museos públicos. Auspicio compra de colecciones para el Museo de La Plata, como los objetos de Francis P. Moreno puestos en remate tras su muerte. También donó objetos de Perú y Bolivia a ese museo y al Museo Etnográfico de Buenos Aires. Sus donaciones muchas veces eran anónimas y se destinaban a hospitales, fundaciones, laboratorios y bibliotecas. También colaboró con las expediciones científicas realizadas desde el Museo de la Plata. Murió en Buenos Aires el 16 de marzo de 1927

\footnotetext{
${ }^{243}$ Este conjunto de biografías no es exhaustivo, sino más bien intenta poner en circulación ciertos datos biográficos de algunas mujeres vinculadas con las ciencias antropológicas que fueron recopilados en el transcurso de la investigación. Algunas de estas biografías han sido resumidas puesto que son casos desarrollados en diferentes capítulos de la tesis. Cabe señalar, por último, la desigual información que se provee de cada una de estas mujeres, la cual responde a las limitaciones en las fuentes consultadas y halladas.
} 


\section{Aretz-Thiele, Isabel (1917-2005)}

Investigadora de folklore y compositora, nació en Buenos Aires en 1917. Estudió en el Conservatorio Nacional de Música de Buenos Aires, del cual egresó en 1931. Allí se formó con Athos Palma y Rafael González. En 1937 y 1938 obtuvo una beca para estudiar orquestación en Brasil con Héctor Villalobos. Entre 1941 y 1950 se formó con el folklorista y musicólogo Carlos Vega, estudiando la música tradicional argentina. En 1947 se casó con Luis Felipe Ramón y Rivera y en 1952 ambos se mudan a Venezuela. Allí, contribuyó en la organización de la sección Musicología del servicio de investigaciones folklóricas nacionales de Venezuela, que en 1970 será el INIDEF, Instituto Interamericano de Etnomusicología y Folklore. En 1997 regresa a Buenos Aires, donde fallece en 2005 (Locatatelli de Pérgamo, 2005).

Grabó para el Instituto de Musicología de Buenos Aires más de tres mil melodías y coleccionó instrumentos musicales indígenas y criollos. Es autora de "Música tradicional argentina. Tucumán, historia y folclore" (1946) y "Costumbres tradicionales argentinas" (1954). Ha publicado así mismo numerosos artículos sobre su especialidad. Allí.

\section{Biró de Stern, Ana (1903-?)}

Nació en 1903 en Oradea (Nagyvárad) ${ }^{244}$. Realizó estudios universitarios en Budapest y luego emigró a la Argentina. Se vinculó inicialmente a la sección de Antropología del Museo de Ciencias Naturales Bernardino Rivadavia de Buenos Aires, donde se desempeñó como adscripta, un nombramiento ad-honoren que le permitía asistir a los laboratorios, acceder a las colecciones y formarse en las actividades de esa sección

\footnotetext{
${ }^{244}$ Ciudad que pertenece a la región de Transilvania de la actual Rumanía, en ese entonces parte de Hungría.
} 
museística. Poco después se mudó al Chaco, acompañando a su marido Emilio Stern. En la década de 1940 se relacionó al Museo Histórico Colonial y de Bellas Artes de Corrientes, donde estuvo encargada de las colecciones antropológicas y arqueológicas. Poco después, asume como directora del recientemente reorganizado Museo provincial de Ciencias Naturales de Corrientes, cargo que desempeña entre 1944 y 1946. Biró y su esposo estuvieron vinculados de Stern estuvo vinculada, junto a su esposo, a diversas actividades artísticas y culturales de la región, tanto en Corrientes como en Resistencia. En esta última ciudad participaron del Ateneo del Chaco.

En las décadas de 1960 y 1970 Biró realizó numerosos viajes por el interior del país y por Centroamérica con el auspicio del Fondo de las Artes, de la OEA y de la Comisión Permanente de Artesanías de la UNESCO, de la cual fue presidenta. Perteneció también a la Sociedad de Americanistas y a la Sociedad Argentina de Antropología. En la década de 1950 vuelve a instalarse en Buenos Aires. Entre 1955 y 1960 ofreció conferencias en Radio Nacional y en la Sociedad Hebraica Argentina. También se desempeñó como docente en la Universidad Popular de Belgrano y estuvo vinculada junto a su marido a la Asociación "Unamonos por Ituzaingó" -o "AUPI", sigla de Asociación Unidad y Progreso de Ituzaingó-, participando de una de sus publicaciones periódicas, “El chasqui” desde 1968.

Publicó trabajos en diarios como La Nacion, en revistas de divulgación como la Revista Geográfica Americana y la Revista do Arquivo Municipal, en otras de instituciones académicas como Humanidades, Boletín del Museo Colonial, Histórico y de Bellas Artes, Anales del Instituto de Etnografía Americana, Revista América Indígena, Relaciones de la Sociedad Argentina de Antropología. Entre 1936 y 1958 publicó varios trabajos dedicados a las artesanías, al arte y el dibujo de los "primitivos" o "arte prehistórico", trabajos sobre estilos de arte plástica, sobre hallazgos arqueológicos en la provincia de Corrientes y en el territorio del Chaco, alfarería, arqueología de sitios hispano-indígenas. Hacia fines de la década de 1950 publicó algunas notas en relación a los hebreos en la "América prehispánica”. A partir de la década de 1960 sus temas se enfocan cada vez más en las artesanías indígenas, en la "supervivencia” de elementos indígenas y al arte popular. Formó 
colecciones de arte indigena y de imagineria popular. Las mismas fueron incorporadas luego de su muerte al Museo Etnografico de Buenos Aires.

\section{Chávez de Azcona, Lilia (1917-1986)}

Egresó de la Facultad de Ciencias Naturales y Museo de La Plata en 1945, con orientación en Biología. En 1941 se había recibido de Profesora de Enseñanza Secundaria, Normal y Especial en Ciencias Biológicas en la misma universidad. Se desempeñó como ayudante alumna de la cátedra de Antropología en el Museo de La Plata entre 1938 y 1947 y entre 1948 y 1956 fue Jefa de Trabajos Prácticos en la misma cátedra, siendo también Ayudante de la Sección de Antropología (AHMLP). Se dedicó principalmente a temáticas vinculadas con el crecimiento y el desarrollo humano desde una perspectiva antropológica (Marcellino, 1985).

\section{Constanzó, María de las Mercedes (1909-?)}

Nacida en Santa Fe en 1909, se graduó como Profesora de Historia en la Facultad de Filosofía y Letras de la UBA en 1932, y se doctoró en Filosofía y Letras en 1940 con la tesis titulada "Antropología Calchaquí: La colección Zavaleta del Museo Argentino de Ciencias Naturales "Bernardino Rivadavia". Se dedicó a la docencia en colegios secundarios y en la misma facultad se desempeñó como técnica del Museo Etnográfico desde 1940. En 1946 es convocada para "reestructurar" el Instituto de Antropología de la Universidad de Tucumán (en reemplazo de Enrique Palavecino), asumiendo interinamente la dirección hasta 1947. En relación a ello, actuó como profesora de Prehistoria y Etnografía en la Facultad de Filosofía y Letras (Universidad Nacional de Tucumán) durante los años 1946-1947. Sus investigaciones se dedicaron a la antropología física, en línea con 
aquellos temas desarrollados por José Imbelloni, del cual fue asistente (Guber, 2006; Arenas y Carrizo, 2010; Perazzi, 2014). Principalmente se dedicó al estudio de los restos óseos de los indígenas prehispánicos, describiendo y estudiando las lesiones dentarias y anomalías que permiten establecer las enfermedades que padecieron.

Publicó numerosos trabajos dedicados sobre todo a la antropología física en revistas especializadas, como el Boletín del Instituto de Investigaciones Históricas de la Facultad de Filosofia y Letras, Anales del Instituto de Etnografía Americana, Relaciones de la Sociedad Argentina de Antropología, América Indígena, Acta Americana, Revista de la Universidad de Buenos Aires, Boletín de la Junta de la Provincia de San Juan, Boletín del Museo Nacional de Historia Natural de Chile, Boletín del Departamento de Estudios Etnográficos y Coloniales de la Provincia de Santa Fe; así como en periódicos y revistas de divulgación como La Nación, Revista Geográfica Americana, Revista de Educación del Ministerio de Educación Pública de Chile, Amigos sanjuaninos y Amicitia. Asimismo, dictó conferencias sobre sus temas de trabajo en radio Nacional. Las publicaciones versan principalmente sobre culturas americanas, la isoaglutinación como elemento para el diagnóstico racial, craneometría, lesiones dentarias, momias y restos humanos en diferentes regiones del país y de países vecinos. Su trabajo de tesis doctoral "Antropología calchaquí. La colección Zavaleta del Museo Argentino de Ciencias Naturales "Bernardino Rivadavia"” fue publicado en 1942 en la Revista del Instituto de Antropología de la Universidad Nacional de Tucumán. También escribió reseñas de otros autores y gran cantidad de notas para el Boletín de la Sociedad Argentina de Antropología.

\section{Correa Morales, Cristina (1897-1984)}

Nacida en buenos Aires el 7 de agosto de 1897, estudió en la Facultad de Humanidades y Ciencias de la Educación de la Universidad Nacional de La Plata, dedicándose luego a los problemas sociales y jurídicos de la mujer. En 1956 fue Secretaria 
General de la Comisión Nacional de la Mujer del Ministerio de Trabajo y Previsión y el mismo año delegada ante la Comisión Jurídica y Social de la Mujer de las Naciones Unidas. Actuó en política, como secretaria general de la sección femenina del partido Acción Argentina ${ }^{245}$. También fue presidenta del Comité de Ciencias Sociales de la UNESCO y miembro de la comisión de homenaje a Juan B. Justo. Ejerció la vicepresidencia de la Federación Mundial de Asociaciones Pro Naciones Unidas con sede en Ginebra y fue miembro del Comité Asesor de Arte de UNICEF. Asimismo, se desempeñó como traductora de textos ingleses al español ${ }^{246}$ y asistió a congresos y conferencias internacionales. Su vinculación con las ciencias del hombre se da en el marco de la mencionada sociabilidad familiar, y también se debe a su vínculo matrimonial con Francisco de Aparicio, con el cual colaboró durante treinta años. Presentó algunas comunicaciones en las reuniones de comunicaciones de la SAA sobre "dibujo y arqueología, "los escritos de Frank Paddington”, entre otros. También publicó algunos artículos en revistas de divulgación como la Revista Geográfica Argentina. Luego del fallecimiento de Aparicio, en 1951, conformó la Fundación Francisco de Aparicio para ayudar al conocimiento de la arqueología y la geografía. Falleció en Buenos Aires el 12 de abril de 1984.

\section{Dillenius, Juliane A. (1884-1949)}

Presentó en 1911 en la Facultad de Filosofía y Letras, su tesis sobre craneometría comparativa de los antiguos habitantes de Tilcara. Este trabajo fue precedido por dos

\footnotetext{
${ }^{245}$ Acción Argentina fue creada el 5 de junio de 1940 a partir de una propuesta del Partido Socialista con el fin de promover el ingreso de Argentina a la Segunda Guerra Mundial integrando el bando Aliado. Otras mujeres que participaron de esta organización fueron Victoria Ocampo y Alicia Moreau de Justo. El partido fue desarticulado en 1943 al ingresar al poder el General Pedro Pablo Ramírez.

${ }^{246}$ Tradujo del idioma original "Los escritos de Frank Paddington" de Samuel Morton; "Viaje al plata" de John Miers, y "El gaucho" de Madaline Nichols.
} 
publicaciones y una comunicación en el XVII Congreso Internacional de Americanistas reunido en Buenos Aires en 1910, siendo una de las tres únicas mujeres que expusieron en ese evento, y en el cual también participó como adherente su padre (Barrancos, 2000: 127144). Como estudiante de la Facultad, pudo disponer de las colecciones del Museo Etnográfico dependiente de esta institución así como las reunidas por el director del mismo y sus colaboradores en las expediciones por el norte del país. Sus investigaciones contaron con el apoyo y la dirección del profesor de antropología, Roberto Lehmann-Nitsche (18721938), con quien luego se casaría y tendría cinco hijos. A partir de ese momento, al igual que las esposas de otros antropólogos y algunos científicos de la época, se convirtió en colaboradora de los trabajos de su marido (García, 2006: 144).

Su tesis fue la primera dirigida por Lehmann-Nitsche. A partir del análisis de los caracteres somáticos del material craneológico recolectado por una excursión de la Facultad de Filosofía y Letras de la Universidad Nacional de Buenos Aires a la zona de la Quebrada de Humahuaca, Dillenius pretendía contribuir a la historia de la mencionada región y de la Diaguita-Calchaquí (Ballestero, 2013). En 1913 apareció el que sería el último trabajo editado de Dillenius, el cual comprendía un análisis craneométrico sobre una colección de calotas medievales encontradas en las refacciones de la Anthropologisch-Prähistorisches Sammlung de la ciudad alemana de Münich. Ese mismo año contrajo matrimonio con Lehmann-Nitsche, naciendo al año siguiente su primera hija. Los hijos del matrimonio Lehmann-Nitsche/Dillenius y sus respectivas fechas de nacimiento son: Hiltrud en 1914; Goetz en 1915; Gudrun en 1917; Helga en 1923 y Gisela en 1925 (Ballestero, 2013).

\section{Garcia Mosquera, Manuela Carolina (1903-2001)}

Se doctoró en Ciencias Naturales con la tesis "Indice cefálico, talla y proporciones en escolares de La Plata” defendida en 1944. En 1945 solicitó la adscripción a la cátedra de antropología a cargo de Vignati, la cual dos años después fue "reprobada" y rechazada por Vignati, luego de evaluar el trabajo de investigación y las dos clases dictadas por la 
aspirante, de acuerdo a la normativa de adscripciones vigente desde octubre de 1945. Finalmente, en 1948 y luego de este rechazo expresado por Vignati, Mosquera solicita que se cancele la solicitud de adscripción ${ }^{247}$. Se desempeñó como directora de escuela en La Plata y también colaboró con su marido Luis María Bergna, realizando mediciones antropométricas durante diferentes comisiones de estudio que coordinó Bergna en el seno del Instituto Étnico Nacional (Soprano, 2009).

\section{González Acha de Correa Morales, María Elina (1861-1942)}

Pintora y geógrafa, nació en Mercedes, provincia de Buenos Aires, el 20 de enero de 1862. Se graduó de maestra en la Escuela Normal de Profesoras, que inició su tarea en 1875 bajo la dirección de Emma Nicolay de Caprile, y tuvo por compañera a Cecilia Grierson. Se dedicó a la pintura un tiempo, pero luego se consagró por completo a la labor pedagógica y científica, realizó en este terreno una trayectoria poco común para una mujer, que fue reconocido incluso por instituciones extranjeras. Desde la fundación del Liceo Nacional de Señoritas $n^{\circ} 1$ en 1907, dictó cátedra de geografía y ciencias naturales, en tanto realizaba trabajos de investigación vinculados a su especialidad.

Se casó con el escultor Lucio Correa Morales (1852-1923), con quien tuvieron seis hijos $^{248}$ que fueron educados en los mejores colegios y realizaban asiduos encuentros culturales en la casa familiar (Curto y Lascano, 2014). Por la casa también pasaron algunas mujeres vinculadas a movimientos políticos y educativos de comienzos de siglo XX, como Cecilia Grierson (1859-1934), madrina de Cristina; Rosario Vera Peñaloza (1873-1950), difusora de los métodos de Froebel y Montessori en la Argentina; María Angélica Barreda

\footnotetext{
${ }^{247}$ AHMLP

${ }^{248}$ Tuvieron cinco hijas mujeres y un hijo varón.
} 
(1882-1963) primera abogada argentina; y Ernestina López de Nelson (1879-1965) y Elvira López, primeras doctoras en Letras de la Universidad de Buenos Aires.

Fundó en 1922 la Sociedad Argentina de Estudios Geográficos (GAEA), de la que fue presidenta vitalicia. Colaboró asiduamente en los Anales de la misma, con artículos como: El arte geográfico y etnográfico, La brújula, clasificación cartográfica, etc. Falleció en Bs As el 13 de agosto de 1942.

\section{Hanke, Wanda (1893-1958)}

Wanda Theressia Leokadia Hanke nació el 9 de diciembre de 1893 en Troppau (población de la actual República Checa), por entonces parte del Imperio Austrohúngaro. En 1918, se doctoró en Filosofía en la Universidad de Munich. Dos años después, terminó los estudios de medicina en Wurzburgo y en 1926, los de abogacía en Marburgo. Trabajó como médica en Alemania y Austria hasta que decidió hacer un viaje de estudio etnológico. Entre 1934 y 1958 realizó numerosos viajes por Sudamérica, especialmente por Argentina, Brasil y Paraguay. Recopiló gran cantidad de material etnográfico, arqueológico y antropológico, el cual fue ofrecido en venta a diferentes museos sudamericanos y europeos. En sus recorridos visitó más de veinte grupos indígenas, tomando fotografías y también realizando en ocasiones mediciones antropométricas y recopilaciones lingüísticas. Escribio trabajos en revistas de instituciones científicas y de divulgación. Fallece el 30 de agosto de 1958 en un viaje de estudios que realizaba en Benjamin Constant, Amazonas.

Iribarne de Dietrich, Eva Arminda (1913-?) 
Trabajó como técnica en el Museo Etnográfico, clasificando material arqueológico y contribuyendo en la misma labor con otras instituciones, como el Museo Nacional de Arte Decorativo. Fue una de las primeras socias activas de la Sociedad Argentina de Antropología, en la cual participó durante un tiempo breve como secretaria. Realizó exposiciones en las sesiones de comunicaciones de esta asociación y también publicó en la Revista Relaciones. Luego desarrolló una carrera como traductora de textos académicos y literarios.

\section{Larguía de Crouzeilles, Amelia (1870-1952)}

Amelia Larguía nació en Santa Fe el 5 de enero de 1875, en el seno de una familia numerosa $^{249}$ y destacada de la élite santafesina. Hija de Mauricia Mercedes Descalzo Gómez (1842-1876) y de Jonás Larguía (1832-1891) $)^{250}$, ingeniero encargado de varias obras públicas en la provincia y de una prolífera actividad política e intelectual. En 1899 se casó con Juan Carlos Crouzeilles (1869-1917), periodista, diputado y miembro del gobierno provincial $^{251}$, con quien tuvo seis hijos ${ }^{252}$. Tras la muerte de su esposo, obtuvo una pensión

\footnotetext{
${ }^{249}$ Puesto que era una de nueve hermanos: Francisco Tomás, Mercedes E., Jonás Isaac, Lucrecia, Constancio F. J., Eduardo A., Eduarda Adelaida, Pedro Regalado y Francisco.

${ }^{250}$ Jonás Larguía realizó numerosas obras públicas en la provincia de Santa Fe y en el país. Su actividad política e intelectual fue prolífera, intercambió correspondencia con Diego de Alvear, Nicolás Avellaneda, Bernardo de Irigoyen y con Dardo Rocha; entre otros. Escribió ensayos sobre la "Educación del pueblo", redactó el proyecto de ley de creación del departamento de ingenieros de la provincia de Santa Fe y publicó diversas notas periodísticas. También actuó como Jefe de la Oficina de Estadística provincial y estuvo vinculado a la compañía francesa de ferrocarriles de Santa Fe (Fondo Jonás Larguía, AHPSF).

${ }^{251}$ Crouzeilles fue diputado en la legislatura provincial entre 1894 y 1904, en 1904 asumió como Ministro de Hacienda y Obras Públicas del gobernador M. Freyre. En 1907 fue miembro de la Convención reformadora
} 
del gobierno provincial ${ }^{253}$. De acuerdo con sus escasas biografías, en 1931 cuando sus hijos ya habían crecido, comenzó a interesarse por los "misterios insondables" de la región (López Rosas, 1993) y a conformar una colección arqueológica que continuo hasta su muerte en 1952. La misma estaba conformada en su mayoría por cerámicas regionales aunque también realizó hallazgos de materiales líticos y de restos óseos humanos e intercambio calcos con los museos de Santiago del Estero y de Paraná. Tras su fallecimiento, los hijos donarán su colección al Museo Etnográfico de Santa Fe.

Publicó algunos trabajos entre 1934 y 1940, dedicados a sus hallazgos y a los "paraderos" indígenas de la provincia de Santa Fe, en los Anales de la Sociedad Científica Argentina. Intercambió correspondencia con científicos y aficionados, intercambiando datos y bibliografía sobre los hallazgos de la región del Arroyo Leyes. Entre otros, mantenía correspondencias e intercambios con los miembros de la Sección Santa Fe de la Sociedad Científica Argentina, especialmente con Horacio Damianovich y Agustín Zapata Gollán. También con Joaquín Frenguelli, Francisco de Aparicio, Víctor Badano, Olimpia Righetti, Federico Daus y los hermanos Duncan y Emilio Wagner.

de la Constitución de la Provincia; asesor letrado de la provincia en la Capital Federal y diputado nacional. Tras su muerte, en abril de 1917, el senado santafesino propuso un proyecto de ley sobre tablas para apoyar a sus herederos, considerando que "la familia ha quedado en la mayor indigencia". (Fondo Juan Crouzeilles, AHPSF).

${ }^{252}$ Estos eran: Amelia (n. 1898), Flora María Teresa (n. 1900), Juan Carlos (n. 1902), Pedro (n. 1904), Lucrecia Eugenia (n. 1907) y María Acha (n. 1910).

${ }^{253}$ Tras la muerte de Crouzeilles, en abril de 1917, el senado santafesino propuso un proyecto de ley sobre tablas para apoyar a sus herederos, considerando que "la familia ha quedado en la mayor indigencia". El senador Gerardo Costanti manifestó que "le han quedado a la señora viuda varios hijos cuya educación se hace indispensable". El proyecto fue sancionado sin discusión. En reiteradas ocasiones, Larguía de Crouzeilles tuvo que pedir la prórroga de la pensión, así como el aumento del monto (Fondo Juan Crouzeilles, AHPSF). 


\section{Millán de Palavecino, María Delia (1902-1994)}

Delia Millán “Titú” como le decían en el ámbito familiar, era la segunda de 10 hijas de María Adelina Méndez Funes (1878-1970) y José R. Millán (1869-1962). Nacida en Mar del Plata en el seno de una familia dedicada a la docencia, al estudio y a las artes. Su madre fue directora de la Escuela Normal $n^{\circ} 1$ de Mar del Plata durante 25 años. Su padre fue docente, inspector de escuela e historiador. Tanto ella como su madre estaban vinculadas con la Liga Patriótica Argentina y ambas participaron de la fundación de la Escuela Industrial de Artes y Oficios de Mar del Plata. En el seno de la familia, Millán aprendió el arte del tejido, con su madre y sus hermanas, como lo recuerda Eloisa Benitez Millán ${ }^{254}$.

En 1930 se vinculó como adscripta a la sección de Etnografía del Museo Argentino de Ciencias Naturales de Buenos Aires, siendo jefa interina de esa sección en 1937. En 1948 fue conservadora de forma interina en el Museo Municipal de Bellas Artes de Buenos Aires y en 1949 se desempeñó como encargada de colecciones del Museo de Motivos Populares Argentinos José Hernández. En 1953-1955 obtuvo el premio nacional de etnología, arqueología e historia de la región noroeste. Fue directora del Museo Folklórico del Noroeste de Tucumán entre 1955-59. En 1957 recibió el 2do Premio Nacional de Arqueología, Etnología e Historia. En 1970, el 3er premio nacional. En 1976 y 1978, distinciones del Congreso de Arqueología Argentina y en 1980 del Congreso Nacional de Arqueología. También fue directora del Museo de Motivos Populares Argentinos José Hernández de Buenos Aires. Se desempeñó como investigadora del CONICET. También fue directora honorífica del Museo Americanista de Lomas de Zamora.

Escribió numerosos trabajos sobre técnicas textiles, motivos decorativos $\mathrm{y}$ representaciones gráficas, métodos de teñido, plantas tintóreas, prendas y vestimentas, y

\footnotetext{
${ }^{254}$ Conversación personal
} 
otros temas vinculados al arte y artesanías tradicionales del Noroeste argentino, el Chaco y la Patagonia. Entre sus publicaciones, destacan "Lexicografía de la vestimenta en el área de influencia Quechua" (1952); "Peleros y caronillas. Prendas aborígenes usadas en el apero criollo" (1954), "El poncho (estudio etno-geográfico)" (1957), "El arte del tejido en la Argentina"(Ed. Culturales Argentinas, Subsecretaría de Cultura, Ministerio de Cultura y Educación, Buenos Aires, 1981).

El tema central de su amplia obra fue el arte textil entre los aborígenes prehispánicos y durante la colonia y en los grupos rurales indígenas y criollos contemporáneos. Sus primeros trabajos se orientaron al análisis de colecciones de diferentes museos, una práctica que era común y permitía el entrenamiento de estudiantes e interesados en las ciencias antropológicas. Luego fue incorporando materiales de sus viajes, en general realizados junto a su marido Enrique Palavecino.

\section{Nosti de Carman, Mercedes (1903-1969)}

Nació el 29 de diciembre de 1903 en Buenos Aires, donde realizó sus estudios de Bellas Artes en la Escuela Nacional Prilidiano Pueyrredón, egresando en 1937. En 1942 se graduó en la Escuela Superior de Bellas Artes Ernesto de la Cárcova. Estudió asimismo en la Facultad de Filosofía y Letras. Contribuyó a organizar el Museo de Bellas Artes de Posadas, Misiones. Proyectó y dirigió exposiciones culturales, como la Exposición Universal de la Máscara, realizada en Buenos Aires en 1954. Fue colaboradora honoraria del Instituto Nacional de Antropología, trabajando en la organización del Museo Nacional 
del Hombre y colaborando con estudios de folklore argentino. Falleció en Bs As el 7 de agosto de $1969^{255}$.

\section{Pastore, Ada (1906-1952)}

Nació en San Luis en 1906, donde se formó como maestra normal. Luego rindió equivalencias en el Colegio Nacional de la capital puntana, “Juan Crisóstomo Lafinur" para obtener el título de Bachiller y poder ingresar a la Facultad de Ciencias Físico-Naturales de la Universidad Nacional de Buenos Aires, donde se doctoró en Ciencias Biológicas. Finalizados estos estudios, volvió a su ciudad, donde dictó la cátedra de Química en la Escuela Normal de Maestros. Más tarde regresó a Buenos Aires, y enseñó Botánica en los Colegios de Avellaneda y Bernardino Rivadavia. Pastore se vinculó luego al Instituto de Botánica Darwinion, creado en 1911 por Cristóbal M. Hicken y donado tras su muerte en 1933 a la Academia Nacional de Ciencias Exactas, Físicas y Naturales. Luego de su reorganización, quedó a cargo del mismo el Ingeniero Agrónomo Arturo Burkart y Pastore se integró como secretaria, bibliotecaria y botánica; trabajando junto a Nélida S. Troncoso, Asistente Botánica, y a Ilse von Reutzell, Encargada de la Biblioteca y dibujante. Pastore se formó con el naturalista Dalmiro S. Adaro y con el botánico Lorenzo R. Parodi, realizando diversas investigaciones botánicas junto a ellos y también por su cuenta, de las cuales publicó varios trabajos en revistas especializadas tales como Darwiniana ${ }^{256}$, la Revista Argentina de Agronomía, la Revista del Museo de La Plata, la Revue Botanique Appliquée, entre otras.

\footnotetext{
${ }^{255}$ Ver: "Mecha Carman (1903-1969)", en pp. 414-415.

256 Publicada desde diciembre de 1922, interrumpida entre 1933 y 1937 por la reorganización del instituto. Continúa en el presente.
} 


\section{Scolni de Klimann, Elena (s/d)}

Trabajó junto con Chillida bajo la dirección de Imbelloni. Su tesis, dirigida por Imbelloni, se tituló "Sobre las características del fémur en los varios grupos de indígenas argentinos" y fue publicada en Physis en $1938^{257}$. Luego se desempeñó como maestra, dictando clases de Física, Química y Mineralogía, Petrografía, y Geología en la Escuela Industrial Nacional "Otto Krause" de Buenos Aires.

\section{Vidal de Battini, Berta (1900-1984)}

Nació en San Luis, donde estudió para maestra normal, trabajando en escuela rurales de la provincia. Luego se doctoró en Filosofía y Letras con la tesis "El Habla Rural de San Luis". Sus actividades articularon la docencia, la literatura y los estudios filológicos. Trabajó en docencia primaria, secundaria y universitaria (en las cátedras de Folklore e Historia de la Lengua Española). También realizó actividades de Didáctica en el Consejo de Educación de San Luis y en el Consejo Nacional de Educación. Publicó artículos científicos y libros dedicados al estudio del habla nacional, al folklore y a la lingüística, y participó en congresos de su especialidad. Se formó con investigadores del folklore y la filología como Amado Alonso y Ángel Rosenblat. También se desempeñó como jefa de la sección de Folklore y Dialectología del instituto de Ciencias Antropológicas. Realizó numerosos viajes por todo el país para recopilar materiales sobre la lengua y el cuento folklórico de las

\footnotetext{
${ }^{257}$ Physis $n^{\circ}$ XII, pp. 197-227, Buenos Aires. La tesis analiza un conjunto de materiales compuesto de 165 fémures, pertenecientes a nueve localidades indígenas que de acuerdo con la clasificación de Imbelloni reúne en 3 grupos raciales: Andidos, Pámpidos y Fuéguidos; junto a los del Delta de Paraná, Neuquén y Chiriguano que considera como indeterminados por carecerse de estudios morfológicos que fijen su posición taxonómica.
} 
diferentes regiones, aprovechando las redes y recursos de instituciones nacionales y provinciales, especialmente del Consejo Nacional de Educación ${ }^{258}$.

\section{Villagra de Cobanera, María Elena (s/d)}

Fue de las pocas personas que estudiaron en la Facultad de Ciencias Naturales del Museo de La Plata y eligieron la orientación en antropología en la primera mitad del siglo XX. Por los registros que se guardan en el AHMLP, estudió entre 1930 y 1935 y fue ayudante alumna de la cátedra Antropología en el Museo de La Plata, entre 1936 y 1947. Publicó algunos trabajos sobre craneología de los "primitivos habitantes" de la Provincia de Buenos Aires. También participó durante un breve período como secretaria de la Sociedad Argentina de Antropología en la segunda mitad del año 1943.

\footnotetext{
${ }^{258} \mathrm{Su}$ trayectoria ha sido más bien estudiada desde su aporte a la lingüística. Ver, entro otros: Kovacci, Ofelia. 2000. "Berta Elena Vidal de Battini y sus estudios de la lengua y el folklore". En Boletín de la Academia Argentina de Letras. Tomo LXV, núm. 257-258.
} 


\section{Bibliografía General}

Althabe, Gérard y Shuster, Félix (comp). 1999. Antropología del Presente. Edicial, Buenos Aires.

Ametrano, Silvia. 2008. "Mujer y Geología: siglo XX y comienzos del XXI en Argentina”. En Geotemas, n 19, pp. 46-58.

Amoroux, Rémy. 2016. "Anne Berman (1889-1979), une «simple secrétaire» du mouvement psychanalytique français?”. En Gesnerus, Vol. 73, n² 2, pp. 360-375.

Aparicio, Francisco de. 1937. "Excavaciones en los paraderos del Arroyo de Leyes". Relaciones de la Sociedad Argentina de Antropología, vol. 1.

Arenas, Patricia. 1998. “Alfred Métraux: momentos de su paso por Argentina”. Mundo de antes, vol. 1, p. 121-145.

Arenas, Patricia. 2005. ""En la noche de los tiempos" Emilio y Duncan Wagner en el campo de profesionalización de la arqueología”. En Mundo de Antes, n4, pp. 159-187.

Arenas, Patricia y Sergio Carrizo. 2010. “Actores, escenas y clases de antropología y arqueología en la UNT". II Congreso sobre la Historia de la Universidad Nacional de Tucumán.

Arias, Ana Carolina. 2017a. "Wanda Hanke y la recopilación de información y colecciones antropológicas (1934-1944)”. En Revista del Museo de Antropología 10 (2), pp. 105-118. 
Arias, Ana Carolina. 2017b. La participación femenina en los primeros años de la Sociedad Argentina de Antropología (1930-1940). En Relaciones de la Sociedad Argentina de Antropología, XLII (1), pp. 181-188.

Ashwell, Anamaría. 2011. "El fútil ejercicio de Lévi-Strauss y Buell Quain en la selva amazónica". En Elementos, nº 81, pp. 3-15.

Babini, José. 1961. Breve historia de la ciencia argentina. En de M. Asúa (1993) (Comp). La ciencia en la Argentina, Perspectivas históricas. Buenos Aires: Centro Editor de América Latina, pp. 27-43.

Ballestero, Diego A. 2013. Los espacios de la antropología en la obra de Robert LehmannNitsche, 1894-1938 (Tesis doctoral). Facultad de Ciencias Naturales y Museo, Universidad Nacional de La Plata.

Ballestero, Diego y Marina Sardi. 2016. "Enseñanza de la Antropología física en la Argentina de comienzos de siglo XX. Robert Lehmann-Nitsche y la formación de discípulos". En Revista del Museo de Antropología, 9 (1), pp. 107-120.

Barberis, Susana. 2009. “Las primeras químicas”. En La Ménsula, Año 3, nº 8, pp. 1-5.

Barrancos, Dora. 2000. "Itinerarios científicos femeninos a principios de siglo XX: solas, pero no resignadas". Montserrat, Marcelo (Comp.) La ciencia en la argentina entre siglos. Textos, contextos, instituciones. Buenos Aires: Manantial. pp. 127-144.

Barrancos, Dora. 2002. Inclusión/Exclusión. Historia con mujeres. Buenos Aires: Fondo de Cultura Económica. 
Barrancos, Dora. 2004-2005. "Historia, historiografía y género. Notas para la memoria de sus vínculos en la Argentina". La Aljaba, 2a época, 9, pp. 49-72.

Barrancos, Dora. 2007. Mujeres en la Sociedad Argentina. Una historia de cinco siglos. Buenos Aires: Sudamericana.

Barrancos, Dora. 2008. La puñalada de Amelia (o cómo se extinguió la discriminación de las mujeres casadas del servicio telefónico en la Argentina). Trabajos y comunicaciones.

Barrancos, Dora. 2010. Mujeres en la sociedad argentina: una historia de cinco siglos, Sudamericana. Bs. As.

Barth, Frederik. 2012 (2005). "Inglaterra y la Commonwealth", en Barth, Parkin, Silverman y Gringrich Una disciplina, cuatro caminos. Antropología británica, alemana, francesa y estadounidenese. Buenos Aires: Prometeo Libros, pp. 15-81.

Barth, Frederik, Robert Parkin, Sydel Silverman y Andre Gingrich. 2012. Una disciplina, cuatro caminos: antropología británica, alemana, francesa y estadounidense. Buenos Aires: Prometeo Libros.

Benzi, Marina, Paula Busso y Rosa García. 2011. "Un museo, una mirada, un discurso, una época: cuestiones de debate". En Revista AMÉRICA, Nº 20, pp. 39-59.

Bianchi, Susana. 1992. “¿Historia de mujeres o mujeres en la historia?”. En: V.V.A.A. Feminismo, Ciencia, Cultura y Sociedad. Buenos Aires: Humanitas, pp. 17-33.

Birabén, Max. 1938. "Excursiones de estudio realizadas durante el año 1938. Relación de viajes: Resultados de un viaje al sud argentino". En Revista del Museo de La Plata, Nueva Serie, Sección Oficial, pp. 117-119. 
Biró de Stern, Ana. 1945. "Aspectos arqueológicos de una población hispana indígena descubierta en el Chaco". Anales del Instituto de Etnología Americana VI, pp. 103-116.

Blache, Martha; Dupey, Ana María. 2007. "Itinerarios de los estudios folklóricos en la Argentina". Relaciones de la Sociedad Argentina de Antropología, vol. 32.

Bohannan, Paul y Mark Glazer (Ed). 2007. Antropología: lecturas. Madrid: McGraw-Hill.

Bonder, Gloria. 1987. "Las mujeres y la educación en Argentina: realidades, ficciones y conflictos de las mujeres universitarias", Centro de Estudios de la Mujer.

Bonomo, Mariano; Farro, Máximo. 2014. "El contexto Sociohistórico de las investigaciones de Samuel K. Lothrop en el Delta del Paraná, Argentina”. Chungará (Arica), vol. 46, no 1, p. 131-144.

Bonnin, Mirta. 2008. Arqueólogos y aficionados en la Universidad Nacional de Córdoba (Argentina): décadas de 1940 y 1950. En: Arqueoweb. Revista sobre arqueología en internet. $\mathrm{N}^{\circ} 10$.

Bourdieu, Pierre. 1994. "Los usos sociales de la ciencia”. En Redes. Revista de Estudios Sociales de la Ciencia, Centro de Estudios e Investigaciones de la Universidad Nacional de Quilmes, Vol. 1, n², pp. 131-160.

Bourdieu, Pierre. 1999. Intelectuales, política, poder. Buenos Aires: Eudeba.

Bousquet, Manuel. 1936. "Habla para "El Pueblo"”. El Pueblo, 29 jul.

Browman, David L. 2007. "La Sociedad Arqueológica de Bolivia y su influencia en el desarrollo de la práctica arqueológica en Bolivia”. En Nuevos Aportes, n 4, pp. 29-54. 
Buchbinder, Pablo. 1997. Historia de la Facultad de Filosofia y Letras. Buenos Aires: EUDEBA.

Buchbinder, Pablo. 2005. Historia de las universidades argentinas. Buenos Aires: Sudamericana.

Buschini, José. 2007. "La construcción de una trayectoria científica en la Argentina de mediados de siglo: Eugenia Sacerdote de Lustig y el cultivo de tejidos "in Vitro" (19421961)", en: XI Jornadas Interescuelas/Departamentos de Historia. Departamento de Historia. Facultad de Filosofía y Letras. Universidad de Tucumán, San Miguel de Tucumán.

Butler, Judith. 1998. "Actos performativos y constitución del género: un ensayo sobre fenomenología y teoría feminista". Debate Feminista, 18, pp. 296-314.

Califano, Mario, Andrés Pérez Diez y Silvia Balzano. 1985. "Etnología", en: Centro Argentino de Etnología Americana, Evolución de las ciencias en la República Argentina 1872-1972, Antropología, t. X, pp. 9-71.

Carabajal, R. S.J. 1936. “Últimos hallazgos arqueológicos del Arroyo Leyes”.

Carrizo, Sergio. 2010. "Documentos, Quipus, clases e indios. Andrés Radamés Altieri en el Instituto de Antropología de la Universidad Nacional de Tucumán”. Revista del Museo de Antropología, vol. 3, no 1, p. 239-250.

Carrizo, Sergio. 2014. "Puntos, líneas y rombos proyectados en el biosólido craneal: los inicios de la trayectoria académica de José Imbelloni en la antropología argentina”. En Guber, Rosana (comp.) Antropologías argentinas. Determinaciones, creatividad y 
disciplinamiento en el estudio nativo de la alteridad. La Plata: Ediciones al Margen, pp. 4386.

CAEA - Centro Argentino de Etnología Americana. 1985. Evolución de las ciencias en la República Argentina 1872-1972, Antropología, t. X.

Caillet-Bois, Teodoro. 1947. "El museo de arqueología de catamarca". En Anales de la Sociedad Científica Argentina, Entrega I, tomo CXLIII, pp. 10-13.

Ceruti, Carlos N. 2012. "Avatares de la colección arqueológica del Arroyo Leyes (Depto. Garay, Provincia de santa Fé, Argentina) o la objetividad científica puesta a prueba". En: Actas del V Congreso Nacional de Arqueología Histórica, Buenos Aires, pp. 207-235.

Charvolin, Florian André Micoud y Lynn K. Nyhart (coord.). 2007. Des sciences citoyennes? La question de l'amateur dans les sciences naturalistes. Loire: Éditions de l'Aube.

Córdoba, Lorena. 2017. "Cartas chaqueñas: Alfred Métraux y Jules Henry”. En Revista de Dialectología y Tradiciones Populares, vol. LXXII, n 2, pp. 555-575.

Corrêa, Mariza. 1995 “A natureza imaginária do Gênero na história da Antropologia”. En Cadernos Pagu (5), pp. 109-130.

Corrêa, Mariza. 1997. "O espartilho de minha avó: linhagens femininas na Antropologia". En Horizontes Antropológicos, ano 3, n. 7, pp. 70-96.

Constanzó, María de las Mercedes. 1942. "Antropología Calchaquí. La Colección Zavaleta del Museo Argentino de Ciencias Naturales "Bernardino Rivadavia"”. En Revista del 
Instituto de Antropología de la Universidad Nacional de Tucumán, UNT, Vol 2, nº 9, pp. 213-308.

Constanzó, María de las Mercedes. 1945. "Segundo viaje de estudio organizado por AKIDA". Amicitia, vol. 5, no 26, p. 55-56.

Curto, Susana, Graciela Jáuregui, Mónica Escuela, Marcelo Lascano y Héctor Pena. 2008. "La fundación de GAEA Sociedad Argentina de Estudios Geográficos - 1922". En Boletín de GEA, $\mathrm{n}^{\circ} 126$, pp. 1-49.

Darnell, Regna. 2008 "North American Traditions in Anthropology: The Historiographic Baseline”. En Kuklick, Henrika (Ed.) A New History of Anthropology. Estados Unidos, Reino Unido y Australia: Blackwell Publishing Ltd, pp. 277-292.

Daston, Lorraine (ed.). 2000. Biographies of scientific objects. University of Chicago Press.

Dávila, Lena. 2015. "Robert Lehmann-Nitsche. Pruebas contundentes sobre su presencia en Napalpí en tiempos de la masacre". Nuevo Mundo Mundos Nuevos. Nouveaux mondes mondes nouveaux-Novo Mundo Mundos Novos-New world New worlds.

Dávila, Lena. 2018. "Robert Lehmann-Nitsche y la enseñanza de la antropología en la universidad argentina a comienzos del siglo XX". Temas americanistas, 40, pp. 213-238.

Denot, Sol. 2007. "La emergencia de las mujeres en la Universidad de Buenos Aires: Transformaciones del campo intelectual y nuevos sujetos, 1889-1930". En: V Encuentro Nacional y II Latinoamericano La Universidad como objeto de investigación, Facultad de Ciencias Humanas, UNICEN. 
Des Jardines, Julie. 2010. The Madame Curie complex: The hidden history of women in science. The Feminist Press at CUNY.

Doello Jurado, M. 1929. Museo Nacional de Historia Natural “Bernardino Rivadavia”. En: Memoria presentada al H. Congreso de la Nación por el Ministro de Justicia e Instrucción Pública. Año 1928, pp. 460-471. Talleres de la Penitenciaría Nacional, Buenos Aires, Tomo II.

Echeverri, Marcela. 1998. "La fundación del instituto etnológico nacional y la construcción genérica del rol de antropólogo". En Anuario Colombiano de Historia Social y de la Cultura, $\mathrm{n}^{\circ} 25$.

Echeverri, Marcela. 2007. “Antropólogas pioneras y nacionalismo liberal en Colombia, 1941-1949”. En Revista Colombiana de Antropología, Volumen 43, enero-diciembre, pp. $61-90$.

Engelke, Matthew. 2004. "The Endless Conversation. Fieldwork, Writing, and the Marriage of Victor and Edith Turner". En Handler, Richard (Ed.) Significant Others: Interpersonal and Professional Commitments in Anthropology. Madison: University of Wisconsin Press, pp. 4-50.

Estebanez, Maria Elina, De Filippo, Daniela y Serial, Alejandra. 2003. "Participación de la mujer en las actividades de investigación y desarrollo en Argentina”. Proyecto Gentec. Informe final.

Farro, Máximo. 2009. La formación del Museo de La Plata. Coleccionistas, comerciantes, estudiosos y naturalistas viajeros a fines del siglo XIX. Rosario: Prohistoria ediciones. 
Farro, Máximo. 2013. Observadores de gabinete, lenguas indígenas y "tecnología de papel": El archivo de trabajo de Samuel A. Lafone Quevedo. Ponencia presentada en VI Jornadas de Filología y Lingüistica, La Plata, Argentina.

Farro, Máximo. 2016. "Sociedad científica argentina" En Podgorny Irina y Pupio Alejandra (coord.) Diccionario histórico de las ciencias de la Tierra en la Argentina. Rosario: Prohistoria Ediciones, pp. 368-370.

Farro, Máximo, Irina Podgorny y María Dolores Tobías. 1999. "Notas para un ensayo sobre la recepción de la "nueva arqueología" en la Argentina". En Rev. do Museu de Arqueología e Etnologia, Suplemento 3, pp. 221-234.

Fausto-Sterling, Anne. 1987. "Society Writes Biology / Biology Constructs Gender" En Daedalus, Vol. 116, No. 4, pp. 61-76.

Fernández, J. 1982. Historia de la Arqueología Argentina. Anales de Arqueología y Etnología XXXIV-XXXV. Universidad Nacional de Cuyo, Mendoza.

Fox Keller, Evelyn. 1983. A Feeling for the Organism, Nueva York: W.H. Freeman.

Fox Keller, Evelyn. 1995. "Gender and Science: Origin, History and Politics”, Osiris, Vol. 10, pp. 26-38.

Fox Keller, Evelyn. 2001. "Reflexiones sobre género y ciencia". En Asparkía XII, pp.149153.

Fox Keller, Evelyn. 2006. "Qual foi o impacto do feminismo na ciência?". Cadernos Pagu, no 27, p. 13-14. 
Frenguelli, Joaquín. 1937. Falsificaciones de alfarerías indígenas en Arroyo Leyes (Santa Fe). Notas del Museo de La Plata, v. 2, n. 5, 1937.

Gänger, Stefanie. 2014. Relics of the Past. The Collecting and Study of Pre-Columbian Antiquities in Peru and Chile, 1837-1911. Reino Unido: Oxford University Press.

García, Susana V. 2003. El Museo de La Plata y la divulgación científica en el marco de la extensión universitaria (1906-1930). Tesis Doctoral. Facultad de Ciencias Naturales y Museo, Universidad Nacional de La Plata.

García, Susana V. 2006. "Ni solas ni resignadas: la participación femenina en las actividades científico-académicas de la Argentina en los inicios del siglo XX". En Cadernos Pagu, 01 December (27), pp.133-172.

García, Susana. 2007. Museos escolares, colecciones y la enseñanza elemental de las ciencias naturales en la Argentina de fines del siglo XIX. En História, Ciências, Saúde Manguinhos, vol. 14, $\mathrm{n}^{\circ}$ 1, pp. 173-196.

García, Susana V. 2010. Enseñanza científica y cultura académica. La universidad de La Plata y las Ciencias Naturales (1900-1930). Rosario: Prohistoria Ediciones.

García, Susana V. 2011. “Museos provinciales y redes de intercambio en la argentina”. En Lopes, M. M. y Heizer, A. (comp.) Colecionismos, práticas de campo e representações. Campina Grande: EDUEPB, pp. 77- 94.

García, Susana V. 2011b. "Mujeres, Ciencias Naturales y empleo académico en la Argentina (1900-1940)" En: R. Inter. Interdisc. INTERthesis, v.8, n.2, pp. 83-103. 
García, Susana e Irina Podgorny. 2000. "El sabio tiene una patria. La primera Guerra mundial y la comunidad científica argentina”. En Ciencia Hoy, vol. 10, n 55, pp. 24-34.

García, Susana e Irina Podgorny. 2010. "Una fuente de fósiles y controversias". En Transatlántico (Centro Cultural Parque de España/AECID), N 10, pp. 4-5.

Gatica de Montiveros, María Delia. 1988. Rescatando la Memoria de la Mujer Puntana. San Luis.

Gavrila, Canela C. 2016. "Las Visitadoras de Higiene Social platenses frente a la problemática de la maternidad a mediados del siglo XX”. En: II Jornadas de Género y Diversidad Sexual, Facultad de Trabajo Social (UNLP), 27 y 28 de octubre, La Plata.

Geertz, Clifford. 2003 (1973). La interpretación de las culturas. Barcelona: Gedisa.

Giordano, Verónica. 2012. Ciudadanas incapaces: la construcción de los derechos civiles de las mujeres en Argentina, Brasil, Chile y Uruguay en el siglo XX. Buenos Aires: Teseo.

Gómez, M. D. (2011). ¿Morirán mis hijos o las frutas del monte se secarán si no canto y uso mi amuleto cada noche? Mujeres tobas (qom) y Misioneros Anglicanos en el Chaco Centro occidental (Argentina). Cadernos Pagu (36), pp. 187-222.

García, Marta I. González; Sedeño, Eulalia Pérez. 2002. "Ciencia, tecnología y género". Revista Iberoamericana de Ciencia, Tecnología, Sociedad e Innovación, vol. 2.

Golde, Peggy. Women in the Field: Anthropological Experiences. Berkeley. 1970.

Graebner, Fritz. 1940. Metodología Etnológica. Universidad Nacional de La Plata. 
Grimshaw, Anna. 2008. "Visual Anthropology". En Kuklick, Henrika (Ed.) A New History of Anthropology. Estados Unidos, Reino Unido y Australia: Blackwell Publishing Ltd, pp. 277-292.

Grossi, Miriam Pillar. 2006. "Duas Germaines e uma Denise: alunas de Mauss”. En Grossi, Mota y Cavignac (org.) Antropología francesa no século XX. Pernambuco: Editora Massangana.

Grupioni, L. D. B. 1998. Coleções e Expedições Vigiadas: Os Etnólogos no Conselho de Fiscalização das Expedições Artísticas e Científicas no Brasil. San Pablo: Hucitec/Anpocs.

Guber, Rosana. 2006. "Linajes ocultos en los orígenes de la antropología social de Buenos Aires”. En: Avá. Revista de Antropología, núm. 8, pp. 1-35.

Guber, Rosana. "Antropólogos-ciudadanos (y comprometidos) en la Argentina. Las dos caras de la "antropología social" en 1960-70". Journal of the World Anthropology Network, 2008, vol. 3, p. 67-109.

Guber, Rosana. 2009. "Política nacional, institucionalidad estatal y hegemonía socioantropológica en las periodizaciones de la antropología argentina". En Cuadernos del IDES, $\mathrm{n}^{\mathrm{o}} 16$, pp. 3-28.

Guber, Rosana. 2011. “Ciro René Lafón y su Pequeña Historia del Museo Etnográfico y la antropología de Buenos Aires”. En Corpus. Archivos virtuales de la alteridad americana, Vol. 1, $\mathrm{N}^{\circ}$ 2, pp. 1-23.

Guber, Rosana. 2013. La articulación etnográfica. Descubrimiento y trabajo de campo en la investigación de Esther Hermitte. Buenos Aires: Ed. Biblos. 
Guber, Rosana; Bonnin, Mirta; Laguens, Andrés. 2007. “Tejedoras, topos y partisanos". Relaciones de la Sociedad Argentina de Antropología, vol. 32.

Gumbrecht, Hans U. 1997. In 1926. Living at the edge of time, Cambridge: Harvard University Press.

Halperín Donghi, Tulio. 1962. Historia de la Universidad de Buenos Aires, Buenos Aires: Eudeba.

Handler, Richard. 2004. Significant Others: Interpersonal and Professional Commitments in Anthropology. Madison: University of Wisconsin Press.

Hanke, W. (1936). “Los primeros guayaquíes”. En: La Prensa, 1 de marzo.

Hanke, W. (1937). "Una excursión entre los indios matacos". En Revista Geográfica Americana, año V, VOL VIII, nº 51, pp. 409-415.

Hanke, W. (1938). "Los indios Guayaquí". Revista Geográfica Americana, año V, VOL X, $\mathrm{n}^{\mathrm{o}} 59$, pp. 117-122.

Hanke, W. (1939). "Jira por la región de los indios lenguas". Revista Geográfica Americana, año VI, VOL XI, nº 69, pp. 441-445

Hanke, W. (1942). "Los indios Sirionó de la Bolivia Oriental". Arquivos do Museu Paranaense. Vol II, julio, pp. 87-96.

Hanke, W. (1946). "Sierras y ciudades del sud de Brasil”. Revista Geográfica Americana, año XIII, VOL XXVI, nº 155, pp. 81-90. 
Hanke, W. (1995). Dos años entre los Cainguá. Buenos Aires: Centro Argentino de Etnología Americana.

Haraway, Donna. 1989. Private Visions. Elsevier.

Haraway, Donna. 1998. "Situated knowledges: the science question in feminism and the privilege of partial perspectives", En Feminist Studies, 14(3).

Haraway, Donna. 2005. “«Género» para un diccionario marxista: La política sexual de una palabra" En: Haraway, Donna J. Ciencia, cyborgs y mujeres. Madrid: Ediciones Cátedra, 1995, pp. 213-251.

Harding, Sandra G. 1986. The science question in feminism. Cornell University Press.

Higgitt, Rebekah y Charles W. J. Withers. 2008. Science and Sociability Women as Audience at the British Association for the Advancement of Science, 1831-1901. En Isis, 99, pp. 1-27.

Hunter, Emily y Pyenson, Lewis. 2005. "Mermaid: Margrete Heiberg de Bose in Europe and Argentina". En Saber y Tiempo, 20, pp. 157-169.

Hynes, Adrienne. 2018. "Perceptions of Scottish pottery: nineteenth-century collecting in National Museums Scotland". En Journal of the History of Collections, Volumen 30, Número 2, pp. 269-280.

Imbelloni, José. 1943. Concepto y praxis del folklore como ciencia..Editorial Humanior.

Imbelloni, José. 1950. "Antropología. Investigadores e investigaciones. Etapas de esta ciencia en nuestro país (Conferencia pronunciada el día 7 de julio de 1949)". En: 
Publicaciones de la Secretaría de Cultura de la Nación, 3. Buenos Aires: Secretaría de Cultura de la Nación.

Imbelloni, José. 1953. Epitome de culturología. Humanior, biblioteca del americanista moderno. Editorial Nova.

Jardine, Nicholas, James Secord y Emma Spary (Eds.). 1996. Cultures of Natural History, Cambridge: Cambridge University Press.

Kaplan, D. y Manners R.A. 1979. Introducción crítica a la teoría antropológica. México: Editorial Nueva Imagen.

Kohler, Robert. 2007. "Finders, Keepers: Collecting Sciences and Collecting Practice", en History of Science, 45 (4), pp. 428-454.

Kohlstedt, Sally G. 1995. "Women in the History of Science: An Ambiguous Place". En Osiris, 2nd Series, Vol. 10, Constructing Knowledge in the History of Science (1995), pp. $39-58$.

Kohlstedt, Sally G. y Longino, Helen. 1997. "The Women, Gender and Science Question. What do research on Women in Science and Research on Gender and Science Have to do with each other?" En Osiris, v.12, pp. 3-15.

Kohn Loncarica, Alfredo Guillermo. 1976. Cecilia Grierson: vida y obra de la primera médica argentina. Editorial Stilcograf.

Kohn Loncarica, Alfredo y Sánchez, Norma Isabel. 1996. "La mujer en la medicina argentina: las médicas de la primera década del siglo XX". En Saber y Tiempo (2), Buenos Aires, Centro de Estudios de Historia de la Ciencia José Babini, pp. 113-138. 
Kohn Loncarica, Alfredo y Sánchez, Norma Isabel. 2000. "La mujer en la medicina argentina: las médicas de la segunda década del siglo XX". En Saber y Tiempo (9), Buenos Aires, Centro de Estudios de Historia de la Ciencia José Babini, pp.89-107.

Kohn Loncarica, Alfredo G., Sánchez, Norma y AL. Agüero. 1998. "La contribución de las primeras médicas argentinas a la enseñanza universitaria”. En Anales de la Sociedad Cientifica Argentina; 228 (2): 39-58.

Kuklick, H. y R. Kohler. (1996). "Introduction". Osiris, Vol. 11, Science in the Field, pp 114.

Lamas, Marta. 2007 "Complejidad y claridad en torno al concepto género". En Angela Giglia, Carlos Garma y Ana Paula de Teresa, (Comp) ¿Adónde va la antropología?. México: División de Ciencias Sociales y Humanidades de la UAM-Iztapalapa.

Lamphere, Louise. 2004. "Unofficial histories: a vision of Anthropology from the margins". American Anthropologist, vol. 106, no 1, p. 126-139.

Larguía, Amelia. 1934. "Algunos datos arqueológicos sobre paraderos indígenas en la Provincia de Santa Fe". En Anales de la Sociedad Científica Argentina, v. 118, pp. 216221.

Larguía, Amelia. 1936. "Datos arqueológicos sobre paraderos indígenas de Santa Fe". En Anales de la Sociedad Científica Argentina, v. 122, pp. 326-334.

Lascano Kezic, M., y Susana Curto. 2015. "El territorio como puente entre la cultura y la política, parte II. El pensamiento de Federico A. Daus 1922-1957”. En Revista Do Departamento De Geografia, 28, 1-24.

Lazzari, A. 2004. "Antropología en el Estado: el Instituto Étnico Nacional (1946-1955)". En Neiburg, F. y Plotkin, M. (comps.) Intelectuales y expertos. La constitución del conocimiento social en la Argentina. Buenos Aires: Paidós, pp. 203-230. 
Liener, S. M. 2010. Wanda Hanke (1893 - 1958). Eine österreichische Ethnologin in Südamerika (Tesis de maestría). Universidad de Viena, Alemania.

Lightman, Bernard (ed.). 2016. A Companion to the History of Science. John Wiley \& Sons.

Lindskoug, Henrik B. 2008. "En la sombra de la arqueología argentina: Jorge von Hauenschild y la formación de la colección von Hauenschild del Museo de Antropología (Universidad Nacional de Córdoba)". En Revista del Museo de Antropología 1(1): 61-70.

Lionetti Lucía. 2001. "Ciudadanas Útiles Para la Patria. La Educación de Las 'Hijas del Pueblo' en Argentina (1884-1916)". En The Americas, Vol. 58, No. 2, pp. 221-260.

Locatatelli de Pérgamo, Ana María. 2005. "Recordando a Isabel Aretz". En Revista de Música Latinoamericana, Vol. 26, No. 2, pp. 158-163.

Lopes, M. Margaret. 1998. ““'Aventureiras” nas ciências: Refletindo sobre gênero e história das ciências naturais no Brasil”. En Cadernos Pagu, 10, pp. 345-368.

Lopes, M. Margaret. 1999. "Aspectos da Institucionalização das Ciências Naturais no Brasil, no Século XIX”, en Quipu, tomo XII, N² 2, pp. 217-230.

Lopes, Maria Margaret. 2006. "Sobre convenções em torno de argumentos de autoridade". Cadernos Pagu, 27, pp.35-61.

Lopes, Maria Margaret. 2008. Proeminência na mídia, reputação em ciências: a construção de uma feminista paradigmática e cientista normal no Museu Nacional do Rio de Janeiro. Em: História, Ciências, Saúde -Manguinhos, vol.15, suppl.0, Rio de Janeiro, 2008 b. 
Lopes, M.M. Consideraciones sobre género y ciencias en la trayectoria feminista de Bertha Maria Julia Lutz (1894-1976). In: Miqueo, C; Barral, M; Magallón, C. (Org.). Estudios Iberoamericanos de género en ciencia, tecnología y salud. Zaragoza: Prensas Universitarias de Zaragoza, p. 509-514, 2008c.

López, Elvira 2009 [1901] El movimiento feminista: primeros trazos del feminismo en Argentina. Buenos Aires: Biblioteca Nacional.

Lorenzo, María Fernanda. 2016. Que sepa coser, que sepa bordar, que sepa abrir la puerta para ir a la Universidad: las académicas de la Universidad de Buenos Aires en la primera mitad del siglo XX. Ciudad Autónoma de Buenos Aires: Eudeba.

Luco, Susana. 2010. Tensión político-académica en la Universidad de Buenos Aires (19751983): el cambio de paradigma en la arqueología patagónica. En Revista del Museo de Antropología, Córdoba, vol. 3, n 1, pp. 211-224.

Madsen-Brooks, Leslie. 2009. Challenging science as usual: women's participation in American natural history museum work, 1870-1950. Journal of Women's History, vol. 21, no 2, p. 11-38.

Madsen-Brooks, Leslie. 2013. A Synthesis of Expertise and Expectations: Women Museum Scientists, Club Women and Populist Natural Science in the United States, 1890-1950. Gender and History.

Maffia, Diana. 2007. "Epistemología feminista: La subvención semiótica de las mujeres en la ciencia”. En Revista venezolana de estudios de la mujer, Vol. 12, №. 28, pp. 63-98.

Mailhe, Alejandra. 2016. "Polémicas ideológicas en la antropología argentina: el americanismo cientificista de la Biblioteca Humanior". En IX Jornadas de Sociología de la 
UNLP 5 al 7 de diciembre de 2016 Ensenada, Argentina. Universidad Nacional de La Plata. Facultad de Humanidades y Ciencias de la Educación. Departamento de Sociología.

Marcellino, Alberto. 1985. "Antropología física”, en: Centro Argentino de Etnología Americana, Evolución de las ciencias en la República Argentina 1872-1972, Antropología, Tomo X, 1985, pp. 105-151.

Martínez, Alejandro. 2012. Fotografía y hechos científicos. Los guayaquíes y las discusiones de la antropología a fines del siglo XIX. En Kelly, T e I. Podgorny (Dir.) Los secretos de Barba Azul, Fantasías y realidades de los archivos del Museo de La Plata. (pp 105-138). Rosario: Prohistoria Ediciones.

Martínez, Ana Teresa; Taboada, Constanza; Auat, Alejandro. 2011 Los Hermanos Wagner, entre mito, ciencia y poesía. Bernal: UNQ.

Mauss, Marcel. 2006 [1947] Manual de etnografía. Buenos Aires: Fondo de Cultura Económica.

McGee Deutsch, Sandra. 1993. "La mujer en la derecha en Argentina, Brasil y Chile 19001940”. En Dora Barrancos (compiladora), Historia y Género, pp. 98-126. Buenos Aires: CEAL.

Merchant, Carolyn. 1980. The Death of Nature: Women, Ecology, and the Scientific Revolution.

Merchant, Carolyn. 2006. "The Scientific Revolution and The Death of Nature", en: Isis, vol. 97 , pp. 513-533. 
Millán de Palavecino, María Delia. 1970. "Prólogo" a "Mitos de los indios tobas" de Enrique Palavecino. En Runa, Archivo para las ciencias del hombre, Vol. 12, n 1-2, pp. $177-197$

Millán de Palavecino, María Delia. 1981. Arte del tejido en la Argentina. Ediciones Culturales Argentinas.

Moore, Henrietta L. 2009 (1991) Antropología y feminismo. Quinta edición. Ediciones Cátedra, Valencia.

Mora Nawrath, 2016. La institucionalización de las Ciencias Antropológicas en Chile. Una aproximación a las dinámicas socio-organizativas y cognoscitivas en la conformación del espacio científico (1860 y 1954). Tesis de doctorado. Universidad Nacional de La Plata, Facultad de Humanidades y Ciencias de la Educación, 264 p.

Moraes de Oliveira Sombrio, Mariana y Lopes, Maria Margaret. 2011 "Wanda Hanke e a formação de coleções etnográficas na América do Sul”. En: Anais do XXVI Simpósio Nacional de História - ANPUH, São Paulo.

Morínigo, M. 1968. Enrique Palavecino (1900-1966). Cuadernos del Instituto Nacional de Antropología, 7, 425-428.

Moscoso, Eduardo Ocampo. Wanda Hanke en La Etnografia Boliviana; Libreria Editorial Juventud, La Paz, Bolívia, 1982.

Nari, Marcela. 2000. "Maternidad, política y feminismo”. En Fernanda Gil Lozano, Valeria Pita, Gabriela Ini (directoras), Historia de las mujeres en la Argentina. El siglo XX, pp. 196-221. Buenos Aires: Taurus. 
Nari, Marcela. 2004. Políticas de maternidad y maternalismo político. Buenos Aires, 18901940. Buenos Aires, Biblos.

Núñez Camelino, María. 2013. Los museos de Corrientes y sus colecciones entre fines del siglo XIX y principios del siglo XX. XIV Jornadas Interescuelas/Departamentos de Historia. Departamento de Historia de la Facultad de Filosofía y Letras. Universidad Nacional de Cuyo, Mendoza.

Ocampo Moscoso, E. (1982). Wanda Hanke en la etnografia boliviana. La Paz: Juventud.

Opitz, Donald L.; Bergwik, Staffan y van Tiggelen, Brigitte. 2016. Domesticity in the Making of Modern Science, Londres, Palgrave Macmillan UK.

Ostrovsky, Ana Elisa. 2008. "La sociedad de psicología en Argentina (1908-1913). Treinta y nueve hombres y una mujer". En Revista de Historia de la Psicología, Universitat de València, vol. 29, núm. 2 (junio), pp: 55-67.

Palavecino, Enrique. 1932. "Áreas culturales del territorio argentino". En Actas y trabajos científicos del XXVo. Congreso Internacional de Americanistas (Universidad Nacional de La Plata. 1934). p. 223-234.

Palavecino, Enrique. 1948. Areas y capas culturales en el territorio argentino. Museo de Historia Natural de San Rafael.

Palavecino, Enrique; Millán de Palavecino, María Delia. 1956. Los indios Chanés del río Itiyuro. RUNA, archivo para las ciencias del hombre, vol. 7, no 1.

Palermo, Alicia I. 1998. "La participación de las mujeres en la universidad". En: La Aljaba, Segunda época, vol 3, pp. 94-110. 
Palermo, Alicia I. 2000 "La educación universitaria de la mujer. Entre las revindicaciones y las realizaciones", Revista Alternativas, año III, núm. 3

Palermo, Alicia I. 2005. "Mujeres Profesionales que Ejercieron en Argentina en el Siglo XIX”, en: Convergencia, UAEM, México, mayo-agosto, núm. 38, pp. 59-79.

Palermo, Alicia I. 2006. "El acceso de las mujeres a la educación universitaria”, en Revista argentina de sociología, 4 (7), pp. 11-46.

Paulme, Denise. 1992. Lettres de Sanga a André Schaeffner. París: Fourbis

Paulotti, Osvaldo L. 1943. Bibliografía Antropológica Argentina, 1941-44. Boletín de Antropología Americana, vol. 7, p. 32-40.

Pegoraro, A. (2003). Estrategias de formación de colecciones del Museo Etnográfico durante el período 1904-1917. Funcionarios de gobierno en la recolección de piezas. En Lorenzano, C. (ed.), Historias de la Ciencia Argentina I. (pp. 17-28). Buenos Aires: EDUNTREF.

Pegoraro, A. (2009). Las colecciones del Museo Etnográfico de la Universidad de Buenos Aires: un episodio en la historia del americanismo en la Argentina 1890-1927 (Tesis de doctorado). Facultad de Filosofía y Letras, Universidad Nacional de Buenos Aires, Argentina.

Penny, G. H. (2002). Objects of Culture. Ethnology and Etnographic Museums in Imperial Germany. Chapel Hill and London: The University of North Carolina Press. 
Perazzi, P. (2003). Antropología y Nación: materiales para una historia profesional de la Antropología en Buenos Aires. Runa. Archivo para las ciencias del hombre, $\mathrm{N}^{\circ} 24$, pp. 83102.

Perazzi, Pablo. 2003 Hermenéutica de la barbarie. Una historia de la antropología en Buenos Aires. Buenos Aires, Sociedad Argentina de Antropología.

Perrot, Michelle. 2009. Mi historia de las mujeres. Buenos Aires: Fondo de cultura económica.

Pigeard-Micault, Natalie. Les femmes du laboratoire de Marie Curie. Éditions Glyphe, 2013.

Podgorny, Irina. 2000. El argentino despertar de las faunas y de las gentes prehistóricas. Coleccionistas, museos y estudiosos en la Argentina entre 1880 y 1910. Eudeba/Libros del Rojas, Buenos Aires.

Podgorny, Irina. 2001. "La clasificación de los restos arqueológicos en la Argentina, 18801940. Primera Parte: La diversidad cultural y el problema de la antigüedad del hombre en el Plata". En SABER Y TIEMPO, 12. pp. 5-26.

Podgorny, Irina. 2002. "La clasificación de los restos arqueológicos en la argentina, 18901940. Segunda parte. Algunos hitos de las décadas de 1920 y 1930". En SABER Y TIEMPO, 13. pp. 5-31.

Podgorny, I. 2002. Ser todo y no ser nada: paleontología y trabajo de campo en la Patagonia argentina a fines del siglo XIX. En Visacovsky, S. y R. Guber (comps.) Historia y estilos de trabajo de campo en Argentina. (pp. 31-77).Buenos Aires: Antropofagia. 
Podgorny, I. 2004b. Tocar para creer. La arqueología en la Argentina, 1910-1940. Anales del Museo de América, n. 12, pp. 147-163.

Podgorny, Irina. 2005. "La derrota del genio. Cráneos y cerebros en la filogenia argentina". En Saber y Tiempo. Separata 20, pp. 63-106.

Podgorny, Irina. 2006. "Emma B. Documentos para servir al estudio de la estructura familiar de los coleccionistas de fósiles: El caso de Emma y Auguste Bravard". En: Cadernos Pagu (27), julio-diciembre: pp. 479-495.

Podgorny, I. 2008. Momias que hablan. Ciencia, colección de cuerpos y experiencias con la vida y la muerte en la década de 1880. Prismas, Revista de Historia Intelectual. Número 12. pp. 49-65.

Podgorny, Irina. 2009 El sendero del tiempo y de las causas accidentales. Los espacios de la prehistoria en la Argentina, 1850-1910. Rosario: Prehistoria

Podgorny, I. 2010. “Coleccionistas de arena. La comisión médico-quirúrgica italiana en el altiplano boliviano (1875-1877)”. Antípoda. Número 11, julio-diciembre. pp. 165-188.

Podgorny, I. 2011. Los viajes en Bolivia de la Comisión Científica Médico-Quirúrgica Italiana. Santa Cruz: Fundación Nova.

Podgorny, Irina. 2012. Charlatanes. Crónicas de remedios incurables. Buenos Aires: Eterna Cadencia.

Podgorny, I. 2013. La febbre dei fossili Pedro de Angelis y el carácter transaccional de la ciencia. Zama. Revista del Instituto de Literatura Hispanoamericana, año 5, número 5, pp. $11-216$. 
Podgorny, Irina. 2014. "Sobre la constitución de los objetos etnológicos en los inicios del siglo XX: museos, falsificaciones y ciencia”. En: Museologia e interdisciplinaridade. Vol.III, n5, maio/junho, pp. 21-35.

Podgorny, Irina et.al. 2016. Diccionario histórico de las ciencias de la tierra en la Argentina. Buenos Aires: Prohistoria Ediciones.

Podgorny, Irina y Margaret Lopes. 2008. El desierto en una vitrina. Museos e historia natural en la Argentina, 1810-1890. México: Limusa.

Podgorny, Irina y Margaret Lopes. 2013. Trayectorias y desafíos de la historiografía de los museos de historia natural en América Del Sur. Anais do Museu Paulista. V.21. n.1. pp. 1525 .

Pomata, Gianna. 2013. "Amateurs by Choice: Women and the Pursuit of Independent Scholarship in 20th Century Historical Writing”. Centaurus, 55(2), 196-219.

Preciado, Beatriz. 2008. Testo Yonk. Madrid: Espasa

Pupio, Alejandra. 2005 "Coleccionistas de objetos históricos, arqueológicos y de ciencias naturales en museos municipales de la provincia de Buenos Aires (Argentina) en la década de 1950”. En História, Ciências, Saúde Manghinos. Vol. 12, pp. 205-229.

Pupio, A. 2011. Coleccionistas, aficionados y arqueólogos en la conformación de las colecciones arqueológicas del Museo de La Plata, Argentina (1930-1950). En Lopes, M. M. y Heizer, A. (comp.) Colecionismos, práticas de campo e representações.(pp. 269-280). Campina Grande: EDUEPB. 
Pupio, Alejandra. 2012. Profesionales y aficionados en la conformación, interpretación y exhibición de las colecciones arquelógicas Coleccionistas y museos de la provincia de Buenos Aires. Tesis doctoral. Facultad de Filosofía y Letras, Universidad de Buenos Aires.

Pupio, A. 2013. "Archivos para una historia de la práctica de la arqueología”, en Revista Electrónica de Fuentes y Archivos, № 4, pp. 24-33.

Pupio, A. y Piantoni, G. 2016. Coleccionismo, museo y saberes estatales. La colección de Enrique Amadeo Artayeta en el Museo de la Patagonia (Argentina)1939-1950. Estudios Sociales del Estado, volumen 3, número 5, pp. 31 a 54.

Pycior, Helena Mary; Slack, Nancy G.; Abir-am, Pnina G. Creative couples in the sciences. Rutgers University Press, 1996.

Pyenson, Lewis y Susan Sheets Pyenson. 1999. Servants of Nature: a history of scientific institutions, enterprises, and sensibilities. Norton and Company, New York-London.

Queirolo, Graciela. 2005. "La mujer en la sociedad moderna a través de los escritos de Victoria Ocampo (1935-1951)", en Zona Franca, n 14, Universidad Nacional de Rosario.

Queirolo, Graciela. 2015. "Dactilógrafas y secretarias perfectas: el proceso de feminización de los empleos administrativos (Buenos Aires, 1910-1950)”. En: Historia Crítica, No. 57, Julio - septiembre, Pp 117-137.

Ramacciotti, Karina y Adriana Valobra. 2011. "Modernas esculapios: acción política e inserción profesional, 1900-1950”. En: Género y Ciencia: hombres, mujeres e investigación científica en América Latina, siglos XVIII-XX. María Eugenia Scarzanella y Jacinto Lizette (comp). Colección Estudios AHILA de Historia Latinoamericana, volumen 8, Asociación de Historiadores Latinoamericanistas Europeos, Madrid/Frankfurt. 
Ramundo, Paola. 2010. "Cerámica y procesos sociales: implicaciones metodológicas para su estudio en la Quebrada de La Cueva, Humahuaca, Jujuy". Temas de Historia Argentina y Americana, 17.

Ramundo, Paola. 2017. Mujeres y arqueología. El aporte de Juliane Dillenius a la historia disciplinar, a través del análisis documental en el Instituto Ibero-americano de Berlín. Actas de las III Jornadas de Investigación y Reflexión sobre Historia, Mujeres y Archivos. UNICEN, Provincia de Buenos Aires. pp. 151-158.

Ravina, Aurora. 1997 "Mujer, historia y espacios académicos. Una experiencia de participación institucional”. En: Investigaciones y Ensayos (47), Academia Nacional de la Historia, Buenos Aires, pp. 509-526.

Rentetzi, Maria. 2008. Trafficking materials and gendered experimental practices: radium research in early 20th century Vienna. New York: Columbia University Press, 2008.

Riccardi, Alberto. 2013. "Joaquín Frenguelli: vida y obra científica”, en Alonso, Rocardo (comp.) Actas III Congreso Argentino de Historia de la Geología, Mundo Grafico Salta Editorial, Salta, pp. 169-219.

Rieznik, Marina. 2005. La incorporación del Observatorio Astronómico a la Universidad Nacional de La Plata. En: Saber y Tiempo, n 20, pp. 107-136.

Rodríguez Shadow, María y Campos Rodríguez, Lilia. 2010. "Los aportes femeninos a la Antropología Social: Las pioneras”. Investigación y Ciencia, 18 (46), pp. 36-42.

Rossiter, Margaret W. 1982. Women scientists in America: Strategies and struggles to 1940. Baltimore: Johns Hopkins University Press. 
Rossiter, Margaret W.1995. Women Scientists in America: Before Affirmative Action, 1940-1972. Baltimore: Johns Hopkins University Press.

Rossiter, Margaret. 1997 “Wich Women? Wich Science?”. En: Osiris, Vol. 12, pp. 169185.

Rubin, Gayle. 1975. "The traffict in Women”. En R. Reiter Toward an Anthropology of Women. New York: Monthly Review Press.

Sábato, Hilda. 2002. "Estado y Sociedad Civil. 1860-1920” En Di Stefano, R., Sabato, H., Romero, L. A., \& Moreno, J. L. De las cofradías a las organizaciones de la sociedad civil. Historia de la iniciativa asociativa en Argentina. 1776-1990. pp. 99-166. Buenos Aires: Edilab.

Santesmases, María Jesús; I Pairet, Montserrat Cabré; Gómez, Teresa Ortiz. 2017. "Feminismos biográficos: aportaciones desde la historia de la ciencia". Arenal. Revista de historia de las mujeres, vol. 24, no 2, p. 379-404.

Schiebinger, Londa. 2004 (1989) ¿Tiene sexo la mente? Las mujeres en los orígenes de la ciencia moderna. Ed. Cátedra 2004, Madrid.

Schöbinger, Juan. 1960-62. El Instituto de Arqueologia y Etnologia de la Universidad Nacional de Cuyo. Boletín Bibliográfico de Antropología Americana, Vol. 23/25, No. 1, pp. 16-18.

Schumaker, Lyn. 2008. "Women in the Field in the Twentieth Century: Revolution, Involution, Devolution?". En Kuklick, Henrika (Ed.) A New History of Anthropology. Estados Unidos, Reino Unido y Australia: Blackwell Publishing Ltd, pp. 277-292. 
Scott, Joan W. 1996 “El género una categoría útil para el análisis histórico”. En: Lamas Marta (comp.), El Género: la construcción cultural de la diferencia sexual, México, PUEG, UNAM, pp. 265-302.

Scott, Joan W. 2011 “Género, ¿Todavía una categoría útil para el análisis?” en La manzana de la discordia, Vol. 6, No. 1, Enero-Junio, Año 2011, pp. 95-101.

Secord, James A. 2004. “Knowledge in transit”. Isis, vol. 95, no 4, p. 654-672.

Serrano, Antonio. 1930. Los primitivos habitantes del territorio argentino. Librería y editorial" La Facultad", J. Roldán \& cía.

Shapin, Steven y Schaffer, Simon. Leviathon and the air pump. 1985. Princeton: Princeton University Press.

Sieben, Graciela N. 2012. "El proceso legislativo de la Ley 11.357 de derechos civiles de la mujer. Los debates en el Congreso Nacional (1924-1926)” Tesis de posgrado. Universidad Nacional de Quilmes, Bernal, Argentina.

Silla, Rolando. 2012. "Raza, raciología y racismo en la obra de Marcelo Bórmida". Revista del Museo de Antropología, vol. 5, no 1, pp. 65-76.

Sombrio, M. (2014). Em busca pelo campo: ciências, coleções, gênero e outras histórias sobre mulheres viajantes no brasil em meados do século XX (Tesis doctoral). UNICAMP, Brasil.

Sombrio Moraes de Oliveira, M. y M. M. Lopes. (2011). Wanda Hanke e a formação de coleções etnográficas na América do Sul. Ponencia presentada en Anais do XXVI Simpósio Nacional de História - ANPUH, São Paulo. 
Soprano, Germán. 2006 Configuración de liderazgos y grupos académicos en la investigación antropológica argentina. Análisis histórico centrado en la FCNyM de la UNLP. 1930-1990. Primer Congreso Argentino de estudios Sociales de la Ciencia y la Tecnología. Universidad Nacional de Quilmes, Bernal, Pcia. Buenos Aires.

Soprano, Germán. 2007 “Continuidad y cambio en los estudios en etnología de poblaciones indígenas contemporáneas y comunidades folk en la Facultad de Ciencias Naturales y Museo de la Universidad Nacional de La Plata (1930-1976)". En: Anuario de Estudios en Antropología Social, Nro 3, pp. 23-52.

Soprano, Germán. 2009a. Autonomía universitaria e intervención política en la trayectoria de liderazgos y grupos académicos en ciencias naturales de la Universidad Nacional de La Plata. 1930-1955. Anuario del Instituto de Historia Argentina; Lugar: La Plata; Año: 2009 pp. $47-82$.

Soprano, Germán. 2009b. "La Antropología Física entre la universidad y el Estado. Análisis de un grupo académico universitario y sus relaciones con las políticas públicas del Instituto Étnico Nacional (1946-1955)”. En Estudios Sociales, n 37, pp. 63 a 95.

Soprano, G. 2014. Lecturas, interpretaciones y usos de la "Escuela Histórico-Cultural" en la producción arqueológica y etnográfica de Fernando Marquez Miranda. En Guber, Rosana (comp.) Antropologias argentinas. Determinaciones, creatividad y disciplinamiento en el estudio nativo de la alteridad. (87-128). La Plata: Ediciones al Margen.

Sosa de Newton, Lily. 1980. Diccionario biográfico de mujeres argentinas. Buenos Aires: Camacho.

Spoliansky, Vivian; Roca, Ignacio; Scarafoni, María Isabel. 2011. El Fondo Documental Enrique Palavecino. Archivo del Museo Etnográfico "Juan B. Ambrosetti”(FFyLUBA). Corpus. Archivos virtuales de la alteridad americana, vol. 1, no 2. 
Sprung, Helga y Sprung, Lothar. 1996. "Women in psychological history-forms of integration in psychology and womens lecturing activities at german psychology congresses 1904-1978”. En Revista de Historia de la Psicología. Vol. 17, n 1/2, pp. 185-202.

Stebbins, Robert. 2001. New Directions in the Theory and Research of Serious Leisure. Edwin Mellen Press.

Stocking, George W. 1968. Race, Culture, and Evolution. Essays in the History of Anthropology. New York: The Free Press.

Stocking, George W. (1993, orig. 1983) "La magia del etnógrafo. El trabajo de campo en la antropología británica desde Tylor a Malinowski”, in H. Velasco, F.J. García y A. Díaz de Rada (eds.), Lecturas de antropología para educadores. El ámbito de la antropología de la educación y de la etnografía escolar, Madrid, Trotta, pp. 43-93.

Suárez, Paula S. 2012. Las mujeres abogadas en la historia y en la Facultad de Derecho de la Universidad de Buenos Aires, en Academia. Revista sobre enseñanza del Derecho, año 10, número 20, pp. 143-183. Buenos Aires, Argentina

Sulca, Olga Liliana. 2004. "Registro, recuperación y conservación de los textiles arqueológicos del Museo de la Universidad Nacional de Tucumán”. Tesis de Maestría en Ciencias Sociales con especialidad en Antropología e Historia; FLACSO, Sede Ecuador: Colegio Andino. Centro de Estudios Regionales Andinos Bartolomé de las Casas. 249 p.

Tarducci, Mónica. 2015. "Antes de Franz Boas: mujeres pioneras de la antropología norteamericana". Runa, vol. 36, n 2, pp. 57-73. 
Valentini, Luisa. 2010. Um laboratório de Antropologia: o encontró entre Mário de Andrade, Dina Dreyfus y Claude Lévi-Strauss (1935-1938). Tesis de maestría en Antropología Social, Universidad de San Pablo, Brasil. 242 páginas.

Valobra, Adriana. 2005. "Algunas consideraciones acerca de la historia de las mujeres y género en Argentina" En: Nuevo Topo/Revista de historia y pensamiento crítico, Buenos Aires; $101-122$.

Valobra, Adriana María. 2010. "La ciudadanía política femenina en la Argentina de la primera mitad del siglo XX. Aportes para una aproximación conceptual y recursos didácticos”. En Clío \& Asociados. La Historia Enseñada, n 14, pp. 86-112.

Valobra, Adriana. 2011 "Claves de la ciudadanía política femenina en la primera mitad del siglo XX en Argentina” En: Revista Estudios; Lugar: Costa Rica; pp. 5-35.

Valobra, Adriana. 2012. "Recorridos, tensiones y desplazamientos en el ideario de Alicia Moreau". En: REVISTA NOMADíAS, Número 15, pp. 139-169.

Vassallo, Alejandra. 2000. "Entre el conflicto y la negociación. Los feminismos argentinos en los inicios del Consejo Nacional de Mujeres, 1990-1910” en: Gil Lozano, F.; Pita, V. eIni, M. G. (dirs.), Historia de las mujeres en la Argentina. Siglo XX, Buenos Aires, Taurus. Tomo 2, pp: 177-195.

Vellard, Jean Albert. 1933. Una misión de estudios al Paraguay. Revista Humanidades, Tomo XXIII, pp. 83-103.

Vellard, Jean Albert. 1939. Civilisation du miel. 
Visacovsky, Sergio, Guber, Rosana, Gurevich, Estela. 1997. "Modernidad y tradición en el origen de la carrera de Ciencias Antropológicas de la Universidad de Buenos Aires". Redes, 4. En línea.

Visacovsky, Sergio Eduardo; Guber, Rosana. 2002. Historias y estilos de trabajo de campo en la Argentina. Editorial Antropofagia.

Wagley , Charles. 1964. “Alfred Métraux 1902-1963”. En American Anthropologist, New Series, Vol. 66, No. 3, Part 1 (Jun., 1964), pp. 603- 613.

Yanzi Ferreira, Ramón Pedro. 2010 "Elisa Ferreyra Videla. Primera graduada de la Facultad de Derecho y los estudios de Economía Política en la Universidad Nacional de Córdoba. 1947-2010”. En: Cuadernos de historia, n 20, pp. 27-58.

Zusman, P. (2012). La Revista Geográfica Americana en la década de 1939: entre el modelo de la National Geographic y la invención de los paisajes argentinos orientados a la práctica turística. Registros, Mar del Plata, año 8 (n.9): 81-96. 